\title{
The place of play : on toys, technological innovations and geographies of play
}

Citation for published version (APA):

Lauwaert, M. G. E. (2007). The place of play : on toys, technological innovations and geographies of play. [Doctoral Thesis, Maastricht University]. Universiteit Maastricht. https://doi.org/10.26481/dis.20080327ml

Document status and date:

Published: 01/01/2007

DOI:

$10.26481 /$ dis. $20080327 \mathrm{ml}$

Document Version:

Publisher's PDF, also known as Version of record

\section{Please check the document version of this publication:}

- A submitted manuscript is the version of the article upon submission and before peer-review. There can be important differences between the submitted version and the official published version of record.

People interested in the research are advised to contact the author for the final version of the publication, or visit the DOI to the publisher's website.

- The final author version and the galley proof are versions of the publication after peer review.

- The final published version features the final layout of the paper including the volume, issue and page numbers.

Link to publication

\footnotetext{
General rights rights.

- You may freely distribute the URL identifying the publication in the public portal. please follow below link for the End User Agreement:

www.umlib.nl/taverne-license

Take down policy

If you believe that this document breaches copyright please contact us at:

repository@maastrichtuniversity.nl

providing details and we will investigate your claim.
}

Copyright and moral rights for the publications made accessible in the public portal are retained by the authors and/or other copyright owners and it is a condition of accessing publications that users recognise and abide by the legal requirements associated with these

- Users may download and print one copy of any publication from the public portal for the purpose of private study or research.

- You may not further distribute the material or use it for any profit-making activity or commercial gain

If the publication is distributed under the terms of Article $25 \mathrm{fa}$ of the Dutch Copyright Act, indicated by the "Taverne" license above, 

(C) Maaike Lauwaert, 2007. All rights reserved.

ISBN: 978-90-9022578-4

Printed for the defense ceremony, not for sale.

Printed with financial support from the Faculty of Arts and Social

Sciences at Maastricht University and WTMC Graduate School. 


\section{The Place of Play}

On Toys, Technological Innovations and

Geographies of Play

Maaike Lauwaert 



\section{The Place of Play}

On Toys, Technological Innovations and

Geographies of Play

$\mathrm{PhD}$ Thesis

Ter verkrijging van de graad van doctor aan de

Universiteit Maastricht, op gezag van de Rector

Magnificus, Prof. Mr. G.P.M.F. Mols volgens het

besluit van het College van Decanen, in het openbaar

te verdedigen op donderdag 27 maart 2008 om 16.00u.

door

Maaike Maria Gabriella Elizabeth Lauwaert

geboren te Antwerpen op 28 februari 1978 
PROMOTER:

Prof. Dr. Ir. W.E. Bijker (Maastricht University)

CO-PROMOTER:

Dr. Joseph Wachelder (Maastricht University)

ADVISORY COMMITTEE:

Prof. Dr. Karin Bijsterveld (Maastricht University, chair)

Prof. Dr. Stephen Kline (Simon Fraser University,

Vancouver)

Dr. Joost Raessens (Utrecht University)

Dr. Renée van de Vall (Maastricht University)

Prof. Dr. Sally Wyatt (Maastricht University)

This research was supported by the Netherlands Organization for Scientific Research (NWO) and was part of the research project "Transformations in Perception and Participation; Digital Games". 
For My Parents,

With Love. 



\section{TABLE OF CONTENTS}

Changing Practices, Shifting Sites ........................................ 1

MY OWN CREATION ......................................................... 1

A ROOM OF ONE'S OWN...................................................5

A MANY-TO-MANY PARADIGM ……………...................... 13

FROM LEGO TOYS TO SERIOUS URBAN GAMES ............... 17

1: New Children, Different Toys ...........................................23

The DePartMent Store: THE ChILD As CONSUMER .....29

A PRIVATE RoOM: Domesticating Play ........................37

THE Playground: THE CHILd IN THE CITY......................45

TOYS AS CONTAINERS.......................................................53

2: Core and Periphery of Play ...............................................59

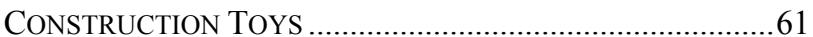

FROM BUILDING TO DESIGNING ……...............................6 68

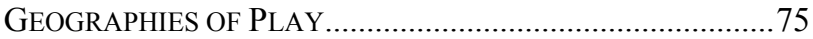

CENTRIFUGAL AND CENTRIPETAL MOVEMENTS................84

3: “The Journey not the Destination " ....................................93

From WoODEN BLOCKS TO PlastiC BRICKS ..................95

BRAND EXTENSION \& PRODUCT DIFFERENTIATION........113

BRINGING THE FANS INTO THE COMPANY.......................124

TOWARDS A MANY-TO-MANY GEOGRAPHY OF PLAY ....136

4: Pimp My Game 141

Toy TownS AND Simulated CitiES ...............................147

A $21^{\text {ST }}$ CENTURY DOLLHOUSE: THE SIMS .........................168

UnWANTED Play PRACTICES IN ThE SiMS ONLINE........189

A COMMODIFIED GEOGRAPHY OF PLAY .........................205

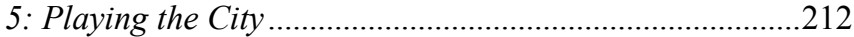

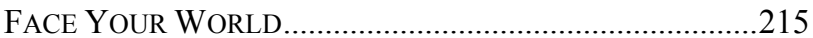

ASSESSING PUBLIC PARTICIPATION.................................228

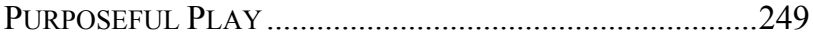

SERIOUS GEOGRAPHIES OF PLAY.....................................259

Changing Geographies of Play .........................................264

MEDIATORS, MiRRORS \& MOTORS ..................................265 


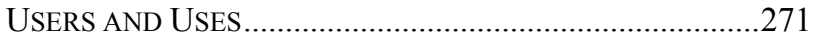

BOUNDARY BLURRING..................................................276

MAKING-DO ...................................................................28

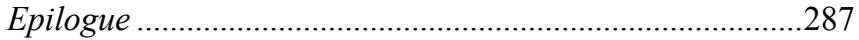

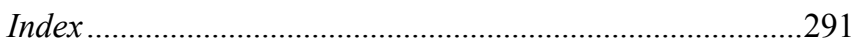

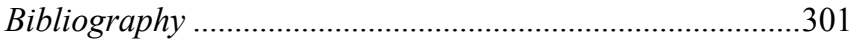

Nederlandstalige Samenvatting ...........................................330

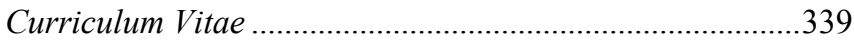




\section{ACKNOWLEDGEMENTS:}

I would like to thank Martijn Hendriks for his continuing support, inspiring discussions and priceless feedback, for simply always being there for me, helping me out on countless occasions and suggesting the title The Place of Play. I want to thank my supervisors Wiebe Bijker and Joseph Wachelder without whose support and advise I could not have written this book. They created this wonderful opportunity and guided me through expertly.

Throughout the four years of working on this thesis many other people were of importance to the project and its progress: Stephen Kline and Joost Raessens provided me with invaluable comments and suggestions at different times, so did numerous colleagues from Maastricht University: Ruth Benschop, Karin Bijsterveld, Marjolijn van Asselt, Johan van de Walle, Karin Wenz, Tannelie Blom, Ernst Homburg, Geert Somsen, Rein de Wilde as well as the members of our Digital Games research group: Renée van de Vall, Jack Post, Jan Simons, René Glas, Rob Zwijnenberg and the external advisors of this project: Vivian Sobchack, Margaret Morse and William Uricchio.

I would also like to thank my fellow $\mathrm{PhD}$ students at the faculty of Arts and Social Sciences who were a source of comfort and reassurance: Vivian van Saaze, Merel Noorman, Niki Vermeulen, Julia Quartz, Sophie Bouwens, Cornelia Racke, Ludo Hellemans, Allissa Brooks, Patrick Bijsmans, Susan van 't Klooster, Saskia Bonjour, Mieneke te Hennepe, Maud Radstake and Babette Muller.

During the first two years of this project, the members and visiting scholars of the WTMC graduate school - Paul Wouters, Annemiek Nelis, Els Rommes, Sally Wyatt, Tom Misa, Jason Rutters and Andrew Webster - provided valuable feedback and inspiration. 
Special thanks go to the people in archives and libraries who helped me find my way through the history of toys: Jackie Britton, Helmut Schwartz and Catherine Howell, to the Face Your World team: Jeanne van Heeswijk, Dennis Kaspori, Ramon Mosterd and Irene den Hartoog, to the ward Slotervaart: Leta Hoeve, Harry Wien and Joris Broekhuizen, to housing corporation De Alliantie, to the The Harbour Game designers: Thomas Fabian Delman, Tobias Løssing, Andreas Lykke-Olesen, to Mathias Fuchs from PlastiCity, to Gerard Kreek and Jan van Dorst for sharing their memories and knowledge with me, to the many players and gamers who took time to answer my questions, to Suzanne de Castell, Mitchel Resnick, Jacqueline Goossens and Yasmin Kafai for their hospitality on my many research trips abroad, to Michael Samyn and Auriea Harvey from Tale of Tales for creating truly moving games and stimulating the discussion on game design.

Last but not least I would like to thank my family: my parents Christine Gruwez and Dirk Lauwaert who gave me the gift of books, writing and their loving support, my sisters Geertrui, Anneke and Swaane Lauwaert, their children Simon, Romain, Joachim, Martin and Remi Menke, Basile de Decker, Fons and Jules Jansen, my brothers Andreas and Dorian Lauwaert, Reinhilde Weyns, Thomas Samaras, Cora and Mark van den Brink. My family supported me throughout and served as a source of inspiration, wonder and joy. 


\section{Changing Practices, Shifting Sites}

\section{MY OWN CREATION}

Daniel Siskind (1971) received his first LEGO ${ }^{\mathrm{TM}}$ set in 1975. His parents had brought it with them from a trip to Europe. Ever since, he has been "hooked on playing with Lego building bricks" (Siskind, personal website). In 2000, Siskind started his personal website to sell his MOC (My Own Creation) LEGO sets. Siskind's favorite themes for MOC sets are castles, trains and war paraphernalia. At the time of writing, his MOC sets are no longer for sale. They have all sold out and Siskind has no time anymore to assemble and ship the sets. When still on sale, he would ship his MOC sets in a box with a printed picture of the design on it, like a real set. A manual with building instructions accompanied the LEGO pieces. His Blacksmith Shop (designed in 1999) contained 637 pieces and sold for 
$\$ 150$. Some of the pieces for the Blacksmith Shop were taken out of production by LEGO and were thus hard to come by. All MOC sets are relatively expensive - definitely more expensive than official LEGO sets - because designing and assembling the sets is a time consuming process and the seller has, of course, to buy all the items for the set him- or herself. Siskind exhibited the Blacksmith Shop at a LEGO event in 2000 where LEGO Master Builders happened to be scouting the fan stands. These LEGO Master Builders loved the design of the Blacksmith Shop and proposed to turn Siskind's MOC set into an official LEGO set. Siskind agreed and sold his rights of the design to the LEGO Company for an undisclosed amount. By the end of 2001 the set was on sale as an official LEGO set (item \#3739) for \$39,99 containing 622 pieces (LEGO, Blacksmith Shop). Some minor changes have been made to Siskind's design both at the exterior and interior of the shop. The out-of-use bricks Siskind originally integrated in his design were not part of the official set. The set is at this time no longer on sale on the official LEGO website.

When the set was launched in 2001, it was promoted as the first in what had to become a series of official LEGO MOC sets. On the LEGO website news section, it read: "The Master Builders search for designs that they like in places like personal home pages, Brickshelf, at LEGO-related events, and - you guessed it! - in the LEGO Club!" (LEGO, Brick Street Journal). However, no second MOC set was released in the official LEGO series. So far, Siskind was thus granted a unique honor: to see his creation be turned into an official, commercial set. Most of the Lugnet (LEGO Users Group Network) users, an international group of LEGO fans, were overjoyed with Siskind's success and they expressed hope that this move by the LEGO Company signaled a turn of events in their policy towards active LEGO users. 

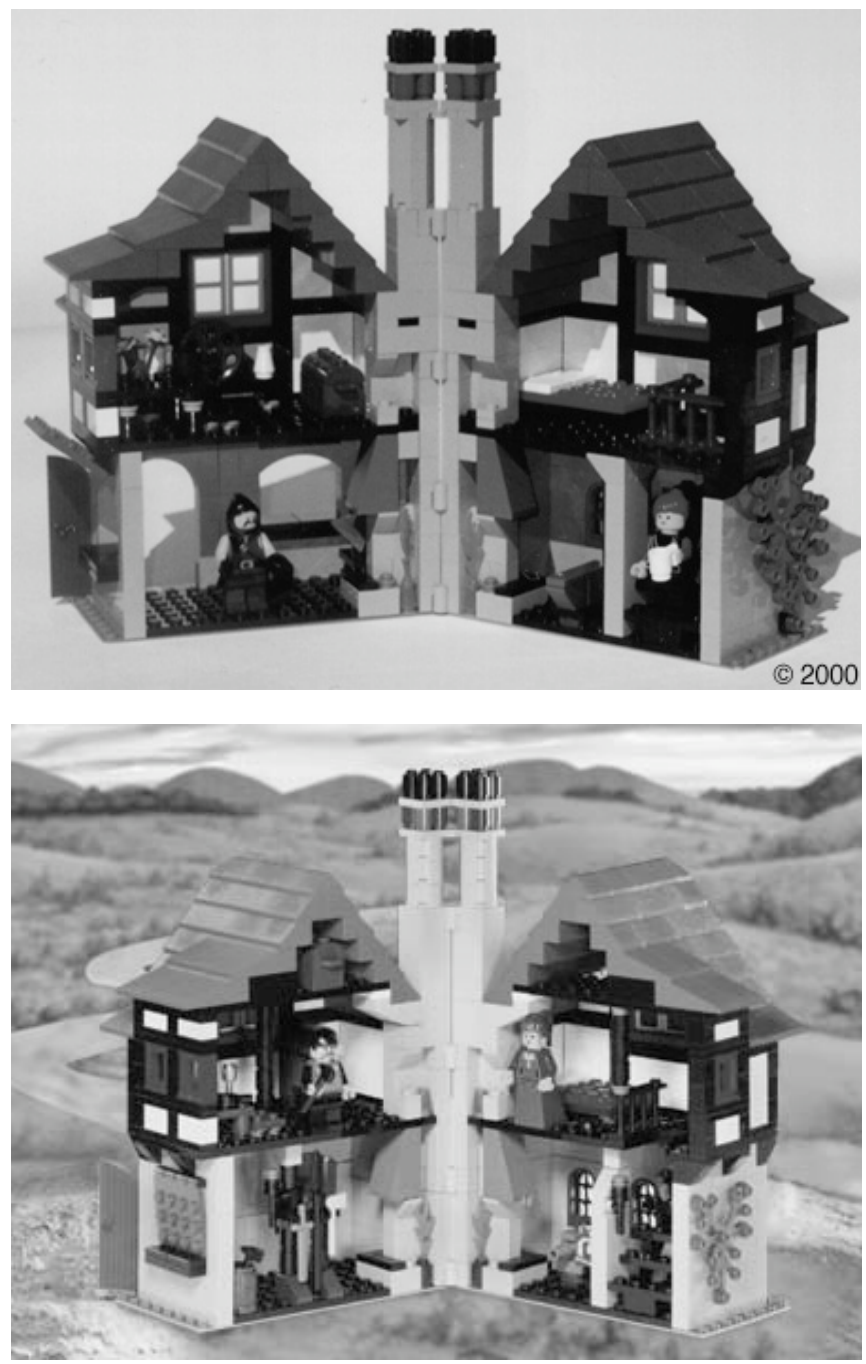

Illustrations $1 \& 2$ : The MOC and official Blacksmith Shop. The top image shows the interior view of the Blacksmith Shop designed by Siskind (Siskind, personal website). The bottom image shows the interior view of the official LEGO Blacksmith Shop (LEGO, Blacksmith Shop). ${ }^{1}$

\footnotetext{
${ }^{1}$ The LEGO Group owns the copyrights to all the images of LEGO products used in this thesis.
} 
Although no second MOC set was released as an official LEGO set after the Blacksmith Shop, the LEGO Company increasingly works together with dedicated LEGO fans. Jake McKee from LEGO Community Development works hard to connect his LEGO colleagues with LEGO fans and thus "bring the fans into the company" (McKee, 2005). The recently launched LEGO Factory - which includes both a digital design tool and an exchange platform - is exactly about this effort to bring LEGO fans into the company (LEGO Factory). In LEGO Factory, fans can design their own sets with the free software, share their designs with other fans and buy any of these custom sets directly from LEGO. The official LEGO online store sells two of these Factory custom sets - an airport and a train - created by AFOLs (Adult Fans of LEGO) (LEGO, Factory Exclusives). LEGO Factory signals a change in how the LEGO Company puts UserGenerated Content (often abbreviated as UGC) to use. Instead of having headhunters browse user sites and visit LEGO events, everyone can now add their creations to the LEGO Factory Gallery.

Bringing the fans into the company marks a wider shift noticeable in many layers of society and culture, a shift based on the early philosophy of the Internet: the many-to-many approach rather than the one-to-many approach. Instead of having LEGO designers work in secrecy behind closed doors on new LEGO sets, invite the fans, the users to 'sit at the table' with the designers and work together on future LEGO kits. With this many-to-many approach, not only money is fed back into the circuit of capital (production $>$ commodity $>$ consumption $>$ production $>$...) but also voluntary, unpaid labor of devotees (Kline, Dyer-Witheford, \& De Peuter, 2003, concerning the circuit of capital, p. 50-51). This tightens the bond between company, commodity and consumer considerably. 
While most Lugnet users were happy about Siskind's success, others worried whether making MOC sets official is not a shrewd way to control the fans (Lugnet, Blacksmith Shop). This points towards a crucial characteristic of the commercialization of this many-to-many model: the fame and glory for having your creation made official entails inevitably a certain degree of control by the companies over the users. The LEGO Factory is then not only a creative tool, it also provides the LEGO Company with a digital database of user creations and thus with invaluable information on their most active fans. Rightfully, fans wonder what the effects are of this commodified many-to-many model on toys and playing.

\section{A ROOM OF ONE'S OWN}

One of the central tensions in contemporary child rearing is the one between domestication and urbanization. Reluctant to let children play outside unsupervised and lacking the time to accompany them regularly, parents tend to keep children safely indoors. Households are organized as such that children have their own room where they can occupy themselves. Many toys are designed to be suitable for indoor, solitary play. Outdoor spaces designated for children's play - playgrounds - are domesticated spaces as well in the sense that they are bordered and supposedly safe areas for play. New media technologies in general and the Internet, personal computers and hand-held gaming devices in particular, have recharged tensions between domestication and urbanization. On the one hand these new media technologies allow for hours of captivating indoors entertainment. On the other hand they facilitate 
frequent transfer between the outside world and the family home by means of personal computers and game consoles connected to the Internet. Also, handheld, portable gaming devices contain the possibility of dislocating play from its interior locality, although players need to stay put in a sheltered environment in order to play on these devices. Portable game consoles are mainly used during car drives and when someone else is using the television set and/or the game console.

Children's bedrooms have become increasingly suffused with personal electronics. In 1999 the Kaiser Family Foundation released its first report on American children and new media. They found that an average of $33 \%$ of children between the ages of 2 and 18 had a video game player in their bedroom, $16 \%$ had a computer and $7 \%$ of those computers were connected to the Internet. More than half of the children had a television in their bedrooms (53\%) (Roberts, Foehr, Rideout, \& Brodie, 1999, p. 13). Six years later, in 2005 , they issued a report stating that an average of $49 \%$ of children aged 8 to 18 had a video game device in their private bedrooms, $31 \%$ had their own computer and $20 \%$ of those were connected to the Internet. $55 \%$ of 8 to 18 year-olds reported having their own hand-held gaming device (Roberts, Foehr, \& Rideout, 2005, p. 13). Only personal television ownership ranked higher with $68 \%$. By 2005, almost all children had some sort of personal music device, either in their room or portable (p. 13). The 2005 report concluded: "most U.S. kids inhabit rooms that seem to be as much media arcade as bedroom" (p. 16). ${ }^{2}$ A year later research showed that children with media devices in their bedrooms spent

\footnotetext{
${ }^{2}$ Although the reports relate to American children, many children in other Western countries have a comparable amount of media devices at their disposal. My youngest brother (aged 11) has, for example, in his room a portable DVD player, television, wireless Internet, laptop, PlayStation, portable PSP gaming device, and a radio. He is by no means an exception among his peers when questioned about it.
} 


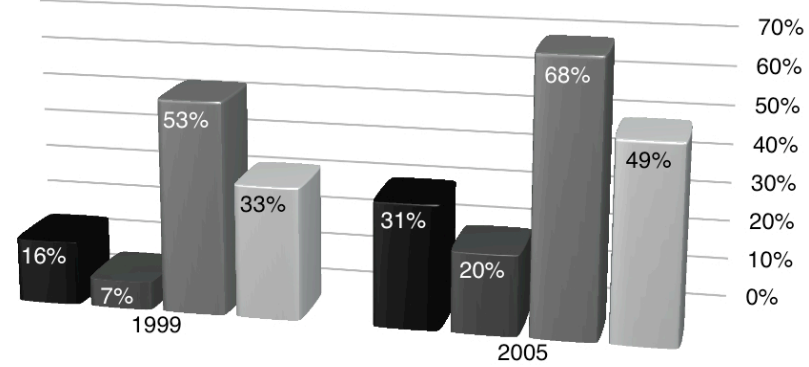

Figure 1: Personal electronics in a child's bedroom. Graphic representation of personal electronics ownership by American children aged 2 to 18 in 1999 and 8 to 18 in 2005 based on two Kaiser Family Foundation reports (Roberts, Foehr, Rideout, \& Brodie, 1999; Roberts, Foehr, \& Rideout, 2005). Hand-held gaming devices are not displayed in this figure because ownership was not measured in 1999. 
more time using them (Rideout \& Hamel, 2006, p. 19).

In total, young people are exposed to $81 / 2$ hours of media messages per day. This amount is compressed into $61 / 2$ hours because $26 \%$ of media time is spent multitasking (that is, using different media at the same time) (p. 57). A report on media multitasking highlighted that playing computer games is most commonly combined with watching television or listening to music. The combination of playing a computer game and watching television indicates that children are either playing with a handheld gaming device in front of the television or have simply stacked two television-sets on top of each other (Foehr, 2006, p. 12).

Personal electronics have become a source of worry among parents, politicians, educators and health counselors. A personal computer connected to the Internet raises issues of children's exposure to pornography and violent content, of pedophiles lurking in chat rooms and engaging young children and teenagers in unsuitable behavior (web cams have added considerably to this worry because the child is made visible to who knows who), of easy access to (pharmaceutical) drugs and drug dealers and of digital bullying among classmates. Since so many personal electronics have moved into the bedroom, it is all the more difficult for parents to keep an eye on what their children are doing online. An American organization called Parents. The Anti Drug advises parents on various forms of drug abuse by children and teenagers. They have a special section dedicated to digital technologies and their possible dangers. Their first advise to parents is to "Limit your teen's time spent online, and put computers in a common area of the house" (The Anti Drug website). The bedroom or playroom, once a safe place for children has become a battleground. 
Notwithstanding these worries, many parents perceive digital technologies as an asset rather than a threat. On the one hand, digital technologies smooth the juggling act of daily life:

Many parents find media a tremendous benefit in parenting and can't imagine how they'd get through the day without it (...). Media allow parents a chance to get their chores done, quiet their kids down, or just have some "me" time, knowing that their kids are "safe" — not playing outside (Rideout \& Hamel, 2006, p. 32).

On the other hand parents express belief in the educational values of these tools (Rideout \& Hamel, 2006, p. 32; Rideout, Vandewater, \& Wartella, 2003, p. $6)$. Even though research on the educational merits of high-tech tools is not conclusive. For example, research conducted among three- and four-year-olds found that "hi-tech devices aimed at infants as young as nine months - are no more effective than traditional ways of introducing basic literacy and number skills" (Ward, 2006). The American Academy of Pediatrics stressed in a 2006 report that toys for "academic enrichment" should be balanced with ample time for "free play", preferably outside in a "safe environment" (Ginsburg, 2007, p. 188).

While parents are thus recommended to let their children engage in free outdoors play activities favored by children as well as a UK report indicated (Ward, 2006) - they are reluctant to let their children outside unsupervised. For outdoors play, parents prefer playgrounds with a high fence bordering the play area and, if possible, a supervisor keeping an eye on things. Increasingly, cities no longer have the funds to maintain public playgrounds and pay for professional supervision. This gap is filled by commercial enterprises - restaurants and shopping malls mainly who provide in- or outdoors playground areas for their customers' children. Fast-food restaurant chain Mac- 


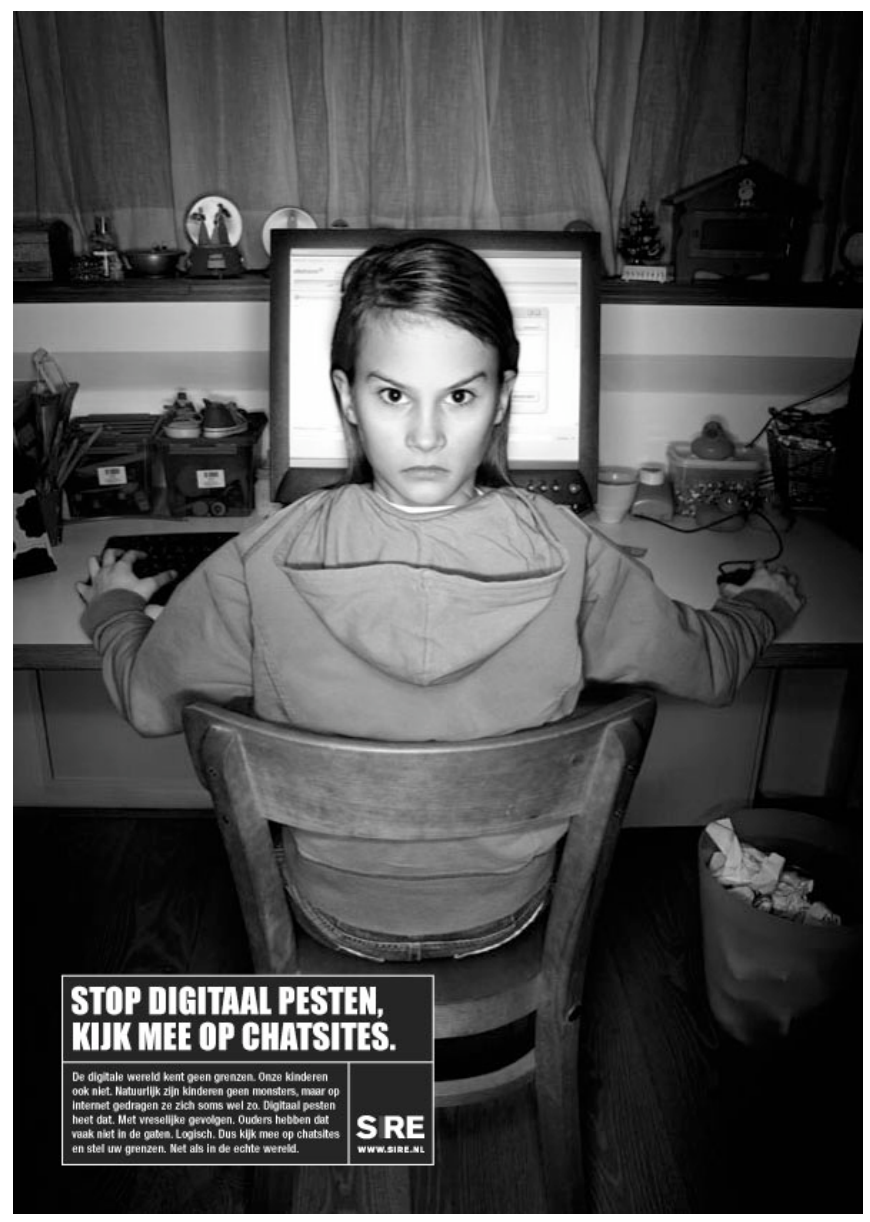

Illustration 3: Poster from an awareness campaign to stop digital bullying. The advertisement campaign 'Stop Digital Bullying' by Dutch watchdog SIRE wants to raise awareness among children, parents and educators concerning the effects of digital bullying and urges parents to keep an eye on their children while they are chatting (Image courtesy of SIRE, 2006). 
Donald's has turned into one of the largest, if not the largest, provider of play areas in the United States.

The domestication of the playing child has reached an extreme height and taken a wicked turn with digital entertainment. Computer games allow children to kill hours and hours of time without having to leave their room. Hand-held gaming devices allow players to take their game with them, thus containing the possibility to dislocate the player from the interior. Contemporary game consoles and personal computers can be linked up to the Internet, which allows players to stay in contact with the outer world from within the family home. These options re-introduce 'the mean world' in children's lives. The question I will address here is what sorts of mechanisms of involving players are at work within this increasingly technological and digitalized bedroom and playworld.

The examples of the Blacksmith Shop, a child's bedroom suffused with personal electronics and the crisis of urban spaces for play, are indicators of transformations in the production and consumption of toys, the place and function of toys in children's lives and the overall household. The broad societal and cultural processes of commodification, domestication and urbanization are of influence on the production, consumption, place, goal and form of play. Importantly, these processes are rooted in history. The $19^{\text {th }}$ century is the kick-off for this research because these three processes are rooted in the Industrial era. ${ }^{3}$ It is during the $19^{\text {th }}$ and early $20^{\text {th }}$ century that our

\footnotetext{
${ }^{3}$ Commodification, domestication and urbanization are not the only processes put into motion by industrialization and modernization. Other processes include but are not limited to mechanization, the rise of classes, democratization, educational revolution. However, in relation to this thesis' subject, the processes of commodification, domestication and urbanization form an interesting focus because these processes relate to and bring to the foreground different forms of play and various discussions regarding play.
} 
Western consumer culture takes shape, the Victorian family becomes the locus of civilization and urbanization leads to tensions between city and citizen. From the $19^{\text {th }}$ century to the post-war period to the $21^{\text {st }}$ century, we see significant changes in how these processes play out. The relationship between commodification, domestication and urbanization, toys and the individual changes drastically during the postwar period with the maturing of commercialism, the suburban obsession with the private sphere and the increasing fear for the world outside of that private (suburban) home. The $21^{\text {st }}$ century witnesses another phase of consumerism with late-capitalism, the reintroduction of the outside world inside the family home via the Internet and attempts at reestablishing a constructive relationship between city and citizen. ${ }^{4}$ Importantly, it is within this changing context of commodification, domestication and urbanization that new technologies are being introduced and their effects experienced. Against the background of these historically changing societal and cultural processes, I will analyze the many-to-many model, the role and function of technological innovations, the effects thereof on toys and play and the mechanisms of userinvolvement at work in the many-to-many model.

\footnotetext{
${ }^{4}$ The telephone, radio, television and fax machine also establish a connection between the outer world and the inner home. However, these communication and information technologies mainly establish a unidirectional flow between the private home and the outside. It is mainly a caller's voice that travels from the inside to the outside. With personal computers connected to the Internet, a complex mix of user information and user data, of spoken and written messages, of still images and streaming video travel from the inside to the outside and visa versa. The Internet facilitates fast transfer between the home and the outside world while making it harder for parents to track this transfer. More often than not, children are more knowledgeable in effacing their online traces than parents are in tracking them. In centrifugal and centripetal movements information, data, text, voice and image are exchanged between the home and the world outside.
} 


\section{A MANY-TO-MANY PARADIGM}

Increasingly, technology is at stake in toys, games and playing. With the immense popularity of computer games, questions concerning the role and function of technology in play have become more pressing. A key aspect of the increasing technologization and digitalization of both toys and play is the vagueness of borders between producers, consumers and players. In these so-called participatory cultures characterized by a many-to-many model, players do not simply play with a toy designed behind closed doors but become codesigners of their own toys.

The many-to-many model originally stems from Internet use and software applications. In the one-toone Internet paradigm users communicate through email or FTP (file transfer protocol) with one another on an individual basis. Websites have added to this the display of information for many visitors to access: a one-to-many paradigm. Technological innovations and new Internet applications such as file sharing (through P2P or peer-to-peer networks), blogging (mostly a free activity of maintaining a personal website that documents or comments), tagging (adding comments on blogs or websites) and Wiki-sites (to which anyone who is registered can add information, make changes or create new entries), have created a situation that is referred to as 'participatory culture', 'many-to-many culture' or the 'Web 2.0 revolution'. Many a software application incorporates sharing and publishing options that encourage the social and participatory use of this software. The term 'prosumers' is often used to indicate the shift in the many-to-many culture towards consumers becoming producers of media content.

Of course, this situation is less utopian and egalitarian as the many-to-many term suggests. People have to have a computer, Internet access and technological skills to enter this many-to-many 
paradigm. Nevertheless, it signals a change on some levels and in some domains from the domination of expert knowledge and content to an increase in enduser knowledge and content.

Outside of specific Internet uses and applications that signal such a change from one-to-one to one-tomany to many-to-many, the dynamics of the many-tomany model and then especially the bond it can create between traditionally remote stakeholders, have been experimented with by diverse and wide-ranging industries. From policy-makers to politicians, from artists to architects, the attraction of the many-to-many approach has resulted in an almost ubiquitous userinvolvement. People can call in on radio shows, email television stations and have their opinions be read on the news within the same hour. Movie directors consult fan communities when considering turning, for example, the Lord of the Rings trilogy into movies. Politicians add to their blogs on a daily basis and 'directly' communicate through these sites with their voters. The booksellers website Amazon publishes reader-written reviews rather than official reviews. Publisher Penguin launched in 2007 the Penguin Wiki project A Million Penguins inviting readers to become writers of a collective novel. This "crowdsourcing" was an experiment into the "open source' movement" (PenguinWiki, 2007). Cosmetics firm Dove motivates Dove users to create their own Dove publicity campaigns for the Cream Oil Body Wash (Brandweek.com, 2006). Mainly female Dove users have answered the call and send in their own pictures and movies promoting the new Dove product. Such user-driven marketing and advertising is on the increase.

The popularity of the many-to-many phenomenon has reached an unprecedented height these examples are only a snippet of a phenomenon in which companies consciously blur the lines between 
consumer and producer to try and bring fans into the company, invite consumers to be not simply consumers but active residents in a brand's world. Admittedly, many of these exercises in many-to-many-ing are watered-down versions of what the term might literally refer to (by us and for us) or they are blatant forms of self-aggrandizement.

To put it bluntly, the attractions of this many-tomany model are the wish to establish a faithful relationship between, for example, brand and consumer, between politician and voter, between city council and citizen. For these consumers, voters and citizens, participatory cultures provide an individualized experiences in a globalized world, carve out a personalized niche in what is increasingly perceived as an impersonal world and give a voice to those who consider themselves otherwise unheard.

However prodigiously utilized, hyped or criticized, the implications of the many-to-many model, the different forms of and reasons for user participation in content creation are not yet well understood nor researched. ${ }^{5}$ This thesis' strategic research site for analyzing the nature, characteristics, mechanisms and problems of the many-to-many model are toys and computer games. The key questions this thesis addresses are: In which manner does the manyto-many model under sway of technological innovations produce changes within the world of toys and playing? What mechanisms of user-involvement are at work in this many-to-many model? Thereby, this

\footnotetext{
${ }^{5}$ Andrew Keen's recent book The Cult of the Amateur: How Today's Internet is Killing our Culture and Assaulting our Economy (2007) is a pessimistic and distopian vision on the effects of the many-to-many activities on culture, politics and economy. When the amateur celebrates over the expert, quality looses terrain to quantity, number of viewing times, popularity and the 'politics' of search engines that rank number of hits above reliability of information. On the other side of the spectrum are writers like Henry Jenkins who celebrate the advent of participatory cultures in terms of the democratization of content generation and the empowerment of consumers (1992; 2006a; 2006b).
} 
thesis aims at adding to our understanding of the nature, characteristics, mechanisms and problems of the many-to-many model. Although these issues are acutely visible within the world of toys and computer games, they are by no means restricted to this research site. Therefore, with this analysis I seek to address not only changes within the world of play but also in other domains and practices.

A conceptual framework is developed to deal with the many-to-many model, the mechanisms at work in this model and the changes it undergoes. Three case studies show the historical framework of the many-to-many paradigm, outline how the model is being used and how it changes over time aided by technological innovations. Together the conceptual framework and case studies hint at 'best' and 'worst' practices of the many-to-many model.

This study's research methodology capitalizes on an interdisciplinary combination of Science and Technology Studies (STS) research methods, historical research methods and comparative cultural analysis. In dealing with the question of the relationship between technological innovations, toys, play and players, the interdisciplinary field of technology studies offers valuable insights, research strategies and key terms. One of the strengths of the STS field is that it does not treat technological innovations in isolation but in their context of design, development, manufacturing, marketing and use. Different actors are recognized as important assets to the shaping and use of technological artifacts. Historiographical accounts as well as comparative analysis of artifacts serve to create this very context to the technological innovations treated in this $\mathrm{PhD}$ thesis.

Research is based both on primary and secondary sources, on literature study and interviews, on policy documents and company reports. Extensive archival study was conducted at the Toy Museum of 
Mechelen (Belgium), at the Victoria \& Albert Museum of Childhood (Bethnal Green) and the British Library (all in London, UK), at the Nuremberg Toy Museum and Nuremberg Public Library (both in Germany) and in various Dutch archives related to the case study of chapter 5. This archival and literature study is supplemented with some 30 in-depth qualitative interviews with players and policy makers and the active participation in and observation of user groups and fan sites. ${ }^{6}$

\section{FROM LEGO TOYS TO SERIOUS URBAN GAMES}

In recent years many scholarly books have appeared on the subject of computer games. While these recent publications all provide valuable insights into the inner workings and cultural context of computer games, they do not focus on the long-term historical perspective of play as a cultural practice, the role of technological innovations within this history and the changing dynamics between players, toys and companies. Notable exceptions are Digital Play: The Interaction of Technology, Culture, and Marketing by Stephen Kline, Nick Dyer-Witheford and Greig De Peuter (2003) and Henry Jenkins' article Complete Freedom of Movement: Video Games as Gendered Play (2000). Erkki Huhtamo also points in his article on arcade gaming to the missing historical component in game studies:

electronic games did not appear out of nowhere; they have a cultural background that needs to be excavated. The existing literature on the history of

\footnotetext{
${ }^{6}$ The author has translated the Dutch, German or French sources used in this study and the interviews of which most were held in Dutch.
} 
video games has done little toward achieving this goal. In fact, the (hi)story is usually told in a remarkably uniform fashion, built around the same landmarks, breakthroughs, and founding fathers $(2005$, p. 4).

'Excavating the culture and history' of computer games is needed, according to Huhtamo, to counter the claims of "industry publicists and corporate 'cryptohistorians,' who like to represent electronic gaming as something unprecedented" (p. 15). The term 'cryptohistory' is used, for example, by Michael Brian Schiffer to describe product histories created by corporations to 'serve their present-day needs, to bolster their image through accomplishments both real and imagined, to use as a weapon in the corporate struggle for the hearts and minds - and money - of consumers and investors' (1991, p. 1).

Generally speaking, when non-digital and digital toys are 'compared' from a game studies point of view, this is generally to claim the uniqueness (in terms of interactive possibilities, massive virtual worlds and unprecedented social opportunities) of the latter. As Huhtamo points out, computer game scholars generally internalize the cryptohistorian point of view and "represent electronic gaming as something unprecedented" (2005, p. 15). When non-digital and digital toys are 'compared' from the more pessimistic point of view of computer game adversaries, this generally leads to an equally simplified comparison that applauds the first ('real' interaction, physical activity, tactile play) and condemns the latter (isolated, immobile and escapist play). A more systematic approach and a historical analysis are therefore called for.

The bulk of contemporary computer game research focuses exclusively on computer games - it's coming into being and maturing, the different genres discernable, the type of rules and systems deductible and the sort of players and player behavior witnessed. The Game Design Reader. A Rules of Play Anthology, 
edited by Katie Salen and Eric Zimmerman (2006), focuses on the design of computer games and possible new directions in game design. The Handbook of Computer Game Studies, edited by Joost Raessens and Jeffrey Goldstein (2005), deals with various aspects of computer games - history, design, reception and aesthetics - separately. First Person. New Media as Story, Performance, and Game, edited by Noah Wardrip-Fruin and Pat Harrigan (2006), studies the relationship between narratives and computer games and new possible forms of narrative expression in digital environments. Understanding Digital Games, edited by Jason Rutter and Jo Bryce (2006), seeks to provide the growing body of computer game students with a textbook on the literature dealing with computer games and the methodologies for studying computer games. In Half-Real. Video Games between Real Rules and Fictional Worlds (2005) Jesper Juul strives to create a basic theory of computer games by comparing them with non-digital games on the level of the relationship between real rules and imaginary, fictional worlds. Ian Bogost's Persuasive Games. The Expressive Power of Videogames (2007b) deals with computer games as an expressive, persuasive medium that presents us with a new and unique rhetorical form - procedural rhetoric - which can affect social and cultural positions. Mia Consalvo deals with the various forms of cheating, the diverse reasons for players to cheat and challenges common notions about 'correct' ways of playing games in Cheating: gaining advantage in videogames (2007).

This thesis aims to mend this gap by reflecting on the manner in which the many-to-many model under sway of technological innovations produces changes within the world of toys and playing and by looking more specifically at the mechanisms of userinvolvement at work in this many-to-many model. Toys and computer games are taken as the strategic 
research site. The context for studying and analyzing the changing interrelationship between technological innovations, toys and players are the societal and cultural processes of commodification, domestication and urbanization. It is within this context that new technologies are introduced and used. These three processes stand in relation to both toys and players and their changes over time are reflected within toys, play, the place of play and the goal of play. A historiographical perspective on the complex interplay between societal processes, technological innovations, toys and players shows the many-to-many model at work and on the move, its up rise, manifestations and ways of involving users.

The first chapter of this thesis "New Toys, Different Children" deals with the processes of commodification, domestication and urbanization in the $19^{\text {th }}$ and early $20^{\text {th }}$ century by focusing on the department store as the temple of consumerism, the playroom as the safe haven where children were kept at a distance from the city's moral decline and the playground as the reformist solution to the lack of safe and healthy places for play in the industrialized city. This historical chapter functions as a point of departure, as the opening of the debate on how societal processes, technological innovations, toys and play practices interconnect. It is within this context that new technologies are introduced and the effects of an increasing technologization and digitalization of toys and play are felt and made visible. Throughout this thesis, the changing context of commodification, domestication and urbanization and the interplay with technological innovations will be reflected upon.

The second chapter "Core and Periphery of Play" outlines the key decisions of this thesis: namely the focus on construction toys and the core/periphery model of differentiation as the conceptual framework for analyzing changing practices of play. Construction 
toys will be used throughout this thesis as the context for analyzing the changing many-to-many model and the role of technological innovations within these changes. The core/periphery model will prove highly suitable for analyzing the many-to-many model, its mechanism and changes because it allows us to differentiate between various user positions and their involvement within this many-to-many model.

"The Journey not the Destination" considers the popular and well-known construction toy LEGO. This case study brings to the forefront the intricate relationship between technological innovations, corporate ideology, branding and marketing strategies, toys and playing. More so, the relatively cheap and standardized plastic bricks, their suitability for indoor play and the (sub-) urban and domestic designs, epitomize the postwar commoditized toy, the emphasis on the domestic realm and the angst-ridden relationship between child and urban environment. More recent developments in the LEGO Company bridge the gap with the $21^{\text {st }}$ century and the changing world of production and consumption in an increasingly digital play environment. From the 1940 s to the present, the LEGO Company's history shows the struggle with not using or using the many-to-many model, the need to comply to this model, some 'best' and 'worst' practices of the use of this model.

Chapter four "Pimp my Game" considers the well-known construction and simulation games created by American game designer Will Wright: SimCity, The Sims and the significantly less popular The Sims Online. These three games will be compared to nondigital forms of play in order to highlight the continuities and discontinuities between digital and non-digital toys. These digital construction games signal another important shift in relation to commodification, domestication and urbanization. Wright's series of games has taken the serial- and 
expansion-pack economy to an unprecedented level, have incorporated hyper capitalist principles in the working of the simulations themselves and have demonstrated both the advantages and disadvantages of the many-to-many model. This chapter shows some extreme forms of the many-to-many model, both in terms of 'best' and 'worst' practices. These games bridge the gap between domestic and urban play because they have been produced for so many different portable platforms, from Nintendo's Game Boy to your average cell phone.

The third case study traverses from the world of entertainment games to the more serious domain of policy-making, public participation in urban planning and urban renewal. Chapter five "Playing the City" focuses on Face Your World, a unique public participation project that took place in Amsterdam, The Netherlands in 2005. With this participation project that allowed children and adults through the use of a digital construction and participation game to take part in the design of a new neighborhood park for their borough, the many-to-many model is taken to the streets and applied in a non-entertainment context. This chapter both addresses 'Serious' play (play meant for other purposes than entertainment) and the nature, characteristics, mechanisms and problems of the manyto-many model when used in 'Serious' domains.

The conclusion of this thesis will retake the central findings of the three case studies and focus on the historically changing manner in which the many-tomany model under sway of technological innovations produces changes within the world of toys and playing.

Before outlining the core/periphery model of differentiation and diving into the three case studies, I will zoom in on the processes of commodification, domestication and urbanization - the historical point of departure for this thesis. 


\section{1: New Children, Different Toys}

It has not always been the case that parents can get lost in gigantic Toys ' $R$ Us stores in search for the toy that is their children's favorite that season. It is a rather recent phenomenon that children have their own rooms to sleep and play in, that they have their own clothing style, their own furniture, food, medicine, therapists, education, entertainment and toys. What has changed since the mid $19^{\text {th }}$ century are on the one hand the way toys are produced and consumed and the scale and variety of this production and consumption and on the other hand the way in which society looks upon children and the function of toys in the lives of these children. In this chapter the focus is on the processes of commodification, domestication and urbanization as exemplary processes illustrating how societal shifts 
and the changing world of toys co-evolve, mirror each other or resist one another. For each of these three processes I have chosen one instance, respectively the department store, the child's private room and the playground. The processes of commodification, domestication and urbanization are part and parcel of the coming into being of a new society; the department store, private room and playground are indicators of or responses to these changes.

The interplay between societal processes, toys and children in the second half of the $19^{\text {th }}$ and first decades of the $20^{\text {th }}$ century needs to be understood within the framework of a drastically altering image of childhood. With the work of various pedagogues and child-rearing experts, artists and writers, the $19^{\text {th }}$ century saw a dramatic change in the image of and thinking about the child and its childhood. The PreRaphaelite painter John Everett Millais in his 1886 Pears soap advertisement has famously immortalized the new-formed ideas about children and the child's culture. The child depicted in the advertisement is a kind of cherub child, a beautiful, innocent, vulnerable dreamer that had to be taken care of, washed, dressed, fed and cured. The Innocent Child was very much situated within the pastoral tradition - with its longing for and wish to preserve childlike innocence. The $19^{\text {th }}$ century has been notably phrased the "Age of the Child" by Swedish pedagogue Ellen Key (1909) because of its focus on the child and it's well-being, education and health. ${ }^{7}$ Specialized shops and products

\footnotetext{
${ }^{7}$ A phrase like the 'Age of the Child' (but also the title of this chapter) might seem in line with the 'Invention of Childhood' reasoning that holds based on Philippe Ariès' influential book Centuries of Childhood (1962) that the concept of childhood as a phase distinct from maturity and parents' feelings of tenderness, love and protection for their children date from the $17^{\text {th }}$ century. Opposing Ariès' theory are historians - most notably Linda Pollock (1983) and Daniel Blake Smith (1980) - who found proof in diaries and letters that even before the $17^{\text {th }}$ century, children did have some sort of separate culture and that tenderness did in fact exist between parent and child. Although it is hard to hold on to the 'Invention of Childhood' theory,
} 
reflected this changing attitude towards the child: the "Victorian awakening to the preciousness of childhood helped ensure that children's goods would expand along with other markets" (Kline, 1993, p. 53).

However, it is crucial to stress that these processes worked out differently for girls and boys, for the working classes, middle classes or upper classes, for people living in rural or urban areas. More so, there were significant geographical differences. The Dutch government formulated a law against child labor in 1874 for children younger than 12 years. ${ }^{8}$ Working as a household help, a personal servant or on a farm was excluded from this law (Boon, 1935, p. 13). The law was intended mainly to reduce the amount of children working in factories. England saw the formulation of factory acts in 1802, 1816 and 1833 that dealt with the hours children were allowed to work and safety in the factories (Kline, 1993, p. 47). Nevertheless, working children were and remained even after laws against child labor were effectuated, one of the thriving forces of the Industrial Revolution. ${ }^{9}$ Sometimes up to two thirds of factory employees were children in mid $19^{\text {th }}$ century England. In most Western countries, it was the laws for school enforcement (passed in The Netherlands as late as 1901) that would constitute an actual decline in child labor.

It is hard to exaggerate the gender differences that mark the interplay between societal processes, toys and children. Toys were mostly objects designed for

it is legitimate to say that the culture of the child was before the $19^{\text {th }}$ century less developed and less crowded with specific, at the child-targeted objects and ideas. The 'Age of the Child' phrase as used here and the title New Children, Different Toys should thus be understood in the sense of 'marking a difference' rather than 'marking a break', as indicators of changing, shifting attitudes towards the child.

${ }^{8}$ The law was designed by Dutch left-liberal politician Samuel van Houten and is referred to as 'Kinderwetje van Van Houten'.

9 Nowadays, we see a comparable situation in China's rapidly industrializing economy with children forming a significant part of the work force. 
boys; girls had dolls and miniature household replicas that were often too fragile to play with. The $19^{\text {th }}$ century Boy and Girl Books exemplify these gender differences. ${ }^{10}$ The "sharp differentiation of male and female roles (...) which accompanied the advance of industrialization (...) mandated separate books for girls and boys" (Segel, 1986, p. 170). British author of children's literature Geoffrey Trease wrote "Books were labeled, as strictly as school lavatories, 'Books for Boys' or 'Books for Girls"' (1975, p. 14). The literary genre of the Boy Book was characterized by Romantic and pastoral notions of a boy's formative years and embodied the male longing to brake free from domestication (Jacobson, 1994; Jenkins, 2000; Segel, 1986). Conservative American theorist William Graham Sumner lamented that boy literature (both books and periodicals) depicted 'quiet home life as stupid and unmanly' and 'real life as breaking with respectability and joining the vagabonds and swell mobs' (1877, p. 684). Bestsellers such as Treasure Island (Stevenson, 1883) promoted the "good bad boy" image of the autonomous, adventurous but honest rascal (Segel, 1986, p. 173).

While Boy Books were about 'escaping domestic responsibilities', Girl Books, such as the equally popular What Katy Did series (Coolidge, 1873), centered on 'accepting domestic obligations' (Jenkins, 2000, p. 280). The Girl Book dealt with

\footnotetext{
${ }^{10}$ The Boy and Girl Book have recently been revitalized along their historical lines: adventure for boys and domesticity for girls (Davidson \& Vine, 2007; Iggulden \& Iggulden, 2006). The Dangerous Book for Boys offers, as its historical forerunners, tips and tricks for outdoors fun (how to make a really good knot, or fold a really neat plane). This comes as no surprise; men have never been so domesticated as in the $21^{\text {st }}$ century. The Boy Book offers an emancipation route for the domesticated $21^{\text {st }}$ century man. So do advertisements such as the 2006 Bavaria beer commercial. This commercial shows men tearing of their office garb, letting the iron burn their dress shirts, leaving their suburban gardens to go back to nature, eat raw meat, sniff their armpits and roar and in the end, of course, drink beer (Bavaria, 2006).
} 


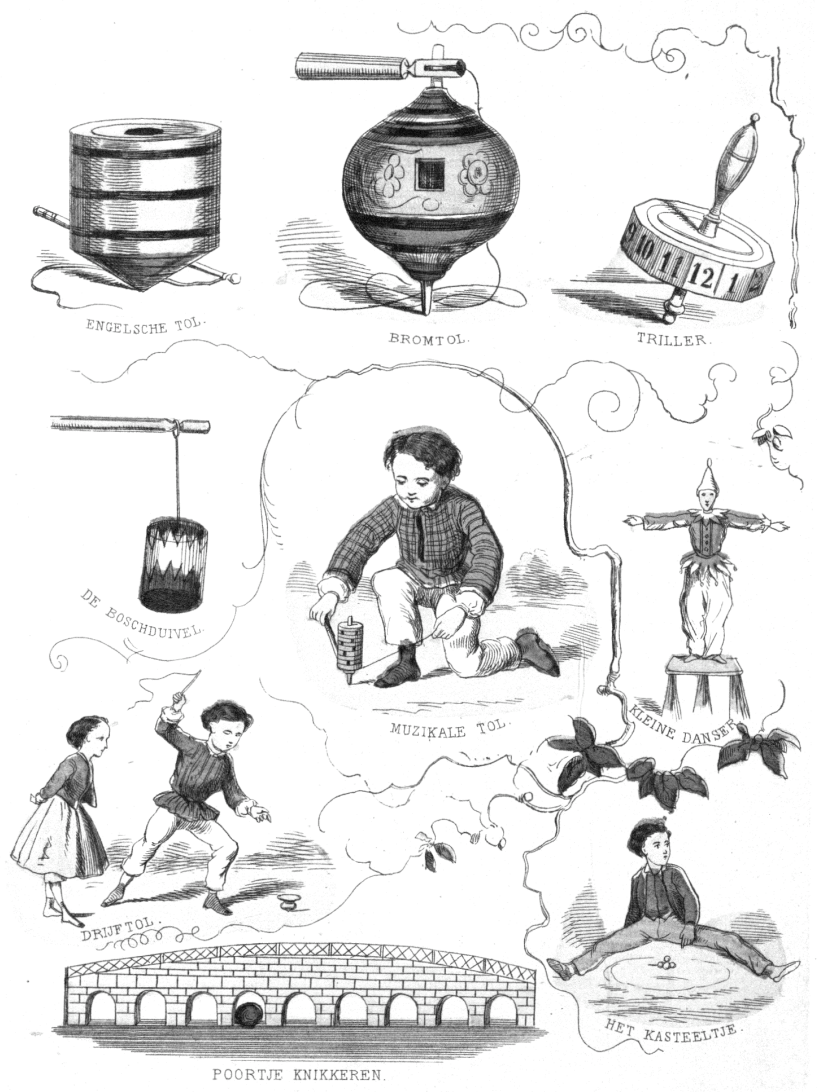

Illustration 4: Toys for Boys. This engraving from a Dutch play instruction book from circa 1865 shows many games that can be played in- or outdoors. Most written explanations of games were accompanied by drawings. The texts and illustrations refer to boys mainly. Girls feature in the book in the role of sisters who can be awed and played tricks upon. In this drawing we see a girl looking with her hands behind her back as a boy spins a top (Beets \& Sandwijk, no page numbers). 
"growing up and becoming little women" (Jacobson, 1994, p. 14), with "devotion", "suffering" and "courage" on the domestic front, with the "fate of a plum pudding boiled by the untrained hands of a girl of fourteen" (Salmon, 1886, p. 516-517).

However, as historian of children's literature Elizabeth Segel notes, girls would often read their brother's books. This "crossing of the well-marked lines (...), unfortunately, did not render ineffective the message of the books regarding the cult of manliness, the counsel of feminine subservience" because "the restrictiveness of the woman's roles as prescribed by girls' books was also embodied in the female characters (when there were any) of boys' books" (1986, p. 177). This schism between boys and girls literature prevailed as late as the 1960s (p. 165).

Domestication mostly affected upper and middle class girls; boys enjoyed more freedom because they were thought less fragile and corruptible. Boys' games are therefore better documented because they were visible to the observer. Percy Green writes in his 1899 A History of Nursery Rhymes, that "Girls' pleasures are by no means so diversified as those of boys" and dismisses the business of girls' games with a few sentences $(1899$, p. 61). At the same time, the changing work conditions and the demand for skilled labor was the hardest on boys "whose adult lives would differ more from those of their fathers than girls' lives would from those of their mothers" (Jacobson, 1994, p. 9 ). The playground marks a minor change in the gender differentiations in the sense that both girls and boys were allowed on the playgrounds. However, children of different sexes were discouraged to play together and different, suitable activities were arranged for both sexes. ${ }^{11}$

\footnotetext{
${ }^{11}$ One feared especially the possibility of sexual excitement in young girls. Therefore, spicy foods, sharing a bed with servants, a nurse or siblings, playing together with boys, and especially sitting on a swing or horse riding
} 
'The awakening to the preciousness of childhood' was a gradual yet irregular process generally taking root first among the upper classes and in urban areas and then filtering through (or being forced upon by reformist movements) to other classes and regions. Although these processes and the problems they brought about played out differently depending on gender, class and geographical location, the broader processes of commodification, domestication and urbanization were felt all through the West. Research in this chapter is based on both primary and secondary texts from both Europe and the United States discussing the situation in England (London mainly), France (Paris mainly), Germany, The Netherlands, rural and urban America between the 1850 s and the 1930s. During these 80 years we see significant changes in how toys are produced, consumed and marketed, where they are being used and what purpose they serve.

THE DePARTMENT STORE: THE CHILD AS CONSUMER

My sled is better than yours; yours was made, mine was bought. (S. Hall \& Smith, 1903, p. 173)

The manner in which shops displayed their goods, priced them, renovated their storefronts, attracted customers, dealt with customers, the types and variety of merchandise they sold, changed drastically in the course of the $19^{\text {th }}$ century. These changes culminated in

were discouraged for girls. This meant that suitable playground activities for girls were different from those for boys. 
the establishment of department stores in the mid $19^{\text {th }}$ century. The change in the display, pricing and dealings with customers was, especially in Europe, at first met with vehement opposition, concern, disbelief and even disgust. ${ }^{12}$ People were used to small, craftsman shops where they could strike a bargain and buy on credit.

However, increasing competition pushed more and more shop owners into displaying fixed prices and creating attractive window-displays and storefronts. The perfection of various technological means to create cheap and large sheets of glass (e.g. with the glasspressing machine built in 1827 or the method for machine-drawn cylinder sheets of glass patented in America in 1903) allowed many shop owners to buy and fix such sheets of glass in their storefront. Artificial lighting - gas and later electricity - increased the visibility of the stores and their goods both from the outside and the inside, during the day and night.

Renovating a storefront in favor of a large piece of glass went often hand in hand with a renovation of the shop as a whole and the annexation of neighboring houses. The resulting bigger shops had more space available for merchandise and instead of selling more of the same they started to sell all sorts of different goods. A former umbrella vendor, for example, would now include in his arsenal of products things such as rain jackets, walking sticks, shawls, bags and the likes. Needless to say, this new way of doing business fuelled competition.

Whereas the shop-keeper of the previous generation was contented to rely upon a solidly built reputation as a sufficient advertisement, the shop-keeper of today, buffeted by an abnormally developed competition, has so to adapt himself to the needs of the times as to seek a more pronounced

\footnotetext{
12 Jan Hein Furnée describes that when a German merchandiser opened a shop in The Hague in the 1850s and displayed in his window not only the fabrics he sold but also their corresponding prices, this caused a massive upheaval; people gathered round the shop and marveled at the cheap prices and the nerve of this merchandiser (2003, p. 80).
} 
advertisement than a good honest reputation. He sees in his shop-front a happy medium for a properly expressed and unique advertisement (Dan, 1907, p. 15).

The refurbished shops put their goods on displays in the most appealing ways, often accompanying these with (sensational) news of the day in word and image.

Shop owners selling diversified products in their expanding stores paved the way for the new shopping concept of the department store. Some of the earliest department stores, Le Bon Marché in Paris or Harrods in London, evolved gradually from small shops into full-fledged department stores. Other cities saw the advent of purpose-built department store, such as Delany's New Mart that opened in 1853 in Dublin, Ireland.

A department store has no dominant merchandise line but sells different products in one and the same store for fixed prices and offers the possibility to return goods or exchange them. The Business Man's Publishing Company published in 1900 the guidebook How Department Stores are Carried on in America which listed some of the basic principles of successful American department stores: "One of the great underlying principles of Modern Department Stores is cash. (...) A few years ago nobody sold for cash. Nobody in those days marked the price on goods in plain figures and stuck to it" (Anonymous, p. 7). Besides cash and fixed prices, the department store differentiated itself from an "ordinary store (...) by being big enough to deal in almost everything that people need" and through its customer service based on ease and comfort and the possibility of 'cheerful refunding' (p. 7-9).

There were, from the first department stores in the 1850s onwards, important differences between European and American department stores. A Dutch accountant, E. Schönberg, gathered information on German, French and American department stores and 
was startled to find that American stores had so many female employees, which would have been fine if only they did not chew so much gum! (1908, p. 72). He also noted that in America the cash-principle was soon replaced once again by the credit principle because this would incline the ladies to buy more (p. 70). European department stores were not so eager to return to the credit-principle that they still associated with the traditional ways of doing business. Schönberg found that American department stores were ridiculously, even offensively generous in changing items or returning money. Even when clothing had already been worn to a party or china had been used to impress guests (p. $70 \& 72$ ). Schönberg also notes differences in the societal acceptance of department stores. Germany knew 'rancorous opponents of the department store' while in America they were 'recognized as a necessary and useful part of contemporary society' (p. $69 \&$ \&1). ${ }^{13}$ German department stores were, for example, restricted in height to minimize 'unfair' competition and could thus never be so large as the American ones who even sported rooftop gardens and playgrounds (p. 68 \&

\footnotetext{
${ }^{13}$ Not only Germany knew such 'rancorous opponents', there was a lot of resistance throughout Europe to department stores. Feelings of contempt towards merchandisers who changed to the department store way of doing business is masterfully described in Émile Zola's famous novel Au Bonheur des Dames (1883). There is a fairly large body of literature on French resistance to the department stores that damaged the livelihood of the shopkeepers. (See for example: Bernard, 1906; Bernard \& Hoffman, 1911; Feyeux, 1883; Garrigues, 1898; Leroy-Beaulieu, 1875; Martin Saint-Léon, 1911). Not surprisingly, France also knew a well-developed discourse on female kleptomania as a hereditary disease spurred on and awakened by seductive window- and shop displays and the abundance of goods (See for example: Boissier \& Lachaux, 1894; Dubuisson, 1902; Dupouy, 1905; Girard, 1845; Lacassagne, 1896; Lasegue, 1879; Letulle, 1887; Lunier, 1848). In Window Shopping Anne Friedberg recounts other neuroses and disorders that accompanied the desires instigated by the new culture of consumption, such as shopping bulimia and compulsive stealing (1993, p. 42).
} 
85). ${ }^{14}$ Many of these differences are obliterated today due to the Americanization of both products and ways of doing business. Most European department stores will have in-house credit cards, flexible return and exchange policies and female employees.

Toys played an important role in the coming of age of the late $19^{\text {th }}$ century department stores. Harrods, one of England's biggest and oldest department stores, held a yearly Christmas Toy Fair that attracted thousands of children and their parents year after year (Dale, 1981, p. 82-83). One of the top five bestselling departments of New York's famous department store Macy's was the dolls and toys department. Schönberg advises the use of a large till with packing table (instead of many smaller tills) in the busiest departments: household goods, food and toys (1908, p. 27). With toys on sale, advertisements tried to lure in children with Christmas specials, clearance sales, children's days and pamphlets stating: "Bring your children along! In our toys department they will sure find diversion and amusement" or "Pay us a visit with your children! In our stores, children are always welcome. The displays entail series of delightful surprises" (p. $32 \& 62$ ). Children were mainly addressed through their mothers with promises of the wholesome effects of this toy or that one. ${ }^{15}$

\footnotetext{
${ }^{14}$ See for example Geschichte der Konsumgesellschaft by Wolfgang König (2000) for more information on the history of German department stores and how they compare with American department stores.

${ }^{15}$ Since the main target of the department store and its' advertisements was the female shopper, the history of the department store is often written from a gender perspective. On the one hand, women acquired with the department store their own public space where they could be the female equivalent of the male flâneur, the city dweller. On the other hand, shopping was also a new means of subjecting women to the game of male onlookers. As salesgirls and as shoppers women were eyed with longing or disgust (Furnée, 2003, p. 94). Schönberg, for example, describes women as 'exited female shoppers' who might need to take a rest from all the excitement in one of the "comfortable beds in the relaxation area that American department stores so conveniently provided for them' (1908, p. $64 \& 68)$.
} 
The department store signals a change in consumerist practices: from consumption as an activity "closely linked with that of production" prompted by necessity rather than desire, to consumption as an act in itself and for itself (Williams, 1991, p. 2-3). As Hannah Arendt states in The Human Condition, the labourers' free time is spent consuming not only "the necessities" but rather "the superfluities of life" (1998 [1958], p. 133). From the 1850s onwards, consumerism was enjoyed by many and feared by some. Consumerist practices and the démocratisation du luxe, entré libre, the fuelling of desires, was condemned and criticized by conservatives, moralists, politicians and the clergy (Bowlby, 1985, p. 1-2; Friedberg, 1993, p. 77). They feared the unsettling effects of democratized luxury on social hierarchies, of free entry on compulsive female buyers, of greed and jealousy on the Innocent Child and they bemoaned the fact that shopping was not rejected as a sinful activity. ${ }^{16}$

We can see some interesting changes in the attitude towards the child and consumerism. During the latter half of the $19^{\text {th }}$ century, both European and American educators, moralists and child-rearing experts "expressed the fear that the dresses, toys, wagons, and other playthings which were being mass produced, and which store windows, catalog pages, and magazine ads prominently displayed, would corrupt the nations youth" writes historian Susan Matt (2002, p. 284). They stressed the need for teaching children emotional control and contentment so that the moral damage caused by the material world and all its temptations would be reduced. Both the growing body of literature on child rearing targeted at parents and the

\footnotetext{
${ }^{16}$ Broader sidewalks, beautiful shops and luxury novelties attracted people from different social standing and sex (although at different times of the day, depending on working hours and free time) (Furnée, 2003, p. 82-90). The new way of doing business with fixed and visible prices attracted crowds of lower class shoppers for whom entering a shop was less intimidating when they knew what they were bound to pay.
} 
textbooks children used in school, preached emotional control and warned for the dangers of envy and jealousy.

In spite of this warning literature, consumerism, desire and envy for material goods and the status they embodied were nourished through the talk of family and friends, catalogues, magazines, advertisements, movies and department stores. In terms of status, there seemed to be a difference between hand made toys and factory made toys, the latter being a status symbol for the families and their children ( $p$. 286). Also, the transformation of holidays (and especially Christmas) into opportunities to purchase gifts and spoil children went contrary to advise on a moderate stance towards consumerism. Psychologist and pediatrician Arnold Gesell found, for example, in 1906 that, based on a 1000 accounts of the reasons, occurrences and forms of jealousy among children, playthings featured prominently (p. 455). Psychologists and educators Stanley Hall and Theodate Smith studied 363 cases of showing off and concluded that girls were more likely to brag about possessions, their clothes and accomplishments while boys would brag most often about "muscular activity" (1903, p. 190). The authors state that the tendency to brag - in itself an evil character trait - is also useful in building a child's selfrespect, as long as it is well balanced against bashfulness and timidity (p. 189).

The idea of jealousy as a positive quality became more common between 1915 and 1930. During those years the message on children and consumerism changed with a new generation of educators and childrearing experts advising parents to give their children more so as not to deprive them and turn them into unhappy adults (Matt, 2002, p. 284). Giving children what they longed for would make them happy and content and eventually lead to a more stable personality. "Much of [the] advice reflected a belief 
that consumer goods might be the solution to children's social and emotional problems rather than the source of their woes" (p. 292). The weakening of the authority of religious writers, the fact that the new generation of advisors had grown up in the consumer society and the overall weakening of the moralistic Victorian tradition lie beneath this change. Rather than preaching contentment, the idea that one could and should aim for a higher status was encouraged. "Schoolbooks (...) implied that envy, discontent, and materialism, traits once considered sins, were now emotions and character attributes worthy of cultivation" (p. 294). Toys went from "corrupting objects which encouraged an immoral love of material things" to "important tools for socializing children" ( $p$. 296). Part of this socialization was training the child for its future role as a consumer.

A 1928 advertisement leaflet in the form of a children's book published by the London based department store Gamages illustrates this neatly. ${ }^{17}$ The advertisement story Edward's Birthday Gift deals with little Edward who is constantly changing his mind about what to ask his auntie for his birthday. He wants what Jones or Jimmy Shaw have and changes his mind from "some soldiers and a model fort" to a "good cricket set" to "a camera" to "a Meccano" set with which you can make "aeroplanes, bridges - anything nearly!" to a "tennis-raquet" (Ingham, 1928, no page numbers). In the end, the aunt sends him a $£ 1$ note so that "he shall choose his gift on the day itself and for himself" hoping to "escape future regrets" (ibid). The story at once shows the rapid succession of fads, the industry's encouragement to want what other children had and the assumed educational effects of handling an allowance.

\footnotetext{
${ }^{17}$ The Gamages department store was established by A. W. Gamage in 1878. See Calloway (1996) for more information on the Gamages stores.
} 


\section{A Private Room: Domesticating Play}

The $19^{\text {th }}$ century process of becoming a consumer was very much related to the family, the private home and more particularly, the private room where the child would play with its new toys. A child's private room knew different forms depending on the child's age and the parent's means and it gained in importance and presence between the mid $19^{\text {th }}$ and early $20^{\text {th }}$ century. From the mid $19^{\text {th }}$ century onwards, moralists, architects and household experts proclaimed the importance of a child's private quarters for reasons of moral, education and health. The private room within the private home had to shield the child from unsuitable influences that might enter the house through visitors, adult conversation or servants. Having a private space to play had to keep children from the streets as well. The city streets were generally considered a 'bad teacher' and an unhygienic place to play. Most $\operatorname{mid} 19^{\text {th }}$ century guidebooks on the building, upkeep and daily ministrations of the private home would combine the advise on child rearing with theories about ventilation, hygiene, warmth, sunlight and space.

Domestication went hand in hand with urbanization; fears for the outdoors made people turn to the inside. Needless to say, differences between classes and locations are numerous. The wealthier Londoners (and many Americans as well) would leave the city altogether and become suburbanites. ${ }^{18}$ Only

\footnotetext{
${ }^{18}$ The flight from the city to the suburb was not only driven by fear for and disgust of the dirt, low morals and dangers of the metropolis, but also by a desire to get away from the developing commercial culture, its pressures, high-paced tempo and demands on everyday life (Mumford, 1961, p. 560). From the 1950s onwards, however, the suburb became itself an epitome of the postwar consumerist culture. The suburb, both the $19^{\text {th }}$ century historical suburb and the postwar suburb, was in essence child-centered. The move to the suburb being motivated by the wish to raise children in a better environment and in proximity to better schools (p. 563).
} 
those rich enough to live in more than one room would be able to afford thinking about a private room for their children. Most working class families, however, rented a room or a 'corner' of a room and their children roamed the streets after work or school. The nursery, schoolroom and private bedroom are therefore truly upper- and middle class phenomena.

In 1838 botanist and garden designer John Claudius Loudon (1783-1843) and his wife novelist Jane Webb Loudon (1807-1858) published the widely read Victorian guidebook The suburban gardener, and villa companion addressing exactly those who had been able to leave the city and who lived in a private, freestanding house on the English countryside. They felt the need to briefly explain what a nursery was indicating that it was not yet a common practice to outfit a nursery room amongst the middle classes in the first half of the $19^{\text {th }}$ century. ${ }^{19}$ "The Nursery is a room set apart for the children, till they are three or four years of age" ([1838] 1982, p. 680). After the age of 4, children should be moved to the schoolroom, a room not exclusively meant for taking lessons, but also described by Loudon \& Loudon as a playroom or exercise room. "The School-room (...) should be sufficiently large for the children to take their dancing lessons in it, and to serve for them to play at battledore and shuttlecock in, or to take other exercise during inclement weather" (p. 680). ${ }^{20}$ Guidebooks alternately situated playing in the schoolroom or (day) nursery, indicating that play did not have as of yet a fixed location within the child's private quarters. Rooms

\footnotetext{
${ }^{19}$ This is not to say that the nursery as such was a $19^{\text {th }}$ century 'invention'. It is mentioned in $18^{\text {th }}$ century educational literature, for example in Practical Education by the Edgeworths (1798). Nursery rhymes, nursery books and children's literature from the early $18^{\text {th }}$ century (especially the work by Jane Johnson who left a handmade nursery library dating from the early $18^{\text {th }}$ century) further demonstrate the existence of nursery rooms. (For more information on Jane Johnson see: Hilton, Styles, \& Watson, 1997).

${ }^{20}$ Battledore and shuttlecock is an old ballgame that could best be compared to badminton.
} 
specifically "designed and furnished for play did not gain popularity until the turn of the century" (Calvert, 1992, p. 131).

Another popular guidebook was the 1883 Our Homes and How to Make them Healthy edited by British physician Robert Brudenell Carter (1828-1918). This book addressed every detail of housekeeping from the amount of pictures one should hang on the walls to the desired position of the bed between window and door. This guidebook also deals extensively with the place of children inside the family home and provides us as such with useful insights in the domestication of children, toys and playing. Chapter 8 on bedrooms, nurseries and bathrooms advises parents to set aside a large portion of the home for their children and their nurses. The authors realize this might be difficult to arrange for parents of less means (let alone for working- or lower class families). Those families who do not have a whole floor to spare for their children and their nurses are advised to use the attic - although never the basement - for child rearing. $^{21}$

When possible, the children's rooms should be close to the 'mistress's bedroom' but not too close. We read:

The nursery department should always be placed within a convenient distance of the bed-room of the parents. At the same time it should be effectually shut off from the rest of the house. This is essential for the comfort both of the elders and of the children: for the elders, because, however fond people may be of children, there are times when the noise and unrest essential to childhood become wearisome; and for the children, because an undue restraint on their amusements, especially in the point of noise, is both unnatural and unfair (p. 87).

The ideal nursery department would consist of a day room, a bedroom for the head nurse and the smaller children, smaller additional bedrooms for the older

\footnotetext{
${ }^{21}$ Calvert quotes from many a diary from which it becomes apparent that children were often raised in basements due to lack of space (1992, p. 131).
} 
children and the under nurse, a scullery, bathroom and toilet. Nurses used the scullery to make tea, dry sheets and store the children's china. A separate schoolroom should be placed 'conveniently near the nursery suite' (p. 89). The day room or day nursery could double as playroom where "children have the whole floor-space for their games" (p. 88). Children would also enjoy their meals, separated from their parents, in the day room - although the toys would then need to be cleared away (p. 844). A nursery corridor would connect these rooms with one another. The guidebook advises the installation of a separate staircase with a lowered handrail formed in "such a manner that sliding on them should be an impossibility" and with adjusted steps for a child's shorter legs (p. 89). To top it of, one is recommended to install a separate door on the ground level so that children and nurses do not have to use the main entrance of the house when they go for a walk or want to go and play in the garden. The children's door would lead to the children's staircase that gave access to the nursery department - completing the separation between the domestic world of children and adults.

'Frequent access to outer air' was considered very important for children (p. 842). However, "younger members of a family" (and "the gentler sex" in general) did spend the largest part of the day indoors. $^{22}$ Therefore, "No attempt should ever be made to rear children in a single room" (p. 844). Change of rooms was a means to provide those staying inside the house with a change of air and it allowed the nurses to ventilate rooms currently not being used. Families of lesser means, whose children slept with the nurse on the top floors, should be allowed to enter the drawing room every once in a while (when there were no visitors) to provide them with a change of air.

\footnotetext{
${ }^{22}$ Concerning the gender division between the private as female sphere and the public as male sphere, see for example Doreen Massey Space, place and gender (1994). 
Markedly, the stress on a child's need for fresh air does not result in the advice to take children outside regularly. Opening windows in unoccupied rooms and changing rooms throughout the day is apparently more advisable than going outside.

Domestication was an attempt at protecting children from the dangers lurking on the outside. Inside the home, even inside the child's private room, the child also needed protection. Furniture such as the crib, swing and jumper, the high chair with a tray and the baby carriage, what historian Karin Calvert has labeled 'furniture for containment', were a means to keep children contained, in one and the same place, out of harms way but also entertained (1992, p. 124-125). This furniture freed the hands of nurse or mother and provided physical exercise for little children. Furniture for containment became more common by the end of the $19^{\text {th }}$ century because finding a good nurse, ideally a virgin or widow from the middle classes became more difficult. ${ }^{23}$ Middle-class girls found better-paid employment, as secretaries or shop assistants, or they would simply attend school until a later age. Besides the scarcity of good nurses, one feared it would be impossible to educate nurses on new practices and standards of hygiene, education and upbringing. Guidebooks often referred to nurses as a problem because they would not behave according to the new hygienic guidelines, would hold on to old-fashioned ideas and customs related to child rearing and might taint the child's moral by their divergent cultural and religious beliefs (immigrant nurses especially were

\footnotetext{
${ }^{23}$ Other incentives that popularized high chairs and swings from the mid $19^{\text {th }}$ century onwards was the growing knowledge on the effects of opiate drugs and the practice of swaddling (wrapping babies tightly in cloth) on children. Both practices - used to keep children calm and suppress their 'spastic' body movements - became discredited because physicians stressed that they accounted for many early deaths as well as mental and physical disabilities.
} 


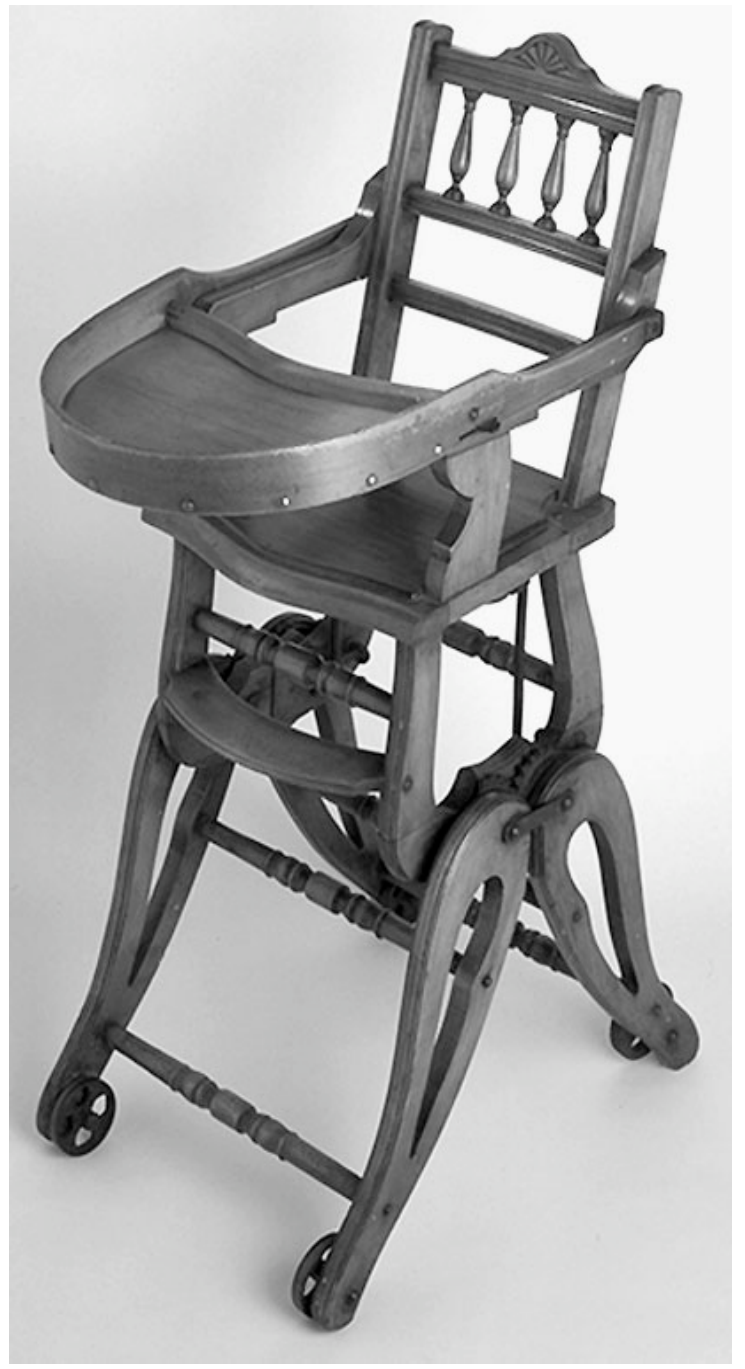

Illustration 5: Furniture for Containment. This high chair from 1860 is part of the collection of the Victoria \& Albert Museum of Childhood in London (collection no.: misc. 45-1961). The chair could be turned into a rocking chair. Feeding trays were added to the basic design of the high chair in the $19^{\text {th }}$ century. "The feeding tray serves several purposes: it restricts spillages to a small area, helps to hold the child more safely in the chair, and provides the child with a play surface" (V\&A, 2007). 
considered a problem in this regard) ${ }^{24}$ With the aid of high chairs and swings, mothers raising children without a nurse would be able to take their work with them into the nursery. While their children were happily swinging away or safely playing in the high chair or crib, mothers could continue with their household chores or hobbies.

The nursery was more than an area in the home dedicated to child rearing. It is described as the locus of the home, as that which makes a house into a home and knits together "generations each to each" (Carter, 1883 , p. 843). All the general requirements of a home, its cleanliness, warmth, air and light, "should be most perfectly represented" in the nursery (p. 844). Certain rooms of the nursery department could therefore double as visitors" rooms because "no better accommodation could be offered to friends or visitors than what is designed for the most cherished members of a family" (p. 843).

The developing culture of the child enforced a redefinition of the child's place and occupations. The world of the middle-class, Western child became the "world of the home, and more specifically, of the toyfilled playroom within the home" as opposed to the "workplace and the public city street" (A. Friedman, 1995, p. 8). Play changed accordingly, from "street games which involved neighbourhood children or strangers" to "play activities such as building blocks, board games, and dolls which could be enjoyed alone

\footnotetext{
${ }^{24}$ Mistrust of servants in relation to children's upbringing is already to be found in the late $18^{\text {th }}$ century, most notably in the work by Maria Edgeworth. In the educational treatise Practical Education as well as in her fictional work (which had a strong educational tone), parents are advised to reduce contact between children and servants, are given ample examples of the erroneous ways in which servants treat children and are warned of servants' and nurses' cunning nature: 'A nurse's wish is to have as little trouble as possible with the child committed to her charge, and at the same time to flatter the mother, from whom she expects her reward" (1801, p. 10). See Sotiropoulos' Where Words Fail (2001) on child-servant relations in Edgeworth's fiction.
} 

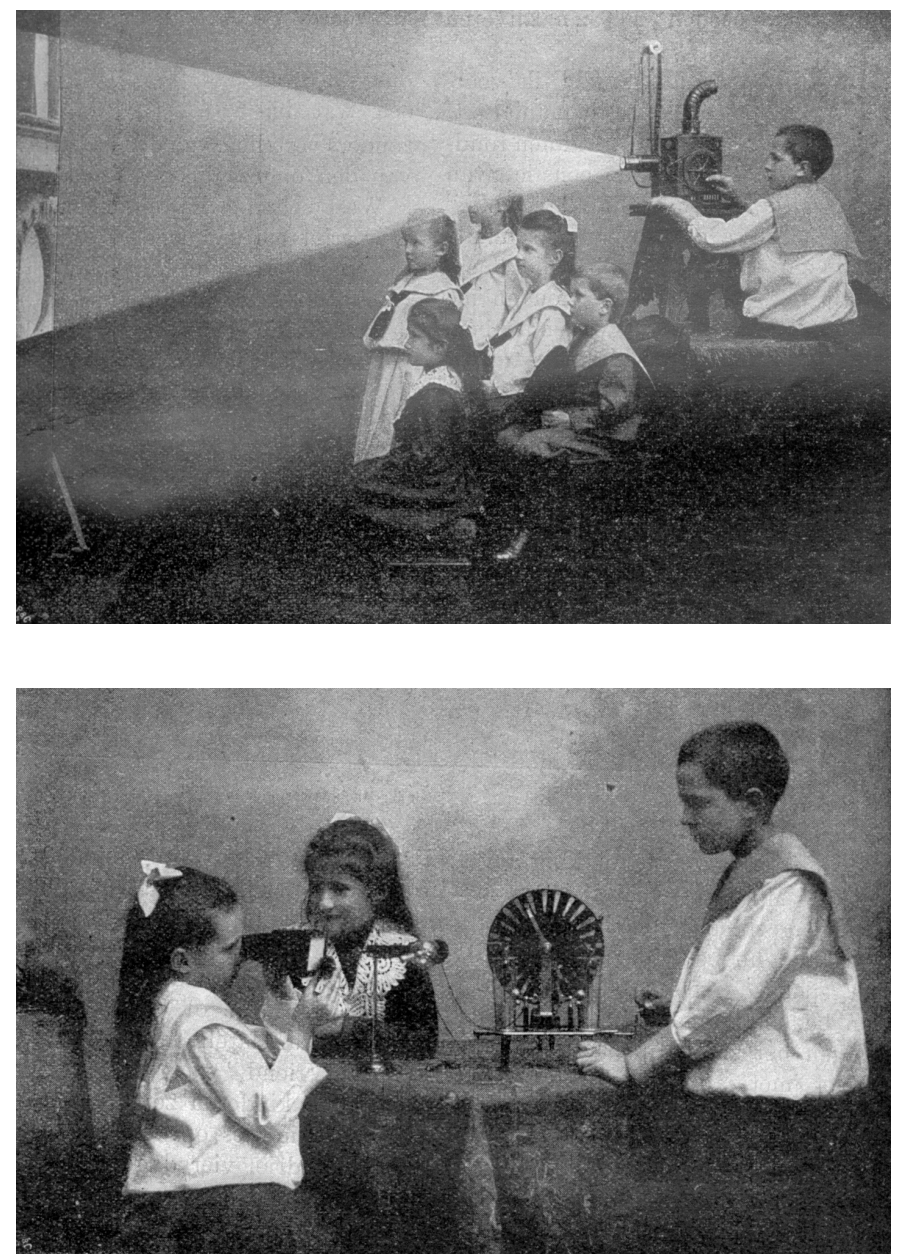

Illustrations 6 \& 7: Mechanical Toys. Almost every scientific breakthrough, technical invention or industrial success was turned into a toy. Here we see children watching a movie on the 'Children's Cinematograph' (Schrijver, 1907a, p. 59) and playing with a Röntgen apparatus (Schrijver, 1907b, p. 122). These complex, fragile and expensive toys were truly indoor toys. 
or with siblings" (p. 8). The $19^{\text {th }}$ century witnessed the design and production of indoor toys. Popular toys were building toys and mechanical toys such as fully functional little cooking stoves, steam engines or model train sets. These toys provided playful learning and socialization - not only in future roles as mother or provider of the family but also in 'solitariness' (SuttonSmith, 1986, p. 23-41). The $19^{\text {th }}$ century toys answered to the need for indoor entertainment while reinforcing the domestication of the child and play in being unsuitable for outdoors play and their requirement of a flat, large and clean surfaces for play. Children's magazines and books would typically dedicate large parts to indoor play, mind games, riddles and tricks illustrating what children could do inside the home, even when they did not have that many toys. ${ }^{25}$ Nursery picture books would bring the wonders of the outside into the home with sketches from the animal kingdom and marvels from Moscow, Egypt and China. ${ }^{26}$

\section{THE PLAYGROUND: THE CHILD IN THE CITY}

Urbanization did not only fuel domestication and suburbanization for those who could afford it. Urbanization had quite a different effect on the rural families migrating to the industrial areas. These families would trade their large farms for small living quarters. Because land in urban areas was expensive and rents were high they could often not afford to rent private rooms. ${ }^{27}$ Sociologist and Benedictine Edgar

\footnotetext{
${ }^{25}$ See for example the playbooks by Bastiaan (1859), Beets \& Sandwijk (ca. 1865a; ca. 1865b), Sutorius \& Midderigh-Bokhorst (1912).

${ }^{26}$ See for example Routledge's Nursery Picture Book (Anonymous, 1862).

${ }^{27}$ Sir Raymond Unwin wrote an inspired pamphlet regarding this problem of high land costs and consequently high rents. In Nothing gained by
} 
Schmiedeler lamented how families went from being proud homeowners to tenants sharing small apartments and the high rent with other families and lodgers. All the moral strength that derived from being a responsible homeowner, the sense of security, protection and a family's privacy had come to ruins among the lower- and working classes living in urbanized areas $(1927$, p. 82$)$. The $19^{\text {th }}$ and early $20^{\text {th }}$ century working class dwellings were so cramped that children could not play inside the home. These slum children dwelled the streets, played on the sidewalks, hustled or went to the movies. ${ }^{28}$ The streets, however, were a dangerous place to play and hang out - that was were children learned bad habits, foul language and turned to crime.

From the mid $19^{\text {th }}$ century onwards, anxiety regarding the physical and moral health of slum children could be felt all over Europe and America. They were considered in need of saving: their health was threatened by the unhygienic streets and poor living and working conditions, by malnutrition and lack of clean, healthy air and physical exercise. With the assumed connection between physical health and moral development, their very soul was at stake as well. $^{29}$ Based on biological and environmental

overcrowding! he wanted to convince landowners who built as many 'lodger-units' as possible that there was no financial gain in doing this. The way they should build and the sort of housing they should offer to the working classes was envisioned by Unwin along the garden city principles. A children's playground was often at the center of his diagrams and drawings (1912, p. 4).

${ }^{28}$ Working class children were expected to hand their pay to their parents. They could keep a small amount to pay for transport to the factories and lunch. Letting children spend money on their own was not considered good practice. Allowances or personally owned money was best spent under supervision of parents. Historian David Nasaw writes that it was easy to protect girls from the bad influences of money because they worked at home for no pay. Boys, however, were hard to control; they would keep money for themselves to spend on candy, toys, adventure books and the movies (1985, p. 131).

${ }^{29}$ The age old adagio Mens sana in corpore sano (sound mind in a sound body) had been actualized through the writing of Charles Darwin (1809- 
assumptions the idea that a healthy body is necessary to house a healthy soul became during the $19^{\text {th }}$ century a key concept in relation to children and child rearing (Cavallo, 1981, p. 50). A child's physical health and moral development were considered related processes, requiring one another. Adding to the concern for urban children's physical and moral health was the growing demand for educated laborers and the pending wars for which many young men turned out to be unfit. ${ }^{30}$

From the 1880s onwards, this fear and anxiety related to the working class urban children grew into various legislative decisions regarding working hours and working conditions, schooling and physical training. The European and American responses to the slum cities and their slum children were different though. As British urban theorist Peter Hall states, the "problem and the perception of it were similar on both sides of the Atlantic. (...) But the remedies were different" (2002, p. 46). In Europe, the "first and overwhelmingly the most important response to the Victorian city was the garden city concept by Ebenezer Howard" (p. 8). Saving the urbanites led at the end of the $19^{\text {th }}$ century to the establishment of the garden city movement by Howard. Garden cities were purposely planned and built, self-contained and green communities with a careful balance between residential, industrial and agricultural areas. Garden cities were built all over Europe and America from the turn of the century onwards. They were utopian cities

1882) and Herbert Spencer (1820-1903) on the connection between bodily health and moral development (Selten, Adriaanse, \& Becker, 1996, p. 22).

${ }^{30}$ With Europe moving fast towards military confrontation, the "quality of the nation's heirs acquired a political significance" (Hardyment, 1984, p. 99). Physical education and outdoor play opportunities became all the more pressing when it turned out that boys growing up in the $19^{\text {th }}$ century industrial cities did not meet the basic physical requirements for entering the military (Hendricks, 2001, p. 16). After the First World War, the American War Department continued "its campaign to reduce the high percentage of physical unfitness discovered by the war" (Anonymous Reporter for the Time, 1923). 
infested with pastoral images, glorifications of a simpler and less tainted life on the countryside where both adults and children would be safe to work, play and live at a secure distance from the industrialized metropolis. ${ }^{31}$

The municipal interventions known in Europe were lacking in America where voluntary reformist movements took on the task of saving the inhabitants of the slum cities (p. 42-43). Reform movements characterized the end of the $19^{\text {th }}$ and the first decades of the $20^{\text {th }}$ century when America was completing its rapid shift from an agrarian to an urban society. These reform movements were concerned with the rights of lower- and working class women and children and the 'Americanization' of the steady gulfs of immigrants. Child saving was "the most widely supported reform movement in the United States between 1880 and 1920" (Cavallo, 1981, p. 1). The inner cities were their battleground and the playground was at the heart of their mission.

One of the principle threats to the moral and physical demeanor of slum children identified by the reformist movements was the way in which children spent their free time. Schmiedeler writes that only onefifteenth of the child's time is spent in relation to school. Minus time spent sleeping, studying, doing small jobs like selling papers (mostly done by boys) and helping around the house (an unpaid job done by girls), the average child is left with 6 to 8 hours of free time (1927, p. 63). And a "surprisingly high proportion" of this time was spent idle. Neither commercial entertainment nor idleness was considered proper ways to while away the free hours. Many were convinced that "Satan speedily found some mischief for idle hands to do" (p. 63). Schmiedeler quotes

\footnotetext{
${ }^{31}$ See Chapter 4 of Hall's Cities of Tomorrow (2002) for more information on Howard and the garden city. As Hall points out, many garden cities were built along the lines of a misinterpretation of Howard's ideas and vision.
} 
studies by American sociologists Henry W. Thurston (1918) and John L. Gillin (1918) that claimed a direct correlation between delinquency and the lack of active play (p. 64). Active play was considered vital to both health and moral. The problem, of course, was the where of this active play.

The playground seemed the perfect vehicle for both moral and physical education of urban children, for socialization and Americanization of immigrants and the regulation of free time. ${ }^{32}$ Instead of spending time idle, in mischief, inactive or at the theaters and movies - children would be better off on a playground. American reformist Jane Addams pleads in The Spirit of Youth and the City Streets (1909) for decent public recreation facilities on the ground that outdoor play will build team spirit among youngsters, keep youth away from delinquency and provide "the activity which cramped muscles of the town dweller so sorely need" (p. 95). American photographer and reformist Jacob Riis complained in Playgrounds for City Schools (1894) that there were not enough playgrounds in New York city and that the streets were the only playground available to poor children. The street, however, was "an educator with its own plan" and that plan was "not a safe one" (Quoted in: Brett, Moore, \& Provenzo, 1993, p. 20). David Nasaw makes a distinction in his Children of the City between children working in factories who were considered to have too little freedom and children working the streets (as vendors, pickpockets or prostitutes for example) who were

\footnotetext{
${ }^{32}$ U.S. President John Calvin Coolidge (1872-1933) launched in 1924 'American Education Week'. The Bureau of Education arranged an official program for the education week and published a brochure that recommended a name and a focus for each of the seven days. Day 5, 'Physical Education Day' would have as its main points "Playgrounds and Athletic Fields Mean a Strong, Healthy Nation", "A playground for every child" and it's slogan would be "A sick body makes a sick mind" (Anonymous Reporter for the Time, 1924). The gulf of youth movements that erupted during the $19^{\text {th }}$ century, such as the Scouts, served these same moral and physical educational purposes (McClary, 1997, p. 40).
} 
thought to have too much freedom (1985, p. 138). As much as the reformers lamented the effects of long hours of factory work on young children, they considered the street workers and the children playing in the streets a nuisance and a threat to adults (p. 20). The conservative theorist Sumner feared the dangers to society coming from the "wild behavior of the idle, vicious and dissipated boys of the great cities' (1877, p. 681).

At the end of the $19^{\text {th }}$ century, places were created where children could play - in parks, next to schoolyards, or on pieces of wasteland. In 1885, Boston saw the construction of a sand garden (commonly considered the first U.S. playground), modeled after a Berlin sand garden. Clarence Rainwater summarizes the most significant changes regarding Boston playgrounds between 1885 and 1900 . These changes give us some insight into how playgrounds evolved. Boston playgrounds increased in number (from 1 to 21 ); their funding went from philanthropy to state support and from small funding to a bigger annual budget; their opening times increased (from 3 days a week to six days, from 18 days a season to 60$)$; their location in the city went from mission yards near churches and tenement courts to schoolyards and public parks; their supervision changed from untrained volunteers to paid and trained superintendents; and finally the attendance increased from 15 children a day at the first playground to 4300 a day at the 21 playgrounds $(1922$, p. 26). The number of playgrounds in Boston (and in many other American and European cities) increased, professionalized and became more popular at the turn of the $19^{\text {th }}$ century. Early playgrounds served a broader communal purpose with clubhouses, libraries and many purposeful activities for not only children but teenagers and adults as well. 
Although playgrounds increased, children did not, as Nasaw indicates, wholeheartedly embrace this form of socialization of play, this domestication of their outdoor play space. New legislative regulations prohibited playing in the streets and street working, children caught committing these crimes were arrested (1985, p. 145). Children struggled to hold on to their former freedoms to play where they pleased and earn their own money the way they pleased. Sumner quotes from a typical late $19^{\text {th }}$ century boy story illustrating the struggle between society's pressures to be a 'good boy' and children's' resistance to this:

"James," said he, "you are breaking my heart with your incorrigible conduct." (...)

"Think of what you might be, a pattern boy, a - "

"Brass-bound angel, silver-plated cherub, little tin missionary on rollers," put in Jimmy (1877, p. 683).

The playground, the equipment especially designed for healthy and purposeful play, the group activities, reflect the projected need for moral and physical education of the urban child. Within the confines of the playgrounds, however, children "did not relish the adult 'supervision' that came along with it" (Nasaw, 1985, p. 36). Interviews with children using the early playgrounds indicate their "disdain for the adult efforts to teach them how to play" (ibid). Nor did all citizens like the introduction of playgrounds - commonly visited by lower- and working class children - in their neighborhoods (Rosenzweig \& Blackmar, 1992, p. 443-447).

In Europe as well, playgrounds were on the rise between the end of the $19^{\text {th }}$ and the first decades of the $20^{\text {th }}$ century. The playground situation in The Netherlands has been well documented by the playground organizations. The incentives for establishing such playground organizations are comparable to the American Reformist mission: moral and physical education for lower- and working-class 
people in dense urban areas. In the beginning, playgrounds were privately funded by the upper classes who lamented the moral and physical decline of the nation's youth and feared the street gangs who made the streets their playground (Boon, 1935, p. 9-15). In 1894, Dutch illustrator Johan Coenraad Braakensiek depicted a street boy as king - high on a throne, surrounded by his gang and a circle of bowing and fearful citizens. In 1880, philanthropist Nicolaas Tetterode created a public playground in Amsterdam to deal with the growing mischief among working-class youth (Selten et al., 1996, p. 15). Many Dutch cities followed Tetterode's lead. Ulke Jan Klaren (known as father Klaren) was probably the most significant and best-known supporter of playgrounds in The Netherlands. He established in 1901 a playground organization that opened playgrounds throughout The Netherlands. Most Dutch playgrounds during these early years served multiple purposes for children, teenagers and adults. The clubhouse would contain a library and on rainy days educational activities were organized in this clubhouse. There were strict rules of behavior for those entering the playground (disobedience was punished with eviction from the playground) and trained supervisors guided children in group play (p. $17 \& 32) .^{33}$

\footnotetext{
${ }^{33}$ See the extensive body of literature by Lia Karsten on the current Dutch situation of city children and public places for play (Karsten, 1995, 2002, 2003a, 2003b, 2004; Karsten \& Beckers, 1995; Wiggers, Kouwenberg, \& Karsten, 1996).
} 


\section{TOYS AS CONTAINERS}

This chapter dealt with changes taking place from the mid $19^{\text {th }}$ century onwards on the level of the production and consumption of toys, the child's place within society and the changing conceptions of childhood and the function of toys in the lives of children. Toys and playing are central in bridging societal processes and changes on the one hand and the individual on the other hand. Toys bring a changing society into the private home and can as such be considered to function as mediators. In this role as intermediary, toys are often at the heart of anxieties, fears, longings and battles. Toys can be considered a terrain, a site, on which crucial battles concerning a changing society are being debated. Toys as containers for emotions and expectations become instrumental, that is to say, they become something else than simply things to play with. They become tools for learning, for socialization and training. Moreover, toys are 'generation-shapers'. Toys can either tie generations to one another through communal play or create a rift between them when (grand-) parents and children cannot find a common ground in play. Toys function as intermediaries in bridging the outside world and the child's universe. As such toys become containers for emotions and expectations, a battleground on which crucial issues related to the upbringing of new generations are being fought.

The up rise of our Western consumer culture during the $19^{\text {th }}$ and early $20^{\text {th }}$ century facilitated the design, development, marketing and selling of diverse toys on a larger scale than witnessed ever before. These toys mimicked the changing world in their miniature versions of technological wonders (e.g. steam engines for boys and cooking stoves for girls) and brought as such these changes into the home. Also, the ritual of buying, of giving and receiving presents 
became an important part in 'becoming a consumer', in training children in how to survive in a consumerist society. Was this aspect of commodification first condemned and considered dangerous and corruptive for the Innocent Child, it later became accepted and even considered valuable to children's upbringing.

The home was the new prime location for wealthier children's play since urbanization had frustrated the outdoors as a safe playground. Urbanization and domestication prompted the need for suitable indoor toys, for toys that would keep children occupied safely indoors. These toys would often mimic the 'dangerous outside world' that children were being shielded off from in building sets that allowed the young engineer to construct, for example, bridges and factories. These toys were mainly targeted at boys because they were expected, when older, to leave the private home on a daily basis to work and provide for their families. Of women, no such thing was expected. Girls therefore did not play with miniature, contained versions of what they could expect on the outside. Neither did their toys prepare them for a career on the outside - as an engineer or architect. Their toys reflected new technologies that were revolutionizing the household and the lives of their mothers. The new toys for girls demonstrated the workings of the girls' future work tools, the engineering of the household (A. Friedman, 1995, p. 14).

The road to the future through play would be sharply divided for boys and girls. Toys designed for boys idealized technology, constant innovation, and the values of competition and teamwork. Those for girls were mostly dolls and were designed to train girls to become "modern" housewives and nurturing mothers (Cross, 1997, p. 51).

Girls' toys were hardly toys but fragile objects best put on display. Ceramic dolls with lace-trimmed dresses were to be handled with care while tin soldiers could be incorporated in the rough and tumble play of boys. Boys were introduced through their toys into the world 


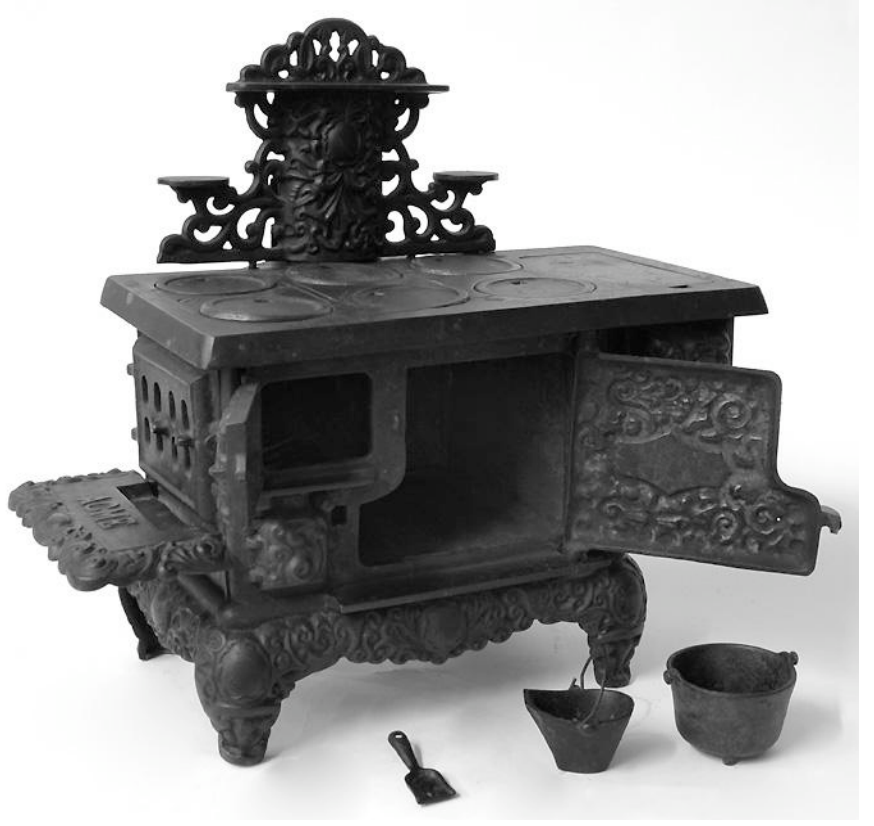

Illustration 8: Gifts for Girls. This cast iron miniature toy stove was created by Chicago based ACME toy company at the end of the $19^{\text {th }}$ century. It is a fully functional stove that came with all the attributes of a life-size stove. It measures 12 inches or 30.5 centimeters high and 13.5 inches or 34 centimeters wide. The stove is sold for $\$ 350$ on the Internet (Pia, 2007). 
of science and industrial production. Girls were introduced into the world of consumerism and modern house making because in a consumerist society "developing shopping skills was becoming an important part of growing up" (p. 51). However, as Aaron Alcorn (2006) demonstrated with his research on model airplanes, boys were also constructed as consumers through the systems of collecting different airplane models, memberships and contests but under the guise of male activities such as airplane building and the creation of future-oriented technological men.

To be sure, many children living in the $19^{\text {th }}$ century industrialized cities did not partake in these upper- and middle class processes of commodification and domestication. Children from the working- and lower classes would often work in the factories producing the new commodities and would share a single room with their family. Saving these children became a late $19^{\text {th }}$, early $20^{\text {th }}$ century effort that crystallized in, among other things, the building of playgrounds in urban and industrial areas. Urbanization had, in other words, two different effects. On the one hand urbanization prompted parents to keep their children indoors if they could afford it financially and space-wise. This in turn stimulated the production of indoor toys (with construction sets as a most important example) that reinforced the domestication of child and play. On the other hand urbanization fuelled the belief that working- and lower class children were in need of saving from the factories, streets and commercial entertainments. This in turn led to the construction of playgrounds and the creation of outdoors play equipment. Slides and swings, balls and hoops, sand gardens and sporting fields were attempts to domesticate outdoors play and socialize the urban child.

The interplay between the societal processes of commodification, domestication and urbanization, toys 
and children still resonates today, although this interplay has changed in shape and direction, intensity and target. The nature and objective of many debates related to the effects of playing computer games illustrate that the mid $19^{\text {th }}$ and early $20^{\text {th }}$ century issues related to toys and children are still very much alive today. ${ }^{34}$ Computer games are, for example, often criticized as the embodiment of a consumptionobsessed culture and society. Computer games are advertised through movies, card and board games, action figures and animated movies. Their heroes feature on pajamas, bed covers and lunch boxes. They are characterized by what could be labeled the 'expansion pack and serial' economy that has children wanting these new additions and installments to their favorite games. ${ }^{35}$ Moreover, many games' internal logic is based on consumerist principles of gathering, trading, accumulating. ${ }^{36}$ Computer games as aggressively advertised commodities are only one aspect that is contested about these digital toys.

Another often-voiced critique on computer games relates to what we could call overdomestication. It has never been so easy, attractive and addictive to stay indoors. Computer games have added to existing couch potato forms of entertainment, such as television, an even more captivating form of staying indoors. Children play computer games indoors, hunched over a keyboard or controller, eyes glued to the screen. They over use certain muscles and totally under use others. Computer games are un-put-down-

\footnotetext{
${ }^{34}$ For a more detailed comparison of fears and expectations involved in the introduction of new media, see Computerspellen en de Geschiedenis van Angst (Lauwaert, Wachelder, \& Walle, 2004). For a more detailed analysis of the historical roots of current debates on the playing of computer see Get Up \& Play (Lauwaert, 2006).

${ }^{35}$ See David Nieborg's The Expansion Pack Economy (2006) for a detailed examination of this mechanism.

${ }^{36}$ In relation to children in our present-day consumer culture see: Buckingham (2000), Kline (1993; 2003), LaPlante \& Seidner (1999), Linn (2004; 2005) and Seiter (1995).
} 
able and while playing, children forget to eat, take a break, go to the toilet, stretch their legs; they just play on and on... Instead of being in the open, getting fresh air and physical exercise, they sit the whole day breathing the stale indoors air. ${ }^{37}$ Although computer games over-domesticate child and play, they also frustrate the private room as a sanctuary. Game consoles and personal computers connected to the Internet, computer games prompting the player to go online for updates and new input as well as hand-held gaming devices reestablish a connection between child and 'the mean world' outside of the private room.

\footnotetext{
${ }^{37}$ The game industry, traditional toy makers and a range of one-product, opportunistic companies respond to this problem of over-domestication with the production of what we could call 'off-the-couch-games'. These games require the player to physically move in order to play. The Smart Cycle by Fisher-Price is "a stationary bike, a learning center, and an arcade game system-all rolled into one!" (Fisher-Price, 2007). One-productcompany XMAT sells the GamerCycle promising to turn "the completely sedentary activity of playing home video games, into a calorie-burning, aerobic activity for your children. (...) the GamerCycle is a way to add fun and exercise to video game time" (XMAT, 2007). Better-known examples are Sony's EyeToy (2005) and Nintendo's Wii (2007).
} 


\section{2: Core and Periphery of Play}

The use of toys, the users of toys and the importance adhered to toys has changed dramatically since the beginning of the $19^{\text {th }}$ century. From objects created from leftovers to machine-made and mass-produced toys, from pastime amusement for adults and children to instruments for a child's education and learning; toys have become invested with expectations, longings and fears. Toys have turned since their commoditized and instrumentalized $19^{\text {th }}$ century incarnation into vehicles for mediation between societal processes and individuals. Not only do toys mirror societal and cultural change, they will often reinforce and spur these changes on. For example, construction toys answer to the need for indoor toys while reinforcing the domestication of child and play in their design. 
Toys are then more than simply a hatch-like object, a passageway or vessel. Toys are at the same time mediators, mirrors and motors. Toys are involved in a relationship of mutual shaping or co-construction with societal and cultural processes on the one hand and with the individual or the player on the other hand. The historiographical approach of this thesis to the changing interrelationship between societal processes, toys and players, is directed at teasing out how the many-to-many model under sway of technological innovations produces changes within the world of toys and playing.

Parallel to this historiographical perspective on the interplay between societal processes, technological innovations, toys and players, the many-to-many model and the mechanisms of user-involvement at work in this model will be addressed. Therefore, the long-term historical perspective on commodification, domestication and urbanization will be supplemented with case studies that zoom in on the relationship between toys and players. Concerning the relationship between toys and players I argue that toys facilitate and stimulate certain practices of play and not others. Would one argue from a technological deterministic point of view that toys determine to the full extent how one can and will play with a given toy, I argue that players use toys in unpredicted and divergent ways as well. Would one argue from a voluntaristic point of view that players can and will play their game notwithstanding the toy they are using and the possibilities that toy offers, I argue that toys do shape play to a certain extent.

Toys and players shape each other, both indirectly and directly. Indirectly, toys and players mutually shape each other through unforeseen or divergent events in the areas of production, marketing, consumption and the eventual use of toys. Directly, toys and players are interconnected through the 
changing relationship between producers and consumers. Not only are players increasingly and inevitable consumers, nowadays they are also to an ever-greater extent being incorporated into production processes. With the shift from a one-to-many production process to a many-to-many model of design, production and marketing, the way in which toys and players shape one another intensifies, becomes more direct and instrumental. This many-tomany model, part and parcel of the history of the computer game industry, has turned from the late 1990s onwards into a template for non-digital toy companies as well. Moreover, the many-to-many model has been used in many areas outside of toy and game production as well. In diverse policy domains, reestablishing a meaningful and positive relationship between 'producer' and 'consumer' is sought through the use of the many-to-many model. This many-tomany model relies precisely on the willingness of users to enter into a process of co-creation, mutual shaping and interdependency with diverse companies and governmental institutions.

\section{CONSTRUCTION TOYS}

Construction toys are an outstanding example to illustrate how toys mediate between societal processes such as commodification, domestication and urbanization and the individual child because construction toys exemplify these very societal processes. ${ }^{38}$ The history of construction toys is closely

\footnotetext{
${ }^{38}$ Although this paragraph gives a brief historical account of the changing world of construction toys, it is by no means complete or exhaustive.
} 
linked with the coming into being of consumerism. The combination of new production processes that facilitated the mass-production of relatively cheap toys with the department stores, secured mass-consumption of toys. ${ }^{39}$ Construction toys - to be assembled with care and patience by fitting little pieces together on a flat surface - are domestic toys pur sang. ${ }^{40}$ They are designed to be played with indoors and will keep children occupied for hours while they are safely inside the family home. As such, these toys reflect the reluctance to let children play outside unsupervised. However, most construction toys would center on urban design: building houses, bridges and other architectural constructions. The outside world was thus brought to the sanctuary of the family home in a safe and containable format.

Construction toys were (and still are) a very popular genre of toys among educators and parents. Their popularity among children has seen some significant swings. From the early 1990s onwards, construction toys suffer from their imago as boring and dull toys. Children prefer digital construction toys or construction toys with some electronic implementations. Euromonitor - offering international market data on industries, countries and consumers -

During the $19^{\text {th }}$ and early $20^{\text {th }}$ century, hundreds of different construction toys were produced and sold. Some companies and their toys survived long enough to be remembered today while others have disappeared and been forgotten.

${ }^{39}$ The Gamages Mammoth Bargain Clearance leaflet, for example, advertises with mechanical trains sold at an incredible low price. The producer explains: "We manufactured tens of thousands. Which enables us to sell this First-class Stock at what may appear to be Impossible Prices" (1913).

${ }^{40}$ According to Tobias Mey, German well-to-do citizens would often devote a whole playroom to construction toys, thereby turning that room into a building room. The little particles could easily be lost and the player simply needed a flat and uncluttered floor to build upon (1999, p. 35). Karin Zachmann points out that not only construction toys prompted the need for a separate playing room but also model trains and other mechanical toys that needed a lot of floor space and clean, flat surfaces (2003, p. 213). 
conducted extensive research into toy buying habits among European countries between 1996 and 2000. While dolls and action figures remain the most bought toys in any European country (with an average market share of 50\%), construction toys are an important market as well with an average market share of $25 \%$ in Europe (Rauno, 2001a, 2001b, 2002). In relation to toy consumption in France, Euromonitor states "construction games which integrate electronic functions have helped to counter the consumer perception of building sets as being outdated" (Rauno, 2001a, p. 141).

The popularity among educators and parents of construction toys is related to the historical entanglement of construction toys with educational notions. From the very start, the educational value of construction toys was stressed: "Construction toys (...) have always been associated with being "educational" (Hewitt \& Roomet, 1979, p. 44). For example, in the British toy trader's magazine Games \& Toys $^{41}$ from July 1914 we find the article Constructional Toys of Merit stating:

We live in the age of construction toys. (...) One thing stands out from the great boon and that is that the average boy of to-day needs a toy which is not only a toy, but one which has an educational value attached to it (p. 80).

Meccano would advertise their toys in the 1924 Gamages department store catalogue with the slogan "He did not buy this fine Crane, he built it!" to indicate that there was more to their construction toys than mere consumerism (Calloway, 1996, p. 126). These toys were more than a fad; they were "Engineering for Boys" (ibid). ${ }^{42}$

\footnotetext{
${ }^{41}$ The British toy traders' magazine Games \& Toys was first published in 1914. In 1979 Games \& Toys amalgamated with Toy Trader. From 1981 onwards it is published as Toys \& Games Trader.

${ }^{42}$ See Carroll Pursell's The Long Summer of Boy Engineering (1992) for a more detailed study on construction toys and engineering for boys.
} 
Reasons for labeling construction toys 'educational' vary, but they all center on the fact that building something is considered a purposeful activity whereby children understand an object through the dismantling and reassembling of it, through being actively involved in decision making and structure forming (Hewitt \& Roomet, 1979, p. 44-45). According to Stevanne "Dr. Toy" Auerbach, construction toys force children to think about fit, angle, gravity, size, space, cause-and-effect (connect what you see with what you can do) while stimulating eye-hand and small muscle coordination, thereby developing self-esteem, independence and increasing language skills, social abilities and imagination (1999, p. 15). More generally, construction toys are considered educational by psychologist Dorothy Singer because they are about planning, patience, thinking ahead, cooperation, sharing, self-control, delay of gratification while increasing insight in building processes, mathematics and natural sciences (2005, personal communication).

German educationalist Friedrich Fröbel (17821852), establisher of the Kindergarten, was both directly and indirectly a key player in the popularization and commodification of construction toys (Hewitt \& Roomet, 1979; Lewis, 1992; Mey, 1999; Noell, 2004; Noschka \& Knerr, 1986; Parkinson, 1999; Poser \& Zachmann, 2003). This is not to say that Fröbel 'invented' the construction toy. Wooden building blocks and alphabetical building blocks dating from the late $18^{\text {th }}$ century are found in many a toy museum. ${ }^{43}$ But their popularity and diversity took a flight with Fröbel's construction toy designs and his writing on the educational merits of these toys. Fröbel established his first Kindergarten in Blankenburg, Germany in 1837. He considered play "the highest

\footnotetext{
${ }^{43}$ The Canadian Centre for Architecture in Montreal holds one of the world's largest collections of construction toys (CCA, 2007).
} 

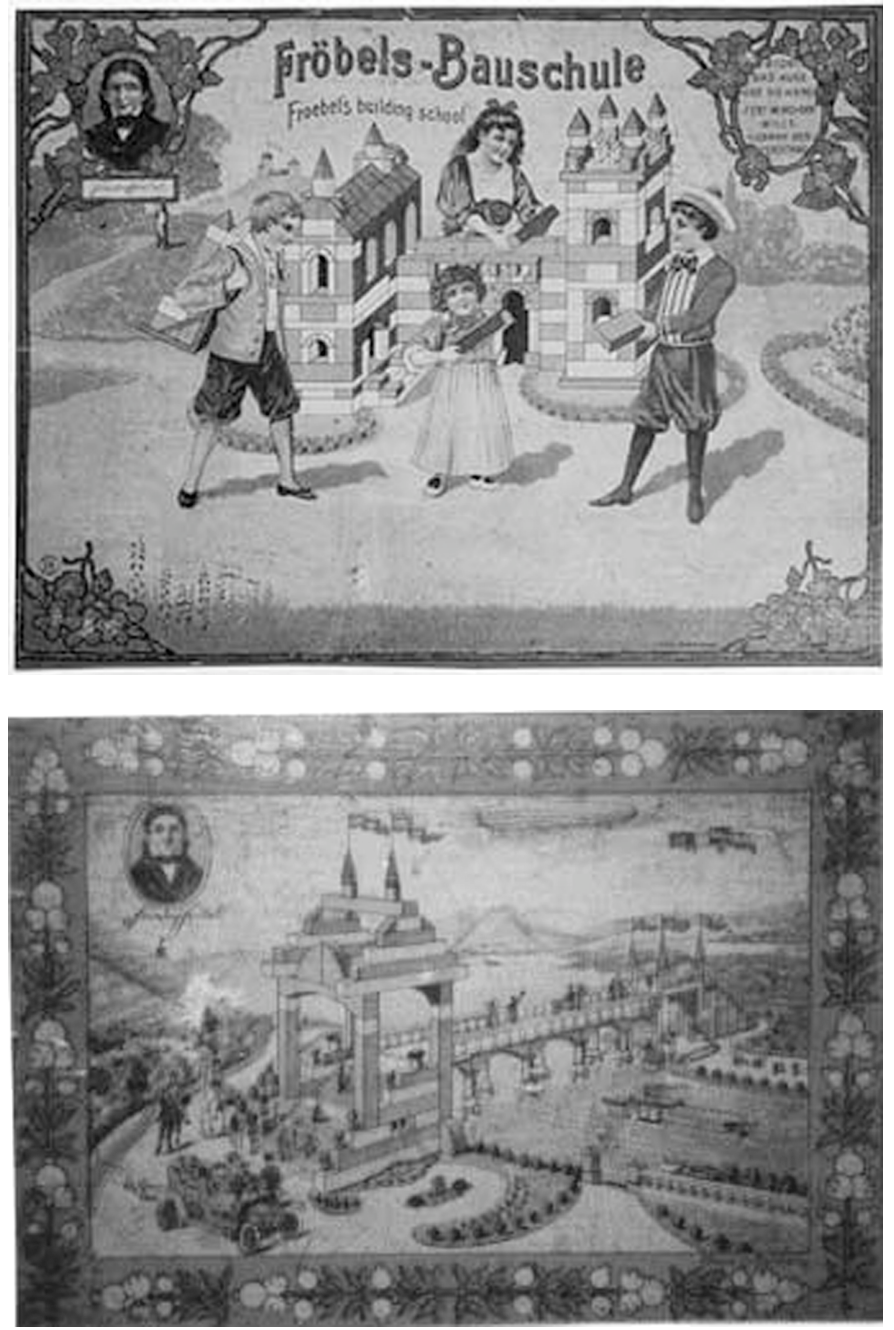

Illustrations 9 \& 10: Commercial Fröbel construction sets (Wetzel, 2006). Gifts number 5 and 6 inspired these mid $19^{\text {th }}$ century Fröbel sets. Fröbel's portrait in the top left corner was a sign of quality and educational soundness. 
phase of child-development" and stressed the fact that "play at this time is not trivial, it is highly serious and of deep significance" (Fröbel, 1887, p. 54 \& 55). He designed toys (which he called gifts) for use in his Kindergartens and wrote detailed instructions on how the gifts had to be used. ${ }^{44}$

Building kits played a central role in Fröbel's Kindergarten system (Mey, 1999, p. 34-35; Parkinson, 1999 , p. 177). For example, Fröbel's toys number 3 to 6 consisted of wooden building blocks. These gifts were popularized and sold in Germany as 'Fröbel's Building Blocks' and 'Fröbel's Bauschule' from the mid $19^{\text {th }}$ century onwards. Many toy manufacturers sold wooden building blocks they claimed to be in line with Fröbel's pedagogy (Zachmann, 2003, p. 214). Magazines like Jugendlust would publish ideas and examples of what one could build with Fröbel's Baukästen (e.g. 1881, ed. 32). ${ }^{45}$ The first German factory to produce wooden building toys - S.F. Fischer Spiel- und Holzwarenfabrik in Seiffen, Oberseiffenbach - produced and distributed Fröbel's toys on a large scale from 1870 onwards.

\footnotetext{
${ }^{44}$ These detailed instructions on how children had to play with the toys or gifts have always been a point of critique on Fröbel's educational system: "The Gifts were also criticised on the grounds that they were too structured and therefore unsuitable for easy usage and adaptation by the children" (Liebschner, 1992, p. 120). As an example, some lines from Fröbel's Pedagogics of the Kindergarten (1897) in which he describes how to present the fifth gift to the child: "Before beginning his play with this gift the child must apprehend it as a symmetrical whole, complete in itself. (...) In conformity with this demand the bottom of the box must be occupied by one row of undivided cubes, one row of halved cubes, and one row of quartered cubes. The eighteen remaining undivided cubes fill the rest of the box. If the cubes be thus arranged in the box and covered with the lid, it is only necessary to place the box on the table with the cover downward, then to draw out the cover and raise the box with a steady hand" (p. 204-205). Irene Lilley writes in her translated collection of Fröbel's writing that these strict guidelines, when turned into an educational system, "became a chilling formalism" (1967, p. 69).

${ }^{45}$ The German youth magazine Jugendlust was published between 1876 and 2001.
} 
Fröbel's toys also inspired the brothers Gustav and Otto Lilienthal in the second half of the $19^{\text {th }}$ century to create a building toy. The brothers experimented with various materials because they wanted to make a construction toy in stone rather than wood. The brothers found that the wooden bricks were not heavy enough and that the constructions collapsed too easily. They were not successful in launching their own toy and sold the rights to Dr. Adolf Richter. Their stone building toy was produced and sold from 1880 onwards as Anchor Stone Building Sets. ${ }^{46}$ Richter also established a club in 1912 (Anker-Steinbaukastenverein) and magazine in 1913 (Anker-Zeitung) for fans of his construction toys. Later, construction toy manufacturers would follow his example and try to establish a bond between producer and consumer through magazines, clubs, contests and loyaltyprograms.

Fröbel's gifts were also manufactured and sold in the United States, most notably by the Milton Bradley Company in Springfield, Massachusetts. ${ }^{47}$ Bradley produced Fröbel's gifts from the 1870s onwards and published on the Kindergarten movement to spread Fröbel's thinking in the U.S. (Bradley, 1896).

Besides such sets claiming to be in line with Fröbel's educational ideas, "Fröbel's gifts were often reproduced purely as toys (...) in the absence of any clear copyright protection" (Lewis, 1992, p. 16). There were both expensive and inexpensive "pirated" versions of Fröbel's toys, in cardboard for "workingclass families" and in stone or other luxury materials for those able to afford it (p. 16).

\footnotetext{
46 These historical sets have recently been reissued with the same packaging, content and drawing of Fröbel on the backside as those early sets (Anker, 2007).

${ }^{47}$ Milton Bradley established the Milton Bradley Company in 1860. In 1920, he bought the McLoughlin Brothers' toy company that had been producing Fröbel inspired toys as well.
} 


\section{FROM BUILDING TO DESIGNING}

Construction toys have changed since their $19^{\text {th }}$ century popularization. For one, the main materials used in creating construction toys changed from wood, stone and steel in the $19^{\text {th }}$ century, to various plastics during the postwar period and digital technologies from the 1980 s onwards. ${ }^{48}$ The nature, type and porté of construction toys has diversified as well over the years. To put it bluntly, construction toys have changed from wooden and stone generic building blocks to designing toys of diverse materials, with different shapes and, crucially, with an interlocking mechanism. Historian of technology Karin Zachmann describes this as a shift from 'building' to 'constructing functional models that the player designs or copies' $\left(2003\right.$, p. 216). The $19^{\text {th }}$ century building toys were generally sets of wooden or stone building blocks that facilitated the constructing of architectural and/or abstract objects. These toys were mainly meant for young children and focused on the development of bodily skills through building or stacking blocks on top of each other (Cross, 1997, p. 60 ). The design possibilities of these building toys were limited because they did not have an interlocking mechanism.

From the turn of the century onwards, these traditional building sets are supplemented with sets specifically focused on designing objects as a form of play. These second-generation construction toys would often mimic the designs that were revolutionizing the public sphere and allowed the player to construct miniature bridges, skyscrapers, cars and planes. These

\footnotetext{
${ }^{48}$ In general, German construction toys have been and still are characterized by natural materials such as wood and stone. An interesting exception to this is the postwar East-German architectural toy Plaspi Grossblock ("Der Kleine Baumeister"). This plastic construction toy allowed the player to recreate the dominant East-German architecture complete with pre-fab walls for fast building.
} 


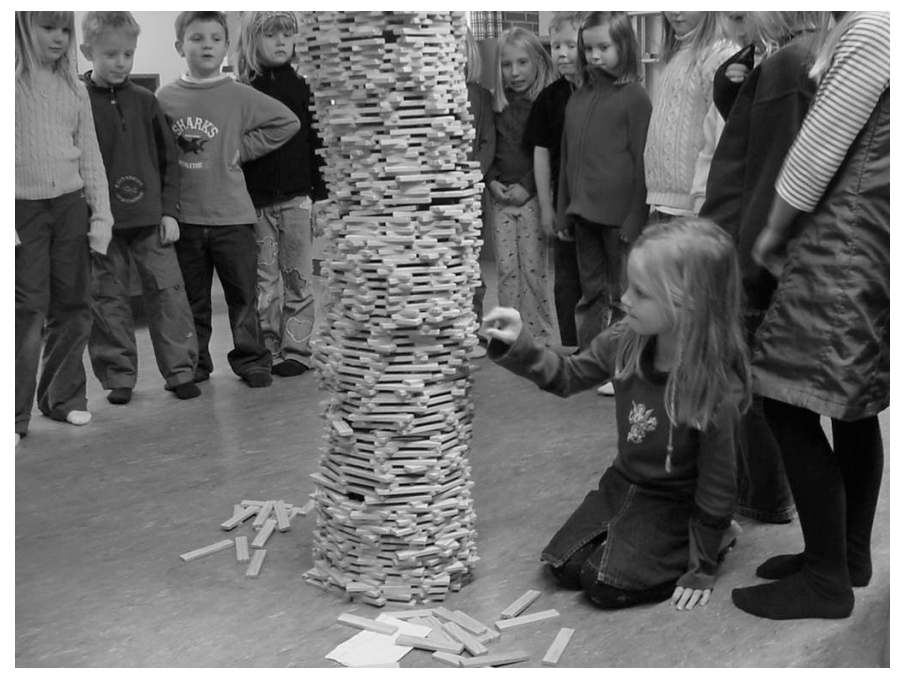

Illustration 11: Construction Toys as Building Toys. These children built a tower with the Kapla building toy of more than 1 meter high. They used some 1000 planks to create this tower (Olsson, 2003). The Kapla building toy is a contemporary first-generation construction toy made of identical small wooden planks without an interlocking mechanism. It was invented in the 1980s by Dutch art historian Tom van der Bruggen (Bruggen, 2007). I have chosen a contemporary example to illustrate that the two sorts of construction toys - building and designing toys - exist side by side. There are still many traditional building sets on sale. 
construction sets were designed to be about design both on the level of play practices and play subject. Meccano, Lincoln Logs and the Erector Sets are wellknown and popular examples of the second-generation construction toys. ${ }^{49}$ Designing more complex and wide-ranging objects was facilitated through more diversified pieced and an interlocking mechanism of one sort or another. The generic building elements of the early construction sets were supplemented with more specified building items, such as wheels or curved pieces. Meccano sets, for example, contained specified items that allowed the player to design elaborate constructions while still facilitating the construction of more than one design. ${ }^{50}$

It is important to stress that the change from building to designing toys was not a clear-cut one; neither did the second-generation construction toys replace the first generation. Both types of construction toys exist side by side. Generally speaking, firstgeneration construction toys are made from wood or stone and second-generation from metal or plastic, materials that facilitated an interlocking mechanism. However, during the transitional phase between building and designing toys, wooden design toys with an interlocking mechanism were also made (ill. 12).

\footnotetext{
${ }^{49}$ The first Meccano factory opened in 1907 producing the famous metal construction toys invented by Frank Hornby. John Lloyd Wright (son of architect Frank Lloyd Wright) designed the Lincoln Logs, which allowed the player to build Uncle Tom's cabin and Lincoln's log cabin, in1916. The Erector Set was patented by A.C. Gilbert in 1911 and was manufactured by the A. C. Gilbert Company.

${ }^{50}$ This characteristic of construction sets, their 'versatility', is one of the five basic characteristics of construction toys outlined by Peter Lingens in Bausteine (1999, p. 17). The other four key characteristics according to Lingens are 'standardization': the pieces in a building set have to be standardized and interchangeable (implying a certain generalness as opposed to uniqueness of building elements); 'reversibility': the building project has be reversible (sets where the pieces have to glued together, for example, are model building kits); 'three-dimensionality': you have to be able to build a three-dimensional shape, not just a flat shape; and finally 'constructive building': a minimum of technical or constructive play has to be made possible (ibid).
} 


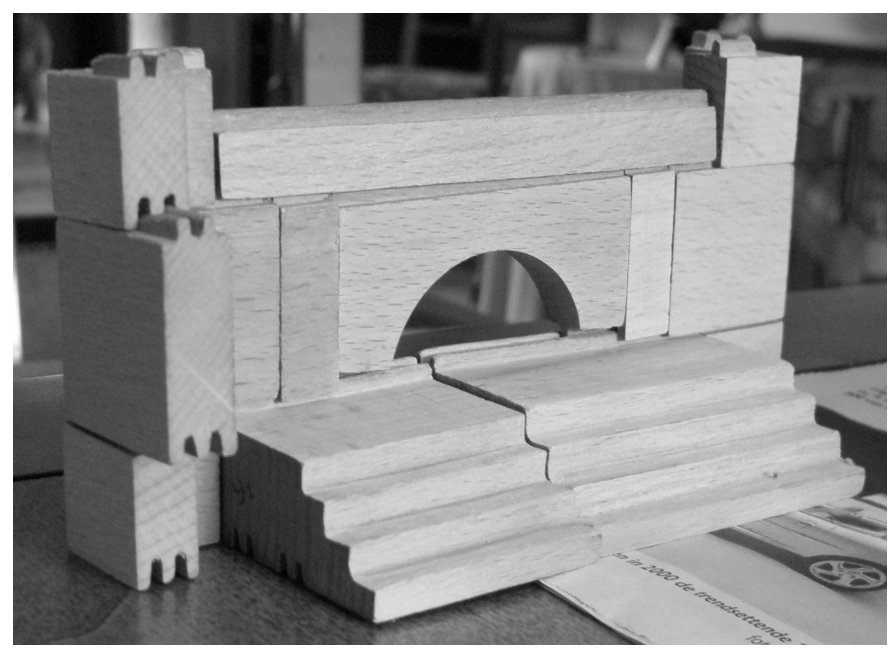

Illustration 12: Transitional Construction Toys. The interlocking mechanism was a crucial factor in the development from building toys to designing toys. This construction toy, of which both name and manufacturer are unknown, alerts us to various aspects of this development. For one, it indicates that the development from building toys to designing toys did not necessarily coincide with the aforementioned material changes. Although wood and stone have been (and still are) the prime materials of the first-generation construction toys (building toys), they have also been used to manufacture second-generation construction toys (designing toys) such as the one depicted above. Especially during the transitional period of the first decades of the $20^{\text {th }}$ century, wood was often used to create second-generation construction toys. Not always with success however. The interlocking mechanism of this toy, for example, is not very precise and the toy therefore came with a little hammer to forge the pieces together. Second, this toy illustrates that, although architectural constructions and models are characteristic of first-generation construction toys, this does not mean that second-generation construction toys would not take architecture or home building as their subject. This toy was given to Jan van Dorst in 1932 when he was 10 years old. He contacted me after an interview on my research appeared in a local newspaper. When he was forced to leave his family behind in The Netherlands and go into hiding in Belgium during the Second World War, he took this toy with him. He made both objects that the manual outlined and invented his own designs (Interview with Dorst, 2007). 

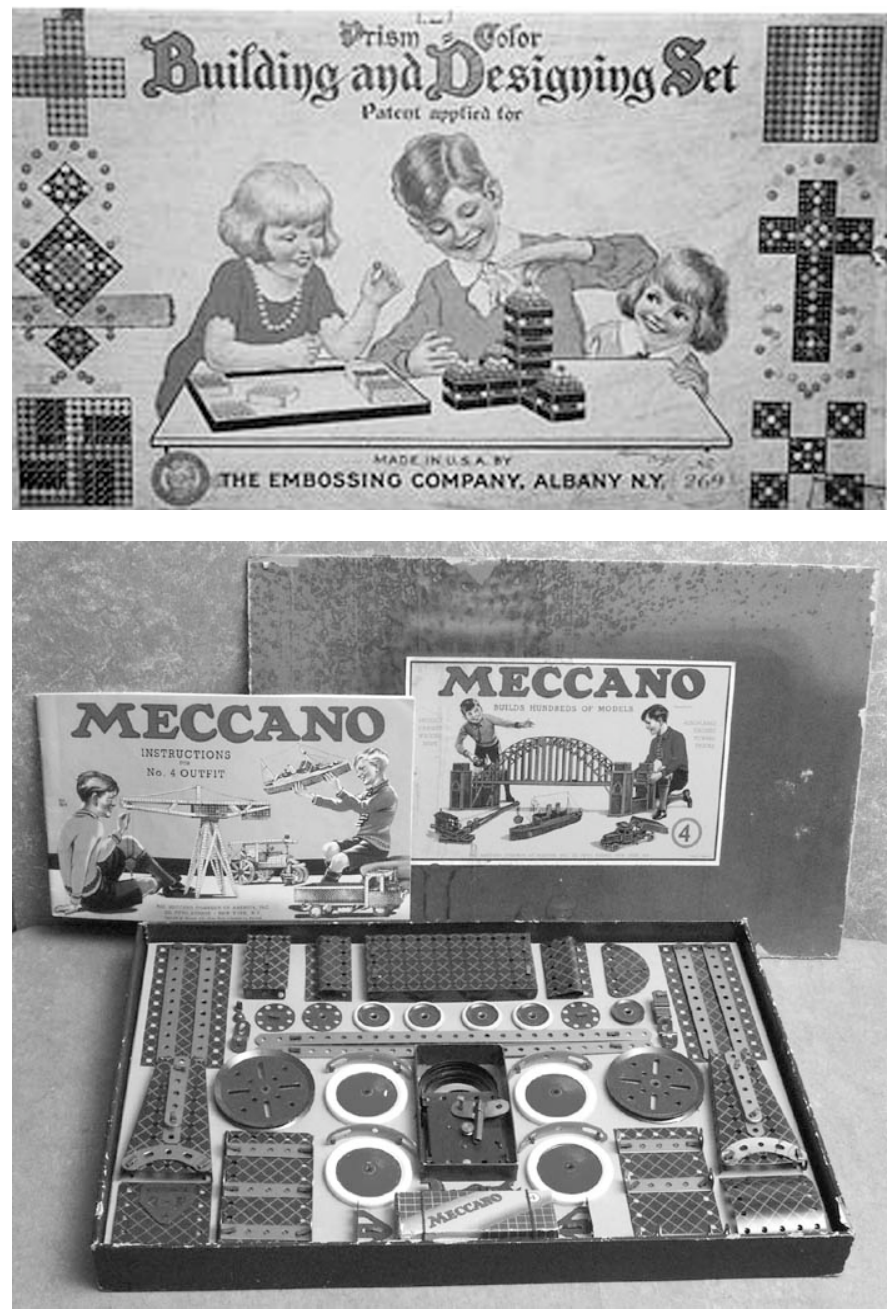

Illustrations 13 \& 14: Towards Construction Toys as Designing Toys. The top image shows the Prism Color Building and Designing Set from 1919. This toy combines the characteristics of both types of construction toys: building and designing. Blocks could be stacked on top of one another and decorated with colored adornments (Wetzel, 2006). The bottom image shows a Meccano set from 1938. The many specified items in the set augmented the design possibilities with this toy (Bisset, 2006). 
And of course, many plastic building blocks are on the market. First-generation construction toys were mostly focused on abstract or architectural construction. Many early second-generation construction toys would still adhere to this idea of construction toys as architectural toys and focus on the designing and constructing of houses (see ill. $12 \& 13$ ).

Second-generation construction toys epitomized a culture's belief and optimism that indeed, thanks to new technologies and materials, everything seemed possible. Construction toys mirror fundamental beliefs of our Western culture in construction, design and 'malleability'. ${ }^{51}$ The main focus in this thesis is on second-generation construction toys.

Design in this context and specific use should be understood as actions taking place at the intersection between the "thinkable" and the technologically "possible", between "models, cultural structures, forms of knowledge", "availability of materials" and "technological development" (Manzini $\&$ Cau, 1989, p. 17). At the turn of the century, newly available materials and production processes expanded what could happen at the intersection of the thinkable and the possible.

Concurrently, this shift from building sets to designing sets entailed a shift from constructions toys meant for both girls and boys to construction sets targeted almost exclusively at boys. Designed-to-beabout-design construction toys were boys' toys, quintessential to the men's world of technology, optimism, progress and new inventions. Would the drawing on the Fröbel's Bauschule set still sport two

\footnotetext{
${ }^{51}$ Bill Brown argues likewise that the $19^{\text {th }}$ century "mass-produced automatic toy" mirrored the rhythm of modernity with its "segmented, repetitive movement" (1995, p. 454-455). These toys affirmed "within the realm of childhood amusement, the fragmenting rhythm of machine discipline and the atomization of the body" thereby mediating between modern life and modern production processes and the domestic everyday ( $\mathrm{p}$. 455).
} 

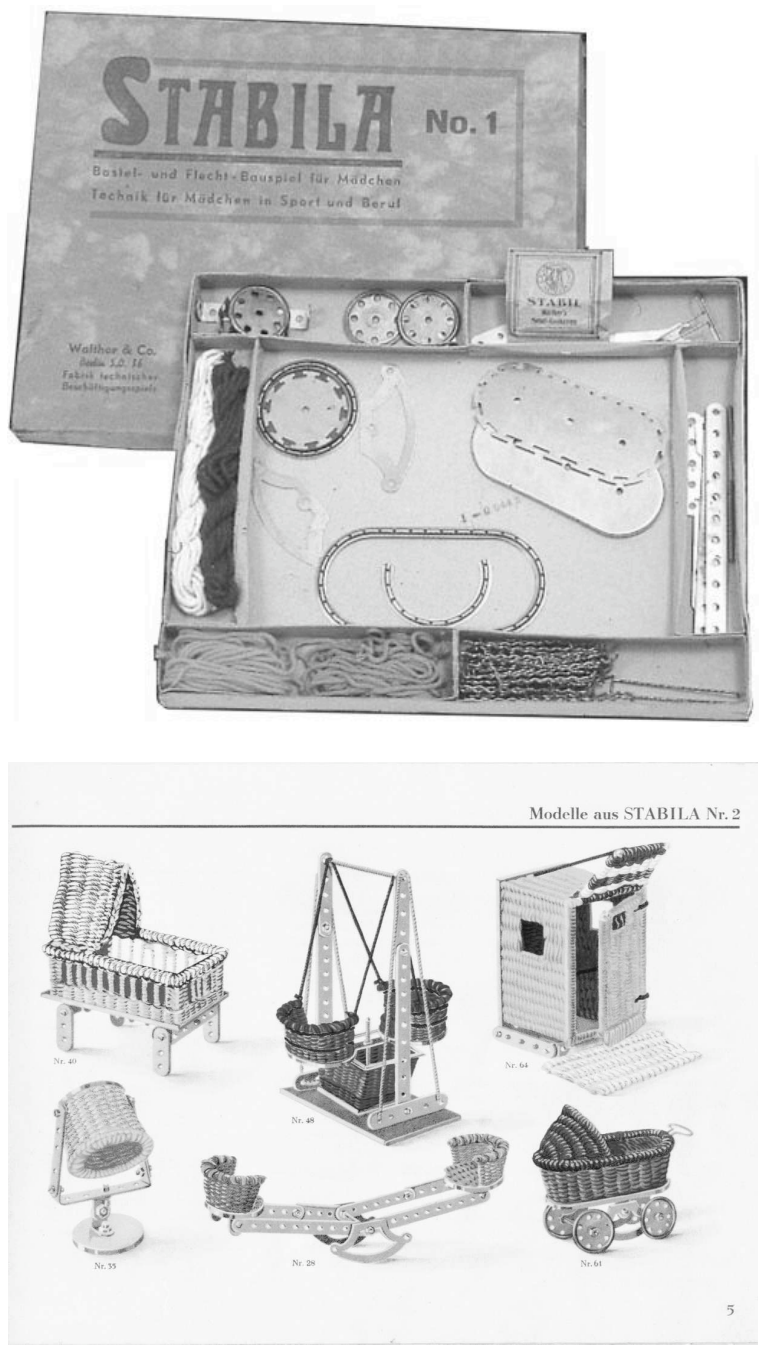

Illustrations $15 \& 16$ : The top image shows the box of the first Stabila set from 1933. The bottom illustration shows examples that accompanied Stabila set number 2 (1933, p. 5). With this more elaborate set girls could make swings, a baby cot, something that looks like a hair drying cap and a beach cabinet for changing into a bathing suit. Both sets combined elements reminiscent of maleoriented construction sets, such as the metal plates, with woolen and colored threads that made the metal constructions more colorful and homely (Sticht, 2002-ongoing). 
girls, one of them actively building, the Meccano set only shows boys (the Meccano-Boys was a popular club for male Meccano fans). Typically, these secondgeneration construction sets would show a boy at play, often with a father or grandfather hovering over the scene. Mothers, if depicted, would look on the scene benevolently from an easy chair. Sisters, when present in these building tableaux, would be helping their brothers. The Prism Color Building and Designing Set (ill. 13) shows two girls and a boy playing. The little sister cheerfully looks on while the older sister hands her brother the design elements, the colorful additions to his construction. The Stabila construction sets by Firma Walther from the 1930s attempted at unifying male oriented construction play and female occupations (ill. $15 \& 16){ }^{52}$ The Stabila sets allowed for the construction of objects in line with a girl's future occupations (pram or baby cot for example). The metal base for the constructions was made homely with colorful woolen threads. ${ }^{53}$

The diversifying construction toys and the material changes that went hand in hand with this diversification also influenced construction play.

\section{GEOGRAPHIES OF PLAY}

In order to unravel and analyze the interrelationship between technological changes, toys and changing

\footnotetext{
${ }^{52}$ Firma Walther was named after Franz Walther (1860-1931) who produced Stabil for boys and Stabila for girls in Germany's first metal construction toy factory. Firma Walther was closed in 1991.

${ }^{53}$ Although construction toys targeted at girls were never as successful as those targeted at boys, there are of course plenty of girls-oriented toys that are designed-to-be-about-design. Such as the fashion dolls - both digital and non-digital - for which girls have to design clothes.
} 
practices of play, a differentiation is made between facilitated and divergent forms of play. The latter is further subdivided in wanted or unwanted play practices. $^{54}$ The tracing and laying-out of these different practices of play will be based on the core/periphery model of differentiation. When considering how the many-to-many model under sway of technological innovations produces changes within the world of toys and playing and what sort of mechanisms of user-involvement are at work in this many-to-many model, the core/periphery model of differentiation is highly suitable.

Using core and periphery as descriptive terms allows us to identify different practices of play and their position inside the 'geography of play'. The geography of play is the sum of core and peripheral play practices and consists both of physical and digital elements, of tactile and non-tactile components, of objects and connections. The changing and differing geographies of play addressed within this thesis are historically located and need to be understood within the context of the processes of commodification, domestication and urbanization. In tracing changing geographies of play, crucial aspects of the nature, characteristics, mechanisms and problems of the manyto-many model are brought to the forefront.

The core/periphery model of differentiation is used by, among other disciplines, sociologists and

\footnotetext{
${ }^{54}$ The differentiation between facilitated and divergent was decided upon after some terminological struggles. Different pairs of terms that were toyed with include internal and external, intended and unintended, facilitated and spontaneous. Although facilitated and divergent is not as symmetrical as, for example, internal and external, it covers the characteristics of the two different groups of play practices most precisely. 'Facilitated' denotes the making (of an action or process) easy or easier, possible, smooth or smoother. To facilitate is to enable and assist but also to promote, encourage and catalyze. 'Divergent' points towards the tendency to be different or develop in different directions. The term 'divergent' further encompasses the wanted - varying, different, dissimilar, unalike - and unwanted - conflicting, incompatible, contradictory - practices of play.
} 
political geographers (Blom, 2004; Chase-Dunn \& Hall, 1991; Gottmann, 1980; Mény \& Wright, 1985; Rokkan, Urwin, \& Aarebrot, 1987; Shils, 1975). ${ }^{55}$ Different authors from different disciplinary backgrounds define the relationship between core and periphery in different terms and determine on different criteria what belongs to the core and what to the periphery. A cross-disciplinary notion is that core and periphery are interdependent. As French geographer Jean Gottmann writes in Centre and periphery: spatial variation in politics (1980), there is no core without a periphery and visa versa: "there is no periphery unless the spatial figure considered has a centre, or central sector; inversely, once a centre is determined, there is to be a periphery around it; otherwise of what is it the centre?" (p. 20).

The key question in relation to using the core/periphery model is determining what is part of the core and what of the periphery. The disciplines using the core/periphery model all tackle this question in a different way. In economy and anthropology, for example, it is not uncommon to determine the core based on interaction frequency and degree of connectedness between the actors (Borgatti \& Everett, 1999).

The core of the geography of play is understood within the framework of this thesis as constituted of facilitated play practices. Facilitated play practices are shaped by the combination of design characteristics of a toy and the discourse surrounding the toy. The structure of a toy, its technological specificities, its materiality, the rules and manuals, examples and guidelines, its 'reputation' and connotations create a network of facilitated play practices. Both the material

\footnotetext{
${ }^{55}$ The core/periphery model is also used within the field of economic geography. (See for example: Baldwin, 2001; Borgatti \& Everett, 1999; Charlot, Gaigné, Robert-Nicoud, \& Thisse, 2006; Currie, 2006; Muñiz \& Carvajal, 2006).
} 
and immaterial aspects of a toy or computer game create a window of opportunities within which boundaries the player can act. ${ }^{56}$ To be sure, as Nelly Oudshoorn and Trevor Pinch ascertain, "there is no one essential use that can be deduced from the artifact itself" but "there may be one dominant use of a technology, or a prescribed use, or a use that confirms the manufacturer's warranty" (2003, p. 2). The core should not be understood as the essential and sole correct use of an artifact but as the facilitated use that is reflected in design and discourse.

The core is shaped by scripts that are embedded in the artifact or practice and that stem from the design process of this very artifact. "The concept of scripts tries to capture how technological objects enable and constrain" (p. 9). Madeleine Akrich compared technological scripts with film scripts that "define a framework of action" (1992, p. 208). During this design process, specific uses and users are preconceived and set in the design. Designers try to configure the user and uses by contributing to a definition of users, by anticipating and defining user preferences and inscribing these into technical design, by establishing parameters for user action. This means that artifact and practices are prestructured by designers and design processes. Norms and values, knowledge and experiences, rules and requirements are embedded into the design and promote specific user behavior. During the design process, designers configure 'the' user, a projected and ideal user or a host of different and maybe even conflicting users (Grint \& Woolgar, 1997, p. 73; Lieshout, Bijker, \&

\footnotetext{
${ }^{56} \mathrm{I}$ use here the terms 'toy' and 'computer game' in referring to the artifacts with which one engages in play. Computer games have brought about a terminological shift: from toys to computer games (often referred to as simply 'games') and from playing to gaming. Toys are generally considered to be non rule-based play objects that induce open-ended play while computer games are commonly understood as rule-based play objects that facilitate rule-based forms of play.
} 
Egyedi, 2001, p. 47; Oudshoorn \& Pinch, 2003, p. 711; Oudshoorn, Rommes, \& Stienstra, 2004, p. 31-32; Woolgar, 1991, p. 69). It is within the core of the geographies of play that practices and tactics of configuring the user are to be found. ${ }^{57}$ They are inscribed into the designed artifacts of toys and computer games and expressed in the discourse that accompanies these artifacts. ${ }^{58}$

However, playing is in essence experimentation and boundary testing, which inevitably results in play activities outside what has been facilitated or prescribed, in other words: in peripheral play activities. Players will almost always, in one way or another, perform play activities that lie outside of the core. The periphery of the geography of play, then, is comprised of divergent practices of play that deviate from the discourse on a toy or game or that use the design of a toy or game in unexpected ways. The latter will almost always implicate a deviation from the discourse as well.

To give an example, the combination of the design and discourse on Meccano toys facilitates the creation of cranes, planes, bridges and comparable industrial objects. Using the Meccano elements to build, for example, an elephant deviates from the discourse of masculine, industrial engineer-play. Once players use a designed object in a way that differs from

\footnotetext{
57 'Configuring the user' is a term that encompasses many different forms and tactics - "defining, enabling, constraining, representing, imposing and controlling" - of configuration as Mackay et. al. write. Furthermore, they rightfully point out that designers themselves are also configured and that the process of 'configuring the user' entails "extra-organizational" forces as well (Mackay, Carne, Beynon-Davies, \& Tudhope, 2000, p. 741-745 \& 752). Many other STS scholars have argued likewise that configuration includes other actors as well, such as "journalists, public-sector agencies, policy makers, and social movements" (Epstein, 2003; Kammen, 2003; Oudshoorn \& Pinch, 2003, p. 9; Parthasarathy, 2003).

${ }^{58}$ This thesis is mainly concerned with what users do with these scripts in their actual use of technological artifacts. Further research would be needed to investigate how and why during the design processes certain scripts are embedded within toys or computer games.
} 
the discourse that companies support, advertise and promote, these activities can be considered divergent. For example, Siskind's militaria MOC sets (ill. 17 \& 18) use the LEGO design in a way that deviates from the LEGO discourse of innocent, playful and educational children's toys.

Players can also move away from the facilitated core by altering the design of a toy or game. For example by programming cheating bots that will affect and change the design of a computer game. The programming, selling, buying and ultimate use of cheating bots in a game does not only alter the design of a computer game but deviates from the game discourse as well. Of course, a toy or computer game can also be used in ways that fall completely outside of the scope of the geography of play. For example, when one uses the Kapla wooden planks not to build a construction but to stabilize a bookcase, then this practice is indeed divergent but it no longer pertains to play. The periphery, then, contains those activities with a toy or a game that divert from the discourse and/or alter the design while still concerning, affecting and relating to playing with that toy or game. These activities are wide-ranging and diverse, from hosting a fan site to selling your custom created sets. Most peripheral user activities operate according to the many-to-many paradigm: by us for us.

In relation to computer games, Consalvo sees these activities as part of what she calls "gaming capital", the conglomerate of user activities that support the game and its communities (2007, p. 4). This gaming capital that 'shapes our experience of gameplay', that "isn't the game industry but is closely related to it" has evolved over the course of the last two decades "from a trickle to a torrent" (p. 8). These "peripheral industries" function, according to Consalvo, as a "paratext" (p. 9). The term paratext is taken from the work by French structuralist Gérard 

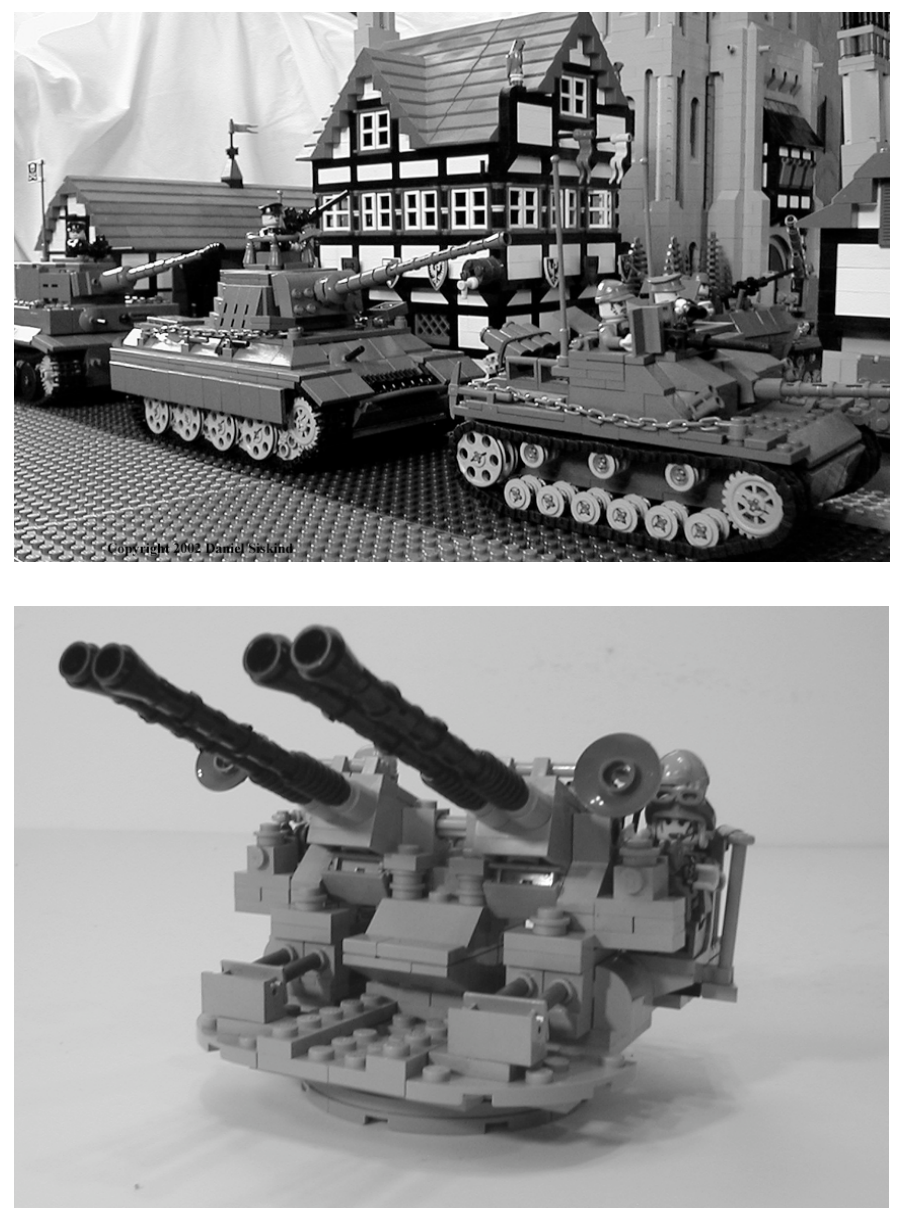

Illustrations 17 \& 18: Deviating from the LEGO Discourse. This German (motorized) Heavy Tank and American AA Mount are World War Two replicas Siskind designed, constructed and sold as LEGO MOC sets in 2002 and 2003 (Siskind, personal website). 
Genette who considered elements that "helped shape the reader's experience of a text", such as "a table of contents, a title, and a review", belonging to the paratext (p. 9). Consalvo considers the use of the word 'periphery' in relation to gaming capital as 'dismissing or ignoring the centrality of these industries to the gaming experience' (p. 8). This is a good point to stress again that core and periphery are interdependent: no core without a periphery and no periphery without a core. It is exactly the changing relations and dynamics between core and periphery that alert us to how the many-to-many model changes toys and playing and the mechanisms of user-involvement at work in this model.

Divergent, peripheral play practices can be situated on a spectrum with wanted play practices on one side and unwanted on the other. Both types of play practices are encompassed within the term 'divergent' that means 'differing and varying' but also 'conflicting, incompatible and contradictory'. Certain excursions outside of what has been facilitated can be useful (capitalizable, insightful, instructive) to the toy or computer game companies, fortify the brand, help or strengthen the user community, or improve the player's experience of the toy or computer game. These play practices are wanted, applauded and welcomed by different actors in the field - from producers to player communities to individual players. For example, the designing and selling of the Blacksmith Shop was a divergent player activity (peripheral) that resulted in a successful commercial design (core), which aided the LEGO Company to overcome its image of an impermeable company and strengthened fans' loyalty to the LEGO Company.

Other transgressions outside of the facilitated core are not capitalizable, might damage the brand image, irritate the user communities or frustrate the player's experience and are as such unwanted play 
practices. One such an example is the user-generated nude patch (a patch is a software application for a computer game) for The Sims that allows players to play the game 'naked'. Because this patch thwarts the age rating of the game it damages the brand image and makes it a target for computer game adversaries. Unwanted play practices illustrate that there is indeed, as Gottmann observes, "some possibility of opposition and confrontation" between core and periphery (1980, p.8). Unwanted, peripheral play practices that succeed in finding their way into the core of the geography of play, create a conflict or crisis. This is illustrated by the unhappy failure of the online version of the immensely popular The Sims. The Sims Online is spoiled by a collection of antisocial player behaviors not only on fansites in the periphery but also in the very core of the game.

Although certain practices of play might be perceived in general as being either positive and constructive or negative and disruptive additions to the geography of play, this is not to say that all actors within the geography perceive and experience these activities in the same way. The LEGO fans that worried on the Lugnet discussion board that turning the MOC Blacksmith Shop into an official LEGO set was a way to control the fans, indicates that a play practice might at one and the same time be perceived as wanted or unwanted by different actors in the field (Lugnet, Blacksmith Shop). In the same vein, those players performing antisocial play practices in The Sims Online benefit from this and their actions, unwanted by others, augment their personal game experience. 


\section{CENTRIFUGAL AND CENTRIPETAL MOVEMENTS}

Sly as a fox and twice as quick: there are countless ways of "making do."

(Certeau, 1988, p. 29)

There are two possible movements between core and periphery: centrifugal (moving away from the core) and centripetal (moving towards the core). Of both movements examples have already been given: when players diverge from design and/or discourse they move away from the core in a centrifugal movement. The Blacksmith Shop illustrated how a peripheral player activity 'migrated' from the periphery to the core in a centripetal movement. These movements or forces within geographies of play can be best understood in terms of appropriation and configuration. As stated, the core of the geography of play is the sum of design and discourse and embodies practices and tactics of user configuration. When users buy an artifact they familiarize themselves with the embedded scripts. Importantly, users will, more often than not, in adopting a new artifact, adapt it, 'modify, design, reconfigure or resist' it (Oudshoorn \& Pinch, 2003, p. 1 ). Users might change the physical properties of the artifact or accommodate the rules to their personal wishes (Lieshout et al., 2001, p. 47).

In Making technology our own? (1996) Lie and Sørensen frame this appropriation of artifacts by users as a form of taming and domestication of technological objects. Users should therefore be considered not as passive consumers but as 'tinkerers or 'bricoleurs', (co-) designers and (co-) producers who use the "room for action at the users' end (...) to shape their lives through creative manipulation of artefacts, symbols, and social systems in relation to their practical needs and competencies" (p. 5, 8-10). To be sure, domestica- 
tion of technological objects is not limited to the private sector, the home. The same processes and tactics of domesticating and taming technologies are at work in the spheres of work, leisure or subcultures (Håpnes, 1996; Lamvik, 1996; Lie, 1996; Lie \& Sørensen, 1996, p. 17; Oudshoorn \& Pinch, 2003, p. 14; Sætnan, 1996).

By appropriating artifacts to personal, local or circumstantial wishes, users deviate from the embedded scripts. They use the design in unexpected and unforeseen ways or they bend the discourse to their own personal needs. In doing this, users and their practices move from the facilitated core to the divergent periphery. This constitutes the first movement within the geography of play: the centrifugal force. To be sure, the core, the facilitated design and discourse, the embedded scripts have to 'tolerate' and sustain these deviations and transgressions, the divergent uses of an artifact and the unforeseen user practices.

Reverse movement is possible as well. Divergent, peripheral play practices can become part of the facilitated core through centripetal movements. This is also a form of appropriation but not of the core but of the periphery. There are two possible ways of centripetal appropriation. First, players can download and use user-generated content for a computer game. This content is created in the periphery and migrates, through downloading and installing, into the core where it becomes part of the design, the code of the game and is used in actual play. These are fast movements between periphery and core that take place in the course of one and the same computer game title. I can, for example, download a user-generated Jennifer Lopez skin (a software layer that changes the outlook of my game character) for my The Sims characters and immediately use it in gameplay. These unforeseen and unexpected peripheral user activities are thus 
incorporated in the core and as such become part of the facilitated design and/or discourse, the embedded scripts. As such, users can, to a certain extent coconfigure the user.

Slower centripetal appropriations of the periphery are manifested as well. These slower movements implicate a new product development for which the companies and designers use peripheral and divergent activities as their input. Companies and designers incorporate actual user activities within a new product or the redesign of an existing product because this might lead to a more successful or popular product where users see their adaptations and usages reflected in the design scripts. The slow centripetal appropriations thus implicate a commodification of the periphery, of the many-to-many activities of players. Divergent peripheral activities, then, become part of the reconfiguring of the user for new products or product updates.

Because of these two forms of centripetal appropriation whereby peripheral activities and actions become part of the core, players can influence to a certain extent the design of and discourse on an artifact. Their divergent play practices can become facilitated play practices. Various forces shape how and when this border crossing happens. There are the powerful actors in the core, the game designers and policy-makers, who, in general, will have to approve of the migration. However, as we will see in chapter 4, some players find ways to circumvent these official and approved channels for border crossing and 'illegally smuggle' their peripheral creations into the core of a game. Besides the powerful actors in the core, the design of a toy or a game has to facilitate the fast and/or slow forms of centripetal appropriations. For example, the fast centripetal movements that take place in the time span of one and the same game title are typically a play practice that has been made possible by 
digital technologies. Fast centripetal appropriations are not to be found in analogue, pre-digital geographies of play. Centripetal appropriation - both slow and fast has gained in presence and importance due to digital technologies that facilitate the use of user-generated content within the context of one and the same product, that sustain and cultivate active peripheries and manyto-many communities, that makes these communities visible and accessible to both players and companies.

The recognition of centripetal and centrifugal forces within geographies of play (but also in many other geographies) allows us to, as Akrich demands, "go back and forth continually between the designer and the user, between the designer's projected user and the real user, between the world inscribed in the object and the world described by its displacement" (1992, p. 208-209).

In order to further clarify how to identify what takes place where in the geography of play, it might be useful to draw some parallels with other user-activities. For example, a famous chef using a coffee grinder not to grind coffee beans but to pulverize herbs and seeds is a divergent use of a designed object that lies outside of the coffee grinder discourse. Or people using a blowtorch not to weld or meld things but to create a caramelized surface on their crème brûlée desserts are diverting from the blowtorch-discourse. In both cases, the designed object is used for a purpose other than the envisioned one. And here it becomes interesting: divergent uses of designed objects will often lead to the design of new consumer objects that have at the intersection of design and discourse, in the core, exactly those unintended uses. For example, one can now buy expensive and fancily designed blowtorch look-a-likes to caramelize crème brûlées (although these objects, tamed and domesticated versions of the blowtorch, do not pull the trick as well as the blowtorch). As a final example let us look at the 


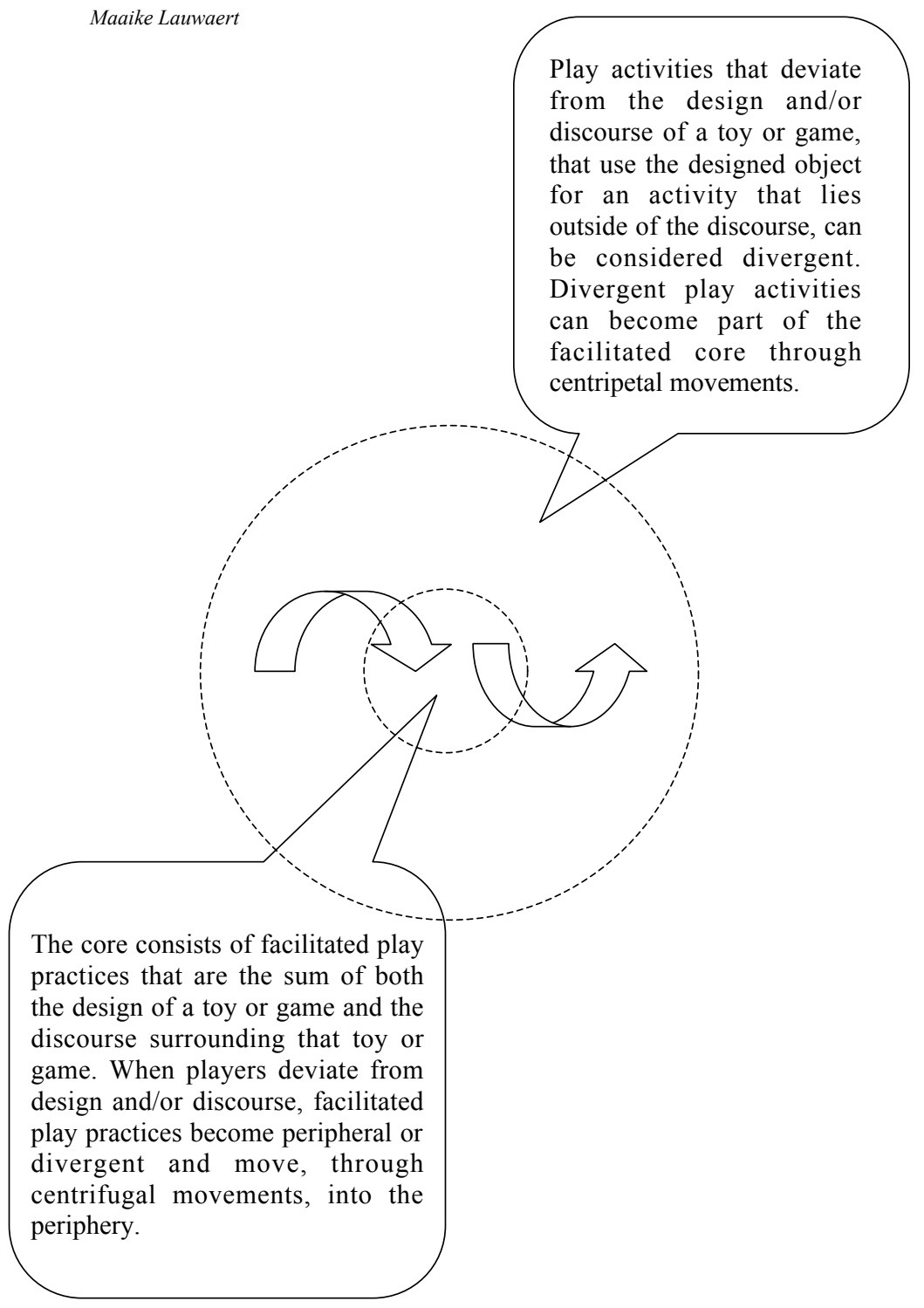

Figure 2: The Geography of Play. Core and periphery of play are interconnected through centripetal and centrifugal movements. Centrifugal appropriation indicates divergent use of the core. Centripetal appropriation can take place within the realm of one and the same product (fast force - implicates the ability to coconfigure the user) or over the course of a new product launch (slow force - reconfiguring of the user). 
fashion industry. Changing a pair of jeans at home, making additions to it or wearing it completely different than projected by the designers is not an uncommon practice among fashionistas. Trend watchers are always on the lookout to spot these divergent manipulations of standardized consumer goods in order to bring exactly such trousers on the market for the next season. These examples illustrate that through centrifugal and centripetal movements between core and periphery, practices and objects can migrate from one area to another and users can influence and shape to a certain extent the facilitated core of consumer goods.

Forms of user appropriation of existing technologies and discourses are also discussed in French philosopher Michel De Certeau's The Practice of Everyday Life (1988). In this book he traces and identifies practices and tactics of what he calls "making do". Consumers, television watchers, walkers, readers, cooks are all involved in 'manipulation', in 'composing an antidiscipline', in 'appropriation and reappropriation', in 'poaching', 'poiesis' ("from the Greek poiein, to create, invent, generate"), 'bricolage' (used by Claude Lévi-Strauss to analyze the production of things from leftover materials), and 'la perruque' (French expression for 'worker's own work disguised as work for an employer') (p. xii, xiii, xv, 25, 165, 174, $205) .{ }^{59}$ These activities are 'hidden and scattered over areas defined and occupied by systems of production', systems that, De Certeau stresses, leave less and less 'place for consumers to indicate what they make or do with products of these systems' (p. xii). Nevertheless, "there are countless ways of "making do" and in these tactics of making do, 'work and leisure flow together, repeat and reinforce each other' (p. 29). Instead of considering consumers passive recipients, De Certeau

\footnotetext{
${ }^{59}$ See: The Savage Mind (Levi-Strauss, 1966).
} 
labels them "unrecognized producers, poets of their own affairs, trailblazers in the jungle of functionalist rationality" (p. 34). The movements within the geography of play are indicative of this: when divergent player behavior becomes part of the core, the lines between player, consumer and producer become unclear.

It is important to stress that the geography of play and the dynamics between core and periphery within this geography, undergo changes. To get a grip on the changing geographies of play and the resulting changing power structures, it is useful to look at the core/periphery structures outlined by sociologist Raimondo Strassoldo in his article Centre-Periphery and System Boundary. Strassoldo describes two models of power structures in societies. In the first model, there is only one center, which is geographically located and the locus "of power and decision-making" (1980, p. 39). Boundaries are controlled and closed, thereby creating peripheries. In this model "commands flow down from the centre to the periphery, while information travels in the reverse direction" (p. 39). The core of the second model is "less bound to spatial determinants" and tends to have "more open boundaries and thus less differentiation between core and periphery" (p. 41). The core is then a "phenomenon" not of coercive political power but of "spontaneous coordination of individual behavior" through "immaterial elements such as images and moral codes", "values" and "norms" (p. 38-40). The second model considers the core a "social space where numerous flows of communication (...) come together and get linked" (Blom, 2004, p. 19). We can put Strassoldo's differentiation to use in tracing changing geographies of play.

We can best, for now, frame the changing geographies of play in terms of a transformation from a one-to-many geography (comparable to Strassoldo's 
first model) to a many-to-many geography (comparable to Strassoldo's second model). Central to this transformation is that players increasingly become producers. Analyzing changing geographies and practices of play will thus inevitably involve taking into account this implosion of different stakeholder positions. Because the positions of player, consumer and producer are increasingly entangled, research into play needs to consider the role and function of players in the process of production and consumption.

This adds to the aforementioned notion of design as something taking place within the realm of the thinkable and the possible, as something involving 'only' the designer and his or her materials or the player and his or her toys. When players not only become consumers but also producers, they become part of the design process and as such, they have a more active role in the practices and tactics of configuring the user. Through the fast and slow centripetal appropriation of the periphery, divergent activities can become part of the embedded scripts.

The transformation from a one-to-many to a many-to-many geography of play largely coincides with a shift from non-digital to digital or digitalized geographies of play. Digital technologies facilitate many-to-many activities. As stated, fast centripetal movements, which are characteristic of the many-tomany geography of play, are facilitated by digital technologies. As we will see, geographies of nondigital toys are also increasingly digitalized and infused with the many-to-many mechanisms. Both in relation to non-digital and digital toys, the many-tomany model has become a dominant framework. The discourse surrounding both non-digital and digital toys has moved accordingly towards a situation in which the 'by us for us' model has become the template for framing advertisements and the engagement of players with toy or game. 
The move from one-to-many to many-to-many geographies of play also entails a power shift or a redistribution of powers on different levels. Would it be correct to situate the company in the core and the user in the periphery of a one-to-many geography, as we will see throughout the tracing of changing geographies of play, this situation becomes more complex in largely digital geographies wherein the core splinters and disperses, companies increasingly enter the periphery and users shape and control the core to a large extent. In the one-to-many geography, the periphery is of less importance to the companies and thus more autonomous than in the many-to-many geography. The result is less movement between core and periphery and as such a more static geography. Access to the core is company-controlled and fast centripetal appropriations are nor manifested. In the many-to-many geography, the periphery gains in importance for the companies, has therefore more influence over the core but looses some of its autonomy. There is more movement between core and periphery making the many-to-many geography almost an organic system.

There are different reasons for this transformation and the increased importance, relevance and power of the periphery. For one, the Internet has made peripheral play activities highly visible and thus important. Within an increasingly competitive toy market, the many-to-many model is a means to create loyalty amongst ones customers, to bring them into the universe of a brand. And the increased costs of generating new content for computer games has made it all the more attractive to rely on peripheral play activities that might result in the creation of content for computer games. 


\section{3: "The Journey not the Destination" "60}

In 2003, the LEGO Company effectuated a color change for certain shades of their grey and brown pieces. $^{61}$ This caused considerable unrest in the community of older fans who associated the colors that would be taken out of production with their childhood. Some of these fans simply refused to accept the new colors (even up till today). Fans wrote about the LEGO Company's "terrible decision to 'improve' the gray, dark gray, and brown colors" (Walters, 2004), confess they are "a bit upset" (White, 2007) and "will not adopt

\footnotetext{
${ }^{60}$ This quote from Per Mollerup (2001) sums up the core of the traditional practice of construction play wherein playing lies in the process, the getting there, the building and the constructing of something rather than the product, the destination, the playing with a construction.

${ }^{61}$ A shorter version of this chapter will be published in 2008 in History and Technology under the title "Playing Outside the Box - On LEGO Toys and the Changing World of Construction Play".
} 
the new colors" (Simmons, 2007). The reason for the color change was related to the characteristics of the ABS plastic (Acrylonitrile Butadiene Styrene) of which LEGO bricks are made. ABS is a very strong type of plastic but it does 'yellow' when it gets older and from exposure to sunlight. The new coloring should prevent this yellowing and also, some fans suggest, make the colors stand out more in stores using tube lights. Both the yellowing of the bricks and the color change had ramifications for the core and periphery of playing with LEGO toys. Some players complained online about yellowed bricks in their constructions and tried soaking them in peroxide to revive their color. Long time LEGO users refused to accept the new colors or buy sets including these colors. And unwary players could end up with slightly different shades of grey and brown in their constructions. The complaints all round were numerous and diverse, ranging from sorting and buying issues to construction problems. But as one fan writes, changing the material of play does change the core of play: "TLG's [The LEGO Company's] emphasis since the introduction of the brick has been on the system of play. Changing a 20-year-old core color is inconsistent with this focus" (Walters, 2004).

This chapter deals with three major instances in the history of the LEGO Company. The first part investigates the development from wood to plastic as main material for LEGO toys and innovations on the level of plastic molding machines that influenced the interlocking mechanism of the LEGO bricks. Second, this chapter looks into a rather unsuccessful episode from the LEGO history, namely the period between the late $90 \mathrm{~s}$ and early $21^{\text {st }}$ century when the LEGO Company felt the need to extend its brand image through diversifying its product range. Unfortunately, this led to a confusing rather than a strong brand image and resulted in heavy financial loss in 2000, 2003 and 
2004. Third, this chapter will look into recent attempts by the LEGO Company to bring the fans into the company in order to revive the LEGO brand and its products. This part will focus on Mindstorms 2.0 and Mindstorms NXT especially in order to illustrate the increase in user involvement in LEGO product development. These three instances in the LEGO history bring aspects of the nature, characteristics, mechanisms and problems of the many-to-many model to the forefront. Throughout the LEGO history we see the struggle with not using or using the many-to-many model, the need to comply to this model, some 'best' and 'worst' practices of the use of this model.

Research in this chapter is based on different sources. Players have been consulted through the observation of and participation in user groups. Studying actual practices of play in a laboratorial setting is difficult because observing players in a research setting might create 'unnatural' practices of play. ${ }^{62}$ Other sources are secondary literature on the LEGO Company and it's history, official LEGO publications such as annual reports, historical accounts and educational literature, LEGO catalogues, manuals and toys.

\section{FROM WOODEN BLOCKS TO PLASTIC BRICKS}

In 1932 the carpenter Ole Kirk Christiansen (18911958) established what is known today as the LEGO Company in the Danish village Billund. He started out

\footnotetext{
${ }^{62}$ For example, anti-social behavior might not be performed in research settings because, as Bruno Latour puts it "humans have a great tendency, when faced with scientific authority, to abandon any recalcitrance and to behave like obedient objects" (2004, p. 217).
} 
by manufacturing houses and furniture but had to change his production line to smaller objects such as stepladders and ironing boards when the depression hit Denmark (LEGO Timeline Online). He ended up making toys in a very typical and at that time common way: most craftsmen used their leftover material to make toys and simple playthings (LEGO, 1982, p. 13). The production line of the factory soon changed from toys as a by-product to toys as the main product and in 1934 the firm was therefore renamed LEGO, the contraction of the Danish words "leg godt", "play well', writes Danish historian Ole Steen Hansen (1997, p. 16). The first wooden toys were produced of timber and were distributed and sold without any packaging. Underneath or on the side of every toy there was a LEGO logo rubber-stamped (LEGO, 1982, p. 15). The LEGO Company kept producing wooden toys until in 1960 a fire destroyed the storage spaces for the wooden toys (O. S. Hansen, 1997, p. 31). Plastics entered the company after the Second World War when the German occupation ended and new materials and production methods became available in Denmark.

To be sure, many toy manufacturers experimented from the First World War onwards with the use of plastics for making toys in response to the shortage of wood and metal for the toy trade. ${ }^{63}$ In January 1915 the Games \& Toys magazine reported that in the North of England a firm had 'a very large quantity of wood in stock' and that it 'is in the position to supply the trade with wood for the manufacture of wooden toys' (Anonymous, 1915, p. 280). Even after the war was over, metal toys were scarce, as Games \& Toys reports in January 1919. For making tin toys, a substitute called black tin was sometimes used: "This material is much cheaper and is of no practical value

\footnotetext{
${ }^{63}$ For a detailed and insightful historical account on the development of plastics, see Of Bicycles, Bakelites, and Bulbs (Bijker, 1995) and American Plastic. A Cultural History (Meikle, 1997).
} 

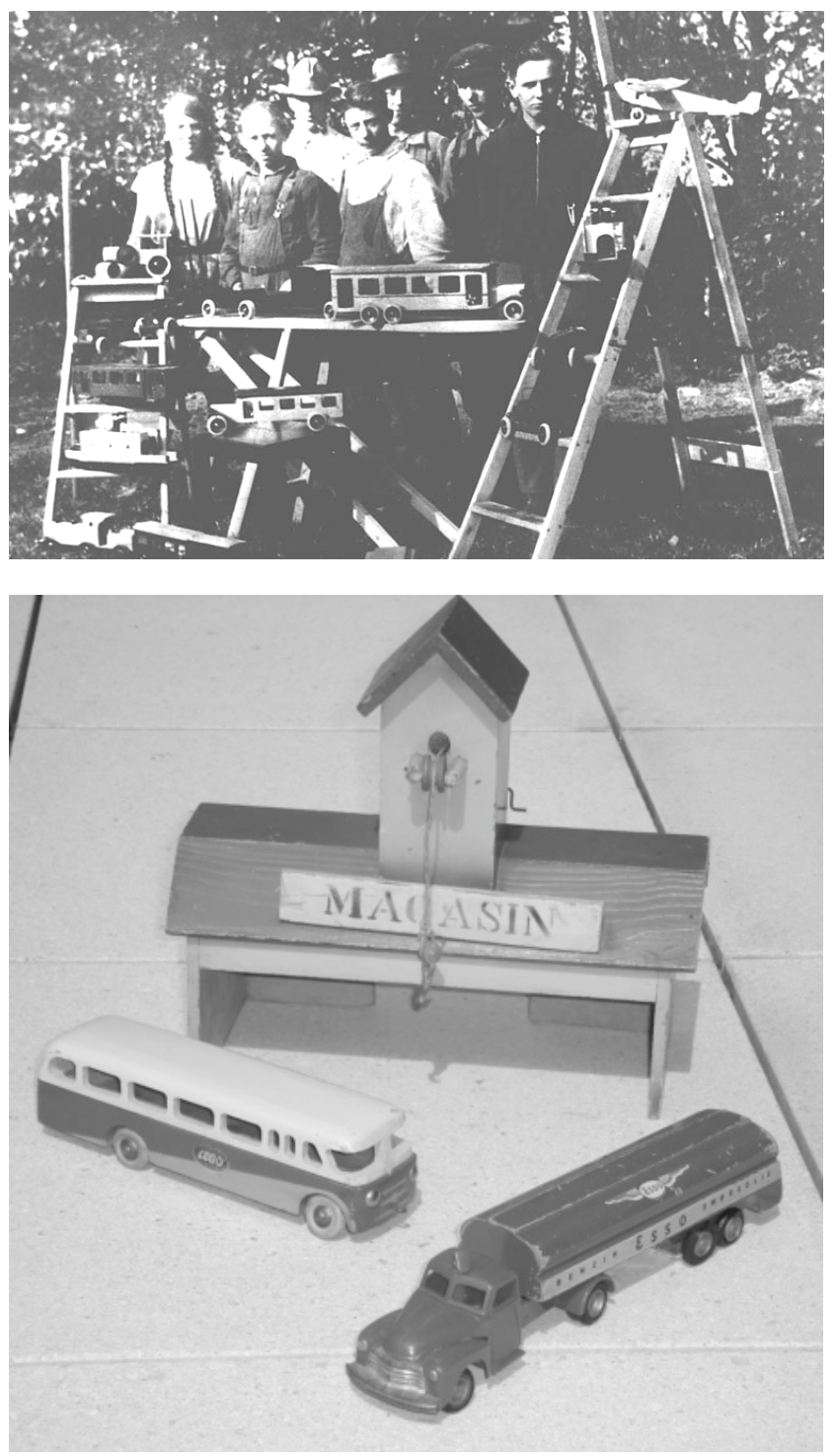

Illustrations 19 \& 20: Wooden LEGO Toys. The first picture dates from 1932 and shows the original wooden LEGO product line (Hughes, 2007). The bottom picture shows three wooden LEGO toys (some with plastic elements) dating from the 1940s-1950s (Brick Brothers, 2006). 

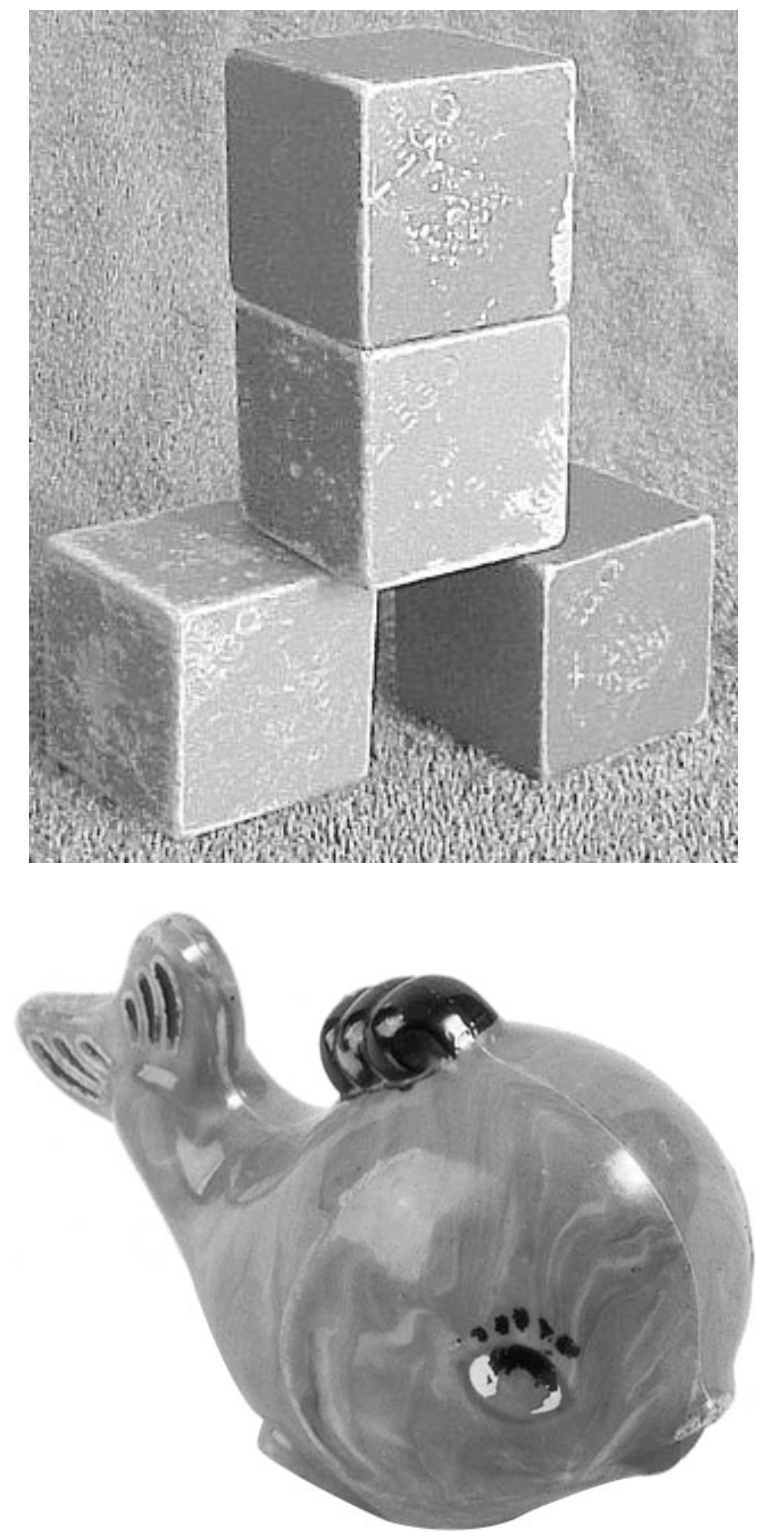

Illustrations 21 \& 22: Early LEGO toys. The first LEGO blocks from the 1940s were made of wood (Vinther, 2005). The fish shaped baby rattle dating from 1949 is one of the first plastic toys the LEGO Company made (Hughes, 2007). 
for the war industries, so it has been given to the toy manufacturers" (Anonymous, 1919, p. 246). Nevertheless, "all manufacturers making lead and metal toys have suffered a great deal" (p. 246). ${ }^{64}$

Toymakers were therefore constantly experimenting with new types of plastic that were noninflammable, cheap and easy to mold (Correspondent, 1914, p. 28). In June 1914, for example, in the first issue of Games \& Toys we see on page 15 an advertisement of the company Hagedorn \& Co. that sells various 'Celluloid Toys'. The problem with celluloid, however, was its inflammability and therefore it was not considered a suitable material for making children's toys (or any other object for that matter). While it seemed at first that the First World War would call a halt to the flourishing toy business, experiments with the use of plastic turned out to be - in the end - successful and the mass production of toys continued (McClary, 1997, p. 35).

Plastic was introduced as the basis for construction toys under the direction of Ole's son Godtfred Kirk Christiansen who, at the end of the 1940s introduced his father to the English Windsor machine (O. S. Hansen, 1997, p. 8). With this plastic molding machine, plastic could be cast into specific shapes (p. 19). The machine had cost the company one fifteenth of the money they made that year but Godtfred was able to convince his father that the investment would be worthwhile (LEGO Timeline Online). In 1947 the LEGO Company was the first

\footnotetext{
${ }^{64}$ Besides the scarcity of materials for the toy trade, the ban on German toys caused problems as well. Germany had the biggest toy industry after all. In Games \& Toys there is constant mention of the shortage of toys and there are some cases described in which "Trading with the Enemy" is harshly punished (Anonymous, 1914b, p. 228). Telling in this account is a onepage-covering advertisement in Games \& Toys of a company called Compocastles. Their advertisement reads: "THE WAR AND THE TOY TRADE Resolved. You must have BRITISH MADE TOYS" (Compocastles, 1914, p. 123). Undisputable, the British toy trade flourished because of the ban on German toys.
} 
company in Denmark that owned a plastic injectionmolding machine for toy production. The LEGO Automatic Binding Brick - the forerunner of the LEGO brick we know today - was created with the Windsor machine and released in 1949. There were two sizes of bricks, with four or eight studs and they came in four different colors. The system that connected the bricks was not based on the stud-andtube coupling system we know today. The bricks had studs on top but no tubes underneath. They had slots to accommodate windows and doors.

Strictly speaking, the LEGO Company did not invent the plastic building brick, they were inspired by the English Kiddicraft Self-Locking Bricks by British child psychologist Hilary Page (1904-1957) (O. S. Hansen, 1997, p. 19-21). Page designed and sold with success Kiddicraft Self-Locking Building Cubes (1940 UK patent \#529580) and Kiddicraft Self-Locking Building Bricks (1949 UK patent \#633055). In Page's educational book Playtime in the First Five Years we find pictures of children playing with the plastic building bricks (1938, p. 51, 79 \& 115). An early reference to Page is made in the article Astonishing secret behind the world's most famous toy by Adrian Lithgow that appeared in The Mail in 1987. According to The Mail, Godtfred - then 66 years old - stated in court (the case LEGO versus Tyco) that "he received sample bricks from a Londoner, Mr. Hillary Page, in 1947" (Lithgow, 1987). ${ }^{65}$ In 1981 the LEGO Company agreed to an "out-of-court settlement of 45,000 (British Pound) for any residual rights of the new owners of Mr. Page's company, Hestair-Kiddicraft" (ibid).

In the 1997 publication Developing a Product,

\footnotetext{
65 "Lego's patents ran out in the United States in 1983. That's when Tyco Toys Incorporated began producing lines of building blocks that connected with Lego-brand building blocks. Tyco's blocks were less expensive and its advertising directly attacked Lego with the slogans 'If you can't tell the difference, why pay the difference?' and 'Tyco looks and acts like Lego blocks.' Lego sued on grounds of deceptive advertising" (CBC, 2004).
} 

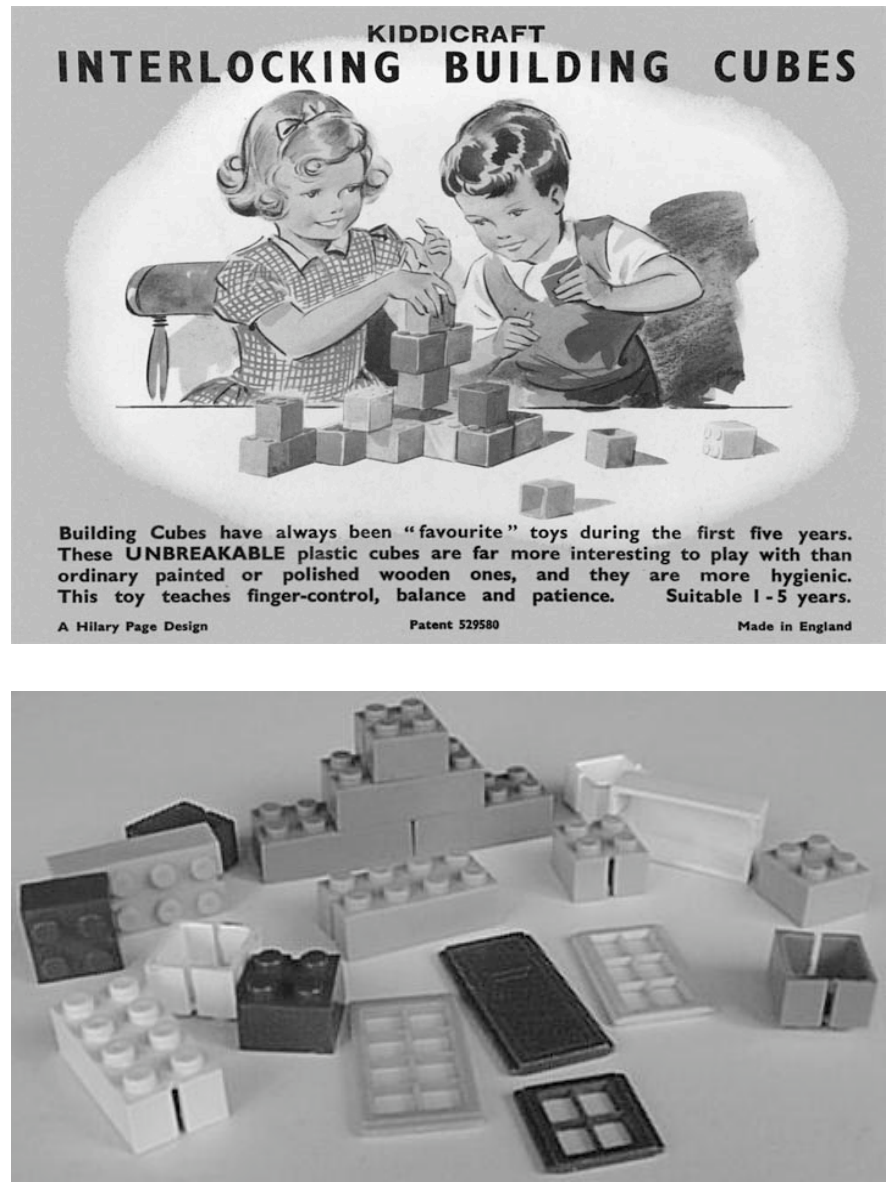

Illustrations $23 \& 24$ : The top image shows a 1950s UK add for Page's Kiddicraft Interlocking Building Cubes. The advertisement also lists the advantages of plastic: unbreakable and hygienic (Hughes, 2007). The bottom image shows the LEGO Automatic Binding Bricks from the 1950s, the forerunner of the LEGO brick we know today (Lilleker, 1998). The Kiddicraft Self-Locking Building Bricks by Page look exactly the same. 
the LEGO Company refers for the first time to Page:

"Automatic Binding Bricks" (...) were inspired by a couple of British plastic building bricks made by the Kiddicraft company and sold only in Britain. (...) we modified the design of the brick (...). The modifications (...) included straightening round corners and converting inches to $\mathrm{cm}$ and $\mathrm{mm}$, which altered the size of the brick by approx, $0.1 \mathrm{~mm}$ in relation to the Kiddicraft brick. The studs on the bricks were also flattened on top" (p. 23).

Then again, Page's Kiddicraft Self-Locking Building Bricks were not the first rubber or plastic bricks with an interlocking mechanism. The Rubber Specialties Company of Pennsylvania sold the rubber Bild-O-Brik from 1934 onwards. Similar to the Bild-O-Brik is the Minibrix by the Premo Rubber Company of Petersfield (UK) patented in 1935 (Hanson, 1993; Smallbone \& Hanson, 2007).

The first type of plastic the LEGO Company used between 1949 and 1963 was Cellulose acetate. But, as technical engineer Ulrik Jørgensen states, this type of plastic was "easily deformed by heat and water and would undergo slight changes over the years" (1998, p. 6). And thus from 1963 onwards "the plastic material was changed into acrylonitrile butadiene styrene (short ABS)" (p. 6). This new type of plastic enhanced the quality of the bricks in terms of life endurance and clutch power. "If you had ten- or twenty-year-old LEGO bricks they would fasten perfectly onto a brick you bought yesterday" writes American historian Henry Wiencek (1987, p. 67). Because ABS allowed for more molding precision, the bricks now fitted together more tightly and constructions became more stable (p. 67). Nowadays, some particles are made from PVC plastic (Jørgensen, 1998, p. 6).

By 1951 plastic toys accounted for half of the LEGO Company's output. Despite this fact, the Danish trade magazine Legetøjs-Tidende (Toy-Times) stated at the beginning of the 1950s, after having visited the 

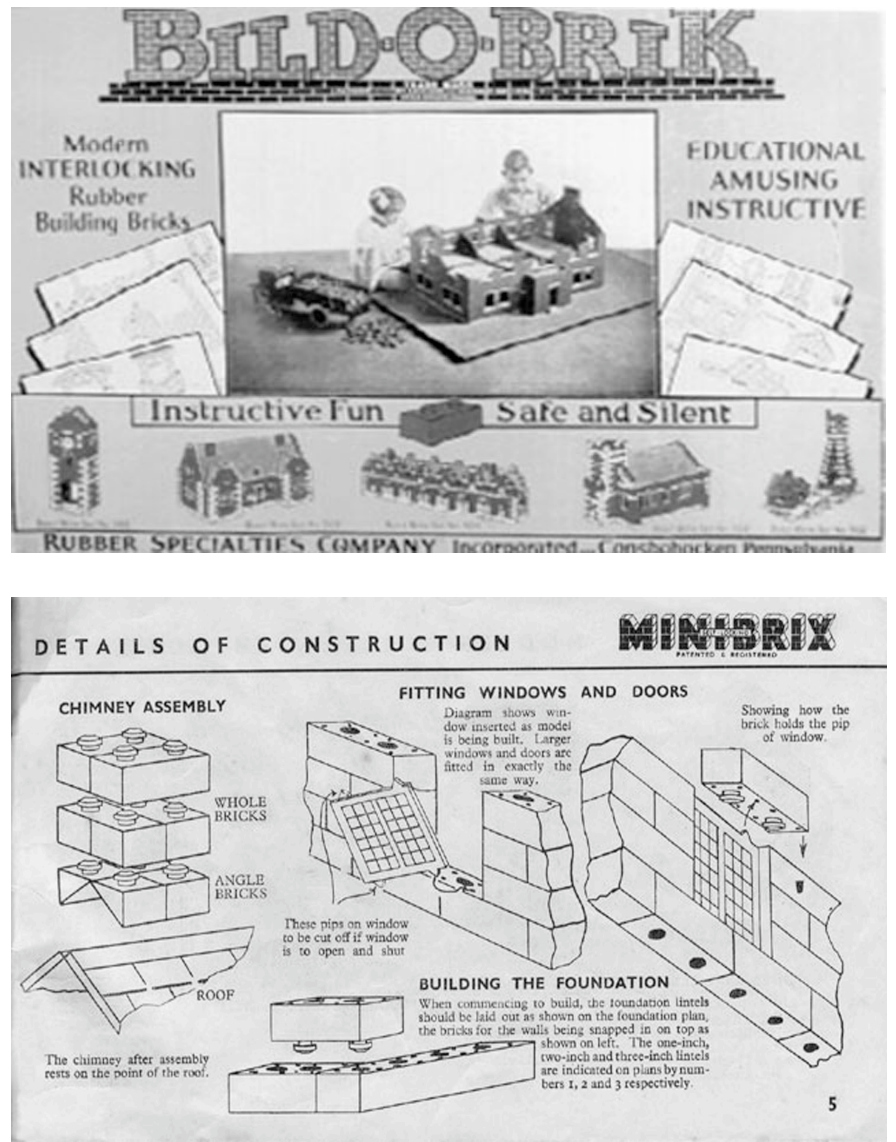

Illustrations $25 \& 26$ : The top image shows the cover of a 1930 s Bild-O-Brik set containing rubber building bricks. Note the tagline "Safe and Silent" and the picture of children playing quietly indoors (Britton, 1996-2003). The bottom image shows page 5 from a 1935 Minibrix catalogue and manual (Smallbone \& Hanson, 2007). Both the Bild-O-Brik and the Minibrix had an interlocking mechanism comparable to the Kiddicraft and LEGO interlocking mechanisms. 
LEGO factory in Billund, that "plastic would never be able to replace good and honest wooden toys" (O. S. Hansen, 1997, p. 22). This outcry demonstrates fittingly how most people fell (and sometimes still feel) towards the use of plastic in toys. ${ }^{66}$ LEGO toys, however, seem to be an exception to this dislike of plastic toys. "Part of Christiansen's genius was to make the new material feel almost as comforting, as domestically reliable, as wood itself" (Lane, 1998, p. 4).

The change in prime material used for making LEGO toys led not only to different products but also to a different interaction of the child with these products. The evolution from wooden building blocks to plastic designing bricks changed the way children could play with LEGO toys. Wooden building blocks as in illustration 21 allow you to make mainly abstract and architectural constructions that are not too high, do not have too many corners, no sloping roof and are mainly two-dimensional. Plastic bricks that fit onto and into one another allow for more design and construction versatility. Plastic and an interlocking mechanism are key factors in this change from building to designing toys. It would have been very hard indeed to make a stud-and-tube coupling system

\footnotetext{
${ }^{66}$ Plastic has been met with both liking and disliking. On the one hand, consumers are for the most part happy with the cheap, easy to clean, colorful and (generally speaking) durable plastic products. On the other hand, plastic, as opposed to wood, is easily associated with artificiality, superficiality and fakeness. The critique on plastic toys was voiced by the elite rather than by consumers. The semiotic theorist Roland Barthes (19151980) was one of many to object to plastic toys. In Mythologies (1957) he states: "Current toys are made of a graceless material, the product of chemistry, not of nature. Many are now moulded from complicated mixtures; the plastic material of which they are made has an appearance at once gross and hygienic, it destroys all the pleasure, the sweetness, the humanity of touch" (p. 54). For a more detailed plea for wooden toys, see for example Karl Debik Holz spielt mit. Erinnerungen an Baukästen aus sächischen Gebirgen und ein Plädoyer für Holz (1998).
} 
in wood. Plastic pieces clutch better than wooden pieces and can endure more resistance. ${ }^{67}$

The interlocking mechanism of the LEGO plastic building bricks changed in 1958 to the new and improved stud-and-tube coupling system that is still being used today. This new coupling system was facilitated by innovations on the level of plastic molding machines. Stud-and-tube coupling bricks have studs on top of the bricks and tubes underneath. With this new stud-and-tube coupling system the slots disappeared completely from the bricks (from 1956 onwards, the LEGO Company had been producing bricks with and without slots).

Thanks to the stud-and-tube interlocking mechanism, how and what one could build with LEGO bricks multiplied and the potential of the LEGO bricks amplified. The first LEGO bricks were "rather limited" in their use, "you could only fit them together in a limited amount of ways" (LEGO, 1979, p. 2). "It was the tubes that gave the product its versatility and building stability" (Wiencek, 1987, p. 50). Are constructions built with the Automatic Binding Bricks shaky, the new system is extremely precise: "The 'tolerance' - the allowable variation of the diameters of studs and tubes - is two-hundredths of a millimeter" which accounts for more stable constructions (p. 67). When in 1958 the constructions became more stable due to the new coupling system, one could build larger

\footnotetext{
${ }^{67}$ As children, my sister and I had a set of wooden railroad tracks and little, wooden, colorful trains to go with it. The trains clung to each other by way of little magnets. We had two different types of railroads. One set of tracks had a coupling system of wooden puzzle-shaped ends that would fit into little dents. The other set of tracks were fastened onto each other with the help of little plastic coupling devises. The tracks with the wooden coupling system always remained a bit loose. The trains might get stuck at a crossing and building the tracks onto some sort of hill-like structure was nearly impossible. The plastic coupling devices clutched harder and allowed you to construct your railroad over bumps. You could even pick up your railroad construction in one piece and move it about the house because the plastic coupling devices clutched that hard.
} 


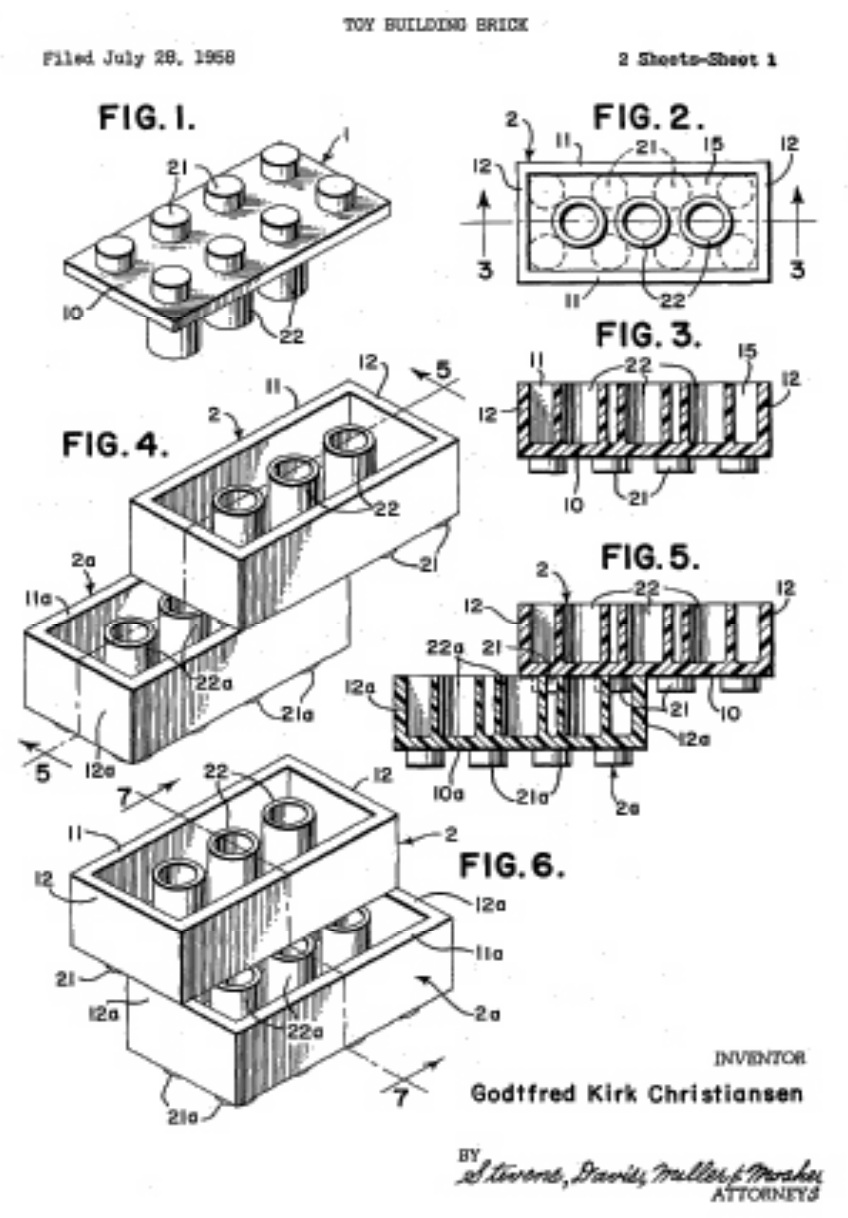

Illustration 27: Patent of the plastic LEGO brick with the stud-andtube coupling system. This is part of the patent for 'Toy building brick' filed July 28, 1958. The inventor is Godtfred Kirk Christiansen (Hughes, 2007). 
and more detailed objects such as cars, planes and boats. And since you no longer had to build your constructions around the slots that would accommodate windows and doors, there was more freedom in where to put the doors and windows and there could be more of them in one construction or none at all.

The 1958 molding machine also changed practices of LEGO play because this new machine could produce different shapes and little detailed particles such as hairdos and helmets, flowers and, in time, walky-talkies. Starting with just two sizes of bricks in 1949, the LEGO Company produced in 2004 12,400 different pieces. With these diverse pieces and bricks, one could make far more detailed and realistic constructions. A good example in this case is the LEGO mini figurine introduced in 1978. Before 1978, people and animals were constructed out of bricks. With the launch of the mini figurines, people and animals became preformed and pre-shaped. While you can still change some parts of the figurines you buy today, they differ immensely from the idea of building figures with LEGO bricks. Figures created with LEGO bricks are big and static while the mini-figures can move their head, arms, hands and legs and can more easily be integrated into a construction.

The introduction of the new interlocking mechanism and small, detailed pieces largely coincided with a transition from LEGO toys as architectural toys to LEGO bricks as the basis for many diverse and wide-ranging constructions and with the introduction of the LEGO System of Play.

LEGO construction sets from the late ' 40 s and most of the " $50 \mathrm{~s}$ were mainly focused on the construction of houses. This is expressed in both the design of the Automatic Binding Brick and the discourse surrounding these early LEGO sets. The slots in the LEGO bricks were meant for the incorporation of doors and windows, that was the only play option 

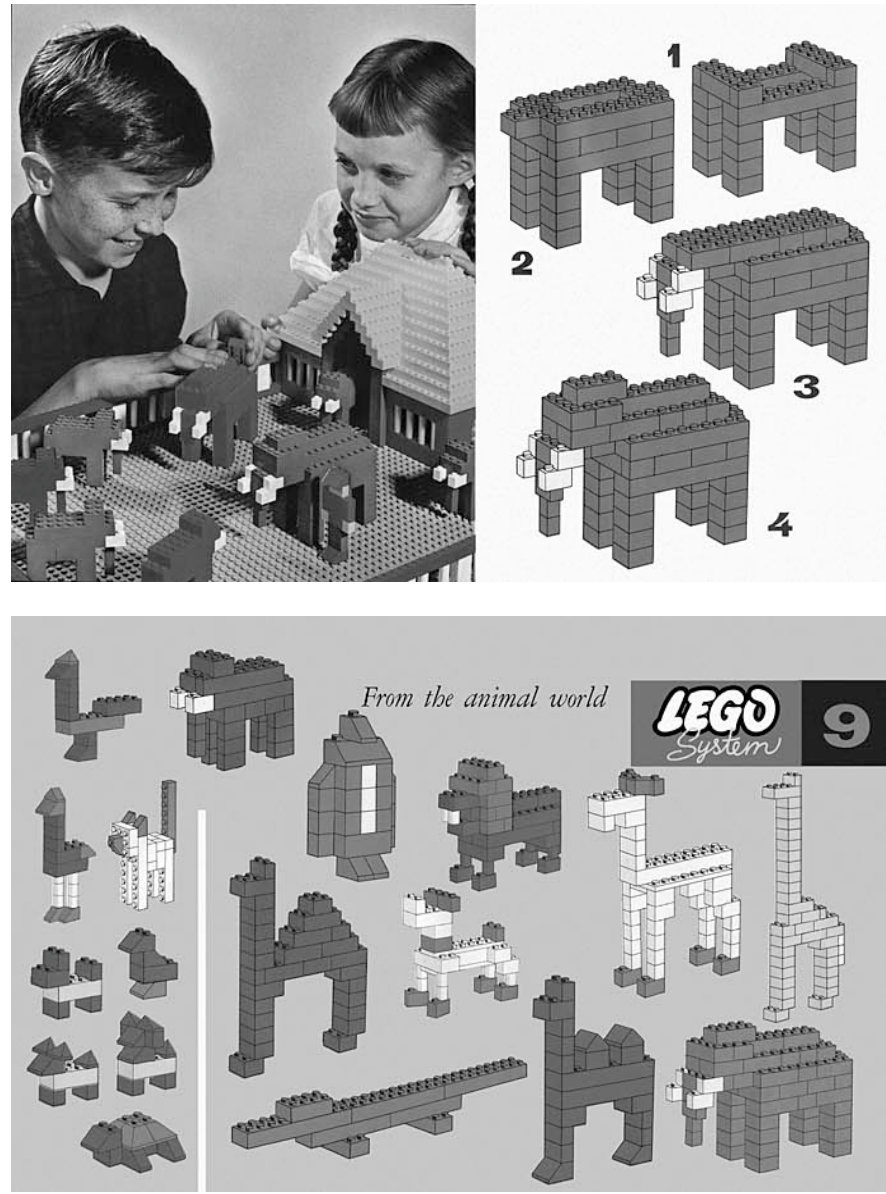

Illustrations 28 \& 29: Build your own LEGO Animals. These illustrations are the pages 22 and 23 from a U.K. Book of Ideas from 1960. It shows ideas on how to build animals. The book was available in many languages (Hughes, 2007). 
these slots facilitated. Moreover, the first interlocking mechanism did not yet provide the clutch power needed for complex constructions. In the words of the LEGO Company itself: “'Automatic Binding Bricks' (...) did not have much clutching power and were best for stacking. (...) all they could be used for was building simple walls and houses" (LEGO, 1997, p. 23 ). The discourse, communicated through the drawings on the boxes for example, focused on architectural models as well.

The emphasis on LEGO toys as architectural toys can also be seen in the name change that was effectuated in 1952. In 1952 the Automatic Binding Bricks were renamed LEGO Mursten (Danish word for 'brick'). In Danish there are two words for bricks, a more neutral Danish word for bricks would be 'klodser' (Jørgensen, 1998, p. 6). The choice for Mursten 'reflects the emphasis on architectural models' (Stephens, 2005) and on "using LEGO bricks for house building" (Jørgensen, 1998, p. 6). The word 'mursten' gradually disappears from LEGO packages by the end of the 1950s.

The new stud-and-tube interlocking mechanism facilitated because of its design characteristics a move away from LEGO toys as architectural toys. Their stability and clutch power facilitated more stable and complex constructions and broadened both design and building options. This increase in possible and facilitated LEGO play practices was furthered by the LEGO System i Leg or LEGO System of Play introduced in 1955. The play system originally consisted of 28 sets and 8 vehicles plus some supplementary elements. The idea behind the System of Play was that not only the individual bricks were interchangeable but the sets as well. All pieces in the system had to be compatible so that a "child who has four LEGO sets can use them all together to create more complex and interesting play- 


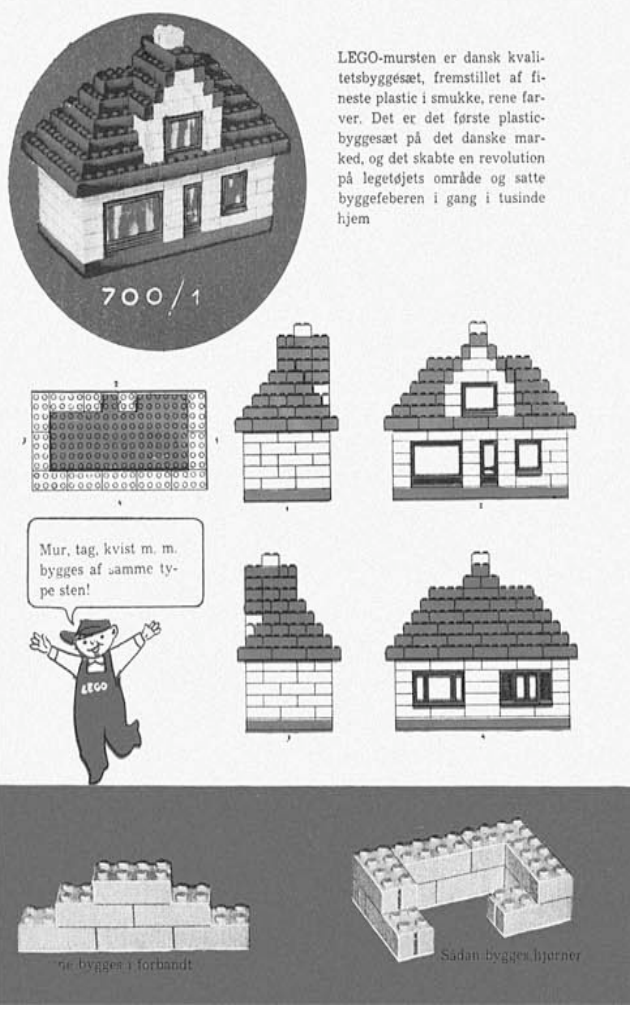

Illustrations 30 \& 31: LEGO Toys as Architectural Toys. The illustration on the left is part of a Danish catalogue from 1945 showing examples of what one could build with LEGO Mursten. All examples are architectural constructions. The bottom illustration shows a generic sleeve that was used for packing LEGO sets between 1953 and 1955. The examples on the sleeve are all architectural constructions (Hughes, 2007).

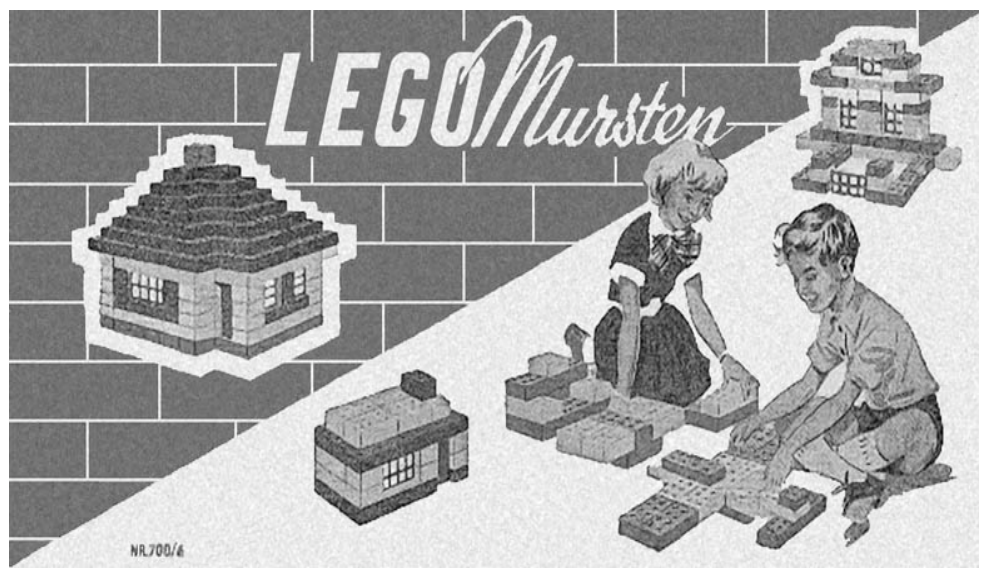




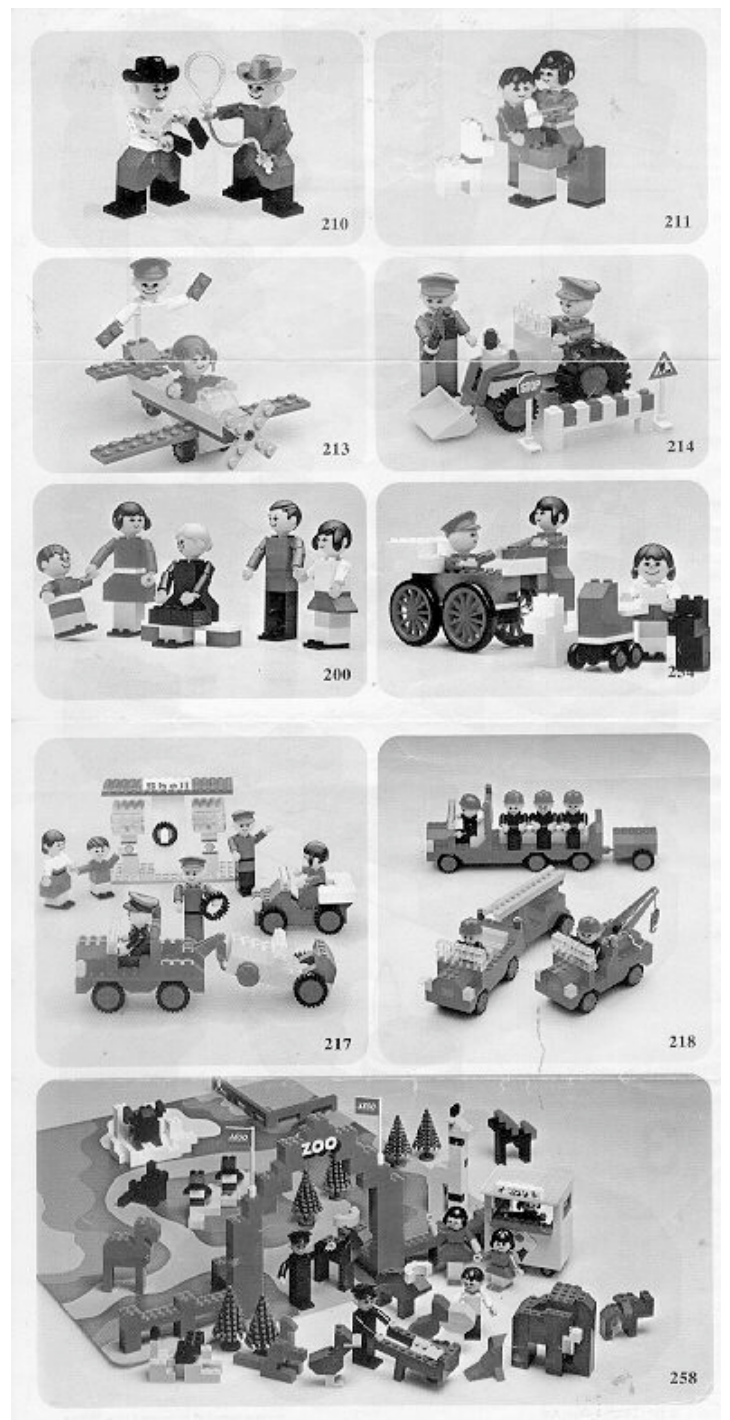

Illustration 32: LEGO toys as the basis for more diverse and wideranging designs and constructions. This scan from a LEGO brochure from 1960 shows the increase in themes, narratives and roles for LEGO play. LEGO set \#210 has cowboys in it, \#217 is a Shell station and \#258 contains a zoo (Brickfactory). 
things than he could with four sets that didn't work together" (Wiencek, 1987, p. 57). The System of Play and its interchangeability of LEGO pieces multiplied the design and construction possibilities and thereby expanded the geography of LEGO play.

With the new interlocking system and the addition of smaller particles to the System of Play, LEGO toys became truly indoor toys. Although one of the advertised and popular advantages of plastic was that it was 'easy to clean', sand and dirt could get stuck insides the tubes underneath the bricks which would ruin the interlocking quality. The creation of an indoor System of Play probably had something to do with the cold Danish climate with its long and harsh winters. In one of the LEGO Company publications of 1975 we read that LEGO bricks are "much more convenient for indoor use" than, say, paint, sand or clay and since LEGO bricks can be combined in so many different ways, "there is enough to do in the long winter evenings" (1975, p. 5 \& 7).

In the $1950 \mathrm{~s}$, the playroom became an integral part of architectural practices. Had the mid $19^{\text {th }}$ and early $20^{\text {th }}$ century guidebooks on housekeeping advocated a separation of the child from worldly affairs, a distancing of the child from the adult world, the 1950s architects designed homes that centralized the child and play in the recreation area and the open plan living room. Processes put into motion during the Industrial Revolution gained force in the postwar period with increased leisure time, more consumer goods and a continuing exodus to the suburbs. Both the suburb and the suburban home centralized "the needs of children" and play became a "space-determining criterion within the domestic environment" writes architectural historian David Snyder (2004, p. 142).

In terms of the core/periphery model of differentiation, we could state that the change in prime material from wood to plastics and the technological 
innovations on the level of molding plastics, expanded the core of LEGO play practices because the modular, plastic bricks and the detailed particles facilitated the design and creation of more diverse constructions than the wooden building blocks. The embedded scripts of the design of the stud-and-tube brick facilitated diverse play practices. Bricks were fairly generic and thus open to adaptation and appropriation by players. The projected user and uses diversified from playing at being an engineer or architect to many diverse uses and more wide-ranging roles. The System of Play ensured that all LEGO elements would go together, thereby opening up a large area for divergent design and construction. Moreover, it was not until the seventies that detailed manuals would be included inside the LEGO boxes. These detailed manuals would outline all the facilitated play options, step by step. Before the seventies, LEGO sets only came with playing advice and building ideas. However, the actual break in the increasing core and peripheral play practices did not occur with more detailed manuals used from the 1970s onwards. It was during the late ' $90 \mathrm{~s}$ and the early $21^{\text {st }}$ century that changing LEGO policies had serious ramifications for the geography of LEGO play.

\section{BRAND EXTENSION \& PRODUCT DIFFERENTIATION}

At the end of the 1990s, the LEGO Company put into motion a plan to extend its brand through diversifying its product range. The core of this plan was the extension of the LEGO brand beyond the connotation of the 'brick'. The LEGO Company wanted to be known for more than construction toys by extending "their brand into new areas of the children's universe" 
write brand analysts Pernille Gjøls-Andersen and Esben Karmark (2005, p. 167). The reasons for putting this plan into action were 'a declining interest in construction play' in the mid ' $90 \mathrm{~s}$, the phenomenon known as KGOY (Kids Growing Older Younger) and technological developments that made LEGO sets look boring and old fashioned' (p. 167). Toy companies use the term KGOY to indicate that children from everearlier ages turn away from traditional toys and fancy technological gadgets (cell phones, MP3 players and personal computers) or lifestyle products (clothes, make-up, accessories). ${ }^{68}$

An analysis in 1996 of the strength of the LEGO brand through the Brand Asset Valuator (BAV) test by the advertising agency Young \& Rubican had grim consequences. The BAV test is commonly used to research and analyze the weaknesses, strengths, popularity and famousness of brands. The BAV test results showed that the LEGO brand was still going strong but scored low on the point of differentiation which is, according to the BAV system, usually a sign of a fading brand (Gjøls-Andersen, 2001, p. 163). According to sociologist Celia Lury in Brands: the logos of the global economy a "brand progresses or emerges in a series of loops, an ongoing process of (product) differentiation and (brand) integration" illustrating the importance of differentiation in relation to brands $(2004$, p. 8$)$.

\footnotetext{
${ }^{68}$ In an article by Erika Kinetz Putting away childish things, this trend is confirmed by examples of toy manufacturers who distance themselves from toys altogether. They are not just selling toys but something more because toys have become painfully unfashionable. Traditional toy makers state that they are in the business of gifts, the family entertainment business, or they simply drop the T word from their company's name (2005, p. 16).

${ }^{69}$ On the website of Young \& Rubican differentiation is defined as: "Differentiation Drives Successful Brands. Differentiation is the foundation of a brand's existence and is critical to brand success. Successful brands are strongly differentiated. The more differentiated, the more likely it will be trialed and less likely it is to be substituted. Differentiation measures the strength of the brand's meaning" (Young \& Rubican, website).
} 
In what is now considered by LEGO employees as an overreaction to the BAV outcome, the LEGO Company pushed their plans for brand extension in a few years to completion. From the mid ' 90 s onwards, as part of this brand extension strategy, new types of toys and life style products were launched, Legoland theme parks opened, electronic games and children's media produced. LEGO products diversified fast and in all directions. Although the differentiation of LEGO products had been going on for decades, the rate and pace increased exponentially from the mid ' 90 s onwards. ${ }^{70}$ Repairing the damage this product differentiation did to the LEGO brand and company (manifested mainly in financial losses) will take 7 years according to the 'rescue' strategy that was put into motion in 2004.

In short, the goal of the brand extension strategy was to replace the 'assembly' aspect of the LEGO brand (which was considered too old-fashioned and not flexible enough in light of the intended product diversification) with the core term 'creativity'. Ironically - and this is what did the brand such damage and caused heavy financial losses - the new toys and products were considered by fans as less creative instead of more. For example, LEGO sets increasingly contained preformed parts. This at once limited the amount of time needed to build a set (which was intended) and the amount of other constructions one could build with the pieces inside the box (an unintended consequence). Including preformed LEGO pieces in toy sets to decrease building time was in line with the LEGO Company's goal to loosen the ties between the LEGO brand and construction play. ${ }^{71}$

\footnotetext{
${ }^{70}$ From 1965 onwards, LEGO produced toys that were gender and age specific. Before 1965, LEGO products were not targeted at specific age or gender groups. The first LEGO sub-brand was LEGO Duplo for younger children followed by LEGO Technic for older boys.

${ }^{71}$ This also solved the problem of those complex and detailed sets which children could only complete with their parents' help.
} 


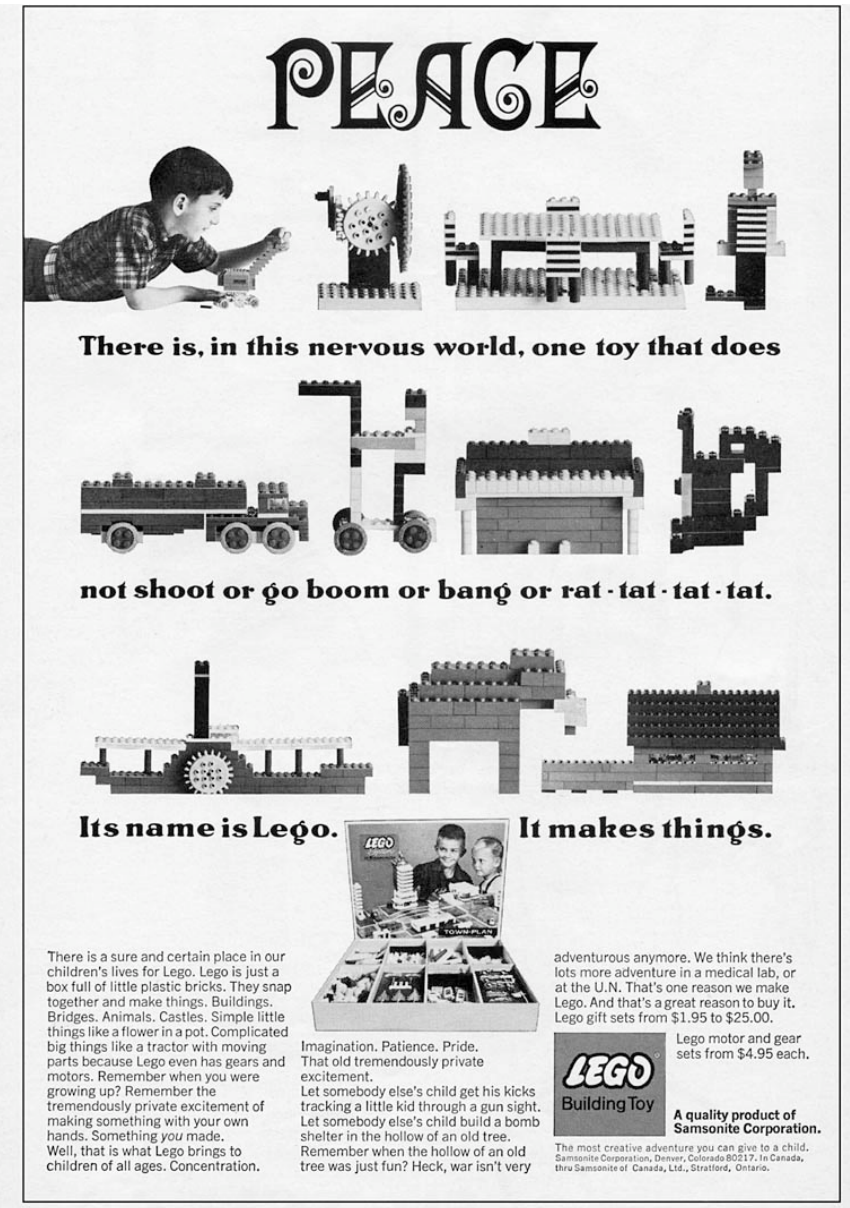

Illustration 33: U.S. LEGO advertisement from 1965. This image of a toy that simply 'makes things' was what the LEGO Company wanted to be freed of by the end of the 1990s so that they could launch diverse and wide-ranging products that did not necessarily center on the LEGO bricks (Hughes, 2007). 
Inadvertently, these preformed elements decreased the play options on the facilitated, core level of playing and the divergent, peripheral level of playing. ${ }^{72}$

Up till the mid ' 90 s, the LEGO Company was best known for its construction toys and the LEGO brand was almost exclusively associated with construction toys and play. Between the late ' 90 s and early $21^{\text {st }}$ century, we can discern a shift in discourse from designing and constructing as the embedded and projected play activities with LEGO toys to narrative and role-playing. Designing and constructing became less important while action, role-playing and narratives were pushed to the foreground. Toys that centered on stories and themes were the key to the brand extension plan. These narrative toys allowed for both the development of more diverse products that did not necessarily have the brick and construction play at its core and for the integration of these products with other media and other areas of the child's world.

This shift can also be framed as a transition from play as construction process to play with finished product. Both in relation to the first and secondgeneration construction toys play centers on the process, the building and constructing of an object. Or in the words of designer Per Mollerup: "The journey not the destination is the purpose - process over product" (2001, p. 77). For example, playing with a Meccano construction set is mainly about the construction process itself, the designing and building of a construction rather than the playing with that construction. The LEGO toys introduced between the

\footnotetext{
${ }^{72}$ Bug, one of the characters in Canadian writer and artist Douglas Coupland's novel Microserfs voices his annoyance at this change: "YYou know what really depresses the hell out of me? The way that kids nowadays don't have to use their imagination when they play with Lego. Say they buy a Lego car kit - in the old days you'd open the box and out tumbled sixty pieces you had to assemble to make the car. Nowadays, you open the box and a whole car, pre-fucking-built, pops out - the car itself is all one piece. Big woo. Some imagination-challenger that is. It's total cheating"” (1996, p. 76).
} 

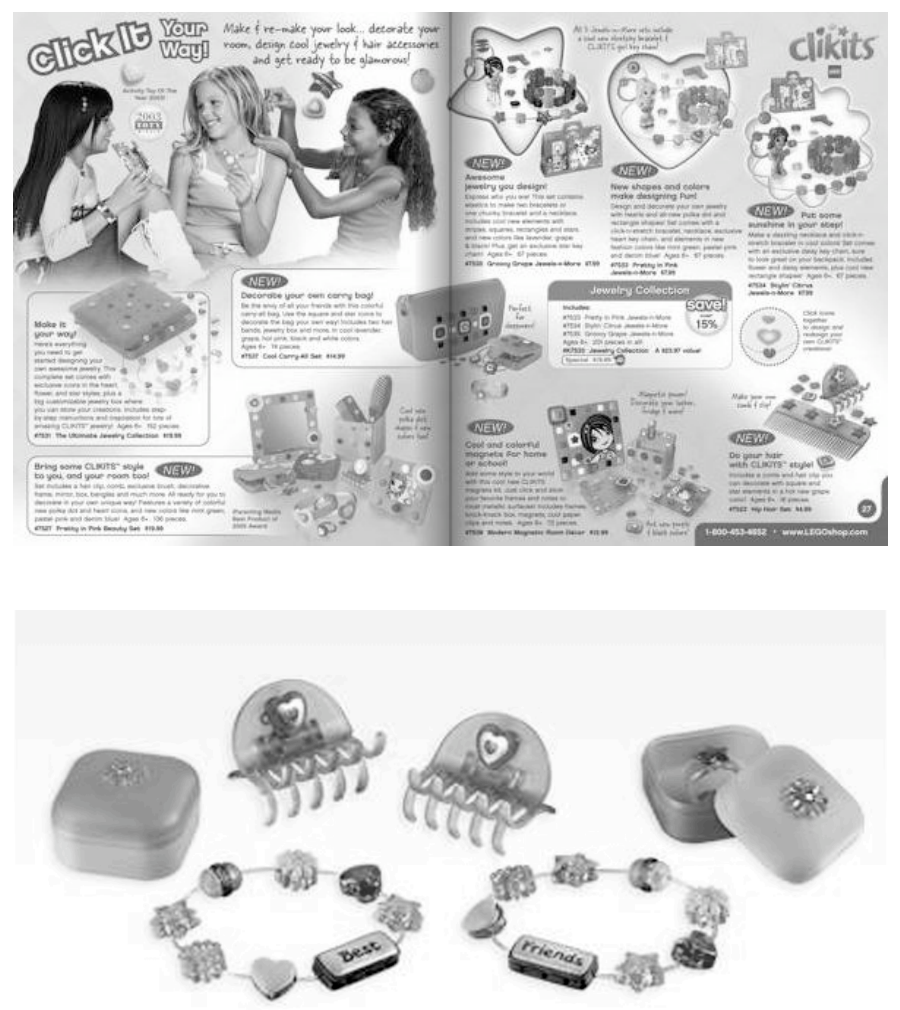

Illustrations $34 \&$ 35: LEGO Clikits are life style products for young girls. These products were designed and produced as part of the LEGO brand extension plan. These life-style and fashion products (bags, bracelets, hair adornments, diaries and so on) are not characterized by bricks and construction play (these LEGO sets simply contain no bricks) but by role-playing and narrative play. The idea of LEGO Clikits is that you click small elements (hearts, flowers and stars) onto a plastic object like a purse or diary. LEGO Clikits has been discontinued as part of the strategy to restore the LEGO Company. The top image is taken from a 2004 LEGO catalogue (LEGO Online Store). The bottom image shows the Clikits set number 7540: Friends 4-Ever Jewels ' $n$ ' More (LEGO Online Store). 


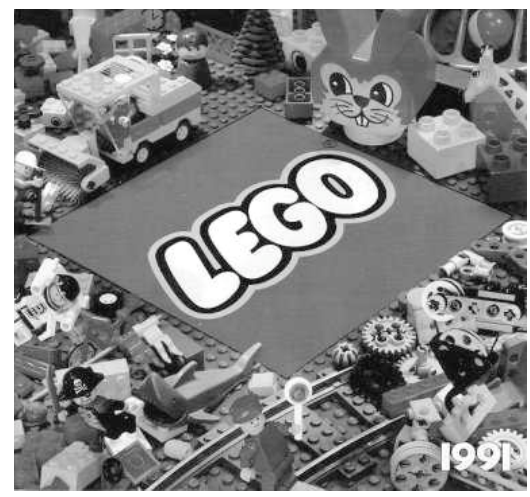

A 1991 cover of a LEGO brochure showing an abundance of bricks.

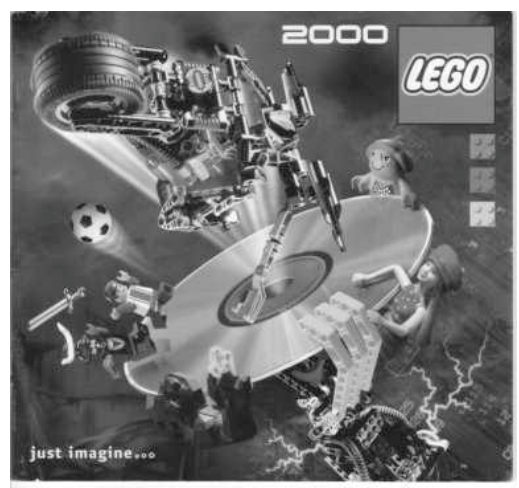

The cover of a 2000 brochure shows the wish to be up to date with a CD on the cover and a Barbie-like doll clinging on to it.

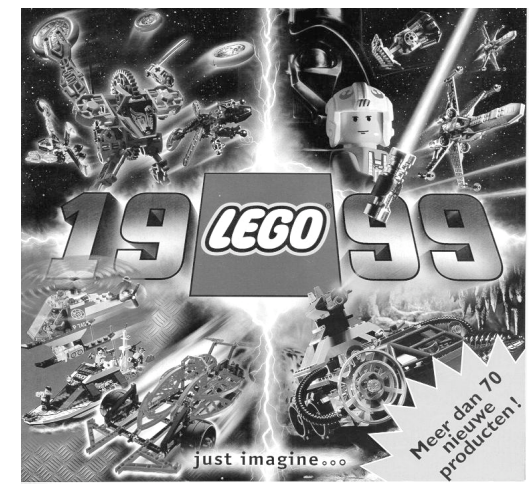

A 1999 cover with hardly any bricks depicted but lots of action.

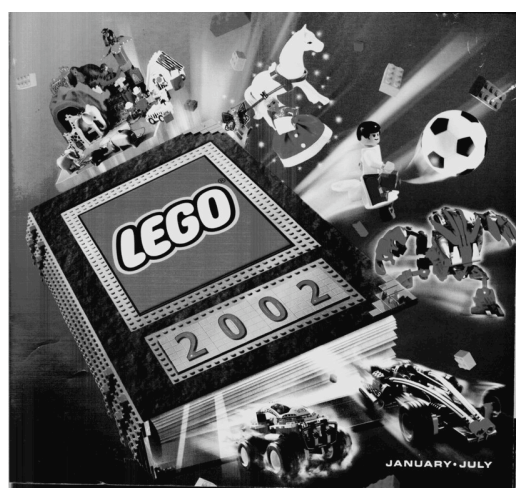

The 2002 cover shows a LEGO book bursting with action.

Illustrations 36 - 39: Extending and Diversifying the LEGO brand. These covers of LEGO brochures illustrate the brand extension through product differentiation and the shift from construction play and bricks to narrative play and action (Brickfactory). 
late ' $90 \mathrm{~s}$ and the early $21^{\text {st }}$ century on the other hand focused heavily on the playing with the construction once it was finished. The preformed elements shortened the building process and thus the journey to the projected play practice with the finished construction. Looking at LEGO brochures introducing the new LEGO toys during this period, we see the discourse changing from bricks to action, from construction to narrative, from process to product (see for example ill. 36 to 39 ).

The narrative and themed LEGO toys were often tied to other media products such as films, television programs, comics, or computer games. Although older LEGO toys were also about roleplaying and narrative play - playing at being a little engineer or a housewife during the " $40 \mathrm{~s}$ and ' $50 \mathrm{~s}$ for example, and a space invader or pirate during the " $60 \mathrm{~s}$ and $70 \mathrm{~s}$ - the roles these toys offered were rather limited and were often in accordance with reality. In contrast, the narrative and themed LEGO toys on sale from the mid ' 90 s onwards presented diverse and wide-ranging roles to play. These roles and narratives were more often than not 'otherworldly'. The 'engineer-hero' was largely replaced with mediaheroes of the Western consumer culture such as Harry Potter, Bob the Builder, Anakin and Batman, as film and media theorist Stig Hjarvard points out (2004a, p. $7 ; 2004 b$, p. 60). Role-playing became more extensively facilitated and embedded in the design of the new LEGO products and in the discourse surrounding these products. It replaced construction play at the core of the geography of LEGO play.

However, the extreme financial losses in the years 2000, 2003 and 2004 made it clear that the brand extension through product differentiation had not been successfully executed. The financial losses were blamed on different things. For example on the production of new media inspired toys, such as 
computer games, which were not within the LEGO Company's area of expertise. ${ }^{73}$ The expensive licensing agreements with, for example, the Walt Disney Company were also identified as a problem. As were the high production costs for LEGO toys. More generally, the extreme and undirected product differentiation led to a diffuse and weakened brand image.

The financial and brand image problems prompted the LEGO Company in 2004 to announce and put into process a seven-year rescue plan. Some of the measures taken reversed in part the product differentiation by selling off or outsourcing certain LEGO divisions such as the software division, clothing line and LEGO theme parks, writes Scandinavian reporter Ivar Ekman for the International Herald Tribune (2005, p. 11). Product lines that do "not directly tie in with the core business of the LEGO group" (LEGO, 2005a, p. 11) or are "less profitable" (such as LEGO Baby, LEGO Quatro and LEGO Clikits) will be or are already cancelled (LEGO, 2006, p. 16). Also, development times will be halved (from 24 to 12 months) so that the company is able to react faster to changes in the toy market (LEGO, 2004, p. 8). A more flexible organizational structure will facilitate faster reactions to consumer feedback and the changing toy market (LEGO, 2005a, p. 14). The amount of unique LEGO particles has been reduced from 12,400 to around 7000 reports business journalist Brendan Koerner (2006). The classic construction toys have been reestablished in 2005 as one of the LEGO Company's core product lines (LEGO, 2005a, p. 20). Importantly, up to $80 \%$ of production will be

\footnotetext{
${ }^{73}$ Most computer games produced by the LEGO Company have not been successful. The LEGO Star Wars computer games however were a big hit with millions of copies sold. The reason for this success might well be the fact that - "in accordance with the LEGO Group's strategy of focusing on core products" the development of this game was outsourced to a more experienced company (LEGO, 2005a, p. 8).
} 
outsourced (mainly to China) to reduce production, packing and distribution costs (LEGO, 2006, p. 14). Finally, closer contact with retailers and consumers should allow for the creation of better products and the successful reestablishment of the brand (LEGO, 2005a, p. 12). Thus far the strategy seems to be paying off. In 2005 the LEGO Company could announce that the "LEGO Group is on the right track" with a net profit of DKK 505 million (LEGO, 2005a, p. 5-6). In 2006, the net profit had almost tripled to DKK 1.430 million (LEGO, 2006, p. 1).

Since 2005 we can indeed see a change (or return) towards more classic LEGO sets that focus explicitly on construction play. Most notably are the product lines LEGO Creative Building, LEGO Creator (with digital and non-digital components), LEGO Digital Designer, LEGO Factory, the retro buckets of bricks with their Book of Ideas and older lines such as LEGO Technic and Mindstorms. Part of the financial success in 2006 was due to the unexpected good sales of "re-launched, classic product lines such as LEGO City, LEGO DUPLO, LEGO MINDSTORMS and LEGO TECHNIC" (LEGO, 2006, p. 7). The return to the bricks, to the classic construction toys does not mean that popular media tie-inns and themed LEGO product that center on narrative play will disappear. Rather, it means that the LEGO Company intends to keep a better balance "between the classic lines and more 'fad-driven' products" (LEGO, 2005a, p. 10). Now the LEGO Company offers both the 'journey' and the 'destination' so to speak, both construction and narrative toys.

In terms of core and peripheral play practices, we can conclude that both areas of play - facilitated and divergent - shrunk during the late '90s and early $21^{\text {st }}$ century period of brand extension through product differentiation. Reasons for this shrinking geography of LEGO play were diverse. Many of the new products 


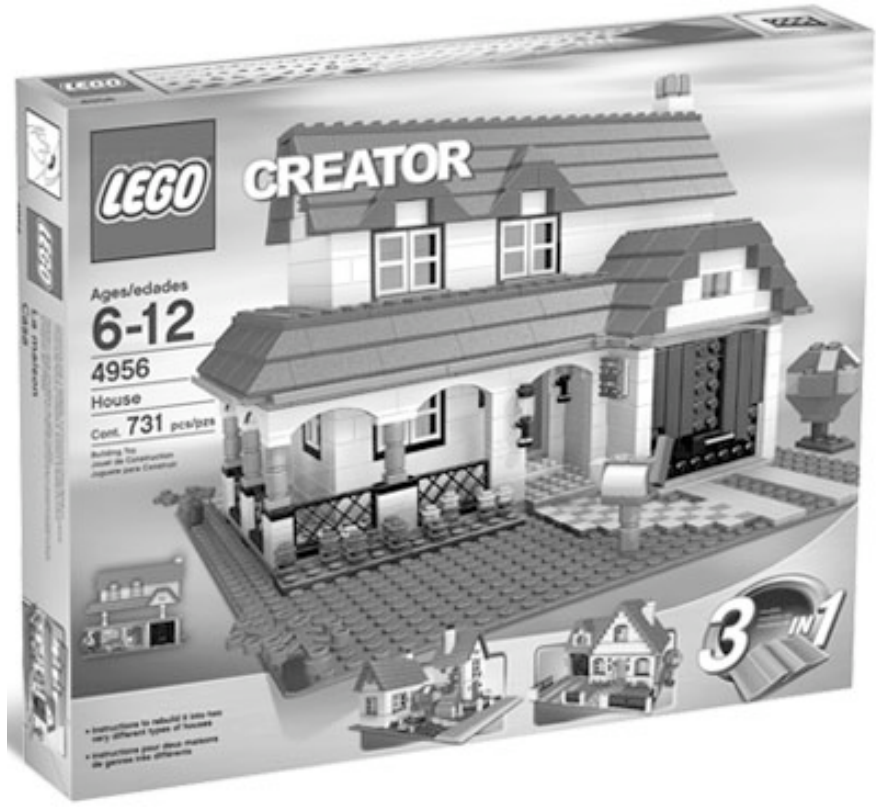

Illustration 40: LEGO Creator: Back to the Bricks. This LEGO Creator set (\#4956) contains 731 pieces and is in many respects a return to the LEGO classic construction toys. The set includes instructions for 3 different houses "plus all the parts you'll need to design your own original creations" (LEGO Online Store). 
were, for example, not compatible with the System of Play. Preformed elements were often only useful in the context of one single LEGO set. These preformed elements frustrated modular, expansive, open-ended forms of LEGO play and restricted the projected uses and users. Some of the new toys, such as LEGO Clikits, contained no bricks at all. Other sets were so specific in terms of narrative and discourse that combining them with other sets seemed unthinkable. Both facilitated and divergent play practices suffered under these late $90 \mathrm{~s}$, early $21^{\text {st }}$ century decisions because the products were more hermetically closed and sealed, less modular and open-ended, leaving little room for designing personal constructions and realizing them.

Although we can still see some of these geography-shrinking elements in current LEGO sets (for example, LEGO Belville for girls contains nonbrick elements and LEGO Harry Potter and LEGO Star Wars are from another symbolic universe), they are less dominant and better balanced against LEGO products that reinforce the System of Play. Most contemporary themed and narrative LEGO toys leave ample room for designing and constructing 'out of the box'.

\section{BRINGING THE FANS INTO THE COMPANY}

Crucially, the LEGO company's future growth and restoration is outlined in the 2006 Annual Report as being based on two major assets: "the classic LEGO products" and the "unique possibilities provided by the close contacts to the users" (p. 19). Having dealt with the re-launch of classic LEGO product in the previous 
paragraph, this part will investigate initiatives to establish close contact with users. The LEGO Company's efforts at developing stakeholder relationships are directed through a new LEGO division: Community, Education \& Direct (CED). CED deals with, among other things, the "cooperation with the company's many fans" (Simonsen, 2006, LEGO press release). I will focus here especially on Mindstorms 2.0 (launched in 1998) and Mindstorms NXT (launched in 2006) to look into how cooperation with fans changes over time, becomes more important and results in the adjustment to the many-to-many paradigm.

Of the first LEGO Mindstorms edition (2.0) - a set of computational LEGO bricks that allow you to create your own robots - almost 1 million sets were sold (at $\$ 199$ per set). ${ }^{74}$ The ongoing popularity of Mindstorms 2.0 prompted the LEGO Company to develop a second edition of the robotics construction toy. One of the goals was to appeal not only to adults but to children as well. Mindstorms 2.0 is a toy with a specific (adult) user embedded in its design, use of technology and requirements on both the financial and computational level. Apparently, 70\% of Mindstorms 2.0 users are adults (Koerner, 2006). The projected user of NXT is younger. Through simplifying the programming language, the LEGO Company wants to broaden the scope of possible NXT users (Koerner,

\footnotetext{
${ }^{74}$ Mindstorms was developed in close contact with the MIT Epistemology and Learning Group founded by Seymour Papert. It is named after his book Mindstorms: children, computers, and powerful ideas (1993). In 1985 the LEGO Company started working together with Papert "with an eye toward introducing a computer-driven LEGO product" (Wiencek, 1987, p. 102). Papert is the founding father of the educational theory constructionism ("learning-by-making"), based on the work by Swiss philosopher and psychologist Jean Piaget (Papert, 1991, p. 1). Mitchel Resnick became the LEGO Papert Professor of Learning Research in 1999. Resnick's MIT research group Lifelong Kindergarten has recently launched the PICO Cricket Kit, financially backed by the LEGO Company, which is not so much about robot building but about creating computerized designs going from signing birthday cakes to meowing cats (PICO, 2006).
} 
2006). The new system is PC and Mac compatible and the programming software is redesigned and now far more intuitive and easier to use. Players from age ten upwards should be able to complete a robot in 30 minutes (as opposed to $11 / 2$ to 2 hours with Mindstorms 2.0.).

Mindstorms NXT (which costs $\$ 249.99$ per set) consists of an 'Intelligent Brick', a 32-bit LEGO microprocessor. Its sensor capabilities are ultrasound, sound, light and touch. The robot has a USB port and Bluetooth technology that enables remote control of the robot (e.g. through a mobile phone or PDA). Overall, the robots look and act more realistically and can perform more complex tasks, such as reacting to voice commands (Koerner, 2006).

However, the most interesting thing about the new Mindstorms kit has been its developing process. "The boldest part (...) is Lego's decision to outsource its innovation to a panel of citizen developers" hoping that this "will lead not only to a better product but also a tighter, more trusting bond between corporation and customer" (Koerner, 2006). Four dedicated Mindstorms users - which innovation expert Eric von Hippel refers to as "lead users" in Democratizing Innovation (2005, p. 22) - had been selected by the LEGO Company to form a Mindstorms User Panel and help with the design of the next generation Mindstorms. Lead users are not only quick in adopting new products (by buying them), but importantly, also in adapting these products so that they might better fit their personal needs. Hippel defines lead users as either persons or companies that are at the edges of market trends and therefore experience needs that others will soon experience as well. More so, lead users innovate products because they anticipate a relatively high benefit from doing so $(2005$, p. 22$)$. In relation to players becoming producers, this "high benefit" is in terms of their experience of play, not financially. Most 
players-as-producers work for free.

Lead users are part of fan communities that, as media theorist Henry Jenkins puts it, do not want to 'jam culture' but see 'unrealized potentials'.

Culture jammers want to opt out of media consumption and promote a purely negative and reactive conception of popular culture. Fans, on the other hand, see unrealized potentials in popular culture and want to broaden audience participation. Fan culture is dialogic rather than disruptive, affective more than ideological, and collaborative rather than confrontational. Culture jammers want to 'jam' the dominant media, while poachers want to appropriate their content (2002, p. 167).

The LEGO fan community knows different poachers who appropriate the tools for play handed to them by the LEGO Company in various ways. Jenkins borrows the term 'poachers' from De Certeau and uses it to indicate the possible active and creative role of media consumers (Jenkins, 1992, p. 24). The creators of MOC sets from the introductory example are such a group of poachers who see 'unrealized potentials' of LEGO designs.

Lead users adopting and adapting Mindstorms was not new. Mindstorms 2.0 has known a vibrant and innovative user community from the very start. The Mindstorms community has, through hacking and modifications "done far more to add value to Lego's robotics kit than the company itself" (Koerner, 2006). The free user-generated software to program your Mindstorms robot NQC (Not Quite C) is a good example of this. Created by David Baum and now being further developed and maintained by John Hansen, this software is very popular among Mindstorms users (Baum, 2007; J. Hansen, 2007). The software allows you to manipulate your robot through typing the programming code rather than through dropping and dragging the digital blocks on your screen. At first unsure how to deal with these hackers, the LEGO Company decided that limiting creativity was against its corporate ideology so it gradually 
warmed to the "open source ethos" and wrote a permission to hack in the license agreement (Koerner, 2006). More so, the "hackers were providing a valuable service" because they made the product more exciting and enhanced the experience with a basic Mindstorms set without getting paid for it (ibid). Mindstorms fans have also written numerous books and manuals on how to build Mindstorms robots.

The LEGO Company tapping into lead user communities and user-driven innovations to design the new Mindstorms NXT was a novel approach for a company known for its rich history of lawsuits against companies or persons unlawfully using their product or brand. Mindstorms 2.0 and the adaptations by users, their poaching and divergent user practices, shows the centrifugal movements in which users and their activities move away from the core and into the periphery. In this movement, users appropriate the configured user and the embedded scripts.

Mindstorms NXT also shows both the fast and slow centripetal appropriation of the periphery and its divergent play practices, by the core. The fast centripetal appropriation is manifested in user-written software for Mindstorms 2.0. that allows players within the scope of one product to change its design, the embedded scripts and projected uses. Through this fast centripetal appropriation, certain players can coconfigure the user of Mindstorms 2.0. The possibility of fast centripetal appropriations is connected to the digitalization of the LEGO geography of play. Slow centripetal appropriations are constituted by the LEGO Company tapping into lead user knowledge and the many-to-many culture to launch a new edition of Mindstorms robotics. An elite group of Mindstorms users has thus been consulted in the reconfiguring of the user of Mindstorms NXT. By drawing on the many-to-many culture to design a new product the slow centripetal movements between periphery and 
core are commodified.

Tapping into lead user knowledge and practices for product development is beneficial both marketingand brand-wise. When the word got out that Mindstorms fans were sitting at the table with LEGO officials to design NXT, the Internet buzz seemed unstoppable. The strategy to draw on user-generated content to improve products and create a solid fan base and loyal community is common among computer game developers. Also in line with the production process of computer games, the LEGO Company recruited 100 beta testers who would be able to buy a pre-release of the NXT at a discounted price in return for four months of heavy tinkering and product feedback.

Besides the user-driven development of NXT, the LEGO Company has initiated many other projects that intend to sustain and support user communities and tighten the bond between brand and consumer. LEGO Factory is one such a tool. LEGO Factory allows you to build your own designs with the free LEGO Digital Designer software. It is important to note, however, that LEGO fans have been programming and using Computer Aided Design (CAD) programs since the mid $90 \mathrm{~s}^{75}$ Adult fans generally prefer these user-generated programs over LEGO Digital Designer because they offer more viewing options, colors, bricks and design flexibility (LOWLUG, 2007). This is not entirely surprising since LEGO Digital Designer is meant for children and inexperienced builders.

Two other examples of community building and 'bringing the fans into the company' are the LEGO

\footnotetext{
${ }^{75}$ LEGO Digital Designer is not the first official LEGO building software. LEGO Creator and LEGO CAD preceded it. LEGO Creator is still on sale but LEGO CAD has been discontinued. Moreover, LEGO fans have created many CAD programs over the years. For example: Ldraw (Jessiman, 1995), SimLego (Eriksson, 1996), LeoCAD (Zide, 1996), Bricksmith (A. Smith, 2005), BrickDraw3D (Olson, 2001) or MLCAD (Lachmann, 1999).
} 
Ambassador Program and the LEGO Certified Professionals Program. Being a LEGO Ambassador does not cost money but only a few people are selected each year. "The Ambassador Programme is an official program which invites adult LEGO fans to share their enthusiasm for the LEGO idea and LEGO products and encourages interaction in the global LEGO communities" (LEGO, 2005a, p. 12). Joining the LEGO Certified Professionals Program costs $\$ 1000$ a year but more people can apply for this title: "the LEGO Certified Professionals programme caters for adult fans who, wholly or partly, live by their LEGO hobby and therefore wish to enter into cooperation with the LEGO Group" (ibid).

The guidelines and rules for being a part of these programs are rather specific. In the FAQ list on the Ambassador program we read:

All LEGO Ambassadors members are expected to exemplify the program fundamentals of building proficiency, enthusiasm, and professionalism towards the public, other fans, the LEGO community and the LEGO group. In addition, LEGO Ambassadors members agree to be active contributors to the LEGO world-wide community by:

Contributing regularly to online discussions

Participate in local user groups, or help to start one in the local area

Advise new fans just joining the hobby (LEGO, Ambassadors Program).

These explicit attempts at establishing an active user community might seem a bit forced when compared to computer game communities that pride themselves on being independent and unendorsed and considering the fact that active LEGO communities have been thriving for a very long time.

One of the advantages of an active user community is invaluable feedback about the products being used by these users. In the 2006 LEGO annual report, this feedback is referred to as "unique" and "extremely significant" knowledge "of the wishes and needs of the users" (p. 18). This knowledge is used in both the development and the marketing of new LEGO products (p. 18). Closing the gap between company 
and consumer through loops of feedback or centripetal forces is a means to include the consumer in the magic circle that is a brand and to keep that brand vital. As Lury puts it: "the aim of the feedback processes in which information about competitors and the consumer is fed back into production is to make the brand itself dynamic" (2004, p. 3). By including the consumers into the design of Mindstorms NXT, the LEGO Company intends both to reestablish its brand as dynamic and vital and to launch a participatory relationship with its consumers.

An often-heard critique on user-driven innovations, on bringing the fans into the company, on tapping into the many-to-many community, is the "free labor' critique. Soren Lund, LEGO Mindstorms Product \& Marketing Development Director, remarks in an interview with Joel Greenberg that this free labor is not necessarily cheap to tap into because a lot of the company's energy and resources are invested in working with user communities (Greenberg, 2006). More importantly, it is exactly the fact that users are not being paid to co-design a new product that makes this system work, according to Lund. Paying users would reallocate them from the communities' 'can culture' to the companies' 'must culture' (Greenberg, 2006; Jenkins, 2006c).

A distinction needs to be made here between adults and children. The consumers the LEGO Company involved in the development process of Mindstorms NXT were adults. The gap between the LEGO Company and children is targeted through initiatives such as LEGO Factory, competitions, forums, exclusive membership advantages and a more 'individualized and branded shopping experience' both online and in stores (LEGO, 2006, p. 18). For example, in many new LEGO stores you can pick and choose your own bricks instead of buying pre-assembled sets. And in 2007, the first indoor Legoland Discovery 
Centre was opened in Berlin on the Potsdamer Platz. This branded LEGO shopping center is far more than a LEGO flag store. It combines an indoor playground with adventure rides, a fun shopping experience with playing and experimenting, learning about how LEGO bricks are produces with a LEGO mini Berlin. The Berlin Discovery Centre is not so much about selling LEGO products as it is about brand strength and involving children (and their parents who can 'relax in the restaurant') within the experience of the LEGO world (LEGO, Discovery Centre website).

The LEGO Company seems to realize that the best ideas for new products are likely to be found within the divergent peripheral play activities of dedicated fans, in the user-driven can culture of fan communities. Importantly, this implies that some of the divergent, peripheral play practices are incorporated through centripetal appropriation in the facilitated, core. This blurs the lines between player, consumer and producer. As Hippel states, 'consumer' is too passive a term for lead users who are actively involved in innovation processes $(2005$, p. 19). Players can become co-producers in direct or indirect ways. Directly through, for example, being invited to partake in design processes or having your creation turned into an official set. Indirectly through online communities that have never been so easy to monitor, take part in, lurk in and learn from. ${ }^{76}$ The fact that peripheral play activities are increasingly 'harvested' for use in the core does not necessarily result in a shrinking geography of play. In 'tolerating' (both in the design that supports open play systems and in the discourse that now includes, for example, in the Mindstroms' license agreement the permission to hack) divergent

\footnotetext{
${ }^{76}$ Lurkers are people who read discussions on fansites, chatsites and the likes without actively participating in these discussions. Most forms of lurking are considered bad netiquette (contraction of 'network' and 'etiquette') and lurkers or non-participants are therefore not popular.
} 
user practices or centrifugal appropriations, the periphery is 'irrigated' and kept from shrinking.

The LEGO Company's tactics for bringing the fans into the company signals a powershift which can be typified in terms of Strassoldo's two models of core/periphery differentiation. In Strassoldo's first model there is only one center that is the locus "of power and decision-making", boundaries between core and periphery are controlled and closed and "commands flow down from the centre to the periphery, while information travels in the reverse direction" (1980, p. 39). The LEGO Company's brand extension and the 2003 color change are exemplary of a one-to-many model in which the powerful actors in the core make decisions that affect design and discourse and thus the facilitated play practices. These decisions can be either accepted or rejected by users. This first model characterized the geography of LEGO play until the beginning of the $21^{\text {st }}$ century. Innovation was manufacturer driven and the geographies of play were rather static with little exchange between core and periphery.

Bringing the fans into the company is in line with Strassoldo's second model, in which the core has "more open boundaries" and influences the periphery not through coercive power but through the "spontaneous coordination of individual behavior", through "immaterial elements such as images and moral codes", "values" and "norms" (p. 38-41). The LEGO Company has made a step from a manufacturerdriven innovation culture to a user-driven innovation culture by tapping into the peripheral can culture of user innovations. In this process, the periphery becomes more important but looses some of its autonomy. Although the periphery has a certain influence on the core, access to the core remains mediated by the LEGO Company. The strict rules for the LEGO Ambassadors, the incorporation of a 

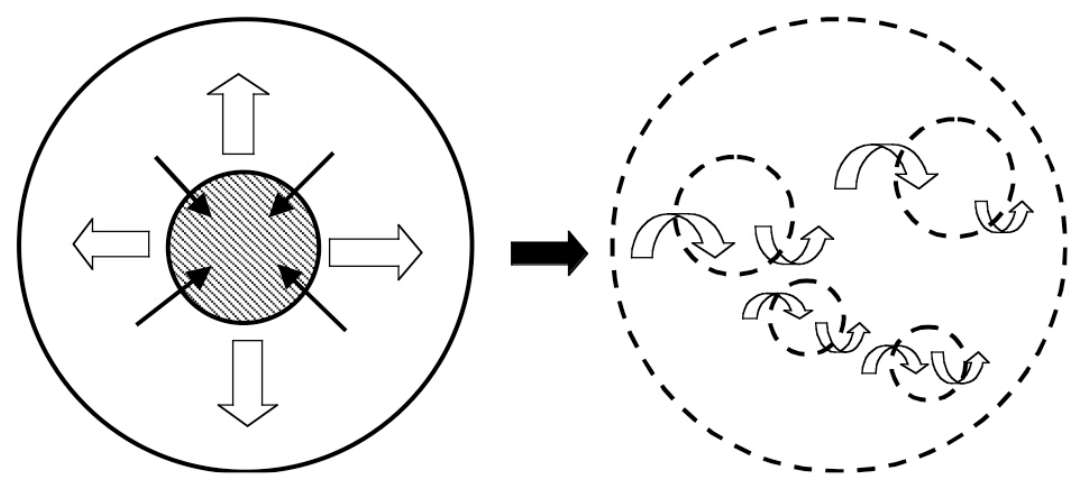

Figure 3: Changing geographies of play. The LEGO Company has moved from one-to-many, manufacturer-driven practices of production (Strassoldo's first model) to many-to-many, user-driven practices of production (Strassoldo's second model). Moreover, a splintered and dispersed core characterizes the many-to-many geography of LEGO play and production. Centrifugal and centripetal movements of appropriation between the dispersed cores and the periphery are facilitated. 
permission to hack in the Mindstorms 2.0 license agreement, indicate that the LEGO Company might have opened its doors to lead users, it still controls what goes through that door.

Importantly, in the many-to-many geography of LEGO play, the LEGO Company not only taps into the periphery, LEGO employees themselves increasingly venture into the periphery. They take part in user groups and post on fansites, data mine personal websites and fan community databases, announce new products and programs on private initiative websites. By doing this, the core is splintered and dispersed.

For an elite group of lead-users (be it codesigners of Mindstorms NXT, the creators and users of CAD software or the designers of MOC sets) who possess the necessary know-how, time and money, the 'journey' of LEGO play is considerably extended through their inclusion in design and production processes. With this extended journey, the geography of LEGO play becomes more complex and expansive and, importantly, is penetrated by practices of design and production. Practices of play and production meet and converge at the intersection of peripheral play practices that become core play practices. The result is a partly commodified geography of play in which certain divergent user practices are 'harvested' and commercially used. Through this partial commodification, the stakeholder positions of player, consumer and producer can implode for certain actors.

Although user-driven innovation is often hailed as the democratization of consumers, they are not the ones earning money from their creative labor. Players gladly work for free for the LEGO Company and give up their creative rights for others to earn money with. In this we see De Certeau's concept of la perruque upended. La perruque indicate the masking of private activities as work activities, for example in "writing a love letter on "company time"” $(1988$, p. 25). Within a 
commodified many-to-many model, the reverse is manifested. In this case it is not so much leisure that penetrates work, as De Certeau describes, but work that penetrates leisure. The effect, however, is the same: "the dividing line no longer falls between work and leisure. These two areas of activity flow together. They repeat and reinforce each other" (p. 29).

\section{TOWARDS A MANY-TO-MANY GEOGRAPHY OF PLAY}

In this chapter I have considered some different aspects of changing LEGO toys. An important aspect of this chapter is the changing means and conditions of postindustrial production and their influence on toys. Changing means of production relates to the 1940s transition from wood to plastics, the 1950s innovation of plastic molding machines and the $21^{\text {st }}$ century strategy of bringing LEGO fans into the LEGO Company - be it directly through making them part of design teams or the Ambassador Program or indirectly through tapping into online and offline fan culture.

A second important aspect deals with the question of how changing toys influence practices of play. We have seen how plastic bricks, the stud-andtube coupling system, the detailed LEGO elements and the LEGO System of Play broadened up both the facilitated/core and divergent/peripheral play activities with LEGO. This broad and expansive geography of LEGO play was challenged during the late ' 90 s and early $21^{\text {st }}$ century due to an unfortunate attempt at extending the LEGO brand into other areas of the child's universe. Product diversification and changes to the System of Play during those years led to a shrinking core and periphery of LEGO play. Financial losses and a weakening brand image prompted the 
LEGO Company to set into motion a seven-year strategy to restore the LEGO brand. This strategy was based on two primary assets: refocusing on the brick and construction play and establishing a substantial relationship with consumers. The strategy is paying off not only in financial terms but also in terms of a return to a broad and expansive area for LEGO play, both on the facilitated and divergent level.

Although this overview of changing practices of play might suggest that the 2007 geography of LEGO play is similar to the 1950 s geography, significant changes have taken firm root. One of these is the increase in themed and media-related LEGO sets and the accompanying diversification of roles, narratives and heroes. LEGO toys have gone from being focused on architecture, houses, the private house in the late $1940 \mathrm{~s}$ and the $1950 \mathrm{~s}$ to mimicking wide-ranging aspects and heroes of our times. The roles and heroes children can relate to when playing with LEGO toys have increased and diversified: from engineer, architect, housefather or housewife in the " $40 \mathrm{~s}$, '50s and ' 60 s to wizard, space explorer, police agent or princess in the $21^{\text {st }}$ century.

Besides the increase in and diversification of narratives and heroes, the most important change has been the move towards a (partly commodified) manyto-many geography of LEGO play. Bringing fans into the company, tapping into user-driven innovative fan culture, incorporating what happens in the periphery of the geography of play into the core, marks the transition from a one-to-many to a many-to-many geography of play. This entails a crucial shift in the design of new products, in the marketing of new products and in dealing with the key stakeholders: the players. More so, in adapting to and tapping into the many-to-many culture of user communities in terms of design, production and marketing, the focus is increasingly on adults. Would it have been unthinkable 


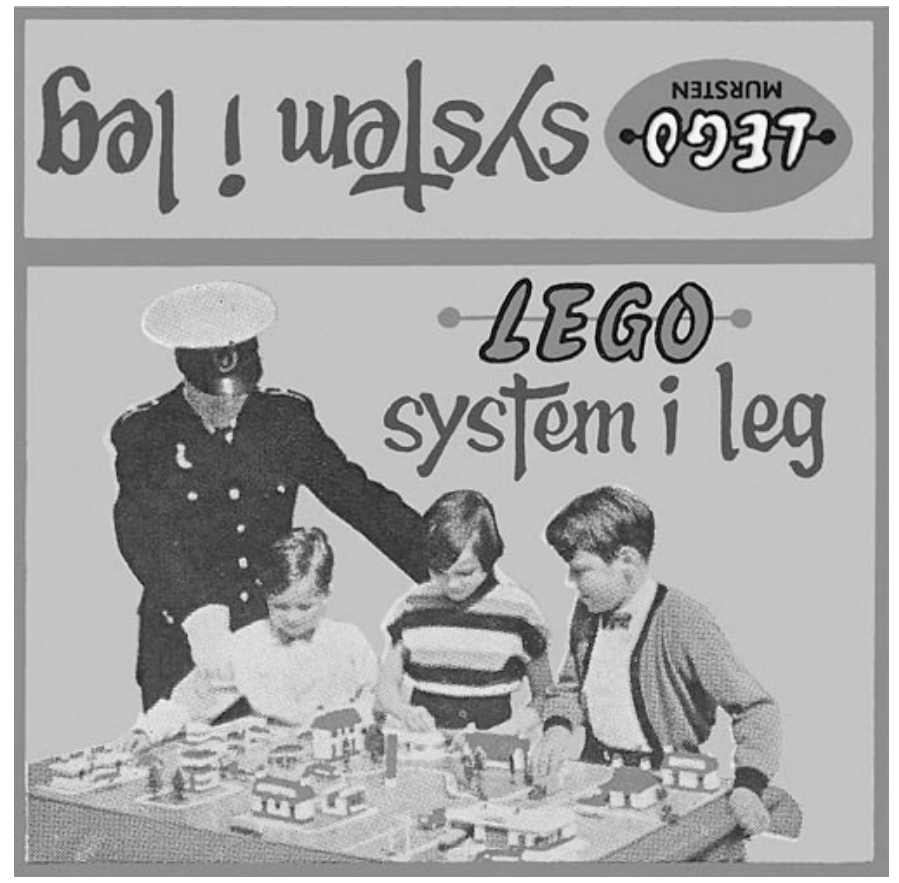

Illustration 41: Supervising LEGO play. This illustration is part of a generic sleeve used for LEGO sets between 1955 and1957. Both 'mursten' and 'System i Leg' feature on the box. The system approach is visualized through the building of a town rather than one single house. The man in uniform is Godtfred (the son of the Ole Kirk) with his children Kjeld (later to be the third generation leading the LEGO Company), Gunhild and Jorgen. The father looks on but does not play with the bricks (Hughes, 2007). 
in the 1950s to envision adults in the geography of LEGO play in any other role than as supervisor or helping hand, now adults are considered a unique and extremely important source of valuable information and input. What the LEGO Company is loosing in the age bracket 7 to 17 due to the KGOY trend, they are gaining in the age bracket 17 to 47 due to the ASYL (Adults Staying Younger Longer) trend.

The many-to-many model has gained in force and importance due to technological innovations that facilitate easy contact and exchange between users. These same technologies also facilitate the participation in and access to many-to-many communities by companies. They become part of the 'by us for us' network of activities and practices. Companies increasingly bank on the many-to-many culture for product design, marketing and brand strength. The slow centripetal appropriation of periphery by core that serves new product developments has become, in the course of the LEGO history, indispensable. By incorporating peripheral, many-to-many activities and practices within new products, these activities and practices are commodified. In such a partly commodified geography of LEGO play, work penetrates play. The periphery of LEGO play at the same time gains in importance for and influence over the core and looses in autonomy. Importantly, in migrating from the periphery to the core through either fast or slow centripetal forces, divergent play practices become part of the embedded design scripts and they co- or reconfigure the user and uses. Within the changing geographies of LEGO play, different mechanisms of user-involvement were manifest: from inviting lead users to join the designers in Billund to creating loyalty programs, from scouting fan creations on- and offline to offering a branded shopping experience.

In light of the processes of commodification, 
domestication and urbanization, this chapter highlights the postwar situation while bridging the gap with the $21^{\text {st }}$ century. During the post-war years, consumerism changes: were the $19^{\text {th }}$ century department stores still class-conscious, the Americanization of consumption and the economic growth after the Second World War secured a new affluence down to the working classes. Part of this maturing consumerism is a renewed emphasis on the home, the private sphere and the nuclear family with consumer goods targeted at the home and family live. The relatively cheap, easy to clean, durable, colorful and standardized plastic bricks epitomized the postwar vogue of indoor plastic products. The (sub-) urban and domestic designs of the early LEGO sets reflected the sanctity of the private suburban home of the 1950s nuclear family.

The mid $19^{\text {th }}$ and early $20^{\text {th }}$ century guidebooks on housekeeping called for the separation of child and adult both in architectural layout of the private home and the upbringing of children. In the postwar family home, child and play (for children as well as adults) are put front center in the recreation area and the open plan living room. LEGO toys answered to and reinforced the increasing domestication of child and play and the angst-ridden relationship between child and the 'mean world' outside of the private suburban home.

More recent developments within the LEGO Company bring us into the $21^{\text {st }}$ century and signal a change in the relationship between players, consumers and producers wherein players increasingly become co-producers of their own commodities. 


\section{4: Pimp My Game}

This chapter deals with the simulation games SimCity, The Sims and The Sims Online created by the American game designer Will Wright. His SimCity and The Sims series of games are surrounded by fantastic stories that involve female and gay gamers, Will Wright as a genius, eyebrow raising sales numbers, a revolution in gaming, the American Dream, a critique on our consumer culture and last but not least, the saving of the gaming industry. In an industry oversaturated with and endlessly criticized for its male machismo, ridiculously oversized guns, wars, battles, blood and more wars, there was a sigh of relief by those who care about computer games either as players or as developers, when these peaceful games about urban planning and domestic life became immense hits. And 
the relief was even bigger when a large part of the The Sims gamers turned out to be female and non-gamers. ${ }^{77}$ The Sims is considered the only game that has as many male as female gamers. ${ }^{78}$ Critique on the game industry on the level of sexism and violence could now be answered with a smug smile and two words: The Sims.

This chapter will investigate SimCity, The Sims and The Sims Online consecutively and compare these games with toy villages, toy homes, dolls and dollhouses, their connotations, underlying ideology and the practices of play they induce. Wright himself will often compare his games with railroad sets and dollhouses and calls them toys rather than games. As computer game designer and analyst Celia Pearce states in her article Story as Play Space, at the core of Wright's games "are fundamental paradigms of play" such as "role-play, constructing miniature towns, 'playing house"' (2002, p. 116). The investigation of continuities and discontinuities between non-digital and digital toys addresses the role and function of the many-to-many model within the geography of digital play and the mechanisms of user involvement at work in this many-to-many structure.

\footnotetext{
${ }^{77}$ The gaming industry considers non-gamers or non-users a problem. They want to attract these non-users not only to extend their market reach but also to shake off the image that computer games are only played by nerds or teenagers with social interaction problems. Sally Wyatt has rightfully pointed out how non-users of technological artifacts (the car or the Internet for example) are generally framed in policy discussions as deprived of something or subject to inequality and therefore in need of remedies that will promote non-users to users. She distinguishes between four different forms of non-users, two of which (excluded and expelled) indicate the "have nots" while the other two (resisters and rejecters) indicate the "want nots". Instead of thinking of non-users as a problem waiting to be solved, Wyatt proposes to consider them as "relevant social groups who might influence the shape of the world" (2003, p. 68, 76 \& 78).

${ }^{78}$ As game critic Charles Paulk has pointed out, the biggest surprise is not so much that female gamers like the game but that male gamers like it as well (2006). Because this interior design game (baptized "the IKEA game" by Celia Pearce) lacks many if not all stereotypical masculine game activities (battles, fierce competition, levels...) that are often thought necessary ingredients for reaching the male gaming market (Pearce, 2004).
} 
In the previous chapter we saw the increased dependency by toy companies on user communities for creating challenging new products or extensions of existing products, for keeping a brand alive and commercially successful. Within the LEGO geography, part of the many-to-many activities are commodified and used for new product developments. This gives players a more active role in the design of new products. As such, players become to a certain extent co-constructors of new products, of the embedded design scripts and user configurations of these products. When individual users or a community of users shifts from being consumers and users of products to co-designers of new products and coestablishers of a brand image, their actions lose a certain inconsequentiality and triviality. With so many user activities now taking place on the Internet, these activities are more easily accessible by larger numbers of users and can, besides establishing a positive and constructive brand image, also damage a company's image.

We could state that the solitary $19^{\text {th }}$ and early $20^{\text {th }}$ century geographies of play have been largely replaced, through the incorporation of the Internet within the geography of play, by densely populated and heavily networked geographies. This impedes the separation of the child from the outdoors, from unwanted contact with strangers and adults. The Internet adds new playground, enlarges existing play areas, interconnects players, facilitates fast traffic within geographies and brings the outside into the private home and the child's private room. This is not to say that the pre-Internet solitary geographies were completely devoid of such participatory elements. There was contact with peers, siblings and adults through and about play. And from the $20^{\text {th }}$ century onwards, toys were increasingly linked to clubs and magazines, radio programs and contests, special days 
and festivities. However, these peripheral, social and participatory activities have increased immensely due to new media technologies. The Internet has knitted players together within the geography of digital play in an unprecedented interconnectedness. ${ }^{79}$ Within geographies of digital play the core/periphery relations tighten, the peripheral play area expands, traffic within that periphery and between core and periphery increases and the tapping into the many-to-many culture intensifies. ${ }^{80}$

When making a distinction in this chapter between non-digital and digital toys, it is important to clarify what this distinction entails. In the second chapter, a transformation within non-digital construction toys was outlined: from building toys to toys designed-to-be-about-design. With the shift to digital (construction) toys, an extra layer is added to this. Computer games are not only designed objects that facilitate designing as a play practice and that take designing as their subject; they are also coded and programmed computer applications. The rules and interactions with the game are inscribed within that programmed code. Wright's games are, like the second generation of construction toys, designed-to-be-aboutdesign. Either the player designs a city in SimCity, a household in The Sims or relationships in The Sims Online. However, they are also procedural - they evolve visually over space and time. Not only through the handling of the toy by the players but through the built-in mechanisms of rules and behaviors that dictate

\footnotetext{
${ }^{79}$ The participatory cultures of computer games cannot only be compared to the participatory culture of non-digital toys but also to that of other media. Computer games are, after all, both game and media object. Radio, television and film are also part of rich and vibrant participative communities. See Raessens Computer Games as Participatory Media Culture (2005) for a detailed analysis of different forms of media related participatory cultures.

${ }^{80}$ Concerning the effects of digital media on the increasing speed of fan communication within fan cultures see Matthew Hills Fan Cultures (2002).
} 
what the evolution is of variable A or B in relation to variable $\mathrm{X}, \mathrm{Y}$ or $\mathrm{Z}$.

Although strictly speaking every designed artifact contains "potential action that can be actualized" through its use, "like a muscle at rest that contains potential energy", computer games do take this actualization of design through its use further than analogue or non-digital objects (Barab, Thomas, Dodge, Squire, \& Newell, 2004, p. 262). Digital, coded objects will continuously provide the interactor (the user who is interacting with the object) with yet another option to actualize the design. Thereby making this actualization into a procedural activity. ${ }^{81}$ Instead of simply 'clenching your fist', computer games involve players in a 'long-term fight'. In the case of Wright's games, characterized by their lack of a "you win" or "you loose" moment, this is even a "never-ending fight' or a never-ending string of actualizations of design potentials. This makes Wright' games toys indeed because they have no clear ending to when the playing stops. But it also very much makes them games in the sense that they are designed and rulebased systems. These digital and procedural construction toys are all about the journey, about process, building and constructing.

Crucial in studying digital practices of play within such designed and coded play environments is the question of 'anarchy' or, in terms of Akrich and Latour, of an "antiprogram": in how far do and can players divert from the facilitated practices of play, counter the original intentions of the designed artifact? (1992, p. 261). Or in De Certeau's words, what is the space players have to "indicate what they make or $d o$ with" consumer products? (1988, p. xii). Can players establish an 'antidiscipline through manipulation, appropriation and reappropriation, poaching, poiesis

\footnotetext{
${ }^{81}$ See also: Frustrating Desire on continuous loops between player and game (Lauwaert, Wachelder, \& Walle, 2007).
} 
and bricolage? (p. xii, xiii, xv, 25, 165, 174). Within these designed artifacts, is there room for the "countless ways of "making do"? (p. 29). For the 'unrecognized producers, the poets of their own affairs, the trailblazers in the jungle of functionalist rationality'? (p. 34). For every game specific instances of centrifugal user appropriation of the core will be brought to the forefront: mods and patches in SimCity, co-creation and the album function in The Sims, beta testing and cheating bots in The Sims Online.

The analysis of play practices within geographies of digital play is based on the observation of and participation in user groups. ${ }^{82}$ Users could be categorized, for example, according to the intensity of their gaming activities: accidental players (e.g. players who play the game at a friend's house or try the game in a store), casual players (players who own the game but play only once in a while), active players (people who play the game regularly but do not create usergenerated content) and pro-active players (active players who also create user-generated content). ${ }^{83}$ These last two groups of players have been studied most actively because they are most often found on fansites, chatsites, forums and discussion boards. To be sure, all users perform not all play practices described in this chapter.

\footnotetext{
${ }^{82}$ This choice excludes certain groups of players since only the most active players will be found regularly on user groups. Also, it excludes all categories of non-users described by Wyatt (2003, p. 76).

${ }^{83}$ Players might, for example, also be categorized according to gender or socio-demographics. 


\section{TOY TOWNS AND SIMULATED CITIES}

The first part of this chapter will deal with the SimCity games. ${ }^{84}$ These games simulate city life and the player is an urban planner turned puppet master trying to create and run the perfect city. The first SimCity game was launched in 1989 and it popularized the genre of the so-called God games and simulation games. ${ }^{85}$ The first SimCity (Maxis, 1989) game, commonly referred to as SimCity Classic, proved to be an immense success and it was followed by SimCity 2000 (Maxis, 1992), SimCity 3000 (Maxis, 1999), SimCity 4 (Maxis, 2003b). ${ }^{86}$ There have been multiple spin-offs from the SimCity idea that enable the player to virtually simulate and manage everything.

Throughout SimCity's history the technology involved in creating and playing these games has changed significantly. Since the late 1980's computational technology has seen a dramatic change towards faster, bigger and cheaper machines. Or as put by Kline, Dyer-Witheford and De Peuter in Digital Play: "Four decades have seen the digital game transform from the whimsical invention of bored Pentagon researchers, computer science graduate students, and nuclear research engineers into the

\footnotetext{
${ }^{84}$ A previous and slightly different version of the analysis of SimCity was published as the article Challenge Everything? Construction Play in Will Wright's SIMCITY (Lauwaert, 2007).

${ }^{85}$ As the story goes, the idea for SimCity came into being when Wright worked as a freelance programmer in Silicon Valley (Piedmont, California) programming a standard shoot-'em-up game called Raid on Bungling Bay (1984). He discovered that he had more fun with the island-generating tool than with blowing up the islands, the actual premise of the game. The first game in the SimCity series was not easy to sell because the company Broderbund for whom Wright worked at the time did not think a game in which you could not win would be commercially successful. Therefore, together with partner Jeff Braun, Wright started his own company Maxis (Beckett, 1996; Seabrook, 2006, p. 94-95).

${ }^{86}$ Maxis was bought by computer game giant Electronic Arts (EA) in 1997 in a period when EA bought a lot of different digital entertainment companies. EA released a number of SimCity titles.
} 
fastest-expanding sector of the entertainment industry" (2003, p. 12). This change means that more and more people are involved in creating current computer games (teams might consist of up to 200 people), they take longer to develop (up to three years) and cost more money to make (typically ten million dollars). On the production side of things computer game development changed from a low-budget, hobbyist basement endeavor to a multi-million industry. On the receiver or consumer side of things this results basically in two things. Bigger game development companies and larger amounts of money involved means a conservative stance towards what sorts of games are being developed. The big game companies will rather produce yet another sequel to a popular game than an altogether new and out of the box game. If violence and skimpy clothes sell, than that is what they will produce. Evidently, this is a self-fulfilling prophecy because it is hard to test the popularity of unconventional games when none are on the market.

Secondly, more money, larger teams and faster technology mean that games become more realistic, three-dimensional and graphically detailed. Computers can nowadays store far larger amounts of information than in 1989. For example, SimCity Classic consisted of 66 objects, 2 transit options and 3 zone types. The sequel, SimCity 2000, had 184 objects, 4 transit options and 8 zone types. Both SimCity 3000 and SimCity 4 have 250 objects and 9 zone types. The transit options increased from 8 with SimCity 3000 to 10 with SimCity 4. Throughout the SimCity history, the map on which players could build increased dramatically as well so that it takes players far longer before they have filled the complete game-canvas. Moreover, since SimCity 2000 game developers rely more and more on the Internet as a means for players to exchange objects or whole cities, stories, tips and tricks. These technological changes demand a heavier investment of 
time and money (to keep both computer and Internet connection up-to-date, for example) by players.

The geography of digital play broadens up due to technological advances that allow for the design of and playing in expansive game worlds. The geography of SimCity is not only to a large extent digitalized but also literally enlarged through the incorporation of Internet domains within the geography of play. A significant part of both core and peripheral play practices now takes place on the Internet. In the 'About SimCity4.com' section on the official website we read for example: "By using this site, you can extend your game play experience and keep on the cutting edge of what's going on in the SimCity 4 community!" (EA.com, "What is SimCity.com?"). On the website players can chat with the SimCity 4 team, other players, find information, goodies, cheats, tips and tricks and download new content for the game. Effects of this digitalization on the practices of play can be brought to the forefront with the use of the core/periphery model of differentiation.

Wright himself uses a pyramid to visualize the different ways players engage with his games through and about user-generated content. The top three activities of the pyramid - creating software, using this software to create objects and distributing these objects - take place in the periphery. The activity on the bottom of the pyramid - using user-generated content in actual gameplay - is situated in the core. Because the pyramid deals with user-generated content alone, it does not cover the whole range of either peripheral or core play practices. Nevertheless, it is a useful starting point for unraveling what sort of play practices take place where in the geography of digital play.

On the top level of the pyramid Wright situates toolmakers, players who have enough technological know-how to write software programs. This is comparable to LEGO fans writing CAD software for 


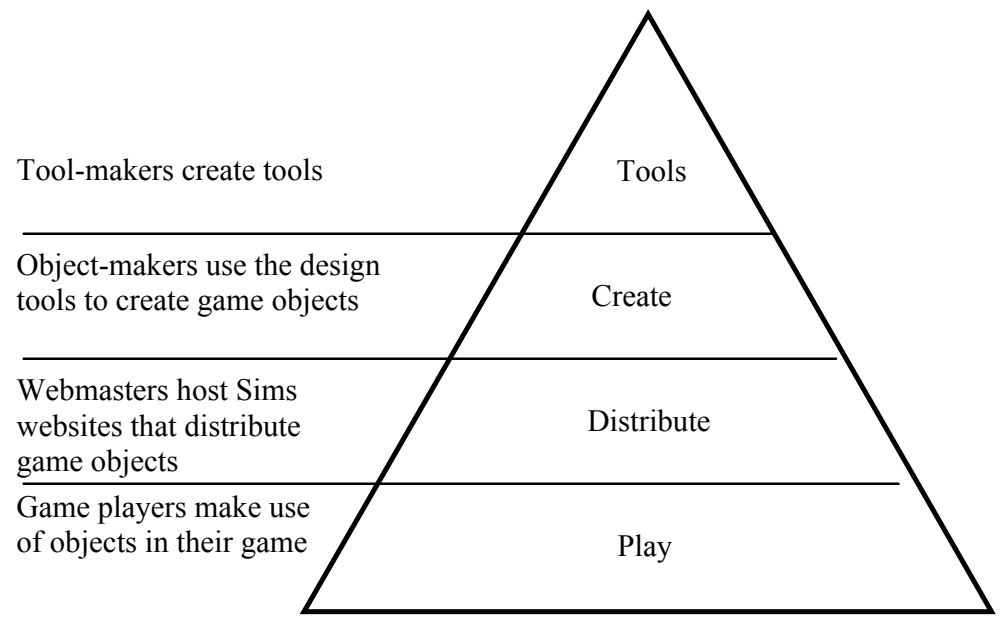

Figure 4: The pyramid lists forms of player-game interaction on the level of user-generated content (Salen \& Zimmerman, 2004, p. $540)$. 
digital LEGO designing. On the second level are the players who use this software tools to create, for example, new buildings for SimCity (doing this requires more technological ability than using $\mathrm{CAD}$ software). The top two levels are rather restricted, specialized and thus elite peripheral play areas mainly populated by adult lead-users who possess the required technological know-how, time and money. ${ }^{87}$ The distribute level is more densely populated. Players massively host SimCity related websites to distribute this user-generated content.

The top three levels of the pyramid do not cover, as stated, the whole range of peripheral play activities. For example, players share more than usergenerated content, they share knowledge, experience and expertise. And they create more than objects. Userwritten walkthroughs might be hundred or more pages long and are written and assembled, corrected and revised by dedicated fans. Some peripheral play practices fall completely outside of the scope of this pyramid; players might, for example, talk about the game offline, illegally download the game, become a beta tester for a new installment of the game or use it as inspiration for an altogether different game. ${ }^{88}$

\footnotetext{
${ }^{87}$ This is a trend that holds true for the computer game industry as a whole. Adults have massively found their way back into the world of games and playing. In the course of the $19^{\text {th }}$ century the child culture took shape and brought about a distancing between the adult and the child's world. The child was 'evicted' so to speak from the adult world and constructed as an innocent being. The place where this innocence was best preserved was in a world dedicated to that innocence, in a secret garden of wondrous innocence irretrievably lost to the adult. Children would often venture their frustration with this idea of - or obsession with according to some - innocence and infantilization by purposely shutting out adults from this secret garden (Cross, 2004). Computer games are often an effective tool for this shutting out. With adults growing participation in computer gaming, they seem to be invading children's secret garden. See also the recently published Children at Play: An American History by Howard Chudacoff (2007) on the history of parents' attempts at controlling children's' toys and games.

${ }^{88}$ A few years ago I happened to witness a very different SimCity being played by my youngest brother and two of my nephews. Their ages at that time varied between 6 and 9 years old. The three boys were playing in my
} 
Two instances of peripheral play activities on the 'create' level of the pyramid deserve further attention: the creation of mods (modifications) and patches. There are roughly two categories of mods: complete mods offer a new game based on the engine of an existing game while partial mods provide players with new levels, weapons, items and the likes to complement an existing game. In relation to SimCity, one can only create partial mods because the game is not an open source game that allows modders to build a new game on its engine. One example of a mod created by a player for SimCity is the Cactus Flora Mod by JonhB: "Finally realistic desert regions are possible! This mod consists of 3 different types of saguaro cacti" (2006). Generally speaking, partial mods operate on the 'cosmetic' level of a game in the sense that they are extensions of the design of the game and provide more variations on the existing themes and scripts.

A patch on the other hand is a small piece of software operating on the core level of the game that offers users an update or fixes a bug in the game. As such, patches can "offer variations on game play" (Salen \& Zimmerman, 2004, p. 539). There are official patches created by game companies and distributed through the official websites as well as unofficial, usergenerated patches. User-generated patches offering

brother's room and when I went to say hello I asked them what they were playing. They told me they were playing simcity. But there was no computer running the game. The three of them were in different corners of the room surrounded by different types of toys: Warhammer, LEGO, Kapla, toy cars. When I asked them what simcity was they told me it was a game about cities and defending them. I then asked whether they knew the computer game that goes by that same name and, rolling their eyes, responded "of course". They explained that the copy of SimCity 3000 my brother owns did not work on his hand-me-down computer and that therefore they decided to play the game without computer. Their simcity involved a complex and ad hoc trading system whereby little scraps of paper were being tucked under the mattress. By doing this they could acquire things (cars, bricks, soldiers, ...) that would help them defend their city. 
variations on game play are instances of player appropriation that result in a change on the level of the design of the game, the embedded scripts and intended uses. Generally speaking, game companies will discourage players to use user-generated patches because these patches might - when designed badly introduce bugs and faults in the game and thus thwart the facilitated game experience.

User-generated mods and patches are centrifugal appropriations of the core and are as such situated in the divergent periphery of play. However, this divergent uses-generated content does not stay in the periphery. These adaptations of the design 'migrate' through a system of online distribution from the periphery of the geography of play where they are created to the core where they are used. These fast centripetal appropriations whereby players use peripheral products in the core within the time span of one and the same game title, are an extremely important form of interaction between player and game because it keeps the community surrounding a game as well as the game world itself, lively and dynamic.

The indispensability of a peripheral many-tomany culture that communicates with the core is best understood by reconsidering the progress in computational technologies since the 1980s. As said, there has been a dramatic change towards faster and computationally stronger personal computers and game consoles. This has not only resulted in more realistic games and bigger play worlds, but also in an economic problem related to the costs involved in creating content for these ever expanding game worlds. Game theorist Julian Kücklich writes that "hit titles can cost up to 6 million dollars to produce, and this figure is likely to double or even triple during the lifecycle of the next-generation consoles" (2006, p. 9). In his talk The future of content (2005a) Wright describes how expensive and time consuming content creation is. To 
win the, what Wright calls, loosing battle of game content, the industry needs to start relying more and more on players and move towards open-ended games that allow for more player input and player-generated content. ${ }^{89}$

Wright stresses that relying on players for content is not a poor alternative since players love custom created content, they love to be able to 'participate' in the game development process. In other words, a win-win situation: on the one hand game developers need this free labor by gamers to keep the game worlds rich and diverse and running smoothly and on the other hand gamers feel taken serious, belonging to a community that they can contribute to.

Game companies rely on, hope for and capitalize peripheral player activity that moves through fast centripetal forces from the periphery into the core. This constitutes a shift in relation to the previous chapter on LEGO toys. Within the geography of LEGO play, many-to-many practices were used and commodified for new product releases or re-releases. An important advantage of online peripheral player activity is that game developers can (and do) data mine user groups, official websites and fansites and learn about how their game is actually being played, what the complaints are and what players wish and hope for. This information is then fed back into new releases or updates of the game series, which ensures a warm welcome from players who might find their wishes reflected in the new installment. In the digital geographies discussed here, the game company not only relies on these slower centripetal movements for new product design and development, but also on the faster forces. This second form of appropriation of the periphery by the core is within the context of Wright's

\footnotetext{
${ }^{89}$ In Wright's upcoming game Spore (a Darwinian life simulator), relying on user-generated content will increase immensely with almost everything in the game being created by the players (Maxis, forthcoming).
} 
games also commodified. Players adding to and filling the game world with user-generated content is counted on, capitalized and their divergent activities commodified.

Although game companies and user communities approve of, support and often capitalize most divergent player activities, one can also find unwanted peripheral activities, such as 'trolling', in geographies of digital play. The occurrence of unwanted divergent user activities is by and large a phenomenon of digitalized geographies that make the periphery more 'visible', accessible and interconnects players more closely. Trolling is a term used to refer to the intentionally disrupting of user groups and online forums through anti-social and offensive verbal behavior (Donath, 1998; Golder \& Donath, 2004; Herring, Job-Sluder, Scheckler, \& Barab, 2002). "Trolls can be costly in several ways. A troll can disrupt the discussion on a newsgroup, disseminate bad advice, and damage the feeling of trust in the newsgroup community" (Donath, 1998, p. 45)..$^{90}$ Trolling is a peripheral activity that goes against the discourse of constructive and helpful user communities and hampers the centripetal and centrifugal movements between core and periphery of a 'healthy' geography of play.

Concerning the core of SimCity play practices, there is much more facilitated than the use of usergenerated content specified in the pyramid. The core of SimCity play - building and running a city - is shaped by the combination of the design of the game and the discourse surrounding the game (advertisement,

\footnotetext{
${ }^{90}$ On official discussion websites, EA beholds the rights to remove trolls and their posts from the discussion boards. EA has been accused by users, however, of not only removing posts by trolls but also by players who questioned EA's policies on players, new game releases and the likes. This has also been the case in relation to the unsuccessful The Sims Online. For example, questions I posted concerning the status and future of The Sims Online on the official weblog called Stratics have been removed.
} 
official manuals, official websites). On the official SimCity 4 website we read for example: "Create, grow, and breathe life into your ideal urban environment. Fight disasters both realistic and fantastic. Govern your own virtual metropolis as you see fit with SimCity 4" (EA.com, "SimCity 4 Experience"). The SimCity discourse does sustain the idea of the game as a borderless playground with phrases like: "your ideal" and "as you see fit". What shapes the core of SimCity play even more than this discourse, however, is its design. The game is designed to evolve based on interactions between variables. Feedback mechanisms alert the player to how this interaction is working out whether the extra green zone you implemented augments the citizens' experience of your metropolis for example.

SimCity 4 has eight different feedback mechanisms: (1) the board of seven city advisors who advise you on city zoning, money, power systems, public safety, health and education, infrastructure and public transport and environment; (2) the city opinion polls on environment, health, safety, traffic, education and land value; (3) the news headlines; (4) the Residential, Commercial, Industrial Demand Meter; (5) the city's monthly budget overview; (6) the data views on everything that concerns your city, ranging from water supply to crime; (7) the graphs that show you how things have been changing over time, from your own popularity as a mayor to commute time; (8) the Sims living in your city. Keeping an eye on the different feedback mechanisms is a way of knowing what needs your attention urgently in the game, what is going well and what is heading for disaster. The feedback mechanisms are also a way to learn how to play the game and to keep an overview over the large amount of things you have to keep balanced.

The interaction between the variables under sway of the player's manipulation results in 
"meaningful play" because players see the results of their actions reflected in the game (Salen \& Zimmerman, 2004, p. 541). But these constant feedback loops are also a way of shaping and forming how the player plays the game. For example, windows with commands and tips from the city advisors will pop up that you simply cannot ignore. Not following the advisors will make playing the game virtually impossible. It is only when you have learned to play the game in the correct manner, that is, when you know how to juggle the variables in just the right way, when you have in other words internalized the design of the game that you can try and play with the feedback toolbar collapsed.

In terms of the norms and values, knowledge and experiences, rules and requirements embedded in the design of SimCity, it is useful to compare this technological artifact with toy villages and toy towns.

Typically, toy villages consist of a set of miniature houses, a church, trees and maybe some people and animals that can be arranged in different formations. The first toy villages date from the $17^{\text {th }}$ century when Germany was still the center of toy production and little hand-carved German villages were exported throughout Europe. These early toy villages consisted of 'a church, town gate, houses, and perhaps some commercial structures or a town hall, a few trees and animals', writes historian Cammie McAtee (1997, p. 15). American toy villages had an equally strong visual vocabulary but were comprised of different elements: "a set of small wooden buildings reflects the organization of a semi-rural New England community" (p. 16). Both European and American toy villages idealized the village (as opposed to the city) as the locus of humanity, as a shelter from debasement ( $\mathrm{p}$. 16). Toy villages are strongly rooted in the pastoral tradition with its longing for a return to rural life and the countryside as the best place to raise a child. Toy 

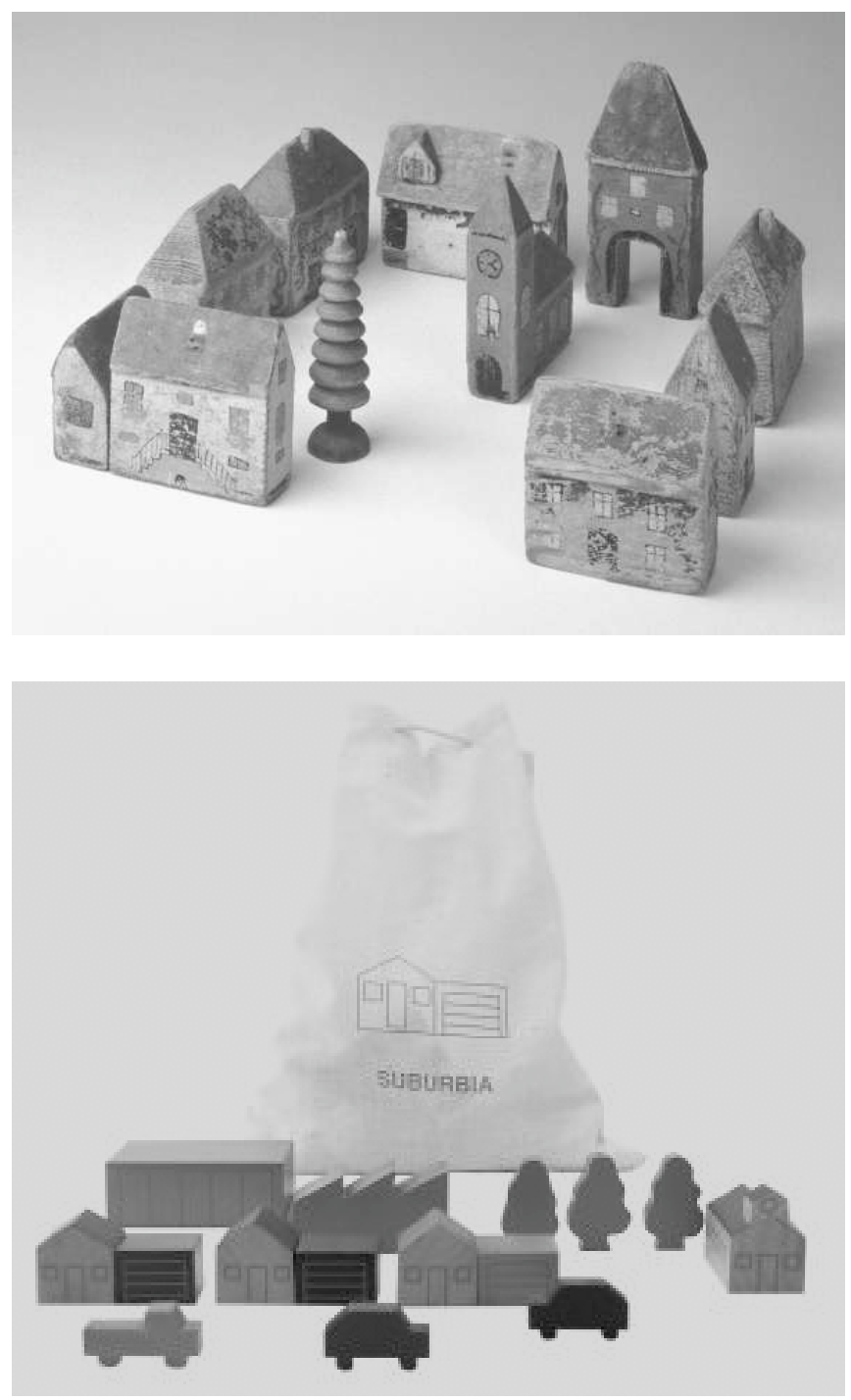

Illustrations $42 \& 43$ : The top image shows a German wooden toy village from around 1800. It is part of the collection (collection no.: TS2301.T7.W6 Z9 1800) of the Canadian Centre for Architecture in Montreal (CCA, 2007). The top image shows a $21^{\text {st }}$ century Suburban Toy sold by Japanese department chain store MUJI. Not visible on this picture but also inside the bag is a piece of tarmac that serves as a large parking space (MUJI, 2007). 
villages were "a suitable way to recapture wholesome country values in the midst of a corrupt metropolis" ( $\mathrm{p}$. $20)$. Toy villages were often accompanied by a moral tale to promote "responsible behaviour and civic duty" and they stressed the civilizing influence of the toy on the child (p. 18).

By the end of the $19^{\text {th }}$ century and the beginning of the $20^{\text {th }}$ century, toy towns and toy cities rather than toy villages started to appear as well. These toys would not mimic rural and pre-industrial configurations but would center on urban and industrial designs. For example, the toy towns made by German toymaker Carl Oehme around 1900 are "devoid of any rural associations; the town is made up of two- and three-storey buildings with commercial space on the main floor" (p. 16).

Both toy villages and towns mediate between the outdoors world and a child's private rooms by bringing rural or urban configurations to the inside in a containable and manipulable format. Through the history of toy towns one sees the changing conceptions and realities of villages and towns. These toys would often serve as a means to come to terms with these very changes by "making new ideas of urban form comfortable and familiar" (p. 15).

SimCity embeds and mediates very specific ideas about the modern American city in terms of space and urban planning and politics and urban planning. Professor of Urbanism Witold Rybczynski "discusses $(\ldots)$ early colonial assumptions about cities that, consciously or not, SimCity has adopted" writes urban designer Daniel Lobo (2004). Rybczynski points to the crucial difference between European and American cities formed through the "sense of abundant and open space" experienced by the early American settlers that created a "laissez-faire" attitude towards the consumption of land (ibid). Early planners envisioned continuous growth and to accommodate 
this, the only form of planning was often the laying out of a grid structure that would "grow proportionately with the population" (ibid).

This grid structure is characteristic of the practical city described by American city planner Kevin Lynch. The practical city is "imagined as a kind of machine, chiefly a machine for commerce. Such cities are pragmatic and functional; they grow according to material needs (...). The streets of the practical city have typically followed an orthogonal grid" (Lynch, 1984; Rybczynski, 1995, p. 43-44). Change and growth are both cornerstones to the playing of the SimCity games, trying to maintain the status quo will not make you a successful player. It is embedded in the internal workings of this simulation that cities have to grow in order to prosper. SimCity is based on a grid structure that will accommodate for this need to grow and change. The game has you recreating the typical American sprawling city space. You do not start to build your city with a square or a church, but by zoning (residential, commercial and industrial) and laying out the grid structure.

Concerning politics and urban planning, we can discern in SimCity elements of Realpolitik as it was practiced in California during the eighties. To make the city of Los Angeles prosperous the solution was sought in a combination of 'low taxes, high land prices and a forceful police corps' (Beckett, 1996; Kerstens, 1997, p. 15). The core of the SimCity geography, the design of the game and the discourse surrounding it, bears witness to the Realpolitik of the eighties. In the official Playing with SimCity 2000 manual the internal dynamics of the simulation are explained. In order to play the game successfully, cities have to grow and high property value is a key factor in this growth. Keeping property value high is achieved by proximity to the city center (the city center is defined by 'attractions' like a zoo or a club), the size of a city 
(bigger is better), proximity to trees, water, a park, or a hillside. Pollution has a bad effect on property value (Dargahi \& Bremer, 1996, p. 405). Property value has a direct influence on criminal rates: high property value means less crime, low property value more crime. By building police stations, enlarging your city, adding water and green areas, the property value will rise and criminal rates will drop (p. 406). Another means to keep criminal rates low is the decreasing of population density (p. 406).

Looking at user-generated walkthroughs for various SimCity games we see yet again the importance of this threesome. A walkthrough written by CaptainSyrup for SimCity Classic has as one of its many tips: "If you keep the crime rate low, your city should quickly progress into a capital. Continue to increase police coverage, (fire coverage isn't important) (...) Drop the tax rate" (2002). Throughout this walkthrough, the importance of a police force and low taxes is stressed, the first will increase the property value and in combination with the second, the Sims (simulated citizens) will be attracted to move to your city. A SimCity 3000 walkthrough by gamer Tim Wuyts (1999) states that you can easily save money on public health because it is 'less important' than, for example, the police force ('no cutbacks'). The SimCity 4 walkthrough by John Jung (2003) indicates the growing sensitivity of the Sims living in your city to pollution and traffic jams. The residential zones, for example, prosper under low pollution, low crime and a short commute to work.

Wright himself often states the influence of architect Christopher Alexander on the development of his games. In an interview with Ingrid Whitehead Wright states: "The Sims (...) is based on the theories of architect Christopher Alexander (...). He's really the 'anti-architect'. His gig is to empower regular people to design their own homes and become their own client 

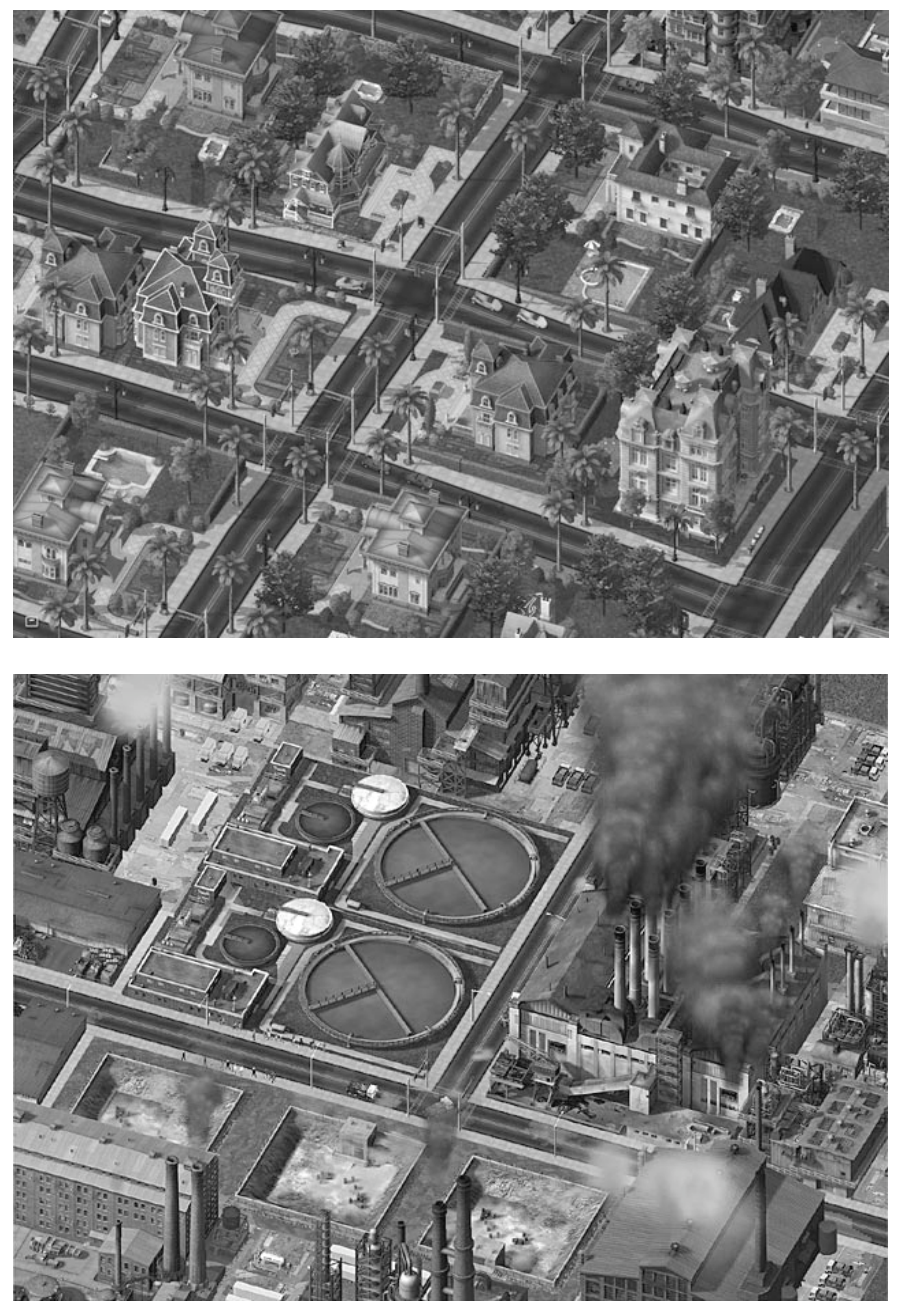

Illustrations $44 \&$ 45: Screenshots from SimCity 4. The top image shows freestanding, comfortable private homes built along a grid structure. The bottom image shows an industrial zone of a sim city and illustrates the segregation or zoning of the sim cities in residential, commercial and industrial zones (EA.com, SimCity 4 Screenshots). 
(...). SimCity was based on similar principles" (2000, p. 246). This empowerment is most clearly expressed in A Pattern Language (1977) in which Alexander pleads for a move away from the modernist top-down approach to architecture and urban planning with the architect as absolute and sole source of ideas and power. Alexander's work has been of significant influence on New Urbanism, a movement in urban planning that strives to give people a choice in the where and how of their urban life. Both Alexander and New Urbanism want a return to community based urban planning where ecological and human needs come before more highways and suburbs that force people to drive long hours to work, school and shops.

Wright claims to be influenced by the works of Alexander and to provide the users of his software toys with an empowering tool that will make them aware of the processes involved in urban planning. However, as a player of SimCity you are always subject to the rules of the game, Wright's vision on what constitutes a city and successful urban planning, the scripts, projected users and uses embedded in the game. As game researcher Shawn Miklaucic states: "While game designers often invoke the open-endedness of such games as SimCity, (...), such games necessarily involve metanarratives concerning human nature, economics, social interaction, technological progress and so forth" (2003, p. 321-322). Contrary to Alexander and New Urbanism's beliefs, the cities you construct in SimCity are zoned and there is no integration of these functions. Moreover, in Wright's games driving is the dominator and not providing a highway network will make your city into a failure. Needless to say, the Realpolitik strategies that are so deeply ingrained in the inner workings of SimCity are very much opposed to the theory and teachings of Alexander and New Urbanism. 
For SimCity to be an empowering game and educative tool that surpasses the internalization of Wright's vision on urban planning, it 'should enable the player to play with the system itself, not just the system's effects', says Jamais Cascio, a designer of future scenarios and games (2004). Bogost counters that integrating " "policy knobs' that could alter the simulation rules of a game like SimCity" does not necessarily lead to opening the black box (2007b, p. 63). Rather, he suggests, players need to be sensitized to the "rules that drive that system". Players have to gain "procedural literacy" through, for example, designing games themselves, which will teach them to read the system critically (p. 64).

Notwithstanding that one can draw parallels between toy towns and SimCity - both are simulations, both consist of modular building elements, both familiarize the player with rural or urban conditions there is a crucial difference between the physicality of the first and the digitality of the second. SimCity is a dynamic, coded and programmed simulation that develops over space and time and that simulates not only the physical objects that constitute cities but also processes of growth, decay, aging, gentrification and the likes.

We could describe the effects of digitalization on play in part as a 'tyranny of the algorithm'. ${ }^{91}$ While new media technologies enlarge playworlds and create new play possibilities (such as the option to incorporate user-generated content in a game), they also constrain. For example, the Realpolitik principles of SimCity or the consumerist ideology of The Sims are unalterable. Needless to say, truly borderless games would be absolutely unplayable. Players need rules, limits and scripts in order to play at all.

\footnotetext{
${ }^{91}$ Stephen Kline suggested using the phrase 'tyranny of the algorithm' in relation to my work on Wright's games after he read this chapter during an expert meeting that took place in Amsterdam on March the $30^{\text {th }}, 2007$.
} 
The use of cheats in SimCity is a way for players to make the facilitated practices of play less pressing, to escape, so to speak, the tyranny of the algorithm. There are many different ways and means of cheating in computer games: from searching solutions to difficult puzzles or riddles online to the activation of codes that make your game character rich or immortal, from the creative use or abuse of design mistakes in the game, so-called 'exploits', to gain the overhand over other players (think for example of players who use a design mistake such as an elevation of the ground to get a better vantage point for shooting) to buying valuable game objects online instead of spending hours and hours looking for them. ${ }^{92}$ Some of these forms of cheating alter the design of the game (e. g. the cheat codes), others use the design in an unexpected way (e. g. the exploits) and still others deviate from the discourse on the game (e. g. buying items online). Some players play no game at all without first activating cheats while other players consider all forms of cheating below the true gamer. However it may be, the fact remains that contemporary computer games are so expansive, complex and time-consuming that the bulk of players will cheat in one way or another, even if it is in the form of simply consulting an online walkthrough for the best way to tackle a complex mission.

Certain cheats, such as the cheat codes, will allow players to divert from the prescripted play path. Cheats can tip the balance between the design of the game and its embedded scripts and the player. This does not mean that cheating is always a divergent or unwanted play practice. Generally speaking, cheats are part of the game's fabric, they have been designed and programmed in the game and finding and using them is

\footnotetext{
${ }^{92}$ On 'twinking', a very specific form of cheating where the player abuses a flaw in the game to create a character that is more powerful than characters created without abusing these flaws, see the research by René Glas (2007).
} 
intended and foreseen by the game companies. Cheats might be leaked on purpose by game companies or be found by players who know what to look for in the software code of the game. Popular and common cheats will make the player rich, immortal or will simply have a funny or weird effect on the game. For example, in SimCity 4 Deluxe Edition activating the "fightthepower" cheat will 'remove power requirement for all buildings' which makes the overall playing of the game less difficult because it makes some design scripts less dominant (Gamespot).

At this point it is interesting to retake once again the account of technological progress within gaming technology. STS scholar Sherry Turkle argues in Life on the Screen that the increase in technological possibilities led not only to more realistic, larger, graphically more detailed games but also to an increasingly difficult set of rules that were less accessible to the player (1996, p. 67-69). She links the growing user communities surrounding games to the fact that games are ever more difficult to play and more and more players need tips and tricks, walkthroughs and manuals to get through a game. They consult lead-players online to tap into their knowledge and expertise. Technological advances in gaming technologies have thus created a divide between leadplayers and players tapping into lead-knowledge.

Turkle takes the argument further and states that there is only a small group of players (hackers and hobbyists) who dive into the rule-based simulation while the largest groups of players are "interested only in the surface of the simulation" (Raessens, 2005, p. 377; Turkle, 1996). This last group therefore does not grasp the 'assumptions that underlie simulations' which is a "key element of political power" (Turkle, 1996, p. 71). Technological innovations that open up a range of playing possibilities and play areas thus come 
with a price: the coded, designed and programmed core is inaccessible to the largest body of players.

This undermines in part the critical potential Ted Friedman attributes to games like SimCity. He states that new media applications like computer games "reveal their own constructedness to a much greater extent than more traditional texts" $(1995$, p. 82). In this he reacts to technophobic accounts of the attractions of simulation games not as $a$ simulation but rather the simulation of reality. "The fear of some computer game critics, though, is that technology may mask the constructedness of any simulation" (p. 82). Friedman states that this constructedness is revealed through gameplay:

Learning and winning (or, in the case of a non-competitive "software toy," "reaching one's goals at") a computer game is a process of demystification: one succeeds by discovering how the software is put together. The player molds her or his strategy through trial-and-error experimentation to see "what works" - which actions are rewarded and which are punished (p. 82).

However, as Turkle states, most players will surrender to the 'seductions of the simulation' (1996, p. 71). Gameplay is then not so much an unraveling and demystification of the underlying ideological biases of the simulation game but an internalization of the rulebased, designed core of the simulation. On the other hand, as Friedman notes, the discourse surrounding a game will reveal to a certain extent the ideological bias of that game $(1995$, p. 82). As we have seen in relation to the official SimCity manual, the authors were clear about the power- and political structures that make the world of SimCity turn. The question is whether any but lead-players will dive into these hefty manuals. Most players will consult online walkthroughs that are free and user-generated. These walkthrough typically explain what works best in a certain game without exploring, like the official manuals, the underlying ideological assumptions. Or as Raessens aptly puts it: "In everyday practice, however, (...) computer game 
players, seem to me, more superficial (...), at least if we define superficiality as staying at the surface of the (...) game" (2005, p. 378).

\section{A $21^{\text {ST }}$ CENTURY DOLLHOUSE: THE Sims}

The Sims 1 (Maxis, 2000b) and 2 (Maxis, 2004a) are digital dollhouse games focusing on domesticity. ${ }^{93}$ They seem to be among the least controversial of all computer games. On the box of The Urbz (a version of The Sims that has your Sims living in a 'city' instead of suburbia), for example, the age indicator reads $3+$, the youngest age indication possible in the PEGI (Pan European Games Information) age rating system (Maxis, 2004b; PEGI, 2004). Moreover, while articles on The Sims might stress the idolization of consumerism and the household as sole raison d'etre, they will almost always end on a positive note by stating, for example, that this game, being focused so heavily on consumption, in fact prompts the player to reflect on his or her own consumerist practices (Herz, 2000). Or people will stress that in The Sims, both male and female characters are confined to this eternal household game, meaning that the game is egalitarian, it treats women and men alike (Flanagan, 2003, p. 187). As such, it is not a stereotypical heterosexual game: no need to be a white, Caucasian male with a

\footnotetext{
${ }^{93}$ There are many expansion and stuff packs that add to the game world of The Sims 1 and 2, such as Livin' Large (Maxis, 2000a), House Party (Maxis, 2001b), Hot Date (Maxis, 2001a), Vacation (Maxis, 2002c), Unleashed (Maxis, 2002b), Superstar (Maxis, 2003c), Makin' Magic (Maxis, 2003a), The Sims 2: Happy Holiday Stuff (Maxis, 2006c), The Sims 2: Family Fun Stuff (Maxis, 2006a), The Sims 2: Glamour Life Stuff (Maxis, 2006b), The Sims 2: H\&M Fashion Stuff (Maxis, 2007a), The Sims 2: Celebration! Stuff (Maxis, 2007b). This list is not exhaustive.
} 
large gun. The game is a "deviation from the dominant game formula of "militarized masculinity" (Kline et al., 2003, p. 275). Consalvo further applauds that sexuality in the game is based on the activity of the player rather than fixed to the identity one chooses (2003, p. 34). You can get friendly with both men and women, at the same time or one after the other. On top of this, the game is often praised because you have to get social in order to survive in The Sims; you don't shoot your way through this game, you socialize and shop it (Flanagan, 2003, p. 187; Twist, 2004).

The Sims was introduced with, among many things, a commercial that demonstrated the differences between SimCity and The Sims. In this advertisement the camera zooms in on a SimCity style metropolis, getting closer and closer until you are level with a riding moving van that crosses a bridge, leaving the sim city behind and heading for unexplored terrain. The van drives on a straight asphalt road, passing some modest homes amidst green surroundings. The van then turns into a plot where a big advertisement announces that new homes are available. We see homes in a new suburban community under construction. A group of people stands chatting near one of the unfinished houses. The one man kisses one of the two women and gets slapped in the face by the other. Then they notice us, the spectator and they start waving at us. As this early commercial shows, the move from SimCity to The Sims is a move from a world simulator to a life simulator, from construction play on the level of cities to construction and narrative play on the level of neighborhoods and interpersonal relationships. The Sims games combine the practices of construction play (the journey) with narrative, roleplaying and the playing with your construction (the destination). ${ }^{94}$

\footnotetext{
${ }^{94}$ It is important to note that narrative play in Wright's games is different from narrative play as discussed in relation to LEGO toys. LEGO toys are
} 
In this, The Sims can be compared to (construction) toy homes that are also characterized by this combination between building a home and life within that home, between construction and narrative practices of play. Both $19^{\text {th }}$ century toy homes and The Sims center on the cult of the private home and the separation of the public and the private sphere. Toy villages and toy towns brought the city into the private home and children's lives. Toy homes mirror and reinforce in their design the focus on the private sphere and the domestication of child and play. Toy homes are typically 'separated, comfortable and safe singlefamily dwellings with a strong emphasis on the domestic sphere' writes historian Alice Friedman (1995, p. 10). Both toy homes and The Sims symbolize and reinforce the "domestication of childhood" by focusing on the home, life within that home and by being toys for indoor use (p. 8).

The private home of The Sims stands in a stereotypical American suburb. As Rybczynski stresses in City Life (1995), the categories of city and suburb are inaccurate stereotypes invested with clichés. In reality, the lives and activities of urban and suburban citizens have come to resemble one another and the borders between city and suburb have blurred. However, The Sims games offer a stereotyped representation of the American suburb, richly invested with all the clichés. It is important to distinguish between the connotations attached to the European and American suburb. Generally speaking European sub-

coupled to media content from which they take narrative structures, figures, and plots. As such, there is a multitude of stories and roles available for children to play with (e.g. Bob the Builder, Star Wars, Harry Potter, Batman...). Wright's games are not explicitly linked to media content but a game like The Sims stands in a tradition of TV soaps, ironic, mediaclastic movies (such as the Scary Movie series that consist almost exclusively of quotes and references to other media products) and a makeover and reality TV culture. The tool to create your own video clips in the game is promoted in these very terms: "Zoom in close to record every detail as your very own Sims sitcom unfolds" (EA.com, "About The Sims 2"). 

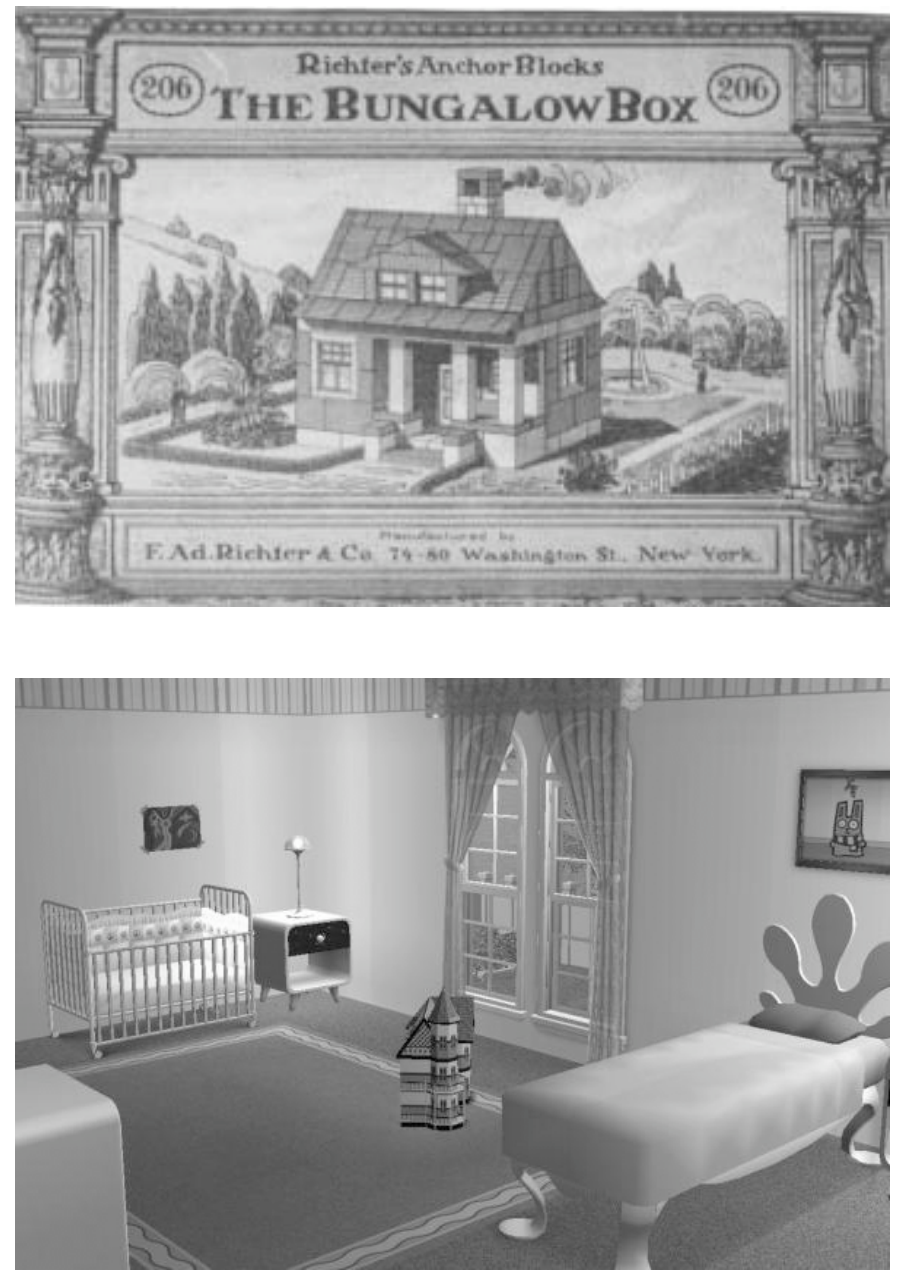

Illustrations $46 \& 47$ : Toy homes and the private sphere. The top image shows an Anchor Blocks Bungalow, a popular $19^{\text {th }}$ century construction toy home (Wetzel, 2006). The bottom picture shows a child's bedroom. This bedroom is part of a user-generated house for The Sims. Inside the bedroom the child can play with its dollhouse (mandmjeffers1, 2007). 
urbs, known as banlieues, are often disadvantaged areas while American suburbs are home to the wealthier classes. While "To most Parisians, then, les banlieues (the suburbs) referred chiefly to the dreary industrial districts that ringed the city like a sooty pall. (...) Americans lived in suburbs by choice" (p. 173 \& 175). One of the key aspects of the American suburb is the freestanding, standardized private home and the car as means to go from A to B. In The Sims you cannot but build freestanding houses, you need a car to go to work, walking might bring you to a neighboring house but the tarmac roads lead to nowhere. The sacredness of private property and the attachment to domestic comforts are part and parcel of the design and discourse of The Sims games. ${ }^{95}$

The Sims mirrors and reinforces domestication in a complex and multi-layered way. The subject of the game and the projected players mirror one another. The game "demonstrates an uncanny mirror-world effect" because "The Sims invites its gamer-subjects to identify themselves with the daily lives of middle-class home-owning professional North Americans" which constitute exactly "the very computer-owning demographic bracket to which the game is predominantly marketed" (Kline et al., 2003, p. 275276).

The gamespace (the suburban private home) and the place where the game is predominantly played (indoors) mirror one another as well. The game takes

\footnotetext{
${ }^{95}$ As such this game is very much in tune with what Elliott and Lemert label "new individualism". With this term they want to indicate that individualism, as it "was coined by Alexis de Tocqueville in the early $19^{\text {th }}$ century to describe an emerging sense of social isolation in American society", has undergone a crucial shift under influence of "globalization, new information technologies and multinational capitalism" (2006, p. 3 \& 7). They describe three changes in individualism - expansion of "the range of personal choice and opportunity", increase in "privatization" and a shift from individualism as an upper class affair to a more widely available or longed for privilege - all of these very much visible in The Sims games (p. $7-11)$
} 
place mainly indoors. In most Sims games you do not follow your Sims to work, they leave the house and the player stays at home. ${ }^{96}$ This is very much a child's perspective on things. Parents leave for work and come back from work while the child goes to school or remains at home. The game itself is suitable for a domesticated lifestyle because computer games in general do not take up much space (far less than many non-digital construction toys) and they will keep children occupied for hours without them needing help, attention or assistance from their parents. So the player is literally domesticated and plays at being domestic and domesticated.

Computer games in general are, in being domestic technologies, at the same time "constitutive of the domestic" as well as themselves "domesticated" (Silverstone \& Hirsch, 1992, p. 6). Within the 'biography' of computer games, the domestic plays a crucial role (Silverstone, Hirsch, \& Morley, 1992). More so, "design and domestication are the two sides of the innovation coin. Domestication is anticipated in design and design is completed in domestication" (Silverstone \& Haddon, 1996, p. 46). On the one hand game consoles and games played on personal computers domesticate the player in the literal sense that these objects are meant for indoor use. Handheld gaming devices that can cut the ties between the child and its domesticated play location, also need a sheltered play space and require the child to stay put in order to play. On the other hand, these technological artifacts are domesticated through their incorporation within the household. Domestication of technological innovations is "quite literally a taming of the wild and a cultivation of the tame" (p. 60).

Most computer games will compensate for their domesticated nature by being violent, rough,

\footnotetext{
${ }^{96}$ The exception being the expansion pack Open for Business that has you simulating exactly the work sphere of your Sims (Maxis, 2006d).
} 
taking place in a digital outdoors or otherworldly realm, as did the $19^{\text {th }}$ century Boy Book (Jenkins, 2000, p. 277). ${ }^{97}$ Generally speaking "the domestic space of gameplay (whether living room, bedroom or rumpus room) is destroyed in the process of gameplay" (Flynn, 2003, p. 559). Because mothers (but fathers as well) were before the domestication of "boy culture" often unaware of what Jenkins calls "the messy process by which western culture turns boys into men", they are often shocked by the violent video game culture that has entered the living room (2000, p. 275). Most mainstream computer games underline the generational gap and want to distance themselves from the place where they are being played. Confined indoors, children seek refuge in computer games in order to distance themselves from the domestic sphere (p. 270). The Sims, however, does no such thing. The game's subject and the digital playground offered to players is this very domestic space. In accordance with television soap operas that mirror the lives of those watching, this game takes the real life place of play and the situation of play as its subject.

Domestication and commodification are intimately connected. "Consumption (...) is (...) deeply ingrained in the structures of the domestic sphere: local, private, persistent" (Silverstone \& Hirsch, 1992, p. 5). The postwar private home has been from the start a domain for entrepreneurs wanting to launch new products and it provided consumers with so many new reasons for spending money. This relationship between the private sphere and consumerism has developed over the years into a cult

\footnotetext{
${ }^{97}$ A home video on the Amazon.com website by a fan of the contemporary Boy Book The Dangerous Book For Boys shows a kid sullenly playing a video game. The father comes home unexpectedly with the Boy Book under his arm. The boy says that he thought his father had to work. The father says he took the day off. With loud music and the shutting out of the cookies baking mother, they have the best day ever trying out all the tricks and adventures the book offers (Anonymous, 2006).
} 
of lifestyle products, trends and fashions. The home has not only become the prime location where Westerners spend their time after school or work (as opposed to church, café or village square) it has also become a (if not the) principal reason for spending money. ${ }^{98}$

Consumption, a key feature in The Sims games, is probably "the most controversial feature" of the game, writes game developer and researcher Gonzalo Frasca (2001). Some people claim the game is a cynical parody on our consumer culture meant to wake players up. Game theorist J. C. Herz writes for example that "By building a window into Sims' souls, it prompts us to consider our own" (2000). Frasca on the other hand finds this hard to believe: "I am not able to find satire within in" (2001). ${ }^{99}$ Does this game function as a wake up call by poking fun at our shopping obsessed consumption culture? ${ }^{100}$ Or does this game train its players in over-consumption? Does it raise awareness on how to deal with money or is it a shameless celebration of shopping as a cure for existential angst? Unhappy? Unsatisfied? The remedy is: consume! Redecorate! Spend money! If playing this game changes anything at all, it normalizes consumerism rather than showing players the absurdity of over-consumption because the game's internal logic, the scripts embedded in the design are based on what amounts to a 'consumerist ideology' and players are not offered the possibility of stepping outside of this design or alter it. Players are configured in The Sims only as consumers and their projected actions within

\footnotetext{
${ }^{98}$ Apparently, since the year 2001, the IKEA catalogue outnumbers the Bible in terms of yearly printed and distributed copies. According to a Christian blogger, an estimated 100 million Bibles are distributed worldwide each year. The Ikea catalog "topped 100 million for the first time in 2001" and has been steadily on the increase ever since (Roth, 2002).

${ }^{99}$ For a discussion of the use and abuse of irony in computer games see Een constante, duizelingwekkende omkering (Lauwaert \& Hendriks, 2006).

${ }^{100}$ See Molesworth and Denegri-Knott (2007) on the actualization of consumer imagination in digital play in general.
} 

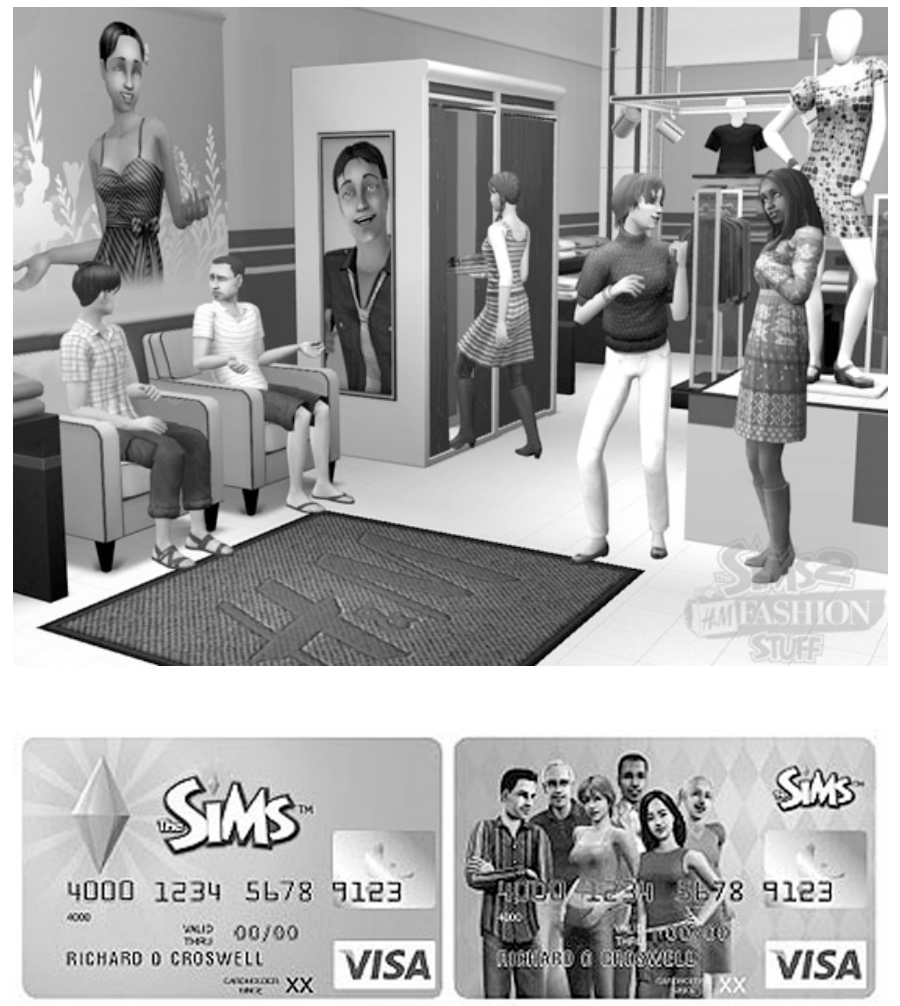

Illustrations $48 \&$ 49: Consumerism in The Sims. The top image is a screenshot from the stuff pack The Sims 2: H\&M Fashion Stuff (EA.com, 2007b). This stuff pack was launched, in part, to familiarize American players with the European H\&M chain stores that are opened around the U.S. In an H\&M press release we read: "The stuff pack contains replicas of garments - all inspired by H\&M's summer collection. Players can also create their own H\&M store and fit it out with mannequins, clothing racks, cash registers, fitting rooms and more" (H\&M, 2007). Contests during the summer of 2007 resulted in one player-designed outfit to be produced and sold in real H\&M stores around the globe. The bottom image shows the newly launched real life The Sims credit card for in-game and real life transactions. 
the game are all in line with hyper capitalist principles. The Sims is at the same time an object "to be consumed" and the "means (...) for the continued stimulation of consumption" (Silverstone \& Haddon, 1996, p. 45).

As said, The Sims games do not only simulate home-building but also the lives within that home. These play practices in The Sims that center on family life inside a suburban home can be compared to dolls play and playing with a dollhouse. Playing with dolls centers on "the building of warm interpersonal relationships", the staging of narratives, practicing for motherhood, being a good friend and a good consumer (Cross, 1997, p. $67 \&$ 73). Dolls are described by Auerbach as "a timeless way for children to relate to the world (...), a source of comfort" and a means to cope with "feelings, developmental stages, (...) social experiences, (...), fear of separation or emotional upsets" (1999, p. 43). There is a crucial difference between the conception of dolls play and playing with the Sims. While the first is described by Auerbach as offering children "a positive, nurturing, and enjoyable experience" (p. 43) the second offers cruelty vis a vis the Sims as a playing option: "Create your Sims, push them to extremes, control their world, fulfill their life dreams or realize their fears" (Maxis, 2004a). Of course, many children perform cruel acts towards their 'real' dolls and stuffed animals as well, the difference lies in the discourse, in how this type of play is described and promoted.

Comparable to (construction) toy homes, the dollhouse symbolizes and reinforces domestication: the move to the inside, the interior and the private. Playing with a dollhouse often consists of creating tableaux inside the dollhouse rather than actively moving the little dolls around. Historically, dollhouses were a means to display wealth. Often, the displayed luxury items were only affordable in their miniature versions 
(Stewart, 1993, p. 61-62). In The Sims as well, players can fill their digital houses with luxury goods that they might never be able to buy in real life.

The same holds true for the digital dolls within this dollhouse, players can dress their onscreen dolls in ever-changing clothes, which they might not be able to do with their real life dolls. As a 9 year old fan of digital dress-up games explains: "With Barbie, if you want clothes, it costs money (...) You can do it on the Internet for free" (Richtel \& Stone, 2007). ${ }^{101}$ In the article Welcome to the New Dollhouse a 12-year-old girl explains why she prefers playing with The Sims to doll play: "in the Sims you're building the houses and putting the characters into different situations. You can actually decide what you want to happen (...) And also you can see how they get older and how they grow over time" (Schiesel, 2006). What this girl values (and many with her) in The Sims is that the more or less static tableaux of traditional dollhouse play and the imaginary world of dolls play come to life in a dynamic simulation and develop visually through space and time.

Another difference between real-life dolls and Sim characters is that these Sims are largely independent and programmed dolls that go about their business while the player meddles with their lives or simply looks in on them. Sims will independently turn on the television, go to the bathroom, sleep, hug, fight and so on without your intervention being needed. In the building and shopping mode of the game, the player is free from possible hindrances from the largely

${ }^{101}$ Girls-oriented dress-up games like Cartoon Doll Emporium (2007), Stardoll ("Your Paperdoll Heaven") (2003-ongoing) or Barbie Girls (Mattel, 2007) are very popular. Dress-up play is also gaining in popularity among male gamers: "Playing dress-up in a digital world is not just for girls. Testosterone-heave male-targeted games now feature costume elements, allowing young men to express themselves through clothing in a way no additional male pastime has allowed" (Healy, 2007). The success of websites like CAWs.ws (stands for Create-a-Wrestler) shows that many men do in fact enjoy dressing up virtual characters (Brunton \& Rice, 2007). 
autonomous Sims. You can let the simulation run on "auto-pilot" but the Sims will never shop, redecorate and renovate on their own. Due to this 'independency', the Sims' behavior is partly unpredictable. Players love this 'independency' of their Sims because it makes them surprising. On user groups players report the latest funny quirks of their Sims: "The funniest event I've had to so far is when Titan (after putting his kid in the crib) turned away and he farted, waved behind his butt and then left the room. The green smoke went RIGHT into the crib and into his kids face!!!" (SmokeD, 2006).

With the focus on narrative in The Sims, construction play shifts from being the core of the game (as in SimCity) to being one of many facilitates play options. Practices of construction play might even, depending on player style, become the bühne for narrative play. By combining home building with narrative play, The Sims unites the journey and the destination. Although strictly speaking there is no destination in the game because you never win or loose. In facilitating both construction and narrative play practices, it might appear as if this game succeeds in combining the world of boys' toys (construction, engineering) with the world of girls' play (housekeeping, narrative play, nurturing, social relationships). However, these two types or forms of play never actually meet in play. The masculine activity of building and the feminine domain of social relations are united within The Sims but not in the playing of The Sims. These two aspects correspond to different playing modes that never merge. When you switch to the (masculine) building mode, the social life inside the house is put on hold. When you have finished rebuilding you can switch to the (feminine) shopping mode or My Sim mode where life will recontinue and the Sims will either be happy or 
disgruntled with the changes you brought down on them.

Having situated The Sims within the context of suburbia and the private home and having outlined some differences and resemblances with toy homes, doll play and dollhouse play, it is time to take a closer look at how Sims play practices are situated within the geography of The Sims play. Let us start with what happens in the periphery. Peripheral, divergent play activities discussed in relation to SimCity, such as the creation and distribution of user-generated content, mods and patches, the anti-social trolling on online forums and discussion boards, are also relevant in relation to The Sims. ${ }^{102}$ The pyramid could also be used in relation to player-game interactions within The Sims. However, I will in this part focus on the extensive cocreation of The Sims 1, a case of user-driven innovation par excellence and on the documentation tools in The Sims 1 and 2. The first example illustrates the extent of the commodification of the fast centripetal movements in the The Sims geography while the second example shows the commodification of the slower centripetal movements.

The extensive co-creation of The Sims 1 by players was part of the development, marketing and launching strategy of the game and the The Sims brand. "Several months before The Sims launched, Maxis released an initial set of design tools. These tools were quickly taken up, shared across the community of players, and prodigiously utilized - before the game ever hit the stores" (Salen \& Zimmerman, 2004, p. 540). What was being leaked was the very programming code for the new game yet to be released, a programming code that was not an airtight, closed system but rather a modular system, a "flexible

\footnotetext{
${ }^{102}$ One example of an official patch for the Unleached extension pack fixes, for example, "Sitting to watch TV - Adult and child Sims again sit to watch TV" (EA.com, 2005).
} 

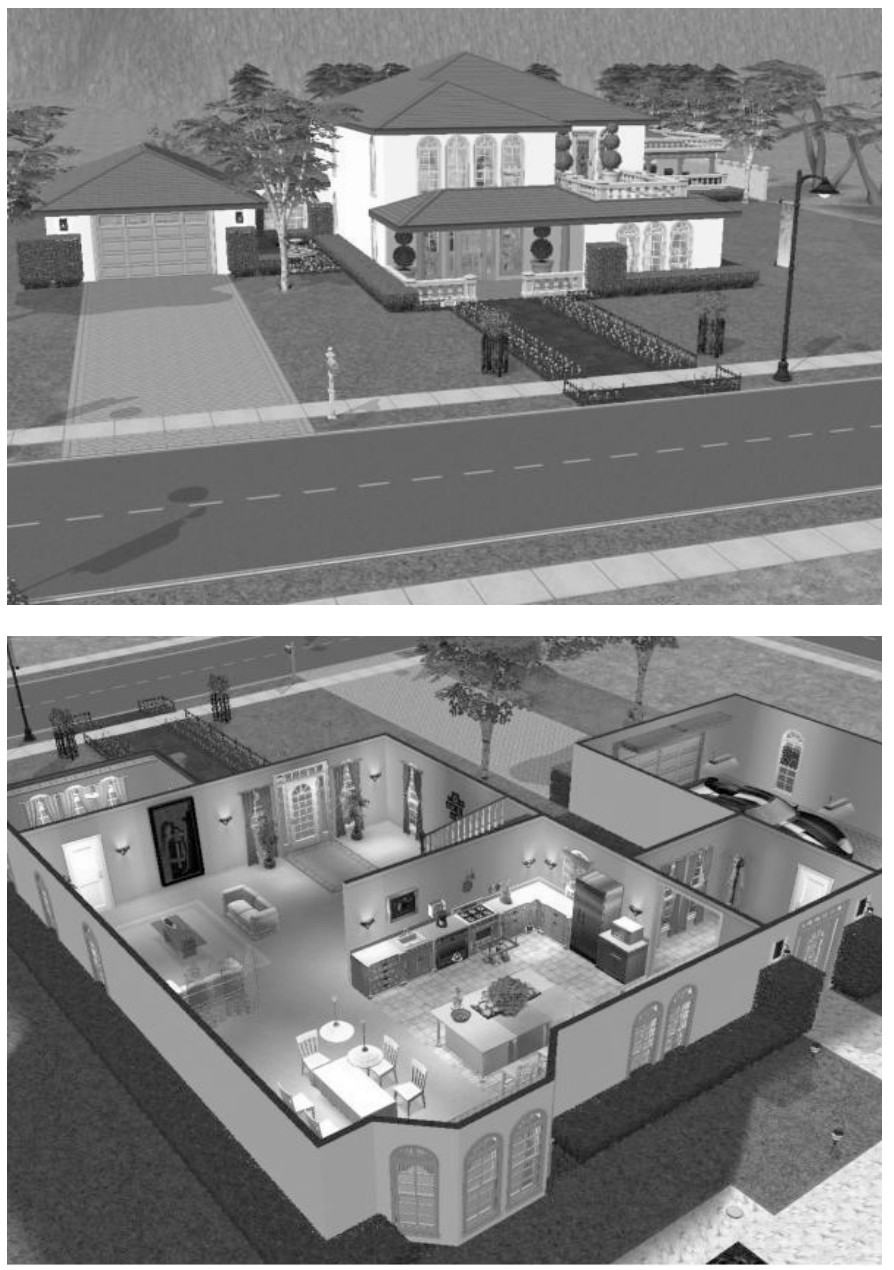

Illustrations 50 \& 51: "Celebrate Mom 2007". This lot was created for Mother's Day by player mandmjeffers1. We see the front and interior view. One can download this user-generated content for free and use it in The Sims 2 (mandmjeffers1, 2007). It is a typical The Sims home: comfortable, freestanding, private and located in a green suburb. 
code" that allowed for expansion and manipulation, for players to become producers (p. 540). This "careful community design" together with an already existing "base of Maxis game fans" resulted in an "immense player-producer community" (p. 540). Herz writes concerning the extent (more than 90\%) to which players co-constructed The Sims 1: "In the months leading up to the game's release, a network of playerrun Web sites sprung up to showcase and exchange 'handcrafted' Sims objects and custom characters. (...) This is a completely bottom-up, distributed, selforganizing process - none of these people are on the Maxis payroll" (2002, p. 3-4).

In this extreme case of commodified centripetal appropriation, fans were given design tools with which they were invited to create content for a game yet to be released. This user-generated content was created in the periphery before the game was released and incorporated within the core of the game that was ultimately launched in 2000. These peripheral activities were orchestrated and harvested in order to create loyalty among SimCity fans for the new game Maxis and Electronic Arts wanted to launch, secure a solid offset for the game upon its release and safe money on the expenses of creating all game content indoors. The many-to-many culture is thereby commodified and becomes part of the circuit of capital.

A good example of the slower centripetal appropriation that implicates a new game release, is the documentation function in The Sims 1 and 2. Game developers working on The Sims games learn from studying and data-mining fansites, chatrooms, discussion boards and the likes. Either they lurk these sites and learn about their fans and how these fans are using their game or they actively post questions and news announcements to gather specific information (for example in relation to what sort of expansion pack is most desired by the user communities). What the 
Maxis team learns from tapping into the user communities is often fed back into later installments of the game, official patches, or expansion packs. This is a slower movement between core and periphery but equally important. Players are being heard and feel taken serious, they are delighted when a new expansion pack features the sort of items they campaigned for.

Originally, the 'Family Album' function in The Sims 1 was intended as a documentation tool that players could use to document how their game was evolving. But players started to use this game feature to document other things than strictly game-related play: "What the designers did not anticipate was that players would use this feature to craft stories starring their Sims" (Frasca, 2001). To create a story inside the world of The Sims, players have to be patient because of the programmed 'independency' of the Sims. Players have to manipulate the Sims into the configuration they want to photograph. However, the Sims never stay put for very long. Orchestrating a story in The Sims is thus a time consuming process. By staging stories in The Sims the game becomes the bühne for a story players want to tell, document and share with others. These staged stories often tell an altogether different story than the one that is evolving in the game at that time. Storytelling and staging stories in The Sims adds a divergent, peripheral play activity to the geography of The Sims play. In these practices of play players use the design of the game in an unexpected way. Players publish their pictures online accompanied by written stories. The end result is a sort of photo roman, with the same type of romantic and personal dramas that typified the photo roman from the fifties and sixties.

Maxis responded to this divergent player practice by facilitating this unexpected use of the Family Album as much as possible in The Sims 2 and on their website. In The Sims 2 a video-making device 
is embedded that allows players to stage moving clips. Maxis will hold contests for best video clip and players can post their clips on the official website. From the massive use players make of the website it is clear that this is a very popular feature. August 2007, some 24.000 user-generated stories are online on the official Maxis Exchange site (EA.com, 2007a). Besides the .com website for The Sims 2, there are 19 other national websites, some of them with their own considerable amount of uploaded user-generated stories. The example of the Album Function illustrates how a divergent peripheral play activity can become part of the facilitated core through slower centripetal appropriation.

However, things are not always harmonious between core and periphery. Unwanted peripheral play practices might damage the brand image, compromise the company's 'moral' stance, damage the user communities or frustrate some player's experience of the game. One example of a divergent player activity that was unwanted by many actors in The Sims geography was the creation and distribution of a nude patch for The Sims 2. Normally, the Sims are never visibly naked - when they change their clothes, take a shower, go to the bathroom or have intercourse - a cloud hides their private parts. With the nude patch, the cloud has disappeared and the Sims are naked. The patch is free to download from the Pandora Sims website which contains many other $18+$ items (PandoraSims, website). The nude patch has resulted in moral outcries from computer game adversaries, has subsequently led to agitation among the users and might interfere with the age certification of the game. ${ }^{103}$ This is not to say that the items offered on the

\footnotetext{
${ }^{103}$ The Sims is very popular among all ages and Electronic Arts would like to keep the age rating of the game as low as possible to have a large market for the game and its extension and stuff packs. The game is currently rated $\mathrm{T}$ for Teens, meaning that 13 years old and up can buy the game.
} 
Pandora Sims website are not enjoyed by other players. Like trolling, the nude patch diverges from the discourse surrounding Wright's games while also altering the design of the game in such a way that the result of this divergent and unwanted play practice is the obstruction of the centripetal and centrifugal movements within the geography of The Sims play.

The core of The Sims play is shaped by the combination of discourse and design of the game. In the official 'About The Sims 2' section on EA's website we read for example: "direct your Sims over a lifetime and mix their genes from one generation to the next. You set your Sims' goals in life: popularity, fortune, family, romance or knowledge. Give them a long, successful existence or leave their lives in shambles" (EA.com, "About The Sims 2"). Although the core is dispersed, open to user-generated content and both fast and slow interactions between core and periphery are manifest, this does not mean that the core is not a powerful influence on what goes on in the periphery. It is striking how true divergent player behavior stays to the overall porté of the game (a suburban lifestyle based on consumer bliss), the discourse that surrounds the game and the scripts embedded in its design. Silverstone and Haddon ascertain that the "freedoms" we have to "impose our meanings" on technological artifacts is limited by the discourse and design of such artifacts: "These freedoms are not infinite. They are constrained (...) by the rhetorics of technology, expressed through design and marketing" (1996, p. 70). On top of this, Consalvo states, "various industry elements work to constrain certain readings or activities, promoting certain ways of seeing gameplay and ways of playing that are valued over others" (2007, p. 2). In other words, the discourse surrounding computer games, the embedded scripts, the projected users and uses have a strong influence over intended as well as divergent play practices. As in 
Strassoldo's second model of core/periphery relations, "individual behavior" is "coordinated" through "immaterial elements such as images and moral codes", "values" and "norms" that players internalize (1980, p. 38-40). Overall, the adaptations and appropriations by players of the core never stray very far from that core and can, as such, easily be reincorporated within the core.

Players' overall 'conservative' peripheral activities can in part be explained by the fact that players cannot alter the designed core of the game. They cannot, for example, design an eco-minded, bikeriding community. There have never been so many building elements to construction play as in the digital realm nor has narrative play ever been so extensively visualized and been made procedural. However, as Kline, Dyer-Witheford and De Peuter argue, abundant options in how to design the décor of your play do not necessary equal constructive freedom:

But the interactive enthusiasts need to take a closer look at the degree and kind of 'active' participation of young audiences in the construction of their 'own' digital culture. Choosing a corridor, character, or weapon (...) can be very absorbing. But it is hardly a matter of radical openness or deep decision about the content of play. Gamers['] (...) actions consist of selections (rather than choices) made between alternatives that have been anticipated by the game designers (2003, p. 18-19).

Exactly because computer games are designed objects and players are not granted access to the programmed, designed core of SimCity or The Sims, there are certain restrictions as to what can be modified, patched, cheated upon or otherwise appropriated. The variables underlying these simulations are not alterable by the players. Frasca considers this a disadvantage in terms of playability. He states that future The Sims games would do good to allow players to create not only narratives but also simulations, for example on the level of the variables that constitute the Sim characters (2001; 2006, p. 91). 
Again, cheats are a means to make the tyranny of the algorithm less pressing on the actual playing of the game. In The Sims, players can activate cheats that will make them never run out of money, have twin babies or have their house surrounded by water (ConsoleCheatCodes). When you have all the money you might ever need in The Sims, the structure of the game, its designed characteristics will be far less pressing on how players actually play the game. When you have a bottomless supply of simolean (the game currency), you can build and decorate all you want, like in an endless LEGO game, without having to rely on your Sims' paycheck, without having to switch to the My Sim playing mode and deal with your Sims' social and professional problems. This results in a completely different game experience.

Moreover, the constant appropriation of the periphery by the core, either through slow or fast appropriative forces, blurs the lines between core and periphery. The result is an increasingly diffuse geography of play in which it is hard to locate what play practices are taking place where. Since game developers increasingly rely on and tap into what goes on in the can culture of user-driven innovations and allow for the fast traffic between periphery and core, peripheral play practices are increasingly commodified and seem to be less and less divergent. Players have taken on the role of co-designer and what they produce is very much in line with the company's discourse. The nude patch is an example of a truly divergent player activity.

In terms of Jenkins' 'jammers' and 'poachers', The Sims poachers are completely legalized, they have become unpaid 'hunters' for EA and it is their activity that is being poached, although with their consent, by EA (2002, p. 167). It is still a "perruque" but what is being masked is not the penetration of leisure within the work sphere but work in the play sphere 


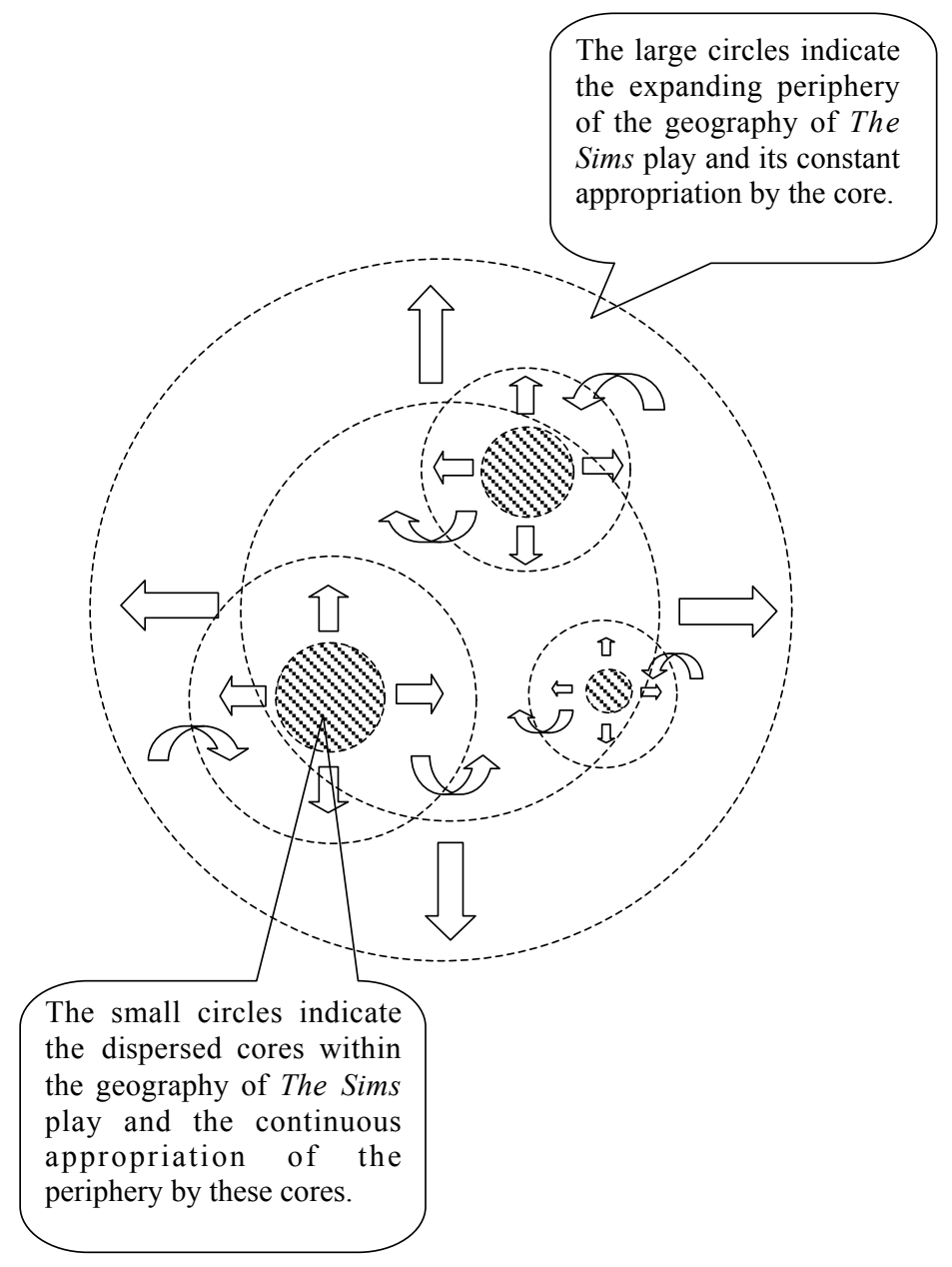

Figure 5: A Commodified Geography of Digital Play. In this geography, both the fast and slow centripetal forces are commodified. Besides this appropriation and commodification of the periphery by the dispersed cores, the periphery is also 'irrigated' and thereby kept from shrinking. The fast and frequent centrifugal and centripetal movements in the The Sims geography make it into an organic system wherein the relationship between players and game designers can become symbiotic. 
(Certeau, 1988, p. 25). Although Herz labels the cocreation of The Sims 1 "bottom-up" and a "selforganizing process", it was EA's decision to release the programming code (2002, p. 3-4). They facilitated this co-creation because this would serve brand, company, user communities and game. As Consalvo stresses, "Such power systems must be carefully delineated (...) lest this account slide into a false celebration of player agency at the expense of understanding the more complex, dynamic push-pull of industry and player currently at work in the gaming universe" $(2007$, p. 2).

This is not to say that players are not enjoying the geography of The Sims play. Considering how the game continues to be successful both in terms of sales numbers and positive community activities, this appropriation is then not perceived as a threat or a negative development. There is enough content and feedback flowing back into the periphery to keep it 'irrigated' and thus alive and active. If not compromising the geography of play, then what is the effect of this appropriation and commodification of peripheral play activities? For one, it makes questions concerning creative rights all the more pressing. Moreover, it prompts us to ask what it is that is being played. Playing seems to have transformed from designing with a game or toy to designing for a game or toy. The periphery thereby looses its ludic inconsequentiality and becomes less autonomous while it gains, at the same time, in importance for and influence over the core.

\section{UnWanted Play PRaCtices IN The Sims Online}

In 2002, EA and Wright attempted at recreating the success of The Sims in an online variant: The Sims 
Online (Maxis, 2002a). The Sims Online is a so-called MMOG (Massively Multiplayer Online Game), a game where 'massive' amounts of players gather online to play against or with each other. The game intended to retake the successful ingredients of the The Sims games within a multi-player online environment. The decision to go into online gaming was a daring endeavor. Online gaming is a difficult, rather closed market with only a few popular games existing side by side. It asks for a different approach to gameplay and facilitated play practices since human players rather than a computer manipulate most or sometimes all onscreen characters. Launching an online variant of The Sims seems to have been based on both Wright's and EA's wishes and visions of the future. EA had been buying numerous companies specializing in online gaming (Origin, AOL and Kesmai for example) and clearly wanted to tap into the growing and lucrative trend of online gaming: "EA's (...) chief financial officer, Stan McKee, announced that the company aimed at getting twenty percent of its sales from online revenues within three years" (Kline et al., 2003, p. 272). And who can blame them? The prospect of 250.000 users paying $\$ 9,99$ per month in subscription fees would be appealing to every game company.

But it seems that EA was too eager to enter this lucrative market. Probably out of fear of loosing potential players to other online games that were being released around the same time, they launched The Sims Online before the beta testers thought the game ready. The game never turned into the hoped-for and prophesized success. The game was hyped to such an extent that it would have been very hard to live up to the expectations. The first few weeks, 80.000 players subscribed to The Sims Online. At its peak, July 2003, The Sims Online had 105.000 subscribers (Woodcock, 2005). The hoped-for 250.000 players never materialized because in a world of active Internet 
users, bad news travels as fast as good news. And The Sims Online has been surrounded by bad news from the very start. Beta testers announced that the game was not yet finished and should not have been released. It also became clear that the game world was too big to function as a social space when so 'little' players logged in. The rules of the game further frustrated players rather than motivating them and soon enough anti-social and criminal behavior became a plague that pestered The Sims Online. The latest number on subscribed The Sims Online users dates from January 2005 and indicates that only some 35.000 players are left (Woodcock, 2005). ${ }^{104}$ Overall, the game did not, as was hoped for, appeal to the large group of devoted SimCity and The Sims players.

At the time of writing, there are no active, independent user groups where The Sims Online players can find each other. The only meeting place for players seems to be the Stratics website moderated by EA. Some claim Stratics is a front to pretend that there is still something going on in The Sims Online and to lure new potential players into joining the game. From browsing the Stratics site, you get the feeling that EA is letting the game die a slow and silent death: there are no updates for the game, there are regular reports of criminal activity and many players announce that they are leaving the game. Also a telltale sign is the fact that the installation $\mathrm{CD}$ for the game is no longer on sale, now the game is free to download and you 'only' pay the monthly subscription fee of $\$ 9,99$. User activity on Stratics is very poor, the most recently uploaded screenshots date from 2003 and only some 30 pictures have been uploaded in total (Stratics, 2003). This stands in shrill contrast to the continuous stream of user-generated content that is uploaded to SimCity and

\footnotetext{
${ }^{104}$ Estimating from the 'buzz' in and around the game, I think there are some 5.000 active players left, including both the social and anti-social gamers.
} 
The Sims websites. A recent Stratics polls asked "How often do you log in?" to which only 334 people responded of which 154 replied that they logged into the game daily (Stratics, 2006). Asking players on Stratics why they still play the game or have been playing it, most reply that they play for the people they meet up with in the game and not for the game itself (LadyWolf, 2006; QueenFerny, 2006; Steele, 2006).

There are different reasons for the failure of The Sims Online. Ranging from a distortion of the symbiotic relationship between players and company to frustrating the design-based play practices that made both SimCity and The Sims so popular. From the outside, it looks as if all the elements present in SimCity and The Sims have been incorporated into The Sims Online: there are houses, cities and communities to be build, social relationships and households to maintain and one needs to work in order to be able to spend money. However, once inside the game, these construction and narrative play elements turn out to be compromised. Meaning that players who enjoy building and decorating houses will find it easier to do this in SimCity and The Sims games. Both games have more building, decoration and shopping options and, importantly, they allow players to import usergenerated content. Without claiming my The Sims Online experiences as universal, I want to illustrate how these play practices are frustrated through a description of my time spent in The Sims Online.

After a very long and tedious process of downloading, registering, waiting for approval, installing, updating, creating a character, loading the game and starting, I am finally inside the online world of The Sims Online. I had read a lot about the game, including the stories about the mafia gangs in the game who exploit casinos and whorehouses, the abuse of both newbies (new players) and long-time players in the form of theft, verbal or 'physical' abuse. Newbies 
reported online that their character had been locked in a closet or room and only been set free again after they had handed over their simolean to the abusers. Other players reported racist and sexist remarks, or floods of pestering messages directed at one character/player. Others reported online sexual harassments or the destruction of their property or even game account (Bray, 2004; Ludlow, 2003; Ludlow \& Wallace, 2006). ${ }^{105}$ Here is just one such story of a The Sims Online player: "Today I was scammed of six million, and now im [sic] pretty broke. I was buying a rare lot from someone in Blazing Falls. (...) To me, at least, 6 million is alot [sic] of work. I was already on my last leg with this game. (...) So I'm canceling [sic] all three accounts" (LuckyHawk, 2006). I started out playing the game feeling anxious. Not only because I somehow expected strange things to happen but also because in this online game you encounter other people and not just computer characters. During the time I played, however, nothing out of the ordinary occurred. In the end I was actually hoping something would happen because the game itself offers so little play options and my job was a lot but certainly not "fun-filled" as the website had promised (EA.com, "About The Sims Online").

This game differs from SimCity and The Sims because you start with nothing and it will take many play hours before you have made enough money to build your own house. Diverting from the intended play course, some players will buy simolean (with real money) on websites like eBay in order to build a house without having to actually work a job for many hours.

\footnotetext{
${ }^{105}$ The underworld of The Sims Online has been researched and documented by Professor Peter Ludlow who 'worked' as a journalist in The Sims Online under the name Urizenus and who got thrown out of the game by EA for reporting on the seedy things going on in The Sims Online. In collaboration with Mark Wallace he has written Only a Game: Online Worlds and the Virtual Journalist Who Knew Too Much about this experience (2006).
} 

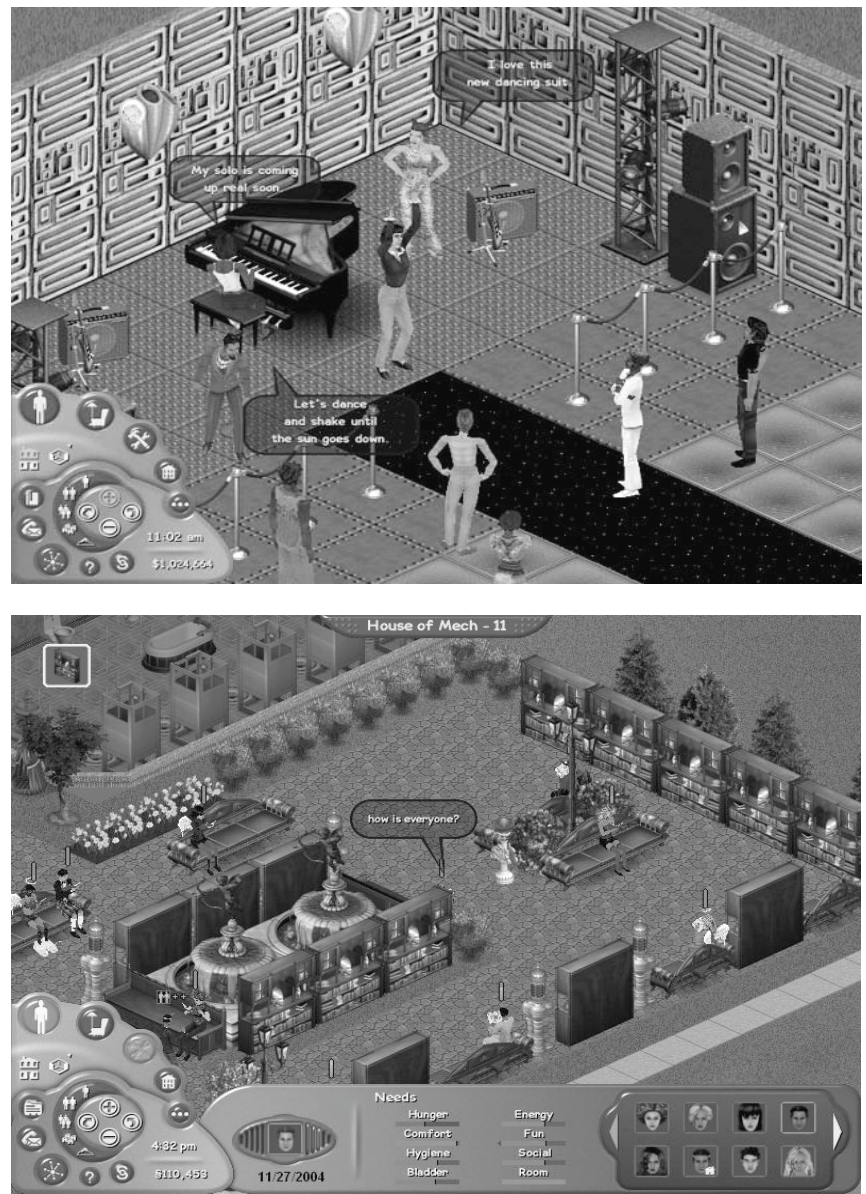

Illustrations 52 \& 53: The top screenshot from The Sims Online dates from 2003 and is one of the most recent screenshots uploaded to Stratics. Because no player has listed his or her name under the picture it is probably uploaded by one of the people who monitor the website. One of the characters in the club exclaims, "I love this new dancing suit". The player at the piano says: "My solo is coming up real soon". And the figure at the left shares: "Let's dance and shake until the sun goes down" (Stratics, 2003). The bottom screenshot shows a group of Sims 'skilling' (upgrading skills) in a house that provides plenty of 'skilling' units to accommodate a multitude of guests. The vertical tubes above the Sims' heads shows the progress they are making (BetaNews, 2005). 
Or players will steal money from other players. Worse, some players will destroy the precious property (the so-called "lot job") that has taken so many hours and so much money to acquire.

But in the 'normal' course of the game, before you have reached the state of home owner, you visit other people's houses and they will most likely welcome you warmly because they get money for every person that enters their home. Houses will typically provide enough sleep, eat, shower, workout and skill enhancing units (for example in the form of pianos that will enhance your Sim's creativity or books that will enhance technological or cooking skills) to make a lot of visitors comfortable at the same time. 'Skilling' is important to get a better-paid job. The owner of the house will cook food and feed the visitors. With friendship being an economy in this game, the idea and intention of this online world as a social meeting place is compromised. Players who enjoy chatting and social interaction will prefer games like There (ThereInc., 2003) or Second Life (LindenLab, 2003) that are considered superior as an online social interaction platform to The Sims Online. Social interaction has been made utilitarian and "instrumental" in The Sims Online and thus far from social (Steen, Greenfield, Davies, \& Tynes, 2006, p. $320)$.

On your startup screen you can see a list of houses that are newbie-friendly. I pick one at random and am teleported there. I ring the bell and someone inside says "hi". I can enter. There are three other female characters in there. I tell them I am new to the game. After a while, I ask them how long they have known each other. One of the women replies that she just started to play the day before. I ask how often they play and the reply is "always". I ask how they manage and they reply "lot of AFK time". In other words, they spend a lot of time Away From Keyboard. In this game 
you can put your character to work on a skill (e.g. through reading, dancing or playing the piano) while you are doing something else in the 'real world'. When players need to do something outside the game, they will type "AFK" and this will appear in a talk bubble above their Sims' head. Then they leave their character alone in the game and other players know that this particular Sim will not be interacting for a while. The AFK practice of play is an unintended play practice, an unexpected and unwanted exploit of the game design and one of the reasons why The Sims Online does not successfully function as a social interaction space. Too many players simply put their characters at work in the game and leave the keyboard.

I try out the piano and it sounds awful because as a newbie I have no skills yet. The other women tell me we should play together because then it will sound better. And it does. In no time at all I am playing the piano with three other women and it sounds and feels great! All my insecurity, anxiety and fear of being rejected or abused have vanished and I feel like I made some friends. We keep playing on and on and I feel really excited about it. Gradually it dawns on me that when you play together your skills get upgraded faster. So this is the reason why people are being social and doing these activities together. This knowledge dampens my feelings of euphoria considerably. Later on, someone needs to upgrade her character's technical skills so she can work in a technical workshop building robots. Everyone who is present at that time in the house (people keep coming and going) starts reading and we sit like a big family in sofas studying the 'technology books'. While the Sims are working in silence on their technical skills, the players chat and joke. Not about personal things but about the game and what to do next as a group. They ask around whom would need a skill upgrade that they could work on together. 
As a newbie I know virtually nothing and the other players are kind enough to explain how the game works. They tell me to get a job to earn some money. So I take a job as a waitress (because I do not have enough skills yet for any other job) and after some explaining from the other players, call a cab and go to work. I have to take orders from customers, be friendly, bring them their food and later the check, clean the tables and so on. It is not a good first day at work however. I only make a few simolean and most customers were very unfriendly. However hard I try to perform all tasks fast and friendly, the customers remain unfriendly and unsatisfied. It is strange and disconcerting to realize that all the customers in the diner and my colleagues are being steered and manipulated by real people.

In the end, I give up playing The Sims Online because I lack the patience to work until I can afford my own home. Especially because once you have built your own home, there is simply more of the same. That is, more of that stripped-down play experience. The only difference would be that I would go from working a menial job to playing host to whoever knocks on my door.

In terms of the core/periphery model of differentiation, we see that The Sims Online facilitates only a meager set of play options. Although all content in The Sims Online is player made (houses, parks, cafes, restaurants...) this does not mean that the construction axis of the game is well developed. For one, it takes an average player very long to gather enough money to build anything at all. When you start the game, you immediately notice that the game canvas is empty. There are houses standing left and right but they are so far removed from each other that they are islands within an otherwise empty playworld. The answers to a Stratics poll revealed that less than half of the respondents was a home owner (Stratics, 2006). On 
top of this, the game provides only a meager set of things players can use to build with. This lack of content and consequent craving for content became clear when the Stratics poll question: "How excited would you be to see new clothes (or clothes from sim page) added to the game" prompted 7256 replies of which $74 \%$ said to be "Very Excited" about such a prospect (ibid).

The lack of content and building elements diminishes not only the construction play elements but also the dollhouse qualities of interior decoration and the pleasures of perfecting a private home. When you have finally become the proud owner of a home in The Sims Online, you have to play host to other players in order to earn money. These players cannot, as in a dollhouse or in The Sims, be put in certain places or situations, they are not for you to manipulate. Because the characters in The Sims Online are steered by humans rather than a program code, the facilitated narrative play practices and the options for narrative manipulation disappear: "The godlike power of The Sims could not be ported to TSO with its many interacting players" (Steen et al., 2006, p. 320). Because the Sims are played by humans rather than a program, the strange behavioral quirks disappear as well. Much to the players' dislike: "The appeal of The Actual Sims, to me, is that THEY ARE SIMULATED! It's those unknown programmed reactions that are fun to watch and to try to control" (Mike, 2002).

In other words, The Sims Online is a designed object, a programmed and coded artifact that promises the player design possibilities on the level of home building, character development and relationships. However, design possibilities on the level of construction play are reduced because constructing is so expensive and the construction options are limited. Designing your onscreen character is equally hard because raising skills is a slow and tedious process. All 
characters are played by real people who might go offline, go AFK, might only be friendly because that will raise their skills or earn them money, which makes designing relationships difficult indeed.

Although the discourse on The Sims Online promises the player a lot of fun, the design of the game, the embedded scripts and the projected uses do not support this discourse. The core of the geography of The Sims Online is characterized by an unfortunate discrepancy between design and discourse. The two elements of the core do not support and reinforce each other and the imbalance between the two frustrates players who might venture their frustration on other players or the game company. The stripped-down and imbalanced core of the geography of The Sims Online does not 'tolerate' many divergent play practices either. Both centrifugal and centripetal movements are therefore largely lacking in the geography of The Sims Online.

A good example of the disrupted slower centripetal appropriation of the periphery can be found in EA's dealings with the beta testers. Beta testers are asked by game companies to tinker with games, to be as divergent as possible, find bugs and design flaws and come up with suggestions and comments. Normally, beta testers' output is taken seriously and dealt with before the game is officially released.

Beta testing, also known as 'black box' testing, is part of a larger testing process and is proceeded by an alpha, 'white box' testing phase. Alpha testing is mostly done indoors by the employees of the game company because white box testers have access to the source code of the game. In the competitive market of MMORPG's (Massively Multiplayer Online Role Playing Games) the testing phase is likely to be open to the public from the alpha stage onwards because launching a new online game is more difficult than launching an offline game. Most MMORPG's ask a 
rather heavy investment on the financial level (monthly payments) combined with a heavy time investment (in MMORPG's, players depend on each other to play the game). In most cases, however, large groups of players only become involved in the testing process during the beta, black box testing phase when the source code is no longer accessible. Beta testers have access to the software through the same user interface that future players will use. During this beta testing phase, testers will look for bugs and report them and make recommendations for enhancements on all levels of the game.

Reasons for game developers to make use of beta testers are on the one hand the prospected loyalty of beta testers to the game they tested, the overall goodwill among user communities that results from game companies using beta testers and the creation of that symbiotic relationship between player, consumer, product and producer. On the other hand, it would be very expensive and time-consuming to have all the testing done in-house. And of course, players new to a game are likely to find other faults than designers who are already accustomed to the game.

Suggestions that do not find their way into the game that is at the time being tested, might be incorporated in patches and mods that will be released once the game is already on sale or they might be used in later installments of the game. The degree to which beta testers can influence the development of a game on the core level differs from one game to the other. But since beta testers are mostly part of a black-boxed testing phase, their influence is mainly on the 'cosmetic' level of the game.

In relation to The Sims Online the testers themselves perceived their degree of influence on the game as being too low. On the user group alt.games.the-sims beta testers expressed hope during the testing phase that EA would realize the game was 
not ready for release: "If it's a good company, they will listen and they will fix the bugs to preserve their good reputation" (AnnieW, 2002). But "EA failed to listen to the TSO testers" and released the game in 2002 before the testers deemed it ready (Squeegee, 2003). Once The Sims Online was released it was soon apparent to EA and the players that the game was performing poorly. Overall, fans of Wright's games blamed EA rather than Maxis or Wright himself for The Sims Online's failure because "It's been the history of Maxis to listen to the fans" (ibid). The failure to take note of the beta testers' many objections created a negative buzz on the Internet and contributed to the overall negative image that has surrounded The Sims Online ever since its release.

Besides the discontinuation of the slower centripetal appropriation of periphery by core (bridging beta and official version of the game), the fast centripetal appropriations whereby players can import and employ user-generated content in the game was discontinued as well. Players cannot import usergenerated content into the game nor the objects they have bought for the other The Sims games. This has angered many players: "Not allowing long-time Sims players to import their custom objects seems a slap in the face to all the hard-core people who have their somewhat average game and making it a phenomenon" (Ckought, 2002). As a consequence, the periphery is not characterized by an active many-to-many culture. Both core and periphery are stripped down play areas within a shrinking geography of play. The geography of The Sims Online is then more in line with Strassoldo's model of coercive power and closed boundaries (1980, p. 39). The core neither 'tolerates' user appropriation of the game (centrifugal) nor does it allow the integration of peripheral products into the core (centripetal). In this geography of closed boundaries and minimal traffic between core and 
periphery, the balance between 'player' and 'game' is askew. There are no tools or means to escape the tyranny of the algorithm, to appropriate the game and its' content. Therefore, many players turn to anti-social and criminal behavior to avert the tedious working and 'skilling' routines.

There is, in the words of Jenkins, not enough room within the geography of The Sims Online for players as 'poachers' to 'appropriate media content' (2002, p. 167). Therefore, players turn into 'jammers' who jam the game, the user communities and ultimately the brand. The emptied out play practices of The Sims Online create a breeding ground for unintended and mostly unwanted practices of play that are at odds with the game company's intentions, the game's code of conduct and the overall discourse on The Sims Online. These practices move away from and take place outside of the circuit of capital, that is to say, the company-circuit of capital. These play activities are not part of what game companies rely on, hope for and can capitalize and are as such not fed back into the production process. However, these practices might form an independent, anarchistic circle of capital as in the case of the The Sims Online cheating bots.

As said, cheats are often used to turn the tables between player and game, to tip the balance and put the player in control of the game rather than the other way around. Players have found a way for their unwanted peripheral play activities to enter the core of The Sims Online in the shape of so-called cheating bots (also a form of exploits). A bot is a software programs that performs automated tasks. Since cheating bots are very much unwanted, their intrusion into the core leads to a crisis within the geography of The Sims Online. These bots create advantages for the cheating players and introduce a divide between the cheaters and the noncheaters. Gottmann pointed towards "some possibility 
of opposition and confrontation" between core and periphery $(1980, p .8)$. In a coercive core/periphery model with one sole center of power and closed boundaries, as manifest in The Sims Online, conflicts between core and periphery are all the more likely to occur.

In relation to a single-player game such as SimCity or The Sims leaking and using cheats will not cause any problems because the game has been bought and players will not 'harm' any other players or the company by using these cheats. These types of cheats are designed and incorporated in the game and are as such not unwanted. In relation to online games such as The Sims Online, the use of cheats is a totally different story because when you are playing with more than one player, cheats become cheating and cheating devaluates the play experience. Many regular players who play according to the facilitated and intended practices of play will leave online games when cheating makes the competition unfair. Game companies will rarely incorporate cheats in their online games because, contrary to single-player games that you purchase with only one transaction, online games ask a monthly subscription fee and as such the loss of every player means less income. If there are cheats for online games these will be mostly player-created, unintended and unwanted.

Johan from MySimsOnlineCheats.com is the chief creator and seller of The Sims Online cheating bots. He promotes his bots with the words: "our bot programs can play the game much faster than you ever can. (...) Playing The Sims Online will become much more fun since you finally don't need to worry about making simoleans any more" (Johan, website). Johan has been programming simolean-generating cheating bots for The Sims Online since the beginning of the game's launch in 2002 as a response to the fact that it 
is hard to raise money and skills in the game. On his website there are eight different cheating bots on sale.

The EYE cheating bot is sold for $\$ 12$ and acts like a real player. This bot makes money in the game without the player having to be present. TSO Guard is only $\$ 9$ and makes sure your game does not go offline when you are inactive for too long. It can monitor up to twenty different accounts/games. Both cheating bots cater to the aforementioned AFK play practice. Without using these cheats, a game becomes inactive when a player is AFK for too long. This rule is installed to counter the unwanted AFK play practice. TSO Auto Code PRO sells for $\$ 21$ and "has been build [sic] with only one idea in mind: to make as many simoleans as possible in the shortest amount of time". TSO Pizza Bot PRO, TSO Auto Maze PRO and TSO Band Perfect all go for $\$ 30$ and promise the buyer unlimited simoleans. TSO Pro Bot can be bought in a $\$ 21$ or a $\$ 39$ edition. This bot has been "designed for the professional simolean seller" and can handle "an unlimited amount of games at the same time". With this bot players can be earning money in different places, in different games and with different onscreen characters from one computer. These bots facilitate practices of play that would normally be impossible. The Rare Pet Finder sells for \$21 and automates the task of looking for rare pets in the vast world of The Sims Online. Finding these pets will gain the player money (Johan, website).

Johan promises potential buyers that simolean they cannot or do not want to spend in the game, can be sold to other players through eBay or comparable websites. However, there seems to be - at the time of writing - no potential buyers for these simoleans to be found. Another 2006 Stratics poll asked the players: "How many Simoleans does your richest Sim have in their account?" Most respondents (26\%) claim that their richest Sims have "1 billion to max allowed" 
(Stratics, 2006). This might mean that players have been playing the game so avidly that they have gained this much money, that they are all using the cheating bots or that they have bought a lot of simolean online. Whatever the case, the market for simolean seems to be smaller than Johan promises his potential customers. The more cheating bots in use, the more the 'market' is flooded and the less the The Sims Online currency is worth. Using these bots in the game will result in a warning and eventually expulsion from the online game world. It is unclear how easy or difficult it is to track players using the cheating bots. According to Johan, "in most cases you don't get caught unless you're telling all your friends about your new bot. Also, when you get caught, you'll always receive a warning first" (Johan, 2007).

These cheating bots both alter the design of the game and go against the discourse surrounding the game. Creating, selling, buying, installing and using these cheating bots are all unwanted play practices because they devaluate the currency used in the online game world, create a divide between the have's and the have-not's and facilitate 'illegal' play practices such as the AFK practice. Cheating bots (but also the The Sims nude patch) are unauthorized and unendorsed (by the powerful actors, the game companies in the core) boundary crossings between core and periphery.

\section{A COMMODIFIED GEOGRAPHY OF PLAY}

This chapter has investigated the computer games SimCity, The Sims and The Sims Online from a double perspective. On the one hand this chapter has drawn parallels between these games and historical comparable toys and forms of play. By doing this, not 
only similarities and dissimilarities between playing with non-digital and digital toys are brought to the forefront but also between the underlying ideologies of these toys. On the other hand this chapter has used the core/periphery model of differentiation to look at what happens where in the geography of digital play.

SimCity is a game designed to be about urban design. It compares to historical toy towns in the sense that both toys bring the urban configurations into the private home and the life of children. Both mimic in miniature format that which the child has to be protected from but also, especially in the case of boys, need to be familiarized with. With The Sims, a game designed to be about domestic design, we see a move towards the suburb, the private suburban home and life within that home. This compares to toy homes, dollhouse play and doll play. The toy home, dollhouse and The Sims mimic the domestic, the place and space of childhood. They combine the male oriented play form of constructing and engineering with female oriented play forms such as making house, building a family and maintaining social relationships. The Sims Online had the suggestion of all these elements but not their actualization. Do both SimCity and The Sims offer the player an intricately designed software program that embodies a never-ending string of design actualizations; The Sims Online offers an intricately designed software program that embodies a neverending string of frustrated design actualizations.

A crucial difference between non-digital and digital toys is the fact that the latter are designed, coded software programs. Computer games visualize the world of play and procedural aspects of the game to an unprecedented level. The technological object the player plays with or against becomes thus more complex, so do the embedded scripts, the rules and requirements, the projected users and uses. 
The results of this digitalization of play are manifold. On the one hand, almost all player-game and player-company interactions are digitalized and take place mainly online. With the advent of private computer ownership and the Internet, the area for digital play increases dramatically. However, the means for companies to tap into the can culture of peripheral play activities increases as well. From SimCity to The Sims, one sees an increase in the traffic between core and periphery, between player and company until this relationship reaches a symbiotic stage. Within the geography of The Sims play, the core grows and incorporates the periphery in a continuous centripetal movement. Because the periphery is not only appropriated but also continuously 'irrigated' by the core with new opportunities for user appropriation, the geography of The Sims play remains alive and 'healthy'. The transition between core and periphery in the geography of The Sims play is fast, smooth and multiple to the extent that the lines between core and periphery, between player and producer are almost rubbed out and the geography acquires an organic character. Making it very difficult to unravel what is taking place where in the geography of The Sims play. With the official LEGO Blacksmith shop, one knows that the product one is buying is a commercialized MOC set because it is advertised as such. With The Sims, one cannot tell whether the objects in the game are user-generated content or manufacturer-generated content.

The LEGO Company occasionally taps into the user-driven can culture of dedicated fans by inviting an elite group of adult LEGO fans to join the designers in Billund, visiting brick festivals and LEGO-dedicated websites. The LEGO Company decides what sort of user-driven innovations, if any, can enter the core of LEGO play. The LEGO Company is thus only partially dependent upon these user-driven 
innovations and chooses if and when to involve the users within product- or brand design. Within this geography, the periphery is only appropriated and commodified by the core in function of the design and development of new products. With SimCity, EA facilitates a constant and unobstructed flow of usergenerated content into the core. However, the functioning and popularity of SimCity is not completely dependent upon these flows. Both the LEGO Company's products and SimCity benefit from a vibrant and active periphery of play without being completely reliant on peripheral activities.

Contrary, The Sims game and brand has been, even before its release, been completely dependent on the periphery of play. The The Sims development team relied on being able to tap into the periphery, to appropriate user-generated content and integrate that content into the game yet to be released. To draw yet another comparison with LEGO toys, The Sims 1 was presented to the public as an almost empty box with only the basic bricks in it and accompanied by the tools to create your own bricks. The fans were expected to create and add more bricks, detailed particles, in other words content, to the box. Their creations were then returned to the company and incorporated within the launched product. Both fast and slow centripetal appropriations are thus commodified imploding the stakeholder positions of player, consumer and producer and creating a symbiotic relationship between player, product and company.

The centripetal and centrifugal movements between core and periphery that have been keeping the Sims brand and the geographies of Sim play vital and dynamic haltered and failed in the process of developing, testing and launching The Sims Online. Both fast and slower traffic between core and periphery came to a standstill, resulting in a shriveling geography of play mainly populated by anti-social 
players and unwanted play practices. While SimCity and The Sims are both characterized by a 'healthy' and active geography of play where movement between the two realms is frequent and fluent, The Sims Online is characterized by a crisis-ridden geography of play. The unwanted peripheral activities in the geography of The Sims Online stray so far from the discourse and alter the design so drastically, that their incorporation in the core results in a crisis.

In Strassoldo's second model of core/periphery relations, "spontaneous coordination of individual behavior" is achieved through "immaterial elements such as images and moral codes", "values" and "norms" (1980, p. 38-40). Both SimCity and The Sims evoke this model, players have internalized the moral codes, values, images and norms of these geographies of play and their divergent peripheral play activities are guided by these internalized values. The Sims Online's geography of play is reminiscent of Strassoldo's first model of coercive power and closed boundaries. This has led players to become recalcitrant, to struggle against the core and to refuse to internalize the values, norms, code of conduct and rules. They do not design with the game, nor for the game but against the game.

A geography of play with open boundaries, traffic between core and periphery and dispersed power centers capitalizes on the many-to-many industry, leaduser driven innovations, the can culture of devoted fans. These fans design, co-create and play with or alongside the designers of the game. A geography of play with closed boundaries, one-way traffic between the core and periphery and centralized power simply cannot capitalize on these user-driven practices of play and thus sees a return to a one-to-many paradigm. Players will then be enticed to design and play against the designers exactly because they lack the opportunities to co-create. A geography of play that is not a can culture, a "possibility space" as Wright 
himself calls it, for interactions between core and periphery, but a must culture, a 'prohibition space' cancels out the potentials of computer games and digital play in general (Wright, 2005b). It is exactly the 'can' aspect of the geography of digital play that makes it the terrain for possible exciting and innovative play practices - both on the level of the facilitated core and the divergent periphery.

The popularity of both SimCity and The Sims demonstrate the success that can result from using and drawing on the many-to-many model. The Sims Online on the other hand illustrated the failure that can result from sidestepping this model. The mechanisms of userinvolvement within the many-to-many culture are diverse and wide-ranging, from programming software to hosting a website, from posting questions on fansites to downloading new skins for your Sims. With companies' increasing appropriation of this many-tomany culture, both for the design of new products and keeping existing products exciting, players become codesigners to an unprecedented extent. Their divergent play practices enter the core and become part of the design, the embedded scripts and projected uses. When, through slow centripetal appropriations, user activities are integrated within new products designs, these users and their activities reconfigure the user. The projected use of the documentation tools in The Sims games was reconfigured after unintended actual uses of the Family Album in The Sims 1. When, through fast centripetal appropriations, user activities are integrated within existing products, these users and their activities co-configure the user. Through the constant flow of user-generated content into the core, how players actually play the game, co-configures the core, the projected user and uses. However, considering how true divergent player activities stay to the design and discourse of these technological 
artifacts, they do not introduce a drastically different user into the core.

SimCity, The Sims and The Sims Online have brought important shifts in the relation between the processes of commodification, domestication and urbanization, toy, player and play practices to the forefront. In relation to commodification, the SimCity and The Sims series of games take the serial- and expansion-pack economy to an unprecedented level, prompting players to keep on buying additions to the games and leaving no one an excuse for not buying the game with its all-round compatibility (from PC to Playstation, from Game Boy to cell phone). Moreover, capitalist principles that amount to what one could call a consumerist ideology drive the The Sims games.

Computer games answer to and reinforce domestication in a multi-layered and complex way. Highly suitable for hours of captivating indoors entertainment, computer games might end up overdomesticating players. However, with the all-round compatibility of these games, players can play these games, in theory, also outside. Hand-held gaming devices and cell phones dislocate players and play from the interior. While the interior and the domestic are the subject of The Sims, SimCity mirrors and simulates an increasingly complex urban environment and brings it in a containable format inside the family home. SimCity is considered highly successful in communicating to players some of the urban issues that dominate city life today. Therefore, the game is often used as an educational tool to raise awareness, to sensitize and explain certain urban issues and complexities to students. The use of computer games outside of the realm of entertainment brings us to the last chapter of this thesis that deals with contemporary urban issues and game-based strategies for dealing with these issues. 


\section{5: Playing the City}

In the previous chapters on LEGO toys and Wright's computer games we have seen how the geography of play became more complex, networked, social and increasingly digital, expanded and allowed for fast and frequent transfer between core and periphery. Increasingly, companies rely on a vibrant and active periphery of play to keep their brand vital and commercially successful, to maintain a positive relationship between player, consumer, game and company. We have also seen how the many-to-many template is becoming common practice among both traditional toy makers and digital game developers. The many-to-many template has attracted a lot of attention of other companies as well who are seeking new ways to involve consumers into the world of their 
brand. The dedication of both LEGO and SimCity and The Sims fans is something most companies dream of. Notably, the attractions of the many-to-many model have not gone unnoticed within the realms of politics and policy-making. Not only commercial companies recognize the potential value of this participative model that can create a symbiotic relationship between different and traditionally remote stakeholders. In this chapter, such a policy domain using the many-to-many model will be investigated. This chapter focuses on the use of (computer) games which I will label Serious Urban Games (SUGs) - as participatory tools in urban planning. ${ }^{106}$ Public participation may be defined at a general level as the practice of consulting and involving members of the public in the agenda-setting, decision-making and policy-forming activities of organizations or institutions responsible for policy development (Rowe \& Frewer, 2004, p. 512). Defining urban planning is a haphazard task because it is not a fixed discipline but rather a term that indicates the coming together of different stakeholders in a process that aims at generating urban change. ${ }^{107}$

Digital technologies are generally considered democratizing tools in the sense that they facilitate

\footnotetext{
106 The name 'urban games' commonly refers to entertainment or artistic games that take place in urban places and typically combine a screen based game world with the 'real world'. These games strive to merge physical and virtual game worlds whereby handheld technology (GPS, digital camera, cell phones) will link players in the real world with those onscreen. Wellknown examples come from the London based group Blast Theory. This group has staged many urban games around the globe such as Can You See me Now? (2001) and Uncle Roy All Around You (2003). Like urban games, SUGs will most likely combine different media and will establish a 'direct' link between the virtual game world and the 'real' world.

107 "Stakeholder is a term commonly used in planning and public policy. A stakeholder is defined as someone with a 'stake,' or interest, in the issues being addressed" (Margerum, 2006, p. 49). I have used the term throughout this thesis outside of the domain of urban planning and policy-making as well to indicate actors within a given field that have a stake in what is negotiated and debated within that field.
} 
democratic involvement in a low-key, nonauthoritarian environment. ${ }^{108} 21^{\text {st }}$ century policy reports are packed with terms like 'e-democracy' - the belief that participation can be democratized through new media applications (many municipalities will, for example, offer online e-services). New media technologies, such as game-based software, used for public participation would then, from the point of view of e-believers, democratize participation.

This chapter has as its leading case study the SUG Face Your World initiated by Dutch artist Jeanne van Heeswijk (Heeswijk \& Kaspori, 2002-ongoing). ${ }^{109}$ Face Your World was designed for and played in the Dutch garden city Slotervaart in 2005. It was initiated to deal with the dilapidated garden city, its poor childrelated facilities and lack of social cohesion. Face Your World is a multi-faceted participation and design process with a multi-player game, the Interactor, at its core. Besides the use of the Interactor, 49 meetings and workshops were organized. Both children and adults participated in the design of a new neighborhood park. The participants worked more than half a year (January till July 2005) on the design of the park and on March the $1^{\text {st }}, 2006$, the city council of Amsterdam decided to go through with the project and realize the design as conceived by the children and neighborhood residents. If all goes as planned, the park will be realized by 2010 .

\footnotetext{
${ }^{108}$ In relation to the democratizing potential of new media, Jenkins and Thorburn write: "Networked computing operates according to principles fundamentally different from those of broadcast media: access, participation, reciprocity, and many-to-many rather than one-to-many communication" (2003, p. 2).

${ }^{109}$ There are many other SUGs that center on public participation of course. See for example Ground Zero Planner (GothamGazette, 2007a), Plan Your Future Park (GothamGazette, 2007b), Geo-Wiki Game (Dormann \& Biddle, 2006) and PlastiCity (Fuchs, Manthorp, \& Schlusmans, 2006). I have chosen Face Your World as primary example because this participation trajectory actually took place and its outcome - the design of a community park - has been approved by the municipality of Amsterdam.
} 
Face Your World will be assessed on the levels of media-specificity of the participation tools (what types of media and forms of participation are being used?), the participation trajectory as a whole and the Interactor specifically. In doing this, this fifth chapter looks into the many-to-many model when used outside of the world of entertainment and considers the impact of Serious Games on geographies of play. The first part of this chapter sketches the background against which Face Your World needs to be understood. The second part looks into the forms of participation used in Face Your World and the Face Your World trajectory as a whole. The final part considers the geography of Serious play.

The sources used in this chapter are literature on public participation and urban planning, documentation of Face Your World (the archive of Van Heeswijk, the ward Slotervaart and the commissioner SKOR have been studied), 28 in-depth interviews with different stakeholders and observations of the use of the Interactor by children in De Kunsthal, Rotterdam (when writing this chapter, Face Your World Slotervaart had already taken place. Therefore, observations of the actual use of the Interactor are based on Face Your World De Kunsthal).

\section{FACE YOUR WORLD}

Before assessing Face Your World on the levels of media-specificity, the participation trajectory and the Interactor, some background information is needed about Slotervaart, Face Your World as part of the renewal plans for Slotervaart, and public participation in urban planning in general. 
The Western garden cities (Westelijke Tuinsteden) in Amsterdam, The Netherlands were built after the Second World War according to the utopian CIAM (Congrès International d'Architecture Moderne or International Congress of Modern Architecture) tradition. CIAM, a think thank of modern architects such as Le Corbusier and Gerrit Rietveld was established in 1928 and disbanded in 1959. Dutch architect and urban planner Cornelis van Eesteren (1897-1988) was the CIAM president from 1930 to 1947. He designed the general expansion plan (AUP, Algemeen Uitbreidingsplan) for Amsterdam in 1934. The Western garden cities were part of this general expansion plan. Air, light and space were leading principles in both the design of the houses and the neighborhoods. In 1954 the satellite city Slotervaart where Face Your World took place - was built.

The Western garden cities of Amsterdam have seen a decline in reputation over the last decades. They have gone from utopian and visionary living areas to neighborhoods fraught with social, economical, infrastructural and reputational problems. The end of the 1980s sees the initiation of the urban renewal of postwar neighborhoods in The Netherlands. There are two important players in the renewal of the Western garden cities. On the one hand there are the different boroughs or wards (stadsdelen) of Amsterdam West (Slotervaart, Osdorp, Bos en Lommer, Geuzenveld/Slotermeer) who all have their own ward alderman and legislative council. On the other hand there are the eleven housing corporations who own the houses in the garden cities. ${ }^{110}$ Based on pilot projects and research conducted in the boroughs (both by the wards and the housing corporations) the report Richting Parkstad 2015 (direction park city 2015) was

\footnotetext{
${ }^{110}$ Initially, these housing corporations were established to handle public, affordable housing but these corporations have largely privatized during the ' 90 s and have thereby become more like profit-oriented real estate agents.
} 
published in 2001. Richting Parkstad 2015 is the basis of the current plans for renewing the postwar garden cities, although it has been revised, changed, discussed and adapted many times over. The situation is very complex (mainly due to re-housing problems) and there is a general sense of insecurity and confusion among the neighborhood residents concerning the future of their homes and neighborhood.

Given the complex situation in Slotervaart and the many conflicting stakeholders in the urban renewal process, it is surprising that some things, like Face Your World, do in fact happen. Securing the commission to undertake this participation project took considerable time and effort and the word 'coincidence' is often used when people describe how Face Your World became a part of the Slotervaart renewal effort (Interview with Engelsman, 2007; Hartoog, 2007; Huisingh, 2007; Wien, 2007).

Van Heeswijk developed the first version of Face Your World in 2002 for the Wexner Centre of the Arts (Columbus, USA). The project in Columbus raised the attention of Wilfried Lentz, director of SKOR (Stichting Kunst en Openbare Ruimte foundation for art and public space). Lentz commissioned Van Heeswijk to develop the Interactor software to educate VMBO (Voorbereidend Middelbaar Beroeps Onderwijs or preparatory middlelevel vocational education) students on the importance of their environment (Interview with Lentz, 2007). Although it is not made explicit by neither Lentz nor Van Heeswijk, the underlying assumption seems to be that children having a hard time learning the traditional way will be more easily reached and engaged through computer-based learning tools. Developing a park and initiating such an intense and long participation project was never the intention of SKOR. SKOR's initial assignment - the development of a re-usable educational software application for VMBO students - 
has, as of yet, not been met (ibid). Van Heeswijk and Kaspori are still working on achieving this goal. They are writing a manual for Face Your World that should allow other people in other situations to use the Interactor for educational purposes (Interview with Heeswijk, 2007; Kaspori, 2007). In securing the commission to design the neighborhood park for Slotervaart, the goal of the project drifted from developing an educational tool to involving neighborhood residents otherwise hard to reach and designing a park with them that would be supported by the different age and ethnic groups in Slotervaart. ${ }^{11}$

After the commission by SKOR, Van Heeswijk presented Face Your World at a media festival for children in Amsterdam (Cinekid). AFK (Amsterdams Fonds voor de Kunst - Amsterdam art council) was present at this demonstration and was interested to join the project. Annemieke Huisingh, who then worked for AFK, tells me she had been in contact with Van Heeswijk for some time and that they had been looking for an opportunity to work together (Interview with Huisingh, 2007). For both Huisingh and Van Heeswijk it was important to link Face Your World with a real life situation. AFK was already working in the Western garden cities so they sought for an opportunity for Face Your World there. Huisingh brought different stakeholders in Slotervaart together in order to find support for Face Your World (ibid). Both Rob van Aarschot, then the project leader of the renewal of part of Slotervaart and Hanneke Engelsman, area developer for housing corporation De Alliantie, were convinced early on of the possible merits of such a participation project (Interview with Engelsman, 2007). They had been looking for new ways of organizing public participation because the regular hearings only attracted the same few elderly white men

\footnotetext{
${ }^{111}$ On drift in policy-making see Software vulnerability due to practical drift by Christian Lundestad and Anique Hommels (2007).
} 
who would always make the same objections or suggestions (ibid). The most difficult to persuade was apparently the ward alderman Henk Goettsch who was - so everyone told me - not fond of artists. In the end he agreed by supposedly saying, "as long as I don't have to call it an art project" (ibid).

Besides the difficult task of convincing Goettsch, the ward council had some reservations. They worried that Face Your World would end in the design of a park that they would not be able to finance. ${ }^{112}$ Designing a park with neighborhood residents that would be too expensive to realize, would damage the image of the ward. Current project leader Harry Wien tells me that neighborhood residents already have the feeling that the ward does not take citizen participation serious. Organizing a large participation trajectory that would result in a park that the ward could not afford to build would only further this feeling and confirms citizens' skepticism concerning their role in the urban renewal process. After some bickering the parties came to an agreement. In retrospect Wien is satisfied with how Van Heeswijk handled the budgetary restrictions and the communication with the citizens concerning what is possible, what will actually make it into the design of the park and what not (Interview with Wien, 2007). Three 'special' elements that were thought up and designed by the children fell outside of the budgetary restrictions and Van Heeswijk is searching for external funding for these elements. These elements are a statue for the park, trees with multiple functions and a recreational area with water.

Another point that was hard to negotiate concerns the pre-set conditions for the park that the ward had assembled (Interview with Broekhuizen, 2007; Hoeve, 2007). The list contains some 25 criteria

${ }^{112}$ The specified budget for the park remains undisclosed until the park is realized. 
for the park that range from the number of times the results have to be shown to a team of supervisors (minimally twice) to the preservation of old trees in the park, from common-sense elements for a park such as lights and dustbins to specific square meters for certain activities (e.g. $2945 \mathrm{~m} 2$ for the playground).

Both communication advisor Leta Hoeve and public space designer Joris Broekhuizen from the ward Slotervaart described the negotiations concerning these conditions as difficult. Some of these conditions were met but others were debated and ultimately changed by Van Heeswijk (e.g. the location of the five entryways into the park). Besides these rather specific conditions, the two main requirements from the ward Slotervaart and De Alliantie were that the participation process would involve neighborhood residents otherwise hard to reach and that the different age and ethnic groups in the neighborhood would support the design of the park.

Public participation in urban planning has a rather short history; it became an important aspect of urban planning processes during the 1960's. This is not to say that since the sixties participation is always exercised. A key texts on public participation in urban planning - A Ladder of Citizen Participation by Sherry Arnstein (1969) - stems from this period. Arnstein distinguishes between eight different forms or degrees of public participation (rungs on a ladder) to reveal that public participation is all too often used to cover up manipulation. Real participation would only be achieved through the redistribution of power, thus resulting in "citizen power" (2003 [1969], p. 245-246). She writes:

There is a critical difference between going through the empty ritual of participation and having the real power needed to affect the outcome of the process. (...) participation without redistribution of power is an empty and frustrating process for the powerless. It allows the powerholders to claim that all sides were considered, but makes it possible for only some of those sides to benefit. It maintains the status quo (p. 246). 

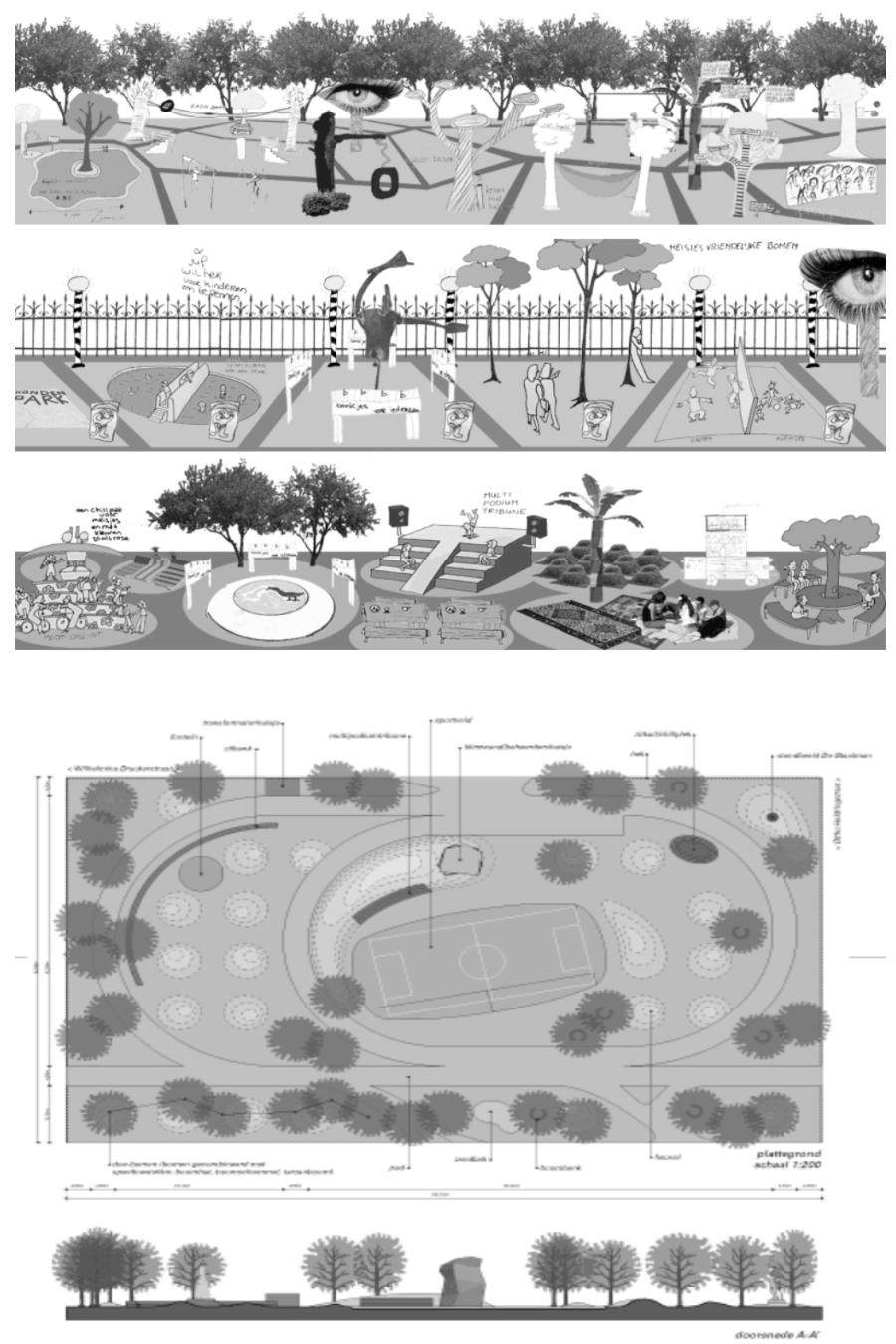

Illustrations $54 \& 55$ : The top image shows an abundance of ideas for the park generated by the children with the help of the Interactor. The bottom image is the final design for the park that resulted from the Face Your World participation trajectory (both images courtesy of Van Heeswijk). 
The municipality of Amsterdam also uses a ladder of citizen participation. The lowest level of participation is informing the citizens, the highest level is coproduction (Interview with Hoeve, 2007). The council of Slotervaart strives to minimally reach the second or third rung of this ladder, which means that citizens will minimally be able to advise the ward on a certain plan (ibid). Although the design of the neighborhood park in Slotervaart through the Face Your World trajectory has not been labeled co-production by the ward, it comes very close to being that says Hoeve (ibid). Van Heeswijk and Dennis Kaspori (the architect on the Face Your World team) both consider the design of the park the product of co-production (Interview with Heeswijk, 2007; Kaspori, 2007).

Jim Burns outlines in another key work on public participation in urban planning a process of user involvement that goes from awareness to perception to decision-making and finally to implementation or action. Concerning the first step in the process, awareness, Burns writes that this can come about both in a negative or positive way: "Negatively, people can be made aware suddenly by a threat to their community and its patterns of life. (...) The usual result is (...) a win-lose situation wherein either the community gets its way or the forces of the other side get to fulfill their plans" $(1979$, p. 21$)$. Characteristic of this situation is that 'decisions have been made before people become aware of them' (p. 27). This leaves the people only an antagonistic position, "either resisting the proposed change or trying to force another change in its place" (p. 27).

The Harbour Game (Kollision, 2002), a SUG designed and played in Århus, Denmark resulted from negative awareness of urban (re)development plans. The Harbour Game concerned the extensive redevelopment plans for the Århus harbor. The Harbour Game was created and played to confront the 
municipality, to raise awareness among policy-makers concerning the importance of public participation in such large-scale planning processes and to alert the public to the existing plans for the harbor (Interview with Delman, Løssing, \& Lykke-Olesen, 2007). As Burns indicates, this is a win/loose situation. In relation to The Harbour Game, the municipality won in the sense that the outcome of playing the game did not affect their redevelopment plans. The plans for the harbor area remain unchanged.

Awareness can also be raised in a positive way and will as such mark the beginning of a "process of agreed-upon change" (Burns, 1979, p. 21). Positive awareness will lead to perception and understanding (p. 25). The problem is that in reality different actors in a participation process might experience and/or understand things differently or experience and/or understand different things. Although Burns sees a direct connection between and movement from perception to decision-making and ultimately implementation, in reality, it is very difficult in participation trajectories to actually cover these last two steps of decision-making and implementation. During participation processes, numerous things can frustrate these final two steps, ranging from citizens losing interest in a given situation to a new political coalition that decides to do things differently, from running out of money to see the process to the end to the disapproval of the decisions by those higher up. Van Heeswijk and Kaspori negotiated until they were authorized to traverse the whole process described by Burns together with the citizens (Interview with Heeswijk, 2007; Kaspori, 2007). Otherwise, participation processes are simply an excuse, a sort of painkiller for difficult urban renewal plans, they state (Interview with Heeswijk, 2007; Kaspori, 2007).

Besides different levels on which the public can be engaged in urban planning - from simply being 
informed about a project to being allowed to co-create a project - there are of course many different forms in which participation can be practiced. SUGs are only one means of exercising public participation and a relatively new one at that. Throughout the decades that citizen participation has been placed on the agenda of planners, architects, municipalities and politicians, it has been practiced in various ways.

The Planning and Urban Design Standards handbook lists, for example, nine different forms of public participation in urban planning. Some of these are common participation methods such as surveys (either in the form of an interview or questionnaire), public meetings and public hearings (Cogan \& Cogan, 2006a, p. 62; 2006b, p. 59; Nishikawa, 2006, p. 51). Other forms of participation are less well known. As, for example, asset mapping ("identifying (...) the individual, organizational, and institutional capacity and gifts of a particular community") (Kretzmann \& McKnight, 2006, p. 53), community visioning ('creating a shared vision for the future') (Ames \& Ames, 2006, p. 55), charrettes ('a multidisciplinary team of professionals develops all elements of a plan') (National Charette Institute 2006, p. 57) ${ }^{113}$, facilitation ("designed to reach consensus through a process that includes meaningful involvement of all parties") (Whorton, 2006, p. 65) and consensus building and dispute resolution (Susskind, 2006, p. 66). ${ }^{114}$

\footnotetext{
113 Bill Lennertz gives the following explanation of the historical background and meaning of the term 'charrette': "The term 'Charrette' is derived from a French word meaning 'cart' and refers to the final intense work effort expended by art and architecture students to meet a project deadline. At the École des Beaux Arts in Paris during the 19th century, proctors circulated with carts to collect final drawings, and students would jump on the charrette with their work and frantically put finishing touches on their drawings. This intense burst of activity is similar to the atmosphere of the Charrette process" (2003, p. 12).

${ }^{114}$ Besides these handbook forms of participation, commissioners seeking the input from their community might also organize, say, a picnic, as did Broekhuizen when designing another park for a Dutch garden city (Interview with Broekhuizen, 2007).
} 
Games and playing were popular participation tools from the very beginning of public participation in urban planning. Henry Sanoff was an early advocate of games and playful activities as participatory tools in urban planning processes. He designed, for example, the 'Best Fit Slide Rule', a discussion tool to examine alternative street infill solutions and their consequences (1988, p. 35). Sanoff would also organize workshops, such as the 'House Activities' workshop, around rulebased games. The rules of the workshop are described on a leaflet: "Each player makes an alternate choice from the activities shown in the pictures below. The point value of each arrangement is displayed in the lower left hand corner of each picture. The total of the choices cannot exceed 45 POINTS" (p. 36). When a certain combination of rooms exceeds those 45 points, players have to trade off rooms and their corresponding functions until they have reached 45 points or below. This workshop was designed and used to raise awareness considering alternative house activities.

The use of computer game-based tools for public participation is a rather new phenomenon. In general, such tools, commonly referred to as Serious Games, have found their way into many professional fields and are widely used and experimented with as training and educational devices. ${ }^{115}$ The name Serious Games came into use when in 2002 the Woodrow Wilson Centre founded the Serious Games Initiative. The Serious Games Initiative is focused on the use of games "in exploring management and leadership challenges facing the public sector" (Rejeski \& Sawyer, 2002). Serious Games strive to combine the entertainment value and technological possibilities of entertainment computer games with an educational and/or political agenda. Serious Games are employed

\footnotetext{
${ }^{115}$ Besides Serious Games that have been designed to educate, inform, simulate or involve, entertainment games are also used and experimented with in classrooms and professional settings.
} 


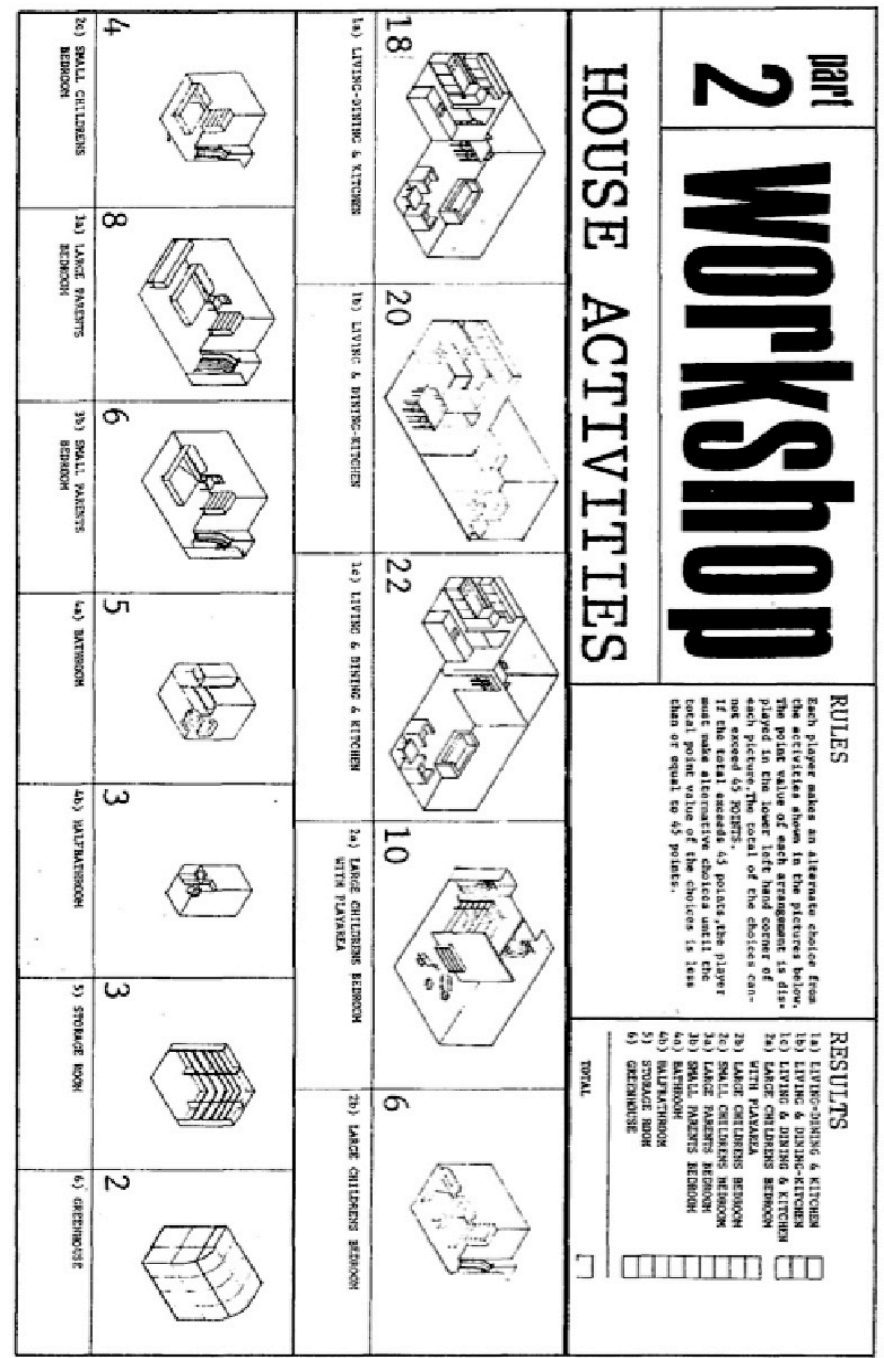

Illustration 56: An early participatory urban planning game: The House Activities Workshop (Sanoff, 1988, p. 36). 
in various areas of education and training. Bogost labels games that either support or disrupt social and cultural positions, persuasive games. ${ }^{116}$ These games are persuasive because of their "procedural rhetoric", the "practice of using processes persuasively" (2007, p. 28 ). Bogost considers the procedurality of computer games, or what I already referred to as a string of potential design actualizations, as an agent for generating political and social change.

Most urban planning projects will use a combination of different participation methods at various stages of the planning process. Face Your World, for example, combined a computer-based public participation game with surveys, workshops, public meetings and public hearings. These different forms of participation were used for different reasons. The Interactor was used to design the park. Surveys were used to get an idea of what the neighborhood residents needed, wished and hoped for in relation to the park. Public meetings and public hearings were either used to gather more data on the local wishes for the park, to educate people on what to expect from a park or to present ideas and designs for the park that people could then comment on. Each and every one of these forms of participation has certain advantages and disadvantages. Some will work well in a certain situation but might not work at all in a different situation. Combining different forms of participation seems the most effective way to actually reach different groups of citizens. None of the participation methods above is in itself successful in reaching out to a whole community.

\footnotetext{
${ }^{116}$ See the website watercoolergames.com for examples of Serious Games outside of the domain of public participation in urban planning (Bogost \& Frasca, 2007).
} 
Participation projects can be assessed in terms of their medium-specificity and the participation trajectory as a whole. Concerning the first, games used as participation tools have changed considerably over the last decades. The paper toys used by Sanoff between the sixties and eighties have been replaced by high-end computer games. There are, needless to say, both advantages and disadvantages to this change in participatory gaming from non-digital to digital. ${ }^{117}$ Kheir Al-Kodmany, professor in urban design and physical planning, identifies some important pros and cons of computer-based public participation. One advantage of digital technologies is the possibility to represent contextual data: "Computerized tools can illustrate abstract concepts, such as environmental impacts, in a way that would be impossible with traditional tools" and these tools "provide so much more specific information that can be provided on the spot, thus enabling the public to explore alternatives quickly and with more competence" (Al-Kodmany, 2006, p. 63). The Interactor makes abstract concepts related to the how and what of designing a public park 'tangible' and visible. In a digital environment such as

\footnotetext{
${ }^{117}$ In popular and scholarly debates on the (negative) influence of computer-based technologies on the practice of urban planning, Sim City takes a prominent place (Beckett, 1996; Cascio, 2004; Lobo, 2005; Lobo \& Schooler, 2004; MacIntyre, 2005; Starr, 1994; Sutherland, 2006). Critics worry about the future of urban planning when SimCity becomes the touchstone both on the technological level and on the content level. They assert that urban planning is not a game, even when the technologies used for urban planning increasingly look like SimCity (Lobo, 2005; Lobo \& Schooler, 2004). A major issue relates to ideological assumptions embedded in SimCity: "Did a conservative or a liberal determine the response to changes in tax rates in SimCity?" sociologist Paul Starr asks (1994, p. 19). However, SimCity is mainly used as a powerful and seductive metaphor in articles and news reports dealing with urban planning in the $21^{\text {st }}$ century rather than as an actual planning tool in urban design.
} 
the Interactor, one can indeed explore alternatives quickly and without lasting consequences.

A second advantage is the possibility to display information selectively: "When working on paper, even a relatively small amount of information can quickly become overwhelming and appear cluttered" (p. 63). The Interactor is first and foremost a design tool and not so much a tool for information dissemination. Therefore, we can locate this advantage on the level of design elements present in the game world. The library of the Interactor contains a standard set of 400 images from which players can pick and choose. Would one make a non-digital version of Face Your World, those 400 objects would indeed appear 'overwhelming' and 'cluttered'.

Third, the ability to navigate the geographical scale is considered an advantage because "With traditional tools, multiple maps are needed for each geographic scale: region, city, community, neighborhood, and individual lots. Computerized mapping allows for zooming in on a region, city, neighborhood, or even a specific house on a single map" (p. 63). In the Interactor, players navigate between a 'micro' level view during the sketch phase (where they work on a single picture of the neighborhood) and a more 'macro' level view of the whole park during the design phase.

Concerns Al-Kodmany raises have to do with the relation between realistic computer generated images and reality:

One drawback of computerized tools is that the images can be so realistic and persuasive that they mislead people. It has been found that computer visualization can lead to false conclusions by the public. (...) there is the danger that audiences may see a generated image as constituting reality. (...) Just as these tools can be used to create compelling representations of future urban development, they can create compelling misrepresentations as well (p. 63).

SUGs in general are rarely "so realistic and persuasive 
that they mislead people" (p. 63). With SUGs it will generally remain clear that what the player is dealing with is a ludic, artistic or architectural vision on a planning project. As Syb Groeneveld from Digitale Pioniers (digital pioneers), one of the sponsors of Face Your World, told me: "SimCity is a realistic environment in terms of design but not in terms of interaction. Face Your World is realistic in terms of interaction but not of design" (Interview with Groeneveld, 2007).

Second, the considerable "costs" involved in using these computerized visualization and simulation techniques are considered a problem (p. 63). The costs of the long and intensive participation trajectory of Face Your World are indeed high: the software development amounted to a total of $€ 180.000$ and the management of the Lab where most activities took place $€ 80.000$. SKOR, AFK, Stedelijk Museum, the ward Slotervaart, housing corporation De Alliantie and Digitale Pioniers have financed this. The high costs, the efforts involved in finding so many different financial investors, communicating with them and delivering a product that all can agree upon, makes these large-scale participation trajectories unfeasible for many cities.

Thirdly, Al-Kodmany criticizes participants' limited options for social interaction when computerbased tools are used:

In general, traditional non-computerized public participation methods are more participatory, experiential, and interactive. They provide more social interaction among participants. (...) Practical experience asserts that the added value of real-time social interaction among neighbors, while using a physical simulation game, for example, surpasses computer simulations even when they have user-friendly computer interfaces (p. 63).

Al-Kodmany is in favor of using a combination between "the social benefits of low-tech methods and the efficiency and power of high-tech methods" ( $p$. 64). Face Your World makes this combination between 
the Interactor on the one hand and meetings, workshops and social events on the other hand. The Face Your World trajectory consisted of more than a computer-based participation tool. Real-time social interaction and experimenting was amply facilitated as well.

Basically, there were three groups of participants: children enrolled in Face Your World as part of their school curriculum, neighborhood children who participated on an individual basis and adult participants. There were roughly two means of participation: computer-based and non-computerbased. Both groups of children participated mainly through the use of the Interactor. This was complemented with lessons, excursions and real-life drawing and modeling. The adults participated almost exclusively through workshops, meetings and surveys. Over the course of the seven months when Face Your World Slotervaart took place, 49 different events workshops and meetings mainly - were organized. These 49 events, except for one workshop for teenage girls, were targeted at the adult participants. The meetings and workshops each addressed a specific group of stakeholders: elderly neighborhood residents, Turkish women, Moroccan women, teenage girls and men in general. There were meetings with local citizen groups such as Sciandri (sports), De Blauwe Olifant (for children with learning and social integration difficulties), the playground organization De Wentelbaan and so on. During these events, an illustrator visualized all ideas and wishes of the neighborhood residents to guide the discussions and make suggestions more 'tangible'.

The central location for all activities was an old sporting hall - renamed Stedelijk Lab (urban lab) that was destined for demolition and stood on the very grounds where the park would be developed. The Lab was open for public on Tuesday, Wednesday and 

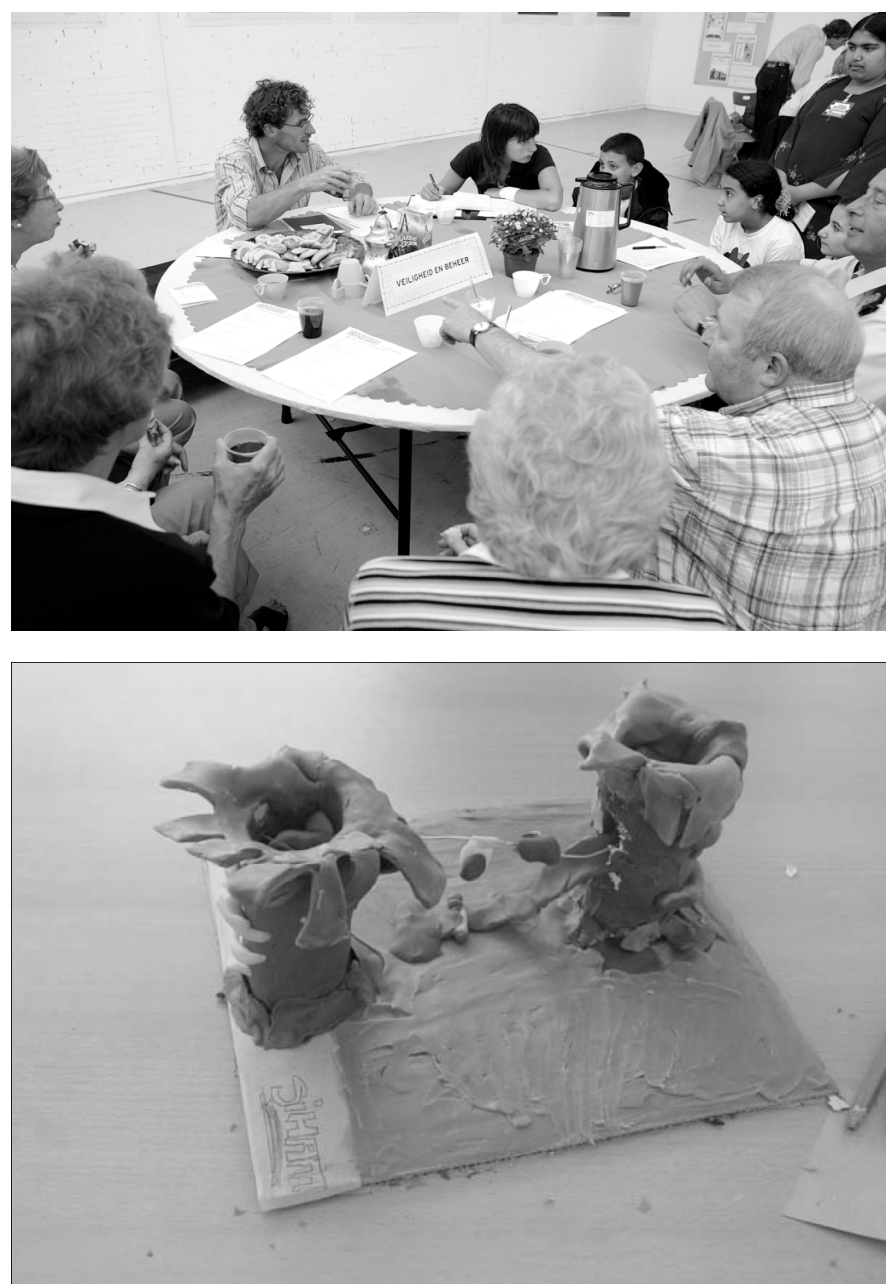

Illustrations 57 \& 58: The top image shows a meeting where different generations and ethnic groups discuss the safety and the maintenance of their future neighborhood park with Wien, project leader at the ward Slotervaart. The bottom image shows a clay model of the trees with multiple functions made by one of the participating children (both images courtesy of Van Heeswijk). 
Thursday from 14 to 18 hours. During these public hours neighborhood residents were free to walk in and make suggestions for the park (these were all noted down in a logbook) and children could come in and join in the design process. The interns managing the Lab - Irene den Hartoog and Nienke van Ankeren guided children working on the design of the park during public hours. The popularity of the Lab increased immensely among neighborhood children during the Face Your World trajectory. Not all of the children intended on working on the design of the park. Since it was the first time for the Face Your World team to be involved in such an extensive participation trajectory, they had to learn how to deal with these problems along the way (Interview with Hartoog, 2007; Heeswijk, 2007; Kaspori, 2007). Over the 26 weeks of the Face Your World trajectory, hundreds of people and children visited the Lab during public hours. To deal with the growing number of visitors, two interns joined the Lab: Maria Klaassen and Willemijn van der Sloot.

The Lab was further used on Tuesday mornings between 9:30 and 12:30 by the students from VMBO school 'Calvijn met Junior College'. The two participating classes came Tuesdays alternately. On Wednesdays between 11:30 and 14 hours the children from elementary school Professor Einsteinschool came to the Lab. It had been the intention that these children would come every other week but due to some miscommunication they showed up at the Lab weekly (Interview with Hartoog, 2007). This called for some improvisation on the part of those managing the Lab.

Combining both low- and high-tech, nondigital and digital participation tools has the advantage of including different users. SUGs appeal especially to younger people already familiar with gaming and not afraid of the technology they need to work with in order to participate. SUGs exclude mainly older people 


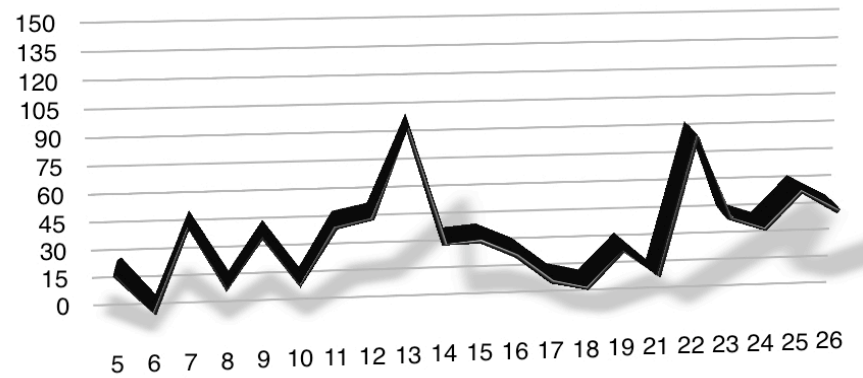

Figures 6 \& 7: Visitors at the Lab. From week 5 onwards, visitors were noted in a logbook according to age and gender. The top graph shows the increase in visitors. After the peak of 108 visitors during week 13 , access to the Lab was restricted to handle the amount of visiting children. The bottom graph shows the total amount of visitors according to age and gender. Graphs based on the Face Your World logbook.

Male

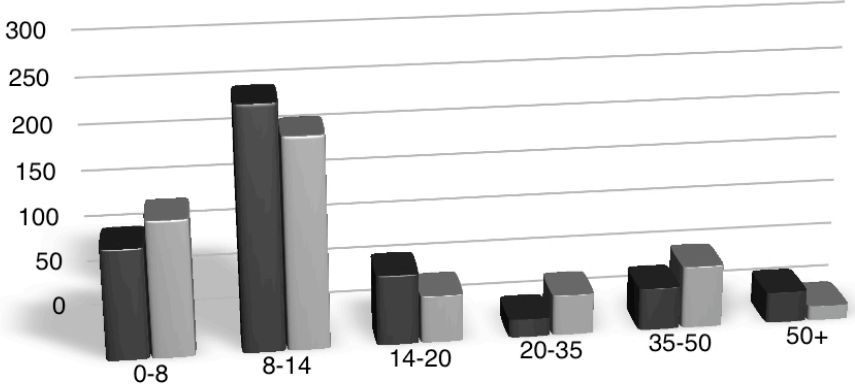


without PC or gaming experience. However, when SUGs are used in combination with non-digital forms of public participation, the group of possible participants diversifies. Children and teenagers have largely been excluded from participation in urban planning. Game-based participatory tools can enable them to become part of participation processes as well. Figure 7 shows that mainly children aged 8 to 14 visited the Lab and participated in Face Your World through the use of the Interactor. But adults were present in large numbers during those 49 activities that were organized and during the public presentations of the design. The progress made on the design of the park was presented halfway through the trajectory during a public event that attracted 600 visitors and the presentation of the final design attracted 1000 visitors.

To be sure, the digital divide is not simply a generational divide separating (grand) parents and children. Among children, boys are often more knowledgeable about and familiar with computer use in general and gaming in particular. When I asked two participants what aspect of their days spent at the Lab they liked best, the girl Khadya Abdi (14 years old) told me anything BUT the computer while the boy Hicham Amakizan (12 years old) liked working with the computers best (Interview with Abdi, 2007; Amakizan, 2007). Abdi did not like working with the computer because she has to work a lot with computers at home to do her homework. More importantly, she found the game difficult at first, especially the placing of objects from the library in the game. When she mastered the workings of the game it became more fun to use the Interactor. According to her, using the Interactor did not decide the design of the park but it did make it easier to see what you were doing and what you were creating (Interview with Abdi, 2007). Amakizan did not experience the Interactor as difficult. He had fun creating his own world and collaborating 
with other players to get new ideas. According to him, the Interactor was an essential addition to the design process because it allowed the players to shape their ideas. Playing with the game also generated new ideas because abstract things would take a concrete shape: "When someone would put, for example, a McDonald's in the game, then I would think: 'a terrace in front of the McDonald's restaurant would be nice so that people can sit outside while eating" (Interview with Amakizan, 2007). According to him, the computer made things easy. You could simply click on an object and place it in the game world. With clay you had to first make the objects (ibid). Abdi's lack of computer game experience made it hard for her to master the working of the game. Amakizan plays a lot of games at home (mostly racing games) and had an easier time learning how to play and design with the Interactor.

Al-Kodmany ends his article by stating: "these tools often fall short in allowing the participants to design and alter the representation" (2006, p. 64). In other words, players are not granted access to the design of the design tool itself. This critique is very much in line with Cascio and Turkle's comments on the black-boxed nature of simulations such as SimCity. Starr argues likewise:

The critical problem raised by simulation is the black-box nature of the models. (...) to most participants in policy debates as well as the public at large, the models are opaque. Only a few can penetrate the black box and understand what is inside (1994, p. 28).

This is true in relation to the Interactor as well. The designed core of the game and the embedded scripts were not open for redesign, centrifugal appropriation, meddling or altering. Children designed the park with the tools provided. They could not redesign or alter these tools. 
Besides the general concerns Al-Kodmany raises in relation to digital participation tools, there are some specific issues concerning the Interactor as a digital game-based participation tool that need to be addressed. These issues not so much relate to Face Your World Slotervaart but might be of importance when the Interactor will, as commissioned by SKOR, be further developed as an educational tool.

When I am researching Face Your World, the Interactor is being used in De Kunsthal in Rotterdam. The museum park of Rotterdam will be completely renovated but the different parties cannot come to an agreement. Schools can enroll their classes in an educational, three-hour session at De Kunsthal during which the children are asked to help solve this deadlock in the redesign of the museum park (Heeswijk, Kaspori, Mosterd, \& Berg, 2006-2007 weblog). The program at De Kunsthal is a very short version of Face Your World Slotervaart. First the children go outside to explore the area and discuss some aspects of what a park is or could be, then they make a pen-and-paper drawing for a new park and finally they translate this design into the Interactor.

At the museum I meet Femke Hameetman who organized to have Face Your World at De Kunsthal, Margriet Brouwer, a final-year intern in charge of the sessions with the schoolchildren and Ratna Werry and Marieke Ooms, second year interns responsible for one aspect of the educational program. All four have reservations concerning the Interactor software. Hameetman tells me that the option to click and drag ready-made objects into the digital world is too easy and attractive. Children completely fill the game world with these objects (Interview with Hameetman, 2007). Werry and Ooms both agree that the availability of the objects under-stimulates the children to actually draw and be creative with the software. Children then simply say they cannot draw and continue to use the ready- 

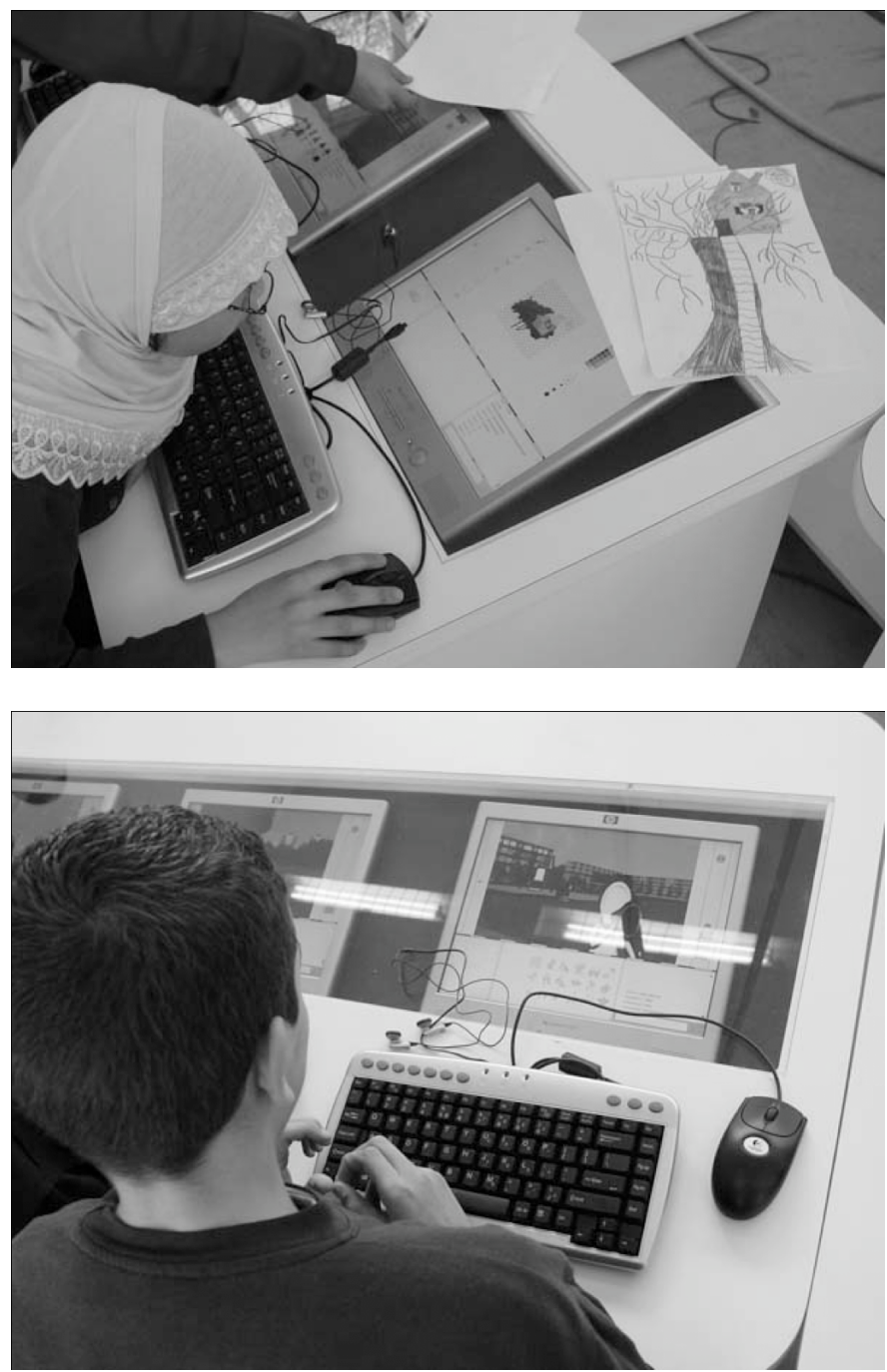

Illustrations $59 \&$ 60: These two images show children at work with the Interactor during Face Your World Slotervaart (both images courtesy of Van Heeswijk). 
made objects to fill the digital park (Interview with Ooms, 2007; Werry, 2007). This problem might be solved when children get to work beyond the sketching phase of the game (the game consists of four phases: exploration, sketching, discussion and design). But because these school classes only have three hours at De Kunsthal, they almost never get to work through the whole cycle of the Interactor. Occasionally, Brouwer can work with a really productive group through the four stages of the game but most groups do not get further than the sketching phase (Interview with Brouwer, 2007).

Werry and Ooms have also noted that the children are frustrated with various aspects of the game and its setup. The ready-made objects are too big, unrealistic and they fill the canvas too quickly. In the designing phase of the game the objects can be scaled and rotated. The game world dooms up when you run through it because the images are generated when you approach them. This is confusing to children not familiar with this aspect of computer games. They run towards a grassy field in the park and when they get there, all at once, the grassy field has filled up with statues or benches or even a large building. While some children know immediately how to make their onscreen character run through the world others are stuck in one place and become irritated and aggrieved pushing the buttons fruitlessly. The screens are embedded in a table design that is part of the Face Your World setup. The computers, on which the Interactor is installed, are placed in a square so that the players are always facing each other. The screens are lowered inside the tables so that the faces of the players are not hidden behind monitors. However, the screens are positioned in an awkward angle that catches the light in such a way that children have to hang over the screens to see anything at all (Interview with Ooms, 2007; Werry, 2007). Another problem 
related to this set-up is that there is no room around the computers where children can put their drawings. Although they are asked to retake their drawn designs for the park inside the game world, they cannot keep their drawings close by.

One important aspect of the game, the embedded chat function meant for discussing the design progress, does not work as it has been intended and projected. Everyone at De Kunsthal agrees that the chat function is a hindrance. The children do not use it for communication about the game, deliberation or consultation. The children simply shout things at each other and use the chat function for nonsense or verbal abuse. Brouwer has therefore decided to forbid the use of the chat function. It works as a negative trigger she tells me (Interview with Brouwer, 2007). The chat function posed a problem during Face Your World Slotervaart as well. Once discovered by the participating children, this chat function was readily abused and used for other purposes than communicating about the design of the park. Pressing issues concerning the design of the park were simply shouted at each other. Amakizan liked abusing the chat function at first but when things got really out of hand, he was happy they put a stop to the verbal abuse (Interview with Amakizan, 2007).

Besides these problems related to the set-up and functioning of the Interactor, the hardest part seems to be the translation of the physical park around them into a pen-and-paper design for a new park and then reworking that design inside the digital world of the Interactor. The translations from physical space to drawing and from drawing to digital world are very hard to master in a three-hour session. In the Slotervaart project, different workshops and specific educational programs had to smooth these translations. Not only need the forms and media used for public participation be assessed, so does the trajectory as a 

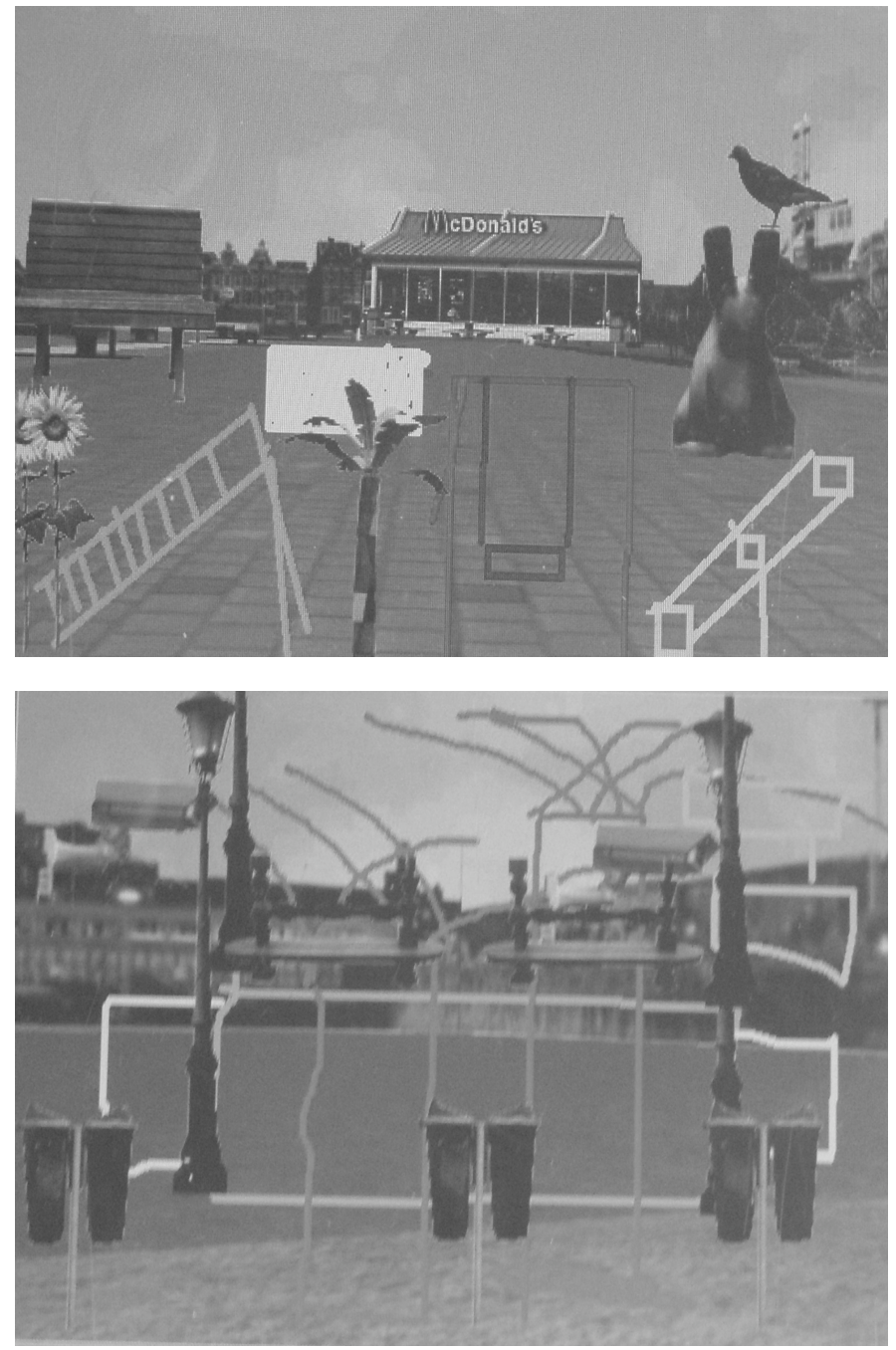

Illustrations $61 \&$ 62: These drawings made with the Interactor show the combination of and struggle with ready-made objects and drawn objects (both pictures taken at De Kunsthal by ML). 
whole. Measuring effectiveness of participation efforts is a difficult task, as risk analysts Gene Rowe and Lynn Frewer state in Evaluating Public-Participation Exercises. "The merits of participation (...) are difficult to ascertain, as there are relatively few cases in which the effectiveness of participation exercises have been studied in a structured (as opposed to highly subjective) manner" (2004, p. 512). The authors confirm that "there is a move away from an elitist model in which expert advice acts as the authoritative source for regulation" but the question "how we can be sure that 'participation' results in any improvement" remains unanswered (p. 513). Rowe and Frewer describe an agenda of sequential steps to evaluate effectiveness in a structured rather than subjective manner.

First of all, effectiveness needs to be defined in terms of process or outcome effectiveness (p. 517522). In relation to Face Your World, both process and outcome effectiveness was intended. The process had to involve neighborhood groups that were otherwise hard to engage and the ultimate design of the park had to be supported by the different age and ethnic groups in the neighborhood.

The explicit aim of Face Your World was to go beyond those participants (lead users) who have the time and interest to attend meetings and hearings and dare to speak up for themselves. I have met three times with such a lead user: Gerard Kreek. He has been living in Slotervaart for forty years and has witnessed the neighborhood change from a utopian garden city where doctors and lawyers lived side-by-side with working class families to a dilapidated, poor and economically underprivileged borough. He has for more than two decades been actively involved in local initiatives that address the living conditions in Slotervaart and citizen participation in the renewal plans for the Western garden cities. He is 75 years old 
and very knowledgeable on the subject of his neighborhood, its residents and goings-on. However, as Rob Hoogeveen, area developer for the De Alliantie, tells me, he is not representative for the neighborhood as a whole (Interview with Hoogeveen, 2007).

Concerning the effectiveness of the participation process, Face Your World did indeed involve neighborhood residents that would never be seen in the town hall during conventional meetings or hearings. However, there were some problems as well. For example, to involve both Turkish and Moroccan women, individual meetings and workshops needed to be organized because they would not attend activities together with men. Some meetings or workshops would start with a two-hour women-only session after which the men were welcome as well. This offended some men who felt discriminated against and refused to further participate in Face Your World (Interview with Kreek, 2007). Both those working at the ward and the city council questioned this measure (Interview with Hoeve, 2007). Kreek tells me that many senior white neighborhood residents felt left out from the participation process in general because they felt it was targeted mainly at immigrant neighborhood residents (Interview with Kreek, 2007). Consequently, the design of the park does not very much appeal to him. From his point of view, the preset goal to engage those otherwise excluded from participation processes was too successful and the intent to design a park that would be supported by the whole neighborhood not successful enough (ibid). Van Heeswijk explains that such a radical participation project as Face Your World, which gives a voice to those otherwise unheard, is a learning process for all those involved (Interview with Heeswijk, 2007). She understands that it must have been difficult for people who are used to be the norm, the standard to become, in such a process, one of many voices (ibid). 
There are two sides to the outcome effectiveness of Face Your World: the design of the park and the actual construction of the park. The park of 13.500 square meters is designed to appeal to different projected users. There is a sports field that can be used for football, basketball, theatre plays and markets, a play area for little children with a slide and swings, a secluded area for teenage girls and benches for elderly people or parents accompanying their children. The ultimate design tries to cater to as many wishes of the park's future users as possible. One of the critiques on the definitive design for the park is that it is too conventional, standard and uninspired (Interview with Broekhuizen, 2007; Hoogeveen, 2007; Lentz, 2007). It is a design based on compromises and as such not an inventive or challenging design. The uniqueness of the park lies in its details, a colorful fountain, a lowered area where teenage girls can talk and hang out, the trees with their multiple functions and so on. As said, three of these special elements fall outside of the budgetary limitations of the ward. Meaning that it is not certain that these elements will be realized. Compromise-based and co-designed plans will easily turn into detail-based designs because that is a practical way to tackle and integrate various and diverging wishes into one and the same design. Moreover, the working of the Interactor as a participation and design tool was detail-based. One cannot have 50 or even more different children working on the same canvas, deleting each other's work and overwriting it with their own ideas. In order to steer the participation between the children and at the same time guide the design of the park, the children focused on details and certain parts of the park rather than the overall design.

The construction of the park should have started in 2006 and have been finished in 2007 . However, the construction of the park has been postponed till 2010. Wien explains that a school from 
the region was looking for housing. The school building that had to be demolished in order to build the park was suited for this school. 'It is impossible to deny a request from a school to be temporally housed in a building that is still useable' (Interview with Wien, 2007). For the neighborhood children and citizens who contributed to the design of the park, the gap between participation and realization is rather long. Abdi told me we would not find her in the park because she is growing older and less interested in hanging out in a park (Interview with Abdi, 2007). What Wien and his team at the ward feared, that this intensive participation project would widen the gap between ward and citizens instead of closing it, became reality although in a different way then he could have foreseen. Many of the neighborhood citizens feel betrayed by the ward and the Face Your World team that after all this energy they put into the park, there is still no sign of it. The Face Your World team works hard to keep the Slotervaart residents involved in their neighborhood in a positive and constructive way. They engage them in the design of the special elements for the park, organize discussions and meetings and they still have an office close to where the Lab used to be which is open to the general public.

The postponed realization of the park illustrates Anique Hommels' theory concerning the obduracy of cities. ${ }^{118}$ In Unbuilding Cities, Hommels

\footnotetext{
118 Bijker has also discussed the obduracy of technological artifacts. According to Bijker, the impact of technology on society can be conceptualized through the hardness or obduracy of technology, a technological artifact or a technological frame. One can either experience closed-in hardness when having "a high inclusion in the associated technological frame" or closing-out obduracy when having a 'low inclusion in the technological frame' (2001, p. 15526). To be sure, technological artifacts or a technological frame will have "different shades of obduracy for actors with different degrees of inclusion" (1995, p. 285). Actors can go from experiencing closing-out obduracy (for example when not having a car in Los Angeles and simply having no choice but to take public transport, walk or bike) to closed-in hardness (when having been able to buy a car). When "the boundary of a technological frame is passed, the character of this
} 
discusses the "confrontation between ongoing attempts to change cities (...) and the obduracy of existing urban structures" (2005, p. 7). Slotervaart has been for years now and undoubtedly for many more years to come, "subjected to "unbuilding activities" (p. 11). Often, the "stakes are so high that years of planning, debate, and controversy may result in no changes at all” (p. 7).

Returning to Rowe \& Frewer, effectiveness needs to be operationalized (for example through participant interviews and questionnaires) so that the extent to which the effectiveness is achieved can be measured (2004, p. 542-548). At the presentation of the design of the park, people could fill in a questionnaire concerning the design of the park. Also, Den Hartoog asked the participating children at the end of the project to write about their experiences with Face Your World. The results of this evaluation then need to be interpreted (p. 548-552). Although some data has been accumulated on the process and outcome effectiveness of Face Your World, this has not led to a structured assessment of the successes and failures of the project.

Daniel Fiorino from the U.S. Environmental Protection Agency provides us with four other "criteria for evaluating institutional mechanism as democratic processes" (1990, p. 229). First of all, direct participation of amateurs (and not only of citizens in their role as professional) in decision-making should be allowed (p. 229). Concerning the two SUGs discussed here, we can deduct some interesting differences. Since The Harbour Game was a confrontational game, the players were all professionals. The makers of the game wanted to show these professionals the importance of

obduracy changes fundamentally" (p. 285). As an actor in the technological frame of motorism in Los Angeles the change from being car-less to owning a car also means a change from experiencing this obduracy as inflexibly and as a mechanism of closing-out to experiencing the differentiation within that obduracy. 
public participation in large scale urban planning projects. Face Your World on the other hand involved children and adult amateurs in the design process, collaborated with citizens in their professional roles (through local organizations for example) and consulted many interest groups (for Turkish education and sport facilities in the neighborhood for example).

Second, Fiorino stresses that the level of participation should be more than "therapeutic, oppositional, or pleading" but should allow citizens instead to share in decision authority and policymaking (p. 229). The Harbour Game was an oppositional game and as such did not succeed in allowing citizens to codetermine policy. But then again, that was not the initial goal of the makers of The Harbour Game. As said, the makers of Face Your World had on beforehand negotiated that the results of their project would be implemented to avoid being merely a therapeutic participation project.

The third and fourth criteria by Fiorino are connected. He states that the structure of participation should allow for face-to-face discussion over some period of time and citizens should be offered the opportunity to participate on the basis of equality with both administrative officials and technical experts (p. 229-230). The Harbour Game was created exactly because both things had been lacking in the creation of the plans to change the harbor of Århus. The game did not succeed in overcoming these two points because it was created and used as an 'educational' game for professionals. Although face-to-face discussion was facilitated over the course of the day when The Harbour Game was played, this discussion took mainly place among the participating experts. The public, consisting mainly of experts but also of a group of interested citizens of Århus, did not engage in this discussion although this had been intended by the organizers (Interview with Delman et al., 2007). Face 
Your World provided ample time for face-to-face discussion during its many workshops, meetings, presentations and the Lab's public hours. During many of these face-to-face sessions, experts in urban planning, architecture and park design as well as policy-makers from the ward Slotervaart and the housing corporation De Alliantie were present.

Besides questions on the effectiveness of citizen participation in urban planning, there is also the issue of democracy and empowerment. Certain participatory tools are therapeutic rather than empowering, others might, albeit unintentionally, create a divide between those having access to the participation tool and those not, or the tool itself might be ingrained with specific biases that will exclude certain users from taking part in the participatory project. ${ }^{119}$ And there are of course always people who cannot or will not participate: the non-users or nonparticipants. Hans Harbers argues for example in Politics of Technology that not everyone wants to participate in direct democracy exercises (1996, p. 313). In a representational democracy people have voted for professional representatives and should thus be exempted from having to spend time and energy on familiarizing themselves with the issues at stake ( $\mathrm{p}$. 313). Harbers argues that consulting the public is not necessarily a sign of democracy, it might just as well be a sign of political incompetence (p. 314). ${ }^{120}$ Whatever the case, non-users - either by choice or by other forms of exclusion - should be taken serious in public participation efforts. As Wyatt ascertains, not

\footnotetext{
${ }^{119}$ For a literature overview and an analysis on how GIS (geographic information system) was shaped through societal and technological influences in such a way that GIS as a participatory tool 'represents certain groups poorly', see Nancy Obermeyer (1998, p. 65).

${ }_{120}$ See Joseph Wachelder Democratizing Science: Various Routes and Visions of Dutch Science Shops (2003) for more information on participation and democracy.
} 
only "the powerful actors" should be followed but the non-actors as well (2003, p. 78).

\section{PURPOSEFUL PLAY}

Not only needs the participation project Face Your World be assessed from the perspective of public participation in urban planning, for our case it is important to look at what happens, in terms of playability, within a geography of Serious play. For this, the core/periphery model of differentiation will be used to analyze the Interactor.

Face Your World is a mixed media participation trajectory with the Interactor, a photorealistic 3D design software application, at its core. The Interactor is created for children aged 8 to 12 . The Interactor software is a game-like environment that guides the players through the different stages of a design process: exploration, sketching, discussion and designing. Throughout the process of playing with the Interactor, the participating children were 'guided by a group of experts in the fields of urban planning, design and landscape architecture' (Heeswijk, Kaspori, \& Mosterd, 2005-2006 weblog). The computers on which the Interactor was played were installed in the Stedelijk Lab.

Serious Games, persuasive games or Serious Urban Games might stretch an essentialist's definition of 'play' or 'game'. There are, for example, no winners or losers amongst the users of the Interactor, no handbook explaining complex rules, no increasing levels of difficulty and no 'boss fights'. ${ }^{121}$ However,

\footnotetext{
${ }^{121}$ A boss fight is a type of battle in a computer game against a powerful enemy. Typically, boss fights take place at the end of a game level and the
} 
some distinctive game-like features characterize the Interactor. Within a rule-based, programmed and designed environment, players are represented by an onscreen character and encouraged to explore, build and construct. They can 'drag and drop', 'pick and choose' from the extensive library and add their usergenerated content to this library. The basic rule of the Interactor is that players have to participate, communicate, cooperate and collaborate if they want to make progress. The four phases of the game do represent to a certain extent levels, although these levels do not demand an ever-increasing finger twitching and button pressing capacity of the player but accumulating insight into urban planning and design. Although not all the mechanisms or ingredients of an essentialist definition of entertainment games are present in the Interactor, the software is built upon a game-like engine and looks and operates like many entertainment games. Furthermore, it knows implicit (e.g. courtesy towards other players) and explicit (e.g. design a park that is supported by the whole neighborhood, cooperate with other participants) rules, it involves many different 'players', it is progressive and invites the children, to a certain extent, to roleplay.

During the first phase of the Interactor, children enter their digitalized neighborhood and start exploring the controls of the game. They are represented in the game by a standard onscreen character. A picture of the player's face can be mounted on this standard onscreen character.

When the participants have familiarized themselves with the workings of the Interactor, they are asked to take a picture in the game of the area they would like to work on. This picture serves as their 
canvas on which they can experiment, explore their ideas and try out different solutions. In this second stage of the game - the sketching phase - children work individually. They can draw on their picture and add objects from the library to this sketch. This library consists of more than 400 digital pictures categorized as nature, people, animals, buildings, vehicles, street furniture, logos, ground and miscellaneous. Importantly, children can also add elements to this library. They can take pictures of real-life objects they find important and add these to the library. They can design objects themselves within the game or alter existing objects from the library. During Face Your World Slotervaart 1207 objects were added to the standard library consisting of original drawings, adaptations of existing objects and pictures taken by the children of their neighborhood. Through this feature, children can, to a certain extent, add to the facilitated core of the geography of Serious play. In adding items to the library, children expand the tools with which they can design the park. This form of fast centripetal appropriation whereby objects made in the periphery become part of the core is a way in which the participants can co-configure the user, can codetermine the designed artifact and their own tools for participation and design. The children participating in Face Your World Slotervaart made a total of 1216 sketches in this phase of the planning project and Kaspori considers this the most creative phase of the process (Interview with Kaspori, 2007).

Third, children discuss each other's sketches, vote for the best sketch and write down why they have voted for that particular sketch. Lastly, children enter the multi-player mode and have to start designing. The designing phase is directed at cooperation between the children, they have to agree on how to design the park and work together to realize their ideas (Interview with Heeswijk, 2007). In this fourth phase, the objects from 

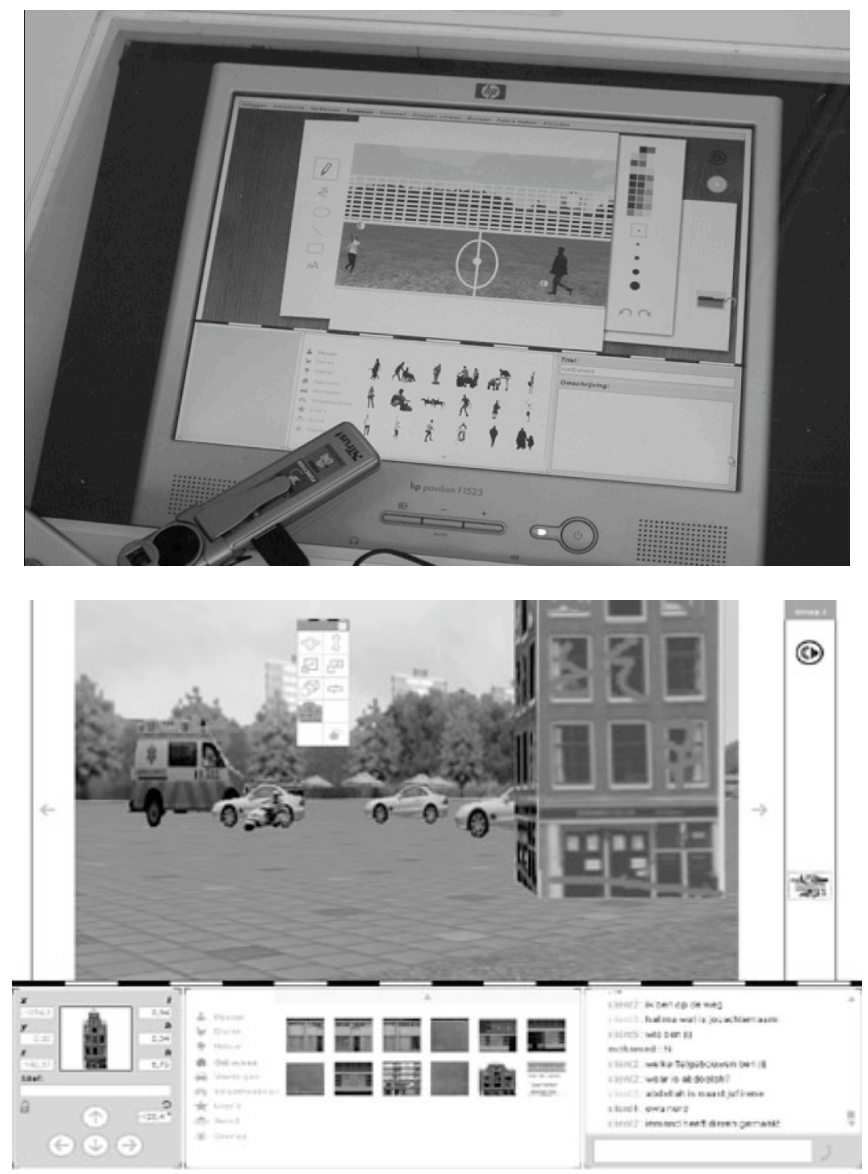

Illustrations 63 \& 64: The top image shows the Interactor during the sketching phase. At the left and right side of the picture on the monitor we see tools and colors for manipulations and sketching. The digital camera at the children's' disposal is seen at the bottom (image courtesy of Van Heeswijk). The second image is a screenshot of the designing phase of the Interactor. We see in the left-hand corner the controls to rotate and scale objects, in the middle we see the library and on the right-hand we see the chat screen (Heeswijk et al., 2005-2006 weblog). 
the library can be scaled and rotated and the objects that were added to the library by the participants, can be used. To realize their ideas, players need to communicate and cooperate. The discussion option of the game is facilitated through a chat function. But in practice, children will also communicate verbally about what is going on in the game.

The core of the Interactor is shaped by the design of the game in combination with the discourse on the game. The Interactor facilitates experimenting with design options for a public park. This experimentation is guided by elements such as the size of the game canvas, the objects in the library, the embedded tools for manipulation and personal design, the municipal restrictions and requirements for the park. Besides these design characteristics of the Interactor, the discourse surrounding Face Your World influenced how the children would use the Interactor. The meetings, workshops, excursions, specialists and experts who guided the children in the design process shaped this discourse. For example, what sorts of images were shown to the children during the workshops or what types of parks were visited during the excursions and served as good or bad examples of public parks? Broekhuizen hinted in the interview that the discourse communicated to the participating children (e.g. through showing them specific pictures of parks and not others) was rather biased (Interview with Broekhuizen, 2007).

The important question is what happens with or to the periphery of a geography of Serious play. The Face Your World team was relying heavily on divergent activities, on unforeseen design solutions and creative input from the participating children. Kaspori considers Face Your World Slotervaart a success because he could never have come up with this particular design himself (Interview with Kaspori, 2007). When a game becomes Serious and its aim lies 
outside of the realm of entertainment, the periphery becomes highly important and looses part of its autonomy and inconsequentiality. Designing a park was the ultimate goal of Face Your World and deviating from that goal was therefore not an option. The Sims fans might come up with outrageous and unforeseen additions to the game, as long as they are commercially feasible, sustain the brand and work with and not against the user communities, they are applauded and welcomed. Participants of Face Your World see these freedoms restricted by the goal of designing a park that will have to be supported by the various age and ethnic groups in the community, the preset conditions of the municipality and the design tools they are offered to work with. Much of the basic layout (green, entryways, pathways) of the park was already determined in the municipal list of requirements for the park. Inside these predetermined parameters the area for both facilitated and peripheral play activities and traffic between the two areas was limited.

Within SUGs, participation between the players, the many-to-many culture, is not an anticipated and hoped for or carefully orchestrated and sustained effect of a successful game, as in entertainment computer games for example, but the very raison d'être of these games. As such, it moves from the periphery to the core. Participation and 'by us for us' activities transforms from divergent player behavior in the periphery of a 'healthy' geography of play to an embedded and facilitated core activity. The Interactor is about creating and designing a park together - for 'us' and by 'us'. The previous chapters indicated the increasing tendency of both toy and computer game companies to tap into the many-tomany community and commodify divergent player activities. In Serious geographies of play, the many-tomany culture and its activities are not so much 
commodified as they are instrumentalized: the manyto-many paradigm is facilitated in the core and its results are put to use.

Because of this purposefulness of SUGs, their instrumental character and nature, the periphery shrinks and the core is relatively large and takes up most of the geography. The shrinking periphery in the geography of Serious play looses both its ludic inconsequentiality and autonomy and its relative power over the core. The outcome of public participation projects is of such importance to so many different stakeholders that there is little room for divergent play activities. Peripheral activities will only be incorporated within the core when useful to the projected outcome of Serious play. As such, the core of the geography of Serious play is a strong and coercive one, as in Strassoldo's first model of core/periphery relations (1980, p. 39). In this model, 'commands flow from the centre to the periphery' (in the form of the preset process and outcome effectiveness of Face Your World) 'while information travels in the reverse direction' (the neighborhood's wishes, hopes and ideas for the park as well as the objects added to the library by the participating children) (p. 39).

In this there is an interesting parallel to draw between garden cities and Face Your World. Both are designed to solve urban problems. While the historical garden city was an attempt at solving problems of urbanization (such as population density and pollution), Face Your World was organized as an attempt to solve some of the problems that pester contemporary garden cities (such as dilapidated public spaces and feelings of threat in these public spaces). Both adhere to a strong core. Garden cities are often mistaken for yet another form of suburbanization, but they are, as historian of science and technology Lewis Mumford stresses, "the antithesis of a suburb" (1965, p. 35). Howard did not want to "break down the dis- 


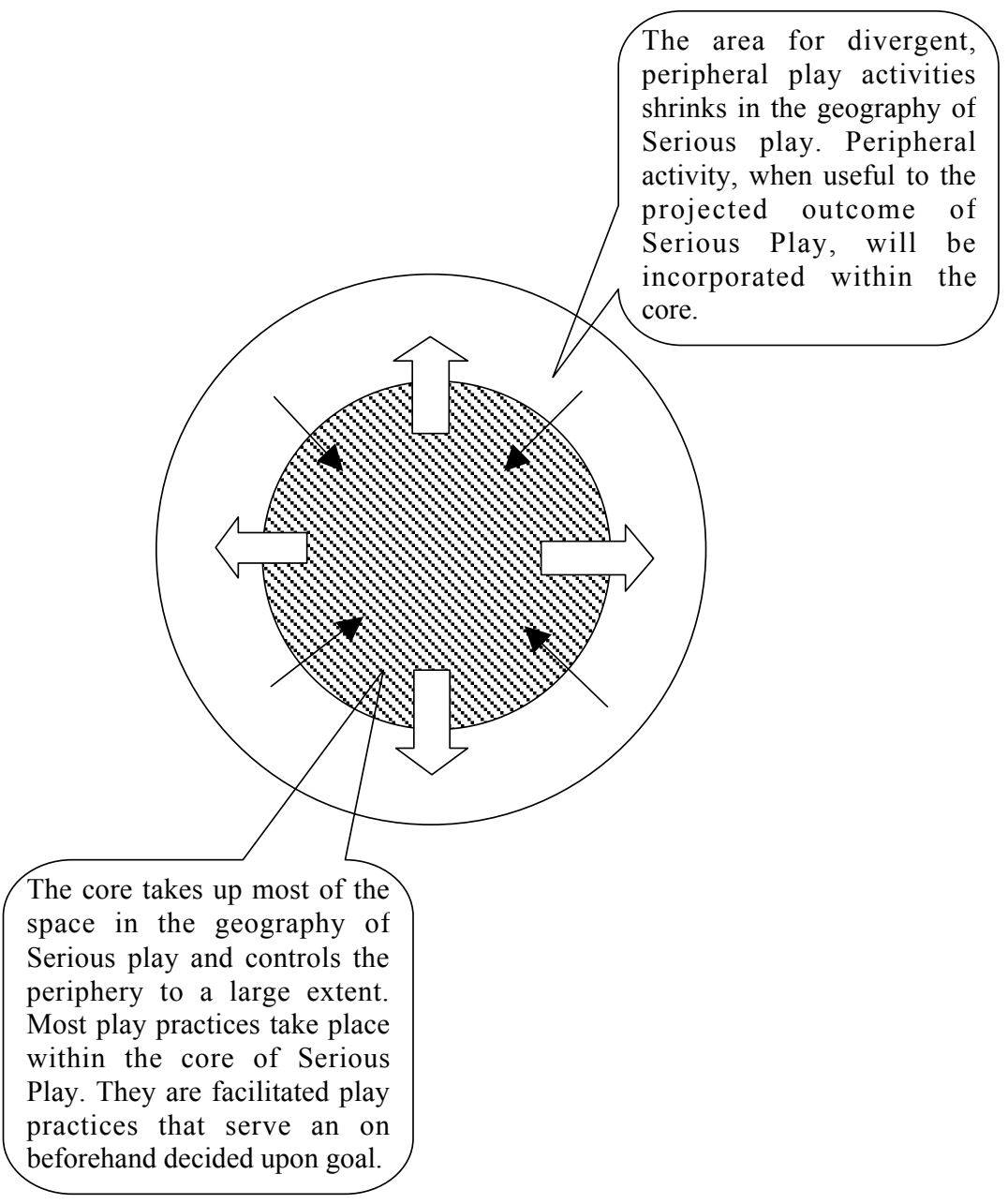

Figure 8: Geography of Serious play with a small periphery and an outsized core. 'Commands' travel from the core into the periphery and information travels from the periphery into the core. 
tinctions of town and country, turning them into an amorphous suburban mass' (p. 34). On the contrary, the garden city "is a rather compact, rigorously confined urban grouping" (p. 34). Likewise, the geography of Serious play is compact and rigorously confined because the outcome of play is anything but trivial or ludic but highly significant and serious in terms of individual careers, financial commitments and stakeholder relationships. Within the geography of Serious play, both core and peripheral play practices are closely monitored and studied.

In the shrinking periphery of Serious play, the space for playing against the design or designers decreases. The game facilitates the playing with the design. Anarchistic play practices are neither facilitated (although this might sound like an oxymoron, computer game companies will often facilitate anarchistic play) nor does the periphery provide enough space for players to manifest such practices of play. ${ }^{122}$ The option to add objects to the library of the Interactor is the only way in which users can appropriate this designed artifact.

We have seen in relation to the many-to-many model in geographies of entertainment play how the periphery gains in importance while at the same time losing some of its autonomy. With SUGs that are created and used for public participation and public codesign in urban planning, the stakes are high and the outcome of the interplay between core and periphery loses its ludic inconsequentiality. As such, the nature and goal of traffic between core and periphery changes from commercial success, strong brand image and vital user communities in entertainment games to trust- and community building, education and design in SUGs.

\footnotetext{
${ }^{122}$ An interesting example in this case is the hacking function that was programmed in the Enter the Matrix (2003) game. Hacking this game is not a subversive, anarchistic ploy because the designers have embedded the hacking function in the code of the game.
} 
SUGs push the masking of work as play (De Certeau's upended perruque) further because play becomes utilitarian, purposeful and outcome-oriented. SUGs take the many-to-many model to the streets and maximize the tapping into the can culture of users.

This brings about changes for both players (who are now playing 'for real' and involved in Serious play) and designers (who need to examine play practices in order to generate useful content). Both these stakeholder positions change within a Serious geography and both parties will need to readjust to these changes. Broekhuizen, for example, had a hard time adjusting to the fact that his role and function changed from the one designing the park to the one monitoring children designing the park (Interview with Broekhuizen, 2007; Hoeve, 2007).

In chapter three we saw how in the geography of LEGO play not only play practices were on the move between core and periphery but also types of players. While in the LEGO geography adults are becoming more important, in the Serious geography, children can become lead users. Since SUGs are participatory games meant to engage citizens in urban (re-) development, it is difficult to speak about lead users. The goal of SUGs is to involve exactly those users who are otherwise and commonly left out. However, the school classes participating in Face Your World as part of their school curriculum formed the core group of participants. They used the Interactor most often and they had to incorporate the wishes, ideas and suggestions of other children and adults that came up during public hours or special activities, into their design. By appointing children as mediators between the neighborhood's wishes and the actual design of the park, these children became in a way lead-users. While the LEGO Company increasingly turns towards adult fans for product development and brand support, policy makers and urban planners 
sometimes turn toward children for urban (re-) design and community building. Face Your World as a participation process tapped into the can culture of children.

\section{SERIOUS GEOGRAPHIES OF PLAY}

This chapter has served a double purpose. On the one hand it has addressed, through the analysis of a SUG by means of the core/periphery model of differentiation, characteristics of geographies of Serious play. On the other hand, it has lifted the many-to-many approach outside of the context of entertainment games. This chapter has taken one 'Serious' field in which the many-to-many approach is utilized as its main focus: public participation in urban planning. More specifically, this chapter has looked into computer game-based approaches to public participation in urban planning. The attractions of new media tools and their many-to-many potentials are manifold and their application has been steadily increasing. By zooming in on the large-scale participation trajectory Face Your World, this chapter has taken a closer look at some of the advantages and disadvantages of SUGs and addressed aspects of the nature, characteristics, mechanisms and problems of the many-to-many paradigm.

With SUGs, crucial aspects of a 'healthy' geography of play, such as a vibrant and expansive periphery for divergent play, easy transfer between core and periphery of play, a certain amount of influence of the periphery over the core, the triviality or purposelessness of the ludic, are compromised. With the increasing commodification of the many-to-many 
model within toy- and game industry, we have seen how the periphery at once gains in influence over the core and looses in autonomy. The fact that SUGs are Serious further erodes the autonomy of the periphery without increasing its influence over the core. The core takes up most of the space within the geography of Serious play because the outcome of playing these games will be put to use. The many-to-many culture is not commodified so much as instrumentalized in this Serious context.

Public participation in urban planning through game-based new media applications intends to maximize the many-to-many approach. In the previous two chapters we have seen how players increasingly become (co-) producers and (co-) designers of the next consumer product, thereby partaking in the cycle of production $>$ marketing $>$ consumption on various levels and at different stages. With SUGs, players become (co-) producers and (co-) designers of their neighborhood and built environment. Through SUGs, players can enter the cycle of policy-making >design> implementation. SUGs are intended to open not only the black-boxed, obdurate city but also the equally black-boxed processes of policy-making. However, as we have seen, SUGs are themselves black-boxed systems in that they do not facilitate the participating public to design their own tools for urban (re-) design.

From assessing Face Your World along the lines of the media and tools used for public participation and the participation trajectory as a whole, we have been able to identify what makes this project unique and successful. Both the intended process (involving remote stakeholders) and outcome (community supported park design) effectiveness were realized in as far as they were within the control of the Face Your World team. The participation trajectory was designed to involve different ethnic communities and different age groups, to go beyond tapping into 
lead user knowledge. Indeed, many people participated who would never have been found in the city hall during a conventional meeting or hearing on urban renewal plans for Slotervaart. The outcome is the design of a neighborhood park supported by the ethnically diverse residents of Slotervaart that contains their wishes and requests (e.g. a fence around the park, benches, a picnic area). The different forms of participation and media (non-digital and digital) that were used explain, in part, this success.

In considering a participation project such as Face Your World in the context of democratizing participation and policy-making, it is important to keep the intended effectiveness in mind. Process (involving remote stakeholders) and outcome (community supported park design) effectiveness of Face Your World were decided before the neighborhood residents became involved. Participation thus fell within these parameters or boundaries. The suggestion of many teenage girls to build a shopping mall on the piece of land that would be made available for the park, was therefore not a feasible option nor a suggestion the Face Your World team could act upon (Interview with Hartoog, 2007; Heeswijk, 2007). Nevertheless, within the given parameters of participation and the intended process and outcome effectiveness, Face Your World can be considered as a process that effectively democratizes a particular aspect of the design phase of an urban renewal plan. Remote stakeholders in general and children in particular were given the chance to become part of urban redevelopment plans. Kaspori made the final drawing of the park but he did not alter or translate the design made by the children with the Interactor (Interview with Kaspori, 2007).

In the same sense that the many-to-many approach within consumerist practices is not the ultimate empowerment of the consumer because power is in the hands of the companies who choose to blur the 
lines between player, consumer and producer and to tap into the user-driven can culture; the many-to-many approach within policy-making is not to the ultimate form of e-democracy. The largest chunk of power is in the hands of those designing policies and tools for exercising e-democracy and deciding when, under what terms and conditions and in which format to involve the public. However, in consumerist and participative practices, a window of opportunity for making-do opens when stakeholder positions implode and users are invited to partake in the design of consumer goods or urban renewal plans.

The shift within this chapter from entertainment toys and play to Serious games and play alerts us to $21^{\text {st }}$ century aspects of the interaction between the individual and the processes of commodification, domestication and urbanization. The attractions of the many-to-many model reach far beyond the world of computer games. This model of user-involvement that has been so successfully used within many commercial domains, has caught the attention from and been experimented with by more 'Serious' domains such as journalism, politics and policy-making.

Face Your World literally takes the many-tomany approach to the streets and utilizes it to facilitate public participation in the design of a new neighborhood park. Although Face Your World took children out of their private rooms and private homes, the goal was the very domestication of the outdoors through the design of a neighborhood park with safe and child-friendly play facilities. Through participating in Face Your World by means of the Interactor, the city or outside world was presented to the children in a containable version emptied of all the real life problems pestering the neighborhood. For once, their neighborhood was tamed and domesticated and could be manipulated. Also, it gave children a 'passport' into 
their neighborhood. They had to make pictures and talk to local residents, they had to take stock and gather information for their project.

In general, this game mediates, as did the construction toy towns and SimCity, between the city and the child. It actively attempted at reestablishing a working community and a positive relationship between city and citizen through the participation in the design of a new neighborhood park. More specifically, SUGs mediate between urban change or unbuilding practices and the public. SUGs are aimed at generating discussion, (re-) creating relationships, generate a common purpose amongst neighborhood inhabitants and re-establish some of the social glue that has been lost in ever-expanding urban areas. ${ }^{123}$ Historically, the city was the core, the rural area the periphery. With the increase in suburbanization in the course of the second half of the $19^{\text {th }}$ century, we see a shift in the relationship between the city as core and what constitutes the periphery to that core. Would rural areas constitute the periphery of the early urban centers, the suburb becomes the $19^{\text {th }}$ century periphery of the city. The white-collar, middle class families who had first inhabited the city or the core would leave and settle in the suburb. Immigrants and newcomers from rural areas would settle in the city (Wade, 1971, p. 7576). Gradually, the suburb became the periphery and then, when both urbanization and suburbanization increased, many built environments lost all reference to either core or periphery. Los Angeles, Tokyo, Mexico City and Sao Paolo are notable examples of the resulting urban sprawl. Public participation projects such as Face Your World try to reestablish a meaningful relationship between city and citizen through the creation of a core within urban sprawl.

${ }^{123}$ In 2008, more than half of the world's population (3.3 billion people) will be living in urban areas the United Nations Population Fund reports (UNFPA, 2007). 


\section{Changing Geographies of Play}

This thesis deals with the changing and shifting places of play. The example of the Blacksmith Shop indicated this change and shift within the realm of the circuit of capital. Players increasingly become (co-) designers and (co-) producers and are far more than passive consumers of commodities. The example of a child's media-saturated bedroom indicated the tensions between domestication and urbanization in (contemporary) child rearing. Even when the place of play is the bedroom, this 'sanctuary' is 'perverted' through the advent of Internet connections accessible from within the child's private room. The manner in which the many-to-many model under sway of technological innovations produces changes within the world of toys and playing and the mechanisms of user- 
involvement at work within this model have been analyzed in the context of the changing and shifting place of play. The nature, characteristics, mechanisms and problems of the many-to-many model are acutely visible and manifested within the world of toys and playing but are by no means restricted to this domain. The manner in which the many-to-many model produces changes within the world of toys and playing and the mechanisms of user-involvement at work have been analyzed within the historically changing context of commodification, domestication and urbanization. A historiographical perspective on the complex interplay between societal processes, technological innovations, toys and players shows the many-to-many model at work and on the move, its up rise, manifestations and ways of involving users. In the context of commodification, domestication and urbanization, new technological artifacts are introduced, consumed, domesticated, modified, appropriated and resisted. The core/periphery model of differentiation has been used to bring characteristics, mechanisms and problems of the many-to-many model within geographies of play to the forefront.

\section{MEDIATORS, MIRRORS \& MOTORS}

Toys and playing are taken to be central forces in bridging societal processes on the one hand and the individual on the other hand. Toys are as such considered to function as mediators, mirrors and motors. In their role and function as intermediaries, toys are often at the heart of anxieties, fears, longings and battles. Toys are sites where crucial battles concerning a changing society and the changing place 
of children within that society are being fought. Toys are not only intermediaries but also 'generationshapers'. They can create connections as well as disconnections between different generations. Computer games, for example, strongly divide generations between gamers and non-gamers.

The first chapter of this thesis "New Toys, Different Children" laid the historical groundwork for the notion of toys as mediators, mirrors and motors. From the mid $19^{\text {th }}$ century onwards the way toys are produced and consumed, the scale and variety of this production and consumption, the way in which society looks upon children and the function of toys in the lives of these children, transforms drastically. The processes of commodification, domestication and urbanization are exemplary processes illustrating how societal shifts and the changing world of toys coevolve, mirror each other and/or resist one another. We have seen how toys mirror and stimulate the up and coming consumerist society, how toys answer to the need for domestication of child and play while reinforcing it at the very same time, how they distance children from the urbanized landscape while mimicking it in their designs. The interplay between societal processes, toys and children in the second half of the $19^{\text {th }}$ and first decades of the $20^{\text {th }}$ century has been understood within the framework of the construction of the Innocent Child and the increasingly diverging (play) paths of boys and girls.

From the mid $19^{\text {th }}$ to the early $20^{\text {th }}$ century, Western consumer culture facilitated the design, development, marketing and selling of diverse toys on a larger scale than witnessed ever before. Toys mirrored the changing Industrial world and brought these changes into the private home and into the lives of children. The family home was the new prime location for the wealthier children to play. The outdoors was no longer considered to be a safe 
playground. Domestication of children and play necessitated indoor toys, toys that would keep children occupied safely indoors. However, many of the children living in the $19^{\text {th }}$ century industrialized cities did not enjoy such upper- and middle class privileges. Children from the working- and lower classes would often work in the factories producing the new commodities. Living in small quarters and sharing the available space with family and lodgers, they would turn to the streets. Saving these children became a late $19^{\text {th }}$, early $20^{\text {th }}$ century effort that crystallized in, among many things, the building of playgrounds in urban and industrial areas.

The interplay between the societal processes of commodification, domestication and urbanization, toys and children changed over the course of the $20^{\text {th }}$ and $21^{\text {st }}$ century. Certain tensions, anxieties and fears still resonate today and are to be found, for example, in debates on the effects of playing computer games where issues of consumerism and over-domestication feature prominently.

The postwar period sees the maturing of commercialism, the suburban obsession with the private sphere and the increasing fear for the world outside of that private (suburban) home. The $19^{\text {th }}$ century department stores were class-conscious but with the Americanization of consumption and the economic growth after the Second World War, Western countries witnessed an unknown prosperity down to the working classes. Part and parcel of the postwar maturing consumerism was a strong emphasis on the domestic realm. The mid $19^{\text {th }}$ and early $20^{\text {th }}$ century guidebooks on housekeeping called for the separation of child and adult both in architectural layout of the private home and the upbringing of children. The postwar family home put the child and play (for children as well as for adults) front center in the recreation area and the open plan living room. 
The relatively cheap, easy to clean, durable, colorful and standardized plastic LEGO bricks discussed in chapter three epitomized the postwar vogue of indoor plastic products. The (sub-) urban and domestic designs the early LEGO sets reflected the sanctity of the private suburban home of the 1950s nuclear family. LEGO toys answered to and reinforced the increasing domestication of child and play and the angst-ridden relationship between child and the "mean world' outside of the private suburban home. More recent developments within the LEGO Company bring us into the $21^{\text {st }}$ century and signal a change in the relationship between players, consumers and producers wherein players increasingly become co-designers and co-producers of their own commodities. The SimCity and The Sims series of games addressed in chapter four, take the serial- and expansion-pack economy to an unprecedented level, prompting players to keep on buying additions to the games and leaving no one an excuse for not buying the game with its all-round compatibility, from PC to Playstation, from Game Boy to cell phone. Moreover, capitalist principles that amount to what one could call a consumerist ideology drive the The Sims games.

The domestication of children, toys and playing has reached an extreme height and taken a wicked turn with digital entertainment. With game consoles and personal computers connected to the Internet the domestic sphere is perverted and the popular hand-held gaming devices might dislocate the player from the interior. Computer games allow players seemingly endless hours of captivating indoors entertainment and might end up over-domesticating players. The Sims mediates, mirrors and reinforces domestication by taking this $21^{\text {st }}$ century domesticated family as its very subject, by situating play in the domesticated indoors.

The SimCity games mediate, mirror and simulate an increasingly complex urban environment and bring 
it in a containable format inside the family home. SimCity is considered highly successful in communicating to players some of the urban issues that dominate city life today. Therefore, the game is often used as an educational tool. Using computer gamebased tools to (re-) establishing a constructive relationship between city and citizen is the subject of the fifth chapter that discusses a 'Serious' game meant for public participation in urban renewal. The participation project Face Your World took children out of their private rooms and private homes to engage them in the design of a neighborhood park, the domestication of their own neighborhood. The game, the Interactor, presented the city and outside world to the children in a containable version emptied of all the real life problems pestering the neighborhood. Face Your World mediates between city and citizen in general and between urban change and the public specifically.

As outlined in chapter two "Core and Periphery of Play", the focus of this thesis is on construction toys, from non-digital LEGO toys to digital construction and simulation games likes SimCity, The Sims and the Interactor. Construction toys, popularized during the $19^{\text {th }}$ century, deal with urban and domestic design, reflect technological innovations - from wood and steel to plastic and digital technologies - and are indoor toys pur sang. Construction toys have proven to be an outstanding example to illustrate how toys mediate between the societal processes of commodification, domestication and urbanization and the player because these toys exemplify and embody these very societal processes. The history of construction toys is closely linked with the coming into being of consumerism. Construction toys were massproduced from the materials of the Industrial Revolution (steel and iron) and thus relatively cheap which allowed for mass-consumption. The toys had to 
be assembled with care and patience on a flat surface, meaning that they facilitated long and quiet hours of indoors play. Although construction toys catered to the reluctance to let children play outside unsupervised, they would center on urban design and the successes of the industrial engineer.

Since the $19^{\text {th }}$ century heydays of the construction toy, the materials used for producing this type of toys has changed: from wood, stone and steel in the $19^{\text {th }}$ century, to various plastics in the postwar period to digital technologies from the 1980s onwards. The porté of construction play changed as well. While early construction toys can be best characterized as building toys, the second-generation construction sets are designed to be about design. The first-generation construction toys are generally wooden blocks without an interlocking mechanism that facilitated the building of abstract and architectural constructions. The secondgeneration construction toys are characterized by interlocking mechanisms, more diverse shapes and materials and allow for the design and construction of more complex objects. Digital (construction) toys add an extra layer to this designed-to-be-about-design characteristic. Computer games are designed objects, coded and programmed computer applications. The rules and interactions with the game are inscribed within that programmed code. Digital construction toys are designed-to-be-about-design and procedural. Meaning that constructions evolve visually over space and time. The actualization of designed objects through their use is turned into a procedural activity, a string of actualizations of design potentials. 


\section{USERS AND USES}

The place of play also changes and shifts within the context of what players (can) do with toys or computer games. This has been analyzed by means of the core/periphery model of differentiation and what I have called the 'geography of play' - the sum of core and periphery.

The core of the geography of play is within this thesis defined as constituted by the facilitated practices of play. Facilitated play practices are shaped by the combination of the design of the toy (technological specificities, materiality) and the discourse surrounding the toy (rules, manuals, examples, guidelines, 'reputation' and connotations). In other words, both the material and immaterial aspects of a toy or computer game facilitate a window of opportunities within which boundaries the players can act. Although this thesis does not hold that there is one essential use of technology, the core contains facilitated uses. Embedded scripts stemming from the design process shape the facilitated core of geographies of play. These scripts both enable and constrain. Like film scripts these scripts "define a framework of action" (Akrich, 1992, p. 208). During design processes, specific uses of the artifact are preconceived and 'the' user configured.

Because playing is in essence experimentation and boundary testing, player activity inevitably results in activities that fall outside of the core, of what has been facilitated. These activities are taken to be peripheral or divergent play practices. These practices deviate from the company-endorsed discourse on toy or computer game, use the design in unexpected and unforeseen ways or do both. These divergent, peripheral play practices can, to certain actors within the geographies, be experienced as positive or negative, constructive or destructive, wanted or 
unwanted. Certain peripheral play activities can be useful (capitalizable, insightful, instructive) to the toy or computer game companies, fortify a brand, help or strengthen the user communities, or improve the player's experience of the toy or computer game. Some peripheral play practices, however, are unwanted because they are not capitalizable, might damage the brand image, irritate the user communities or frustrate the player's experience of the game or toy.

Crucially, peripheral play activities can (and do) become part of the core. Different movements within geographies of play have been identified: centrifugal (moving away from the core) and centripetal (moving towards the core). When players' activities diverge from design and/or discourse they move away from the core in a centrifugal movement. The core of the geography of play is the sum of design and discourse and embodies practices and tactics of user configuration. When users buy an artifact, they adopt it but also adapt it, change it, modify and alter it to fit their personal needs, wishes and preferences. In doing this, users and their practices move from the facilitated core to the divergent periphery. When these peripheral and divergent activities become again part of the core, this constitutes a centripetal movement. Both fast (within the context of one product) and slow (over the course of more products) centripetal forces have been identified. Many contemporary computer games and software applications allow the use in the core of user-generated content that has been created in the periphery. Companies will also 'harvest' and data mine the peripheries surrounding their products to look for ideas for new products or ways to enhance existing products. Centripetal appropriations thus entail a commodification of the periphery and the many-tomany activities.

In both cases, divergent, peripheral play practices can become part of the facilitated core 
through centripetal appropriation. Because of both slow and fast centripetal appropriation, players can influence to a certain extent the design of and discourse on an artifact. Their divergent play practices can become facilitated play practices and thereby they can contribute to the reconfiguring of users or even coconfigure the user. Centripetal appropriation - both slow and fast - has gained in presence and importance due to digital technologies that facilitate the use of user-generated content within the context of one and the same product, that sustain and cultivate active peripheries and many-to-many communities, that makes these communities visible and accessible to both players and companies.

In tracing changing geographies of play, the distinction made by sociologist Raimondo Strassoldo between two different core/periphery models has played a central role. Strassoldo differentiates between a core/periphery model with closed boundaries, one core and commands flowing "from the centre to the periphery, while information travels in the reverse direction" and a model with more open boundaries, a core that is spatially less defined and that is not based on coercive power but the "spontaneous coordination of individual behavior" through "immaterial elements such as images and moral codes", "values" and "norms" (1980, p. 38-41). The changing geographies of play can be framed in terms of a transformation from 'solitary' to 'networked' or from 'one-to-many' (comparable to Strassoldo's first model) to 'many-tomany' (comparable to Strassoldo's second model).

The more or less solitary and individual geographies of $19^{\text {th }}$ century play practices have been largely replaced, through the incorporation of the Internet within the geography of play, by densely populated and heavily networked geographies. $19^{\text {th }}$ century geographies of play were characterized by contact with peers, siblings and adults through and 
about play. From the $20^{\text {th }}$ century onwards toys are increasingly linked to clubs and magazines, radio programs and contests, special days and festivities. Today, these peripheral, social and participatory activities have increased immensely due to new media technologies. Innovations such as the Internet have knitted players within the geography of digital play together in an unprecedented interconnectedness. In this, players increasingly become (co-) designers and (co-) producers within $21^{\text {st }}$ century geographies of play. The stakeholder positions of player, consumer and producer are increasingly entangled up to a point where the differences implode and many players embody the three positions.

These transformations also bring about the redistribution of powers on different levels. Would it be correct to situate the company in the core and the user in the periphery of a one-to-many geography, this situation becomes more complex in largely digital geographies wherein the core splinters and disperses, companies increasingly enter the periphery and users shape and control the core to a large extent. In the oneto-many geography, the periphery is of less importance to the companies and thus more autonomous than in the many-to-many geography. The result is less movement between core and periphery and as such a more static geography. Access to the core is companycontrolled and fast centripetal appropriations are nor manifested. In the many-to-many geography, the periphery gains in importance for the companies, has therefore more influence over the core but looses some of its autonomy. There is more movement between core and periphery making the many-to-many geography almost an organic system.

There are different reasons for this transformation and the increased importance, relevance and power of the periphery. For one, the Internet has made peripheral play activities highly visible and thus 
important. Within an increasingly competitive toy market, the many-to-many model is a means to create loyalty amongst ones customers, to bring them into the universe of a brand. And the increased costs of generating new content for computer games has made it all the more attractive to rely on peripheral play activities that might result in the creation of content for computer games.

From the three case studies - LEGO toys, Wright's Sim games and Serious Urban Games - we have seen how the core/periphery relations evolve from relative independency in pre-1990s LEGO toys to symbiotic dependency with The Sims, from an autonomous periphery of play in the one-to-many geography to an instrumental, appropriated and far less autonomous periphery in the many-to-many geography, from an expansive periphery and a splintered core in contemporary entertainment geographies to a shrinking periphery and an outsized core in Serious geographies.

With the advent of digital technologies in general and the Internet in particular, the periphery of play has expanded considerably and gained in importance as a source for new input and ideas. With the core increasingly tapping into and appropriating the periphery, boundaries between the two areas are blurred. Because of this boundary blurring, players might feel in command, empowered and thus inclined to be loyal to a brand. And players are to a certain extent in command: their products and practices of play all too often become part of the facilitated core. In the contemporary geography of play, the grassroots character of the many-to-many approach has been successfully commodified. 


\section{BOUNDARY BLURRING}

Besides the rather rudimentary observation that $21^{\text {st }}$ century geographies of play have turned into networked geographies that interconnect players within a many-to-many structure, the case studies have each brought specific changes of geographies of play to the forefront.

Chapter three "The Journey not the Destination" dealt with the LEGO Company and the toys they produced from the 1940s till the present. The intricate relationship between technological innovations, corporate ideology, branding and marketing strategies, toys and playing is at the heart of this chapter. A key aspect in studying changing practices of LEGO play is the changing means and conditions of postindustrial production. This relates to the 1940s change from wood to plastics, the 1950 s change in plastic molding machines and the $21^{\text {st }}$ century strategy of bringing LEGO fans into the LEGO Company. These changing means and conditions of postindustrial production have ramifications for LEGO play practices. The new studand-tube coupling system and the LEGO System of Play broadened up both the facilitated/core and divergent/peripheral play activities with LEGO toys. This broad and expansive geography of LEGO play was challenged during the late ' $90 \mathrm{~s}$ and early $21^{\text {st }}$ century due to an unfortunate attempt at extending the LEGO brand into other areas of the child's universe. Product diversification and changes to the System of Play during those years led to a shrinking core and periphery of LEGO play. Financial losses and a weakening brand image prompted the LEGO Company to set a rescue strategy in motion. This strategy was based on two primary assets: refocusing on the brick as the core product and establishing a substantial relationship with the LEGO fans.

The LEGO history exemplifies the shift from a 
one-to-many to a many-to-many geography of play. This post-1990s geography of LEGO play has a splintered and dispersed core and taps into the periphery and the many-to-many activities for new product designs. In the pre-1990s geography of play, the facilitated core was shaped and designed by LEGO employees. They had exclusive access to what would enter and exit the core. The periphery was a largely individual and autonomous affair of minimal interest to the company. The periphery did matter to the players of course, because the periphery was the terrain for meeting each other, venting creativity and divergent play practices. In the post-1990s geography of play the periphery has more influence on the core because it is 'harvested' for product development. However, LEGO product designers maintain their privileged access to the core and outsiders' access remains mediated. In taking the peripheral play activities more serious and establishing slow centripetal forces of appropriation, the nature of both core and periphery changes, the relationship between the two alters and both players and company designers need to readjust to this changing geography of play. More so, in becoming more important and instrumental, the periphery looses some of its independence and sovereignty. The periphery gains in importance but loses in autonomy.

With chapter four, "Pimp my Game", the focus has been on SimCity, The Sims and the significantly less popular The Sims Online. SimCity, a game designed to be about urban design, compares to historical toy towns in the sense that both toys bring the urban configurations into the private home and the life of children. Both mimic in miniature format that which the child has to be protected from but also, especially in the case of boys, need to be familiarized with. With The Sims, a game designed to be about domestic design, we see a move towards the suburb, the private suburban home and life within that home. 
This compares to toy homes, dollhouse play and doll play. The toy home, dollhouse and The Sims mimic the domestic, the place and space of childhood. They combine the male oriented play form of constructing and engineering with female oriented play forms such as making house, building a family and maintaining social relationships. The Sims Online had the suggestion of all these elements but not their actualization. The online variant of The Sims is characterized by an emptied out play experience which has resulted in anti-social behavior of players within the online game world. These games have been compared to non-digital forms of play (not only construction toys but also dollhouse- and doll play) to get a grip on the nature and characteristics of the geography of digital play.

One of the key characteristics of the geography of digital play is the increasing and far-reaching appropriation and commodification of the periphery both through slow and fast forces. New media technologies generate an expansive periphery of play that is appropriated by the core to an unprecedented extent. The splintered and dispersed cores of the geography of digital play spread across and absorb the periphery, traffic between the two areas is frequent and fluent and the digital geography acquires organic and symbiotic qualities. In the largely non-digital geography of LEGO play, we can often still trace and mark the point where, when and why the LEGO Company taps into the user-driven can culture of dedicated fans. In the digitalized geography of Sims play, EA facilitates and counts on a constant and unobstructed flow of user-generated content into the core. The Sims has, even before its release, been completely dependent on the periphery of play. Because the periphery is not only appropriated but also continuously 'irrigated' by the core with new opportunities for user appropriation, the geography of 
The Sims play remains alive and 'healthy'. This is not the case in relation to The Sims Online; both fast and slower traffic between core and periphery was hampered, effectuating a return tot Strassoldo's first model of core/periphery relations and resulting in a shriveling geography of play mainly populated by antisocial players and unwanted play practices.

In chapter five "Playing the City" the leading case study is a Serious Urban Game (SUG) entitled Face Your World initiated by Dutch artist Jeanne van Heeswijk. Face Your World, a unique public participation project, took place in The Netherlands in 2005. Face Your World is a multi-faceted participation and design process with a multi-player game, the Interactor, at its core. It was initiated to deal with the dilapidated garden city Slotervaart and its poor childrelated facilities. This participation project allowed children and adults to take part in the design of a new neighborhood park for their borough. Face Your World has been analyzed and assessed along three main lines: the medium-specificity of this participation trajectory, the trajectory as a whole and the Interactor specifically. This chapter dealt with the many-to-many model used outside of the world of entertainment and considered the impact of Serious Games on geographies of play.

The implosion of the different stakeholder positions of player, consumer and producer signals the loss of a certain triviality and inconsequentiality of play. The periphery becomes more important but less autonomous. When games are instrumentalized as planning tools, participation tools, simulation models or policy devices, the loss of triviality and inconsequentiality amplifies and intensifies. Both the core and the periphery in the geography of serious play gain in importance because the outcome of play will be put to use. Because of this instrumentalization and the projected outcome of play, the periphery of the geography of Serious play shrinks while the core takes 
up the greater part of the geography. Players have to perform within strict perimeters and boundaries. As such, Serious Games compromise crucial aspects of a 'healthy' geography of play such as a vibrant and expansive periphery for divergent play, easy transfer between core and periphery of play, a certain amount of influence of players within the periphery to influence the core, the triviality or purposelessness of the ludic.

Needless to say, there is more to Serious games than the aspect of play. Public participation in urban planning through game-based new media applications intends to be a maximization of the manyto-many approach. Through SUGs, players can enter the cycle of policy-making $>$ design $>$ implementation. SUGs are intended to open not only the black-boxed, obdurate city but also the equally black-boxed processes of policy-making. Within SUGs, participation between the players, the many-to-many culture, is not an anticipated and hoped for or carefully orchestrated and sustained effect of a successful game, as in entertainment computer games for example, but the very raison d'etre of these games. As such, it moves from the periphery to the core. Participation and 'by us for us' activities transforms from divergent player behavior in the periphery of a 'healthy' geography of play to an embedded and facilitated core activity. The Interactor is about creating and designing a park together - by 'us' and for 'us'. Chapters 3 and 4 indicated the increasing tendency of both toy and computer game companies to tap into the many-tomany community and commodify divergent player activities. In relation to Serious geographies of play, the many-to-many culture and its activities are not so much commodified as instrumentalized, put to use.

The increasing use and importance of both the many-to-many model and Serious Games signals a shift in context and meaning of play. Not only the 
practices of play and the sites for play are changing, so are the very context of and reasons for play. Both the many-to-many model and Serious (Urban) Games undo playing of its triviality and inconsequentiality and turn it into an instrumental activity, either for commercial or policy-related ends. As such the 'occupants' of core and periphery, the 'residents' of geographies of play shift and change as well. Throughout the three case studies we have seen how the residents of entertainment geographies of play are increasingly teenagers and adults. They have the time, money and technological know-how to create in the periphery those products and play practices that are vital to keep a brand commercially successful and of interest to consumers. Within the geography of Serious play, the opposite was the case with children becoming lead users in policy domains traditionally occupied by adults. While toy and game companies tap into the can culture of adult fans and adult lead users, policymakers tap into the can culture of children. Assuming, no doubt, that children have creative potentials adults lack and that, in having to negotiate with traditionally remote and often conflicting stakeholders within complex and sensitive urban renewal plans, children are good mediators and messengers of change.

\section{MAKING-DO}

By studying the many-to-many model at work within geographies of play, this thesis aims at adding to our understanding of the nature, characteristics, mechanisms and problems of the many-to-many model. Based on research in this thesis, the two main conclusions concerning the changing many-to-many model under sway of technological innovations and the 
mechanisms of user-involvement at work in this model, relate to the commodification and instrumentalization of the many-to-many activities.

The many-to-many model, originally stemming from Internet use and software applications, indicates a shift from the domination of expert knowledge and content to an increase in end-user knowledge and content. Technological innovations and Internet applications such as file sharing, blogging, tagging and Wiki-ing have created platforms for end-users to meet, exchange, comment, learn and help each other. The dynamics of the many-to-many model, and then especially the bond it can create between traditionally remote stakeholders, have been experimented with by diverse and wide-ranging industries - from politics to journalism, from art practices to marketing, from education to policy-making. The popularity of the many-to-many phenomenon has reached an unprecedented height and we witness an almost ubiquitous user-involvement. The attractions of the many-to-many model are the wish to establish a faithful, positive, constructive relationship between, for example, brand and consumer, between politician and voter, between city council and citizen. For these consumers, voters and citizens, the attractiveness of this model is the feeling of an individualized experience in a globalized world, a personalized niche in what is increasingly perceived as an impersonal world, a voice for those who consider themselves otherwise unheard.

Needless to say, the situation is less utopian and egalitarian than the diverse users of this model will often proclaim. To become part of this many-to-many culture, people need a computer, Internet access and technological skills, they need time and interest and the willingness to enter this many-to-many paradigm. The question of non-users (either by choice or circumstances beyond their control) becomes all the 
more pressing when a model that proclaims to be 'many-to-many' gains in popularity and importance. What if you do not care about 'MySpace' and being 'LinkedIn'? What if you do not want to post your every thought to a personal 'blog' nor feel the need to leave your ramblings as 'tags' over the Internet? What if you have nothing to share or nothing that you want to share? What if you do not see the purpose of chatting with political wannabes or vote for this statement or against that one? What if you do not want to film your friends acting weird and post it on 'YouTube' or find your old classmates again and chat with them? Tracing and following not only the powerful actors but also the non-users (who can be equally powerful) within a many-to-many culture deserves further research. In relation to play, we need to question the effects of many-to-many geographies on players who, consciously or not, remain outside of the many-to-many model.

Adding to issues of non-users is the increasing commodification and instrumentalization of the manyto-many model. Although it has always been instrumental to certain users, the many-to-many model is now increasingly put to use for purposes lying outside of the 'original' function of this model, namely personal expression, user-to-user assistance, free enduser advise and the likes. The 'by us for us' activities are tapped into, commodified and used. The 'us' in this 'by us for us' model now contains various industries and non-profit organizations as well. Companies and industries can profit from the many-to-many culture in terms of financial gains, brand strength and marketing. In some cases, this has led to 'controversies' or has prompted angry reactions from users who feel used. For example, the 'prosumers' of YouTube.com, who have, through their avid use of the video sharing website turned it into a phenomenal success, were affronted when 'Chad and Steve' sold their 
YouTube.com website to Google for $\$ 1.65$ Billion in 2006. Some 60 video responses to the sale, which Chad and Steve happily announced on YouTube, appeared on YouTube itself ridiculing Chad and Steve and demanding a share of the money (YouTube, 2006).

Soren Lund, LEGO Mindstorms Product \& Marketing Development Director, stressed that tapping into user communities takes up companies' energy and resources and is therefore not exactly cheap or free (Greenberg, 2006). However, these costs do not amount to the energy, resources and money companies would need to invest in call centers, help centers, stores, trained and experienced personnel would they want to perform all the many-to-many activities themselves. Let alone that a social media website like YouTube could ever be worth $\$ 1.65$ Billion if not for the users and producers of the content on YouTube.

The blurring and mingling of different stakeholder positions within the many-to-many paradigm might be perceived as the ultimate empowerment of consumers and citizens now that they are consulted, tapped into or asked to (co-) design new commodities or policies. However, the power holders are unmistakably those deciding to consent to this boundary blurring for the sake of a healthy brand, prosperous company or positive community relationships. The many-to-many approach is not, as is often assumed, the ultimate empowerment of the consumer or citizen. As Jenkins puts it: "The interactive audience is more than a marketing concept and less than 'semiotic democracy' (2002, p. 158). He finds consumer power in the current era of "expanded corporate reach" (as demonstrated, the corporate reach has extended well into the periphery of play) within the culture of blogging and poaching rather than jamming (p. 168).

In relation to play, however, blogging does not create an "antidiscipline" within the geography of play 
because blogging does not directly pertain to playing but might reflect on it (Certeau, 1988, p. xv). Poaching is a strategy of "making-do" within geographies of play, of "trailblazing in the jungle of functionalist rationality' (p. 29 \& 34). Unfortunately, as we have seen, within a commodified geography wherein players become producers, players are more 'company hunters' than poachers and their activities are very much in line with and affirmative of this corporate reach. With the blurring of boundaries between players, consumers and producers, poaching and trailblazing is an activity difficult to sustain.

The area for making-do should then be sought outside of existing geographies of play and within the area of low-budget, 'home-made' computer games. Players, and then mainly adult players, are increasingly using game-design itself as a tool and vehicle for making-do. The website watercoolergames.com, for example, provides a platform for such user-generated games targeted at creating political or social changes (Bogost \& Frasca, 2007). These games seek to raise awareness concerning issues the users-as-gamedesigners find important. For example in relation to the bad working conditions in FedEx Kinko's stores (Disaffected by Bogost, 2006), the fraudulent cycles of food production in McDonald's (McDonald's Videogame by Molleindustria, 2006) or the relationship between obesity and the politics of nutrition (Fatworld by Bogost, 2007a).

Users-as-gamedesigners do not simply appropriate content for or of existing games, they use the tools for game design itself to appropriate content and to establish an antidiscipline or antiprogram to counter corporate reach. Although such persuasive games might not provide the most heterogeneous, active nor expansive geographies of play (these games have a clear purpose and goal after all), they do provide players-as-gamedesigners with expressive 
tools for their visions and ideas. Although De Certeau stresses that tactics and practices of making-do are to be sought within the manipulation of products by "users who are not its makers" (p. xiii), in an era of expanded corporate reach it seems that users do have to become the makers of alternative products and games to make-do. 


\section{Epilogue}

There are three play related objects that distinctively stand out in my memories of childhood. The first is a small-sized matchbox that I had emptied of its matches and crammed full with miniature wooden building blocks. They were the type of blocks that would allow you to build a tiny temple-like construction. I had somehow succeeded to squeeze in a small wooden animal (a horse?) and a cylindrical human figurine as well. They would fit in the matchbox only in a certain order and constellation. The bulging matchbox had to be closed and opened with care so as not to destroy the paper box. I guess that some ten wooden pieces were in that box. Most blocks had a natural wooden coloring; some were painted a fiery red (the figurine for example). I carried the matchbox with me wherever I 
went for what seems to have been a very long time (although it might as well have been only a couple of weeks or even days - considering how time stretches or folds when you are a child and the tricks memory can play on our sense of time). I took the matchbox out of my pockets when bored and played with the little pieces - building things or simply ordering them.

The second distinctive play related memory is of my dollhouse. My parents had ordered the dollhouse from a carpenter; it was hand- and custom made. It was completely made of wood, with an open front, a sloping roof, two levels and large windows all around. Unlike the matchbox, I still have the dollhouse and most of the treasured items that came with it. The carpenter had also created beds, tables and chairs, closets and a wooden fireplace. All the other items I received over time as additional gifts, or bought with my allowance or simply made myself. I don't distinctly recall 'playing' with the dollhouse so much as that I was constantly organizing things and creating tableaux, like setting the table and then clearing it all away again, putting the family to bed or have them sit around the fireplace. What I did most often though was adding to the miniature world. I made little white and blue striped dishtowels, folded them neatly and put them in the kitchen cabinet. I sewed pillows for the beds and made flowery blankets. I even broke matches in tiny pieces so that they could serve as firewood. The dollhouse was both an endless source of joy and of anxiety - lest my sister would touch it and mess up my little universe. Many a bitter fight involved my dollhouse. (It is at the time of writing used as a garage by my sister's eldest son).

The third place of toy memories is shared by my collection of metal cars (filled with dried, yellowish pudding from an overtly adventurous ride through my dessert), a set of wooden trains and rails and LEGO bricks. If I had to pick a favorite, I would 
have to go with LEGO though (although I loved the cars and trains as well) for the simple fact that my sister and I spent so much of our time with these bricks throughout the years. Although we never believed our neighbor's oldest son who solemnly declared (and even swore on it by biting hard on two of his fingers) that he would play with LEGO until the age of 21 , we were hooked on the bricks as well. In the attic we made a LEGO village - challenging ourselves to use each and every one of our bricks. I still remember the sound of those plastic bricks colliding and scraping together in their container. I can still feel how the top of your fingers and your nails would feel after too much digging between those bricks. One LEGO object stands out from my LEGO memories - it was the first really 'themed' set I got. This set stood out because we had previously simply owned LEGO bricks, we had no LEGO boxes or manuals, just loads of plastic bricks. Now I had a carton box with a picture on it of what I could make with the pieces inside the box. In hindsight, I recognize the house that this set allowed me to build as a typically postmodern, eighties construction: angular and with a flat roof. It came with those tiny, red flowers - three to a bundle - that you could arrange in your garden. I loved those flowers more than anything.

My happiest memories are from when I was playing and I have worked on this thesis with never-ending love and fascination for this subject. However, my incentives for conducting this research are not only my own fond memories of toys and playing but also the questions that arose from observing my brothers and nephews at play. Every family gathering was a battle between children wanting to play computer games and adults' horror of these very games. Sunday mornings they would sneak downstairs, get a bowl of cereals and 
sit smack in front of the bluish television screen playing some racing or shooter game, their necks at an angle that must have been uncomfortable and painful. I have to admit that it horrified me every time. I wanted to drag them into the garden - which they were lucky enough to have I felt - and have them play in the sun with a ball. I guess it was not simply the playing of computer games that horrified me but their obsession with computers as such. Not only did the un-put-downable factor of gaming worry me, so did the many-tomany approach to doing your homework. If I would have to capture my feelings in one word, it would have to be 'lethargy', the lack of energy and enthusiasm. Even though they wanted to play these games or sit behind computers all day, it did not seem to make them particularly happy.

I have to admit that I flip-flopped through this thesis, defending computer games at certain times and condemning them at other times. I have tried in this thesis to come, in the end, to a more balanced assessment of what it is that sometimes horrifies me in these games, what has prompted me to defend or condemn them. It is especially the consumerist and violent mechanisms of these games that worry me. Children aged six and up have seen and done it all, are blasé about violence and (over-) consumption. I have admired their media-savvyness and defended this quality until it became apparent that within the context of traditional school curricula, this knowledge would not lead them to the finish. Playing computer games and being able to work with computers accumulates in a specific set of skills that are, in themselves, not a bad thing. But considering how much time children spend with these technologies, I still feel the gaming industry has to do a better job in diversifying the product range of their games and sensitizing users to issues of violence and over-consumption - the two core ingredients of mainstream computer games. 


\title{
INDEX
}

\author{
A \\ actors, 16, 77, 79, 82, 83, \\ $135,184,213,223,245$, \\ 249,283 \\ Americanization, 33, 48, 49, \\ 140, 267 \\ antidiscipline, 89, 145, 284, \\ 285 \\ antiprogram, 145, 285 \\ appropriation, 84, 85, 88, \\ $89,113,134,145,153$, \\ 154, 187, 188, 189, 201, \\ 207, 210, 257, 278 \\ centrifugal appropriation, \\ $12,84,85,87,88,89$, \\ $128,133,146,153$, \\ 155, 185, 199, 201, \\ 208, 236, 272 \\ centripetal appropriation, \\ $12,84,85,86,87,88$, \\ $89,91,128,131,132$, \\ $134,139,153,154$, \\ $155,180,182,184$, \\ 185, 188, 199, 201, \\ 207, 208, 210, 251, \\ $272,273,277$ \\ reappropriation, 89,145

\section{B} \\ beta testers, 129, 151, 190, \\ 191, 199, 200 \\ beta testing, 146, 199, 200 \\ blog, 283 \\ blogging, 13, 282, 284 \\ boundary blurring (between \\ core and periphery), 275, \\ 284 \\ brand, 15, 82, 100, 114, 115, \\ $128,129,131,132,143$, \\ 258, 272, 275, 281, 282 \\ Brand Asset Valuator \\ (BAV), 114, 115 \\ brand design, 208 \\ brand extension, 94, 113, \\ $115,117,120,122$, \\ $133,136,276$ \\ brand image, $83,94,121$, \\ 136, 143, 257, 272, \\ 276 \\ brand strength, 139, 283 \\ brand universe, 15,92 , \\ 275 \\ branded, 131, 132, 139 \\ branding, 21, 276 \\ healthy brand, 284 \\ LEGO brand, 95, 113, \\ $114,115,117,118$, \\ 137 \\ The Sims brand, 180, 208 \\ bricolage, 89,146 \\ bricoleur, 84 \\ building toys, $45,66,67,68$, \\ $69,71,144,270$ \\ building blocks, 43,64 , \\ $66,68,73,100,104$, \\ 113,287 \\ building kits, 66,70 \\ building sets, $54,63,68$, \\ $69,70,73$ \\ Kapla, 69, 80, 152 \\ wooden blocks, 270 \\ can culture, $131,132,133$, \\ 187, 207, 209, 258, 259, \\ $262,278,281$ \\ capitalism \\ capitalist principles, 211, \\ 268
}

184, 189, 202, 212, 254, 
circuit of capital, 4, 182, 202, 264

hyper capitalism, 22, 177

late-capitalism, 12

chatsites, 132, 146

chatting, 8, 10, 149, 169, $195,196,240,252,253$, 283

cheating, 19, 80, 117, 146, 165, 202, 203, 204, 205 cheats, 149, 165, 187, 202, 203, 204

cheating bots, 80,146 , 202, 203, 204, 205 exploits, 165, 192, 196, 202

commodification, 11, 12, 20, $21,22,23,29,54,56,60$, $61,64,76,135,139,174$, 180, 189, 211, 259, 262, $265,266,267,269,272$, 278, 282, 283

commodified, 5, 129, $135,136,137,139$, $143,154,155,182$, $187,188,208,255$, $260,275,280,283$, 285

commodities, 56, 57, 140, 264, 267, 268, 284

computer games, $8,11,13$, $15,17,18,19,57,78,79$, $80,92,120,121,129$, $141,142,144,145,148$, $151,165,167,168,173$, $175,185,186,187,205$, 206, 210, 211, 212, 225 , $228,239,254,262,266$, $267,268,270,272,275$, $280,285,289,290$ digital toys, 18, 57, 142, 144, 206

configuring the user, 78, 79, $84,91,128,175,271$, 272 co-configuring the user, $86,88,128,210,251$, 273

reconfiguring the user, 139,210

construction play, 75, 93, $114,117,118,120,122$, 137, 169, 179, 186, 198, 270

construction toys, 20,59, 61, 62, 63, 64, 68, 69, 70, 71, 72, 73, 75, 99, 109, $113,117,121,122,123$, 144, 158, 269, 270, 278

Bild-O-Brik, 102, 103 construction sets, 56, 65, $70,73,74,75,107$, 117,270

digital construction toys, $62,144,270$

Erector Sets, 70

Kiddicraft, 100, 101, 102, 103

Lincoln Logs, 70

Meccano, 36, 63, 70, 72, $75,79,117$

Minibrix, 102, 103

Plaspi Grossblock, 68

Stabil, 75

Stabila, 74, 75

constructionism, 125

consumer culture, 12,53 ,

120, 141, 175, 266

consumerist ideology, 164, 175, 211, 268

consumerist society, 54 , 56, 266

consumerism, 12, 20, 34, 35, $56,62,63,140,168,174$, $175,267,269$

consumers, $4,13,15,18,36$, $37,53,54,56,57,61,62$, $63,67,84,87,89,90,91$, 104, 112, 120, 121, 122, $129,131,132,135,137$, $140,141,143,145,148$, 
174, 175, 177, 185, 200, 208, 212, 260, 261, 262, 264, 266, 268, 274, 279, $281,282,284,285$

consumption, 4, 11, 21, 23, $32,34,53,57,60,62,63$, $91,127,137,159,168$, 175, 260, 266, 267, 269, 290

core/periphery model of differentiation, 20, 21, $22,76,77,90,112,133$, 144, 186, 197, 203, 206, 209, 249, 255, 259, 265, $271,273,275,279$

crowdsourcing, 14

\section{D}

department stores, 20, 24, $29,30,31,32,33,34,35$, $36,62,63,140,158,267$ design, 1, 4, 16, 19, 22, 42, $45,53,59,61,62,68,70$, $72,73,75,77,78,79,80$, $82,84,85,86,87,91$, 102, 104, 107, 109, 113, $117,120,123,125,126$, $128,129,131,132,135$, $136,137,139,142,143$, $144,145,149,152,153$, $154,155,157,161,165$, $170,172,173,175,180$, $182,183,185,186,192$, 196, 198, 199, 205, 206, 208, 209, 210, 214, 216, $218,219,220,222,227$, $228,229,230,233,235$, 236, 237, 239, 240, 242, $243,244,245,246,247$, $248,249,250,251,253$, $257,258,260,261,262$, 263, 266, 269, 270, 271, $272,273,277,279,280$, 285 designing, 2, 68, 69, 70, $71,72,73,82,104$, 117, 124, 144, 151, 189, 199, 218, 224, 228, 233, 239, 249, $251,252,254,258$, 262,280

designer, 4, 78, 79, 86, 89, $135,139,163,183,186$, 188, 200, 207, 209, 257. $258,277,285$

co-designers, 13,84 , $135,143,187,210$, 260, 264, 268, 274, 284

digital technologies, 8,9 , $68,87,228,269,270$, 273,275

digitalization, 13, 20, 149, 164, 207

digitalized, 11, 149, 155, 207, 250, 278

discourse (on toy, computer game), 32, 77, 78, 79, 80, $84,85,86,87,107,109$, $117,120,124,155,156$, $165,167,172,177,185$, 187, 199, 202, 205, 209, $210,253,271,272,273$ discussion boards, 146, 155, 180,182

divide (digital, generational, playstyle, gender), 166, 202, 205, 235, 248, 266 doll play, 180, 206, 278 dollhouse, 142, 168, 171, 177, 178, 180, 198, 206, 278, 288

dolls, 26, 33, 43, 54, 63, 75, $142,177,178$

domestication, 5, 11, 12, 20, $21,22,23,26,29,39,45$, 51, 54, 56, 59, 60, 61, 76, $84,140,170,172,173$, 174, 177, 211, 262, 264, 266, 267, 268, 269 
domesticated, 5, 26, 87, 173, 262, 265, 268

over-domestication, 57 , $58,211,267,268$

\section{E}

e-believers, 214

e-democracy, 214, 262

engineer (play), 54, 63, 79, 113, 120, 137, 179, 206, 270, 278

expansion-pack economy, 22, 211, 268

\section{F}

fan culture, 127, 136, 137

fans, 2, 4, 5, 14, 15, 17, 67, $75,80,82,83,94,95$, $115,125,127,128,129$, 130, 131, 132, 133, 135, 136, 137, 139, 144, 151, 174, 178, 182, 201, 207, $208,209,213,254,258$, 278,281

fansites, 83, 132, 135, 146, $154,182,210$

forums, 131, 146, 155, 180

Fröbel, 64, 65, 66, 67, 73

\section{G}

game console, 6, 11, 58, 173,268

game content, 182 game studies, 17, 18 garden city, 46, 47, 48, 214, $216,217,218,224,242$, $255,257,279$

geography of play, 76, 79, $84,87,90,133,134,189$, 209, 212, 215, 254, 259, $265,272,273,275,276$, $277,279,280,281,285$ core (of the geography of play), 20, 21, 22, 76, $77,78,79,80,82,83$, $84,85,86,87,88,89$, $90,92,93,94,112$, $113,115,117,120$, $121,122,128,129$, $132,133,134,135$, $136,137,139,142$, 144, 146, 149, 152, $153,154,155,156$, $167,179,182,183$, $184,185,186,187$, 189, 197, 199, 200, 201, 202, 203, 206, 207, 208, 209, 210, $211,212,214,236$, 249, 251, 253, 254, 255, 256, 257, 258, 259, 260, 265, 271, $272,273,274,275$, 276, 277, 278, 279, $280,281,290$

geography of digital play, $142,144,149$, 188, 206, 210, 274, 278, 279

geography of LEGO play, 112, 113, 120, 122, 135, 137, 139, $154,258,277$

geography of Serious play, 253, 254, 255, 256, 257, 260, 275, 279,280

geography of SimCity play, 149

geography of The Sims

Online play, 201, 202, 209 geography of The Sims play, 187 many-to-many geography, 91, 92, $134,135,137,143$, 273, 274, 275, 277 
non-digital geography of play, 278

one-to-many geography, 90, 92, 137, 143, 273, $274,275,277$

periphery (of the geography of play), $22,76,77,79,80,82$, $83,84,85,86,88,89$, 90, 91, 92, 94, 128, 133, 134, 135, 136, 137, 139, 144, 149, $153,154,155,180$, $182,183,184,185$, 187, 188, 189, 199, 201, 202, 203, 207, 208, 210, 212, 249, $251,253,254,255$, 256, 257, 258, 259, 260, 265, 271, 272, $273,274,275,276$, $277,278,279,280$, 281, 284

Google, 284

\section{H}

hackers, 127, 166

hacking, 127, 257

hand-held gaming devices,

$5,11,58,268$

cell phone, 22, 114, 211, 268

Game Boy, 22, 211, 268

\section{I}

indoor toys, 45, 54, 56, 59, $112,267,269$

indoors entertainment, 5, 211, 268

indoors play, 5, 270

Industrial Revolution, 20, $25,48,56,112,266,267$, 269
Innocent Child, 24, 34, 54, 266

interlocking mechanism (of construction toys), 68 , $69,70,71,94,102,103$, $105,107,109,270$

Internet, 4, 5, 6, 8, 11, 12, $13,14,55,58,92,129$, 142, 143, 148, 149, 178, 190, 201, 207, 264, 268, $273,274,275,282,338$

\section{J}

jammers, 127, 187, 202, 284

\section{K}

KGOY (Kids Growing Older Younger), 114, 139

Kindergarten, 64, 66, 67, 125

\section{L}

la perruque, 89, 135

lead users, 126, 127, 128, 129, 132, 135, 139, 242, 258, 261, 281

LEGO, 130, 152, 207

Belville, 124

Clikits, 118, 121, 124

Creator, 122, 123, 129

Digital Designer, 122, 129

Harry Potter, 120, 124, 170

LEGO Ambassadors Program, 130, 135, 136

LEGO Automatic Binding Bricks, 100, 101, 102, 105, 107, 109 
LEGO bricks, 94, 101, 102, 105, 107, 109, $112,125,132,268$, 288, 289

\section{LEGO Certified}

Professionals

Program, 130

LEGO communities, 130

LEGO Company, 2, 4, 5, 21, 82, 93, 94, 95, 96, 98, 99, 100, 102, 105, $107,109,112,113$, $115,118,121,122$, $125,126,127,128$, $129,131,132,133$, 134, 135, 136, 137, 138, 139, 140, 207, 208, 258, 268, 276, 278

LEGO designers, 4

LEGO employees, 115, 135, 277

LEGO Factory, 4, 5, 122, 129,131

LEGO fans, 2, 4, 83, $127,129,130,136$, 149, 207, 276

LEGO game, 187

LEGO Master Builders, 2

LEGO pieces, 1, 112

LEGO products, 115 , $120,122,124,130$, 132

LEGO sets, 1, 2, 4, 83, 107, 109, 110, 111, $113,114,115,122$, $124,137,138,140$, 268

LEGO system of play, 94, 107, 109, 112, $113,124,136,276$

LEGO toys, 94, 97, 98, 104, 107, 109, 111, $112,117,120,121$, 124, 136, 137, 140,
154, 169, 208, 212, 268, 269, 275, 276

LEGO website, 2, 4

Mindstorms 2.0, 95, 125, 126, 127

Mindstorms NXT, 95, $125,126,129,131$, 135

Star Wars, 121, 124, 170 LinkedIn, 283 ludic, 189, 230, 255, 257, 259,280

lurking, 8, 41, 132, 182

\section{M}

making-do, 262, 285, 286

manuals (for play), 1, 71, $77,95,103,113,128$, $156,160,166,167,218$, 271, 289

many-to-many, $13,14,15$, 134, 214 by us for us, 80,139 , 254, 280, 283 many-to-many activities, 139, 143, 272, 277 , 282, 283, 284

many-to-many approach, 4, 14, 259, 260, 261, $262,275,280,284$, 290

many-to-many communities, 87, 131, 139, 254, 273, 280

many-to-many culture, $128,137,139,144$, $153,182,201,210$, $254,260,280,282$, 283

many-to-many industry, 209

many-to-many model, 5 , $12,13,14,15,16,19$, 20, 21, 22, 60, 61, 76, $82,92,95,136,139$, 
$142,213,215,257$, $258,260,262,264$, $265,275,279,280$, $281,282,283$

many-to-many paradigm, $14,16,80,125,255$, 282, 284

many-to-many phenomenon, 14, 282 many-to-many practices of play, 154

many-to-many structure, 142, 276

many-to-many template, 212

marketing, 14, 21, 53, 60, 130, 137, 185, 260, 266, 276, 284

media-specificity (of participation tools), 215, 228, 279

MOC (My Own Creation), 1, 2, 3, 4, 5, 127, 135, 207

mods (modifications), 146, $152,153,180,200$

multitasking, 8

must culture, 131, 210

MySpace, 283

\section{$\mathbf{N}$}

narrative, 19, 117, 120, 122, 124, 137, 169, 170, 177, 179, 186, 192, 198

netiquette, 132

new media, 5, 6, 120, 144, $164,167,214,218,259$, $260,274,278,280$

New Urbanism, 163 non-digital games, 19 non-digital toys, $21,45,61$, 142, 144, 173

non-participants, 132, 248 non-users, $142,146,248$, 282,283

\section{$\mathbf{O}$}

obduracy (technological artefacts, cities), 245, 246, 260, 280

off-the-couch-games, 58 one-to-many, $13,14,61,90$, $91,92,133,134,214$ one-to-many approach, 4 one-to-many paradigm, 13, 209

one-to-one, 14 one-to-one paradigm, 13

Online games MMOG, 190

MMORPG, 199, 200

open source, 14, 128, 152

\section{$\mathbf{P}$}

participation, 127, 151, 186, 214, 248

participatory cultures, 13 , $15,131,143,144,274$

participatory games, 228 , 258

participatory project, 248

participatory tools, 213, 225, 235,248

pastoral, 24, 26, 48, 157

patch, 83, 146, 152, 153,

180, 183, 184, 187, 200, 205

personal computer, 5, 6, 8, $11,12,58,114,153,173$, 268

plastic, $21,68,70,94,96$, 97, 98, 99, 100, 101, 102, 104, 105, 106, 112, 113, $118,136,140,268,269$, 270, 276, 289

plastic molding machine, 94 , 99, 100, 105, 107, 136, 276

playability, 186, 249 
playground, 5, 9, 20, 24, 28, $29,32,46,48,49,50,51$, $54,56,124,132,136$, 143, 156, 174, 220, 231, 267, 276

poachers, $89,127,128,145$, $187,202,284,285$

policy-making, $22,213,218$, $247,260,261,262,280$, 282

practices of play, 20, 60, 76, 91, 95, 136, 137, 142, $146,149,155,170,177$, 180, 187, 192, 202, 210, $258,273,281$

digital practices of play, 145

divergent practices of play, $76,79,82,85$, $86,92,113,122,124$, $128,132,135,136$, $139,149,151,152$, $182,185,186,187$, 189, 199, 205, 208, 209, 210, 254, 257, $271,272,273,274$, 275, 276, 277

facilitated practices of play, $76,77,135$, 145, 165, 190, 203, 204, 271, 273

LEGO practices of play, 107, 109, 111, 113, $124,135,136,137$, 138, 139, 207, 276, 278

unwanted practices of play, 76, 82, 83, 155, $165,184,202,203$, 204, 205, 209, 272, 279

wanted practices of play, $76,82,83,190,271$

private home, $12,37,53,54$, 140, 143, 170, 171, 172,
174, 180, 198, 206, 266, 267, 268, 277

private room, 5, 24, 37, 38, $41,58,143,264$

bedroom, 6, 7, 8, 11, 38, $39,171,174,264$

nursery, 28, 38, 39, 40, 43,45

playroom, 8, 20, 38, 40, $43,62,112$

procedural (play, rhetorics), $19,144,145,164,186$, 206, 227, 270

producers, $15,61,62,67$, $90,91,132,135,182$, 200, 207, 208, 262, 274, 279

co-producers, 84,132 , 140, 260, 264, 268, 274

product differentiation, 120 , 122

prosumers, 13, 283

public participation, 22, 213, 214, 215, 217, 218, 219, $220,222,223,224,225$, 227, 228, 230, 231, 233, 235, 240, 242, 243, 244, 245, 246, 247, 248, 249, $254,255,257,259,260$, $262,269,279,280$

\section{$\mathbf{R}$}

reform movement, 20, 29, $48,49,51$

role-playing, 117, 118, 120, 169

\section{S}

scripts, 78, 84, 85, 86, 91, $113,128,139,152,153$, $163,164,165,175,185$, 199, 206, 210, 236, 271 
Serious Games, 215, 225, $227,249,279,280$

Serious Urban Games, 213, 224, 229, 233, 246, 254, $255,257,258,259,260$, 275, 280

Face Your World, 22, 214, 215, 216, 217 , $218,219,221,222$, 227, 229, 230, 231, $233,234,235,237$, 239, 240, 242, 243, 244, 245, 246, 247, 248, 249, 251, 253, $254,255,258,259$, 260, 261, 262, 269, 279

The Harbour Game, 222, 223, 246, 247

SimCity, 21, 141, 142, 144, $147,148,149,151,152$, $155,156,159,160,161$, $162,163,164,165,167$, $169,179,180,186,191$, 192, 203, 205, 206, 207, 208, 209, 211, 230, 268, 277

simulation games, 21, 141, $147,167,230$

stakeholders, 14, 91, 125, 135, 137, 208, 213, 215, $217,218,231,255,257$, $258,260,261,262,274$, $279,281,282,284$ suburb, 37, 168, 170, 206, $255,263,277$

suburban, 12, 26, 38, $112,140,169,170$, $172,177,185,206$, 257, 267, 268, 277

suburbanites, 37

suburbanization, 45, 255, 263
T

technological artifacts, 16 , 142, 173, 185, 211, 245, 265

technological innovations, $12,15,16,17,19,20,21$, $22,60,76,113,139,173$, $264,269,276,281$

television, $6,8,12,14,57$, $89,120,144,174,178$, 290

The Sims, 21, 83, 85, 141, $142,144,146,155,161$, 164, 168, 169, 170, 171, 172, 174, 175, 176, 177, $178,179,180,181,182$, 183, 184, 185, 186, 187, 189, 193, 198, 201, 203, 205, 206, 207, 208, 209, 210, 211, 213, 254, 268, 269, 275, 277, 278

The Sims Online, 21, 83, $141,142,144,146,155$, 190, 191, 192, 193, 194, 195, 196, 197, 198, 199, 200, 201, 202, 203, 204, 205, 206, 208, 209, 211, 277, 278, 279

toy homes, 142, 170, 177, 180, 206, 278 toy towns, $157,159,164$, 170, 206, 263, 277 toy villages, $142,157,159$, 170 trolling, 155, 180, 185 tyranny of the algorithm, 164, 165, 187, 202

\section{$\mathbf{U}$}

urban planning, 141, 159, $160,163,164,213,220$, $223,227,228,235,248$, $249,259,260,280$ 
urbanization, 5, 11, 12, 20, $21,22,23,29,37,54,56$, $60,61,76,140,211,255$, 262, 264, 266, 267, 269

user communities, 82, 129 , $131,137,143,155,166$, 182, 184, 189, 200, 202, 254, 257, 272, 284

User-Generated Content, 4, $83,85,87,127,129,146$, $149,150,151,152,153$, $154,155,161,164,167$, $180,181,182,184,185$, 191, 192, 201, 207, 208, $210,250,272,273,278$ users, 2, 4, 5, 13, 14, 20, 59, $61,78,79,84,85,86,89$, $94,124,125,126,127$, $128,130,131,135,139$, $142,143,146,151,152$, $155,163,184,185,190$, 191, 206, 208, 210, 233, 242, 244, 248, 249, 257, $258,262,265,272,273$, $281,282,283,285,286$, 290

user-driven, 14, 128, 131, 132, 133, 134, $135,137,180,187$, 207, 209, 262, 278 user-driven innovation, $128,131,133,135$, 180, 187, 207, 208 user-involvement, 11, 12 , $14,15,19,60,76,82$, $139,210,262,265$, 282

\section{W}

Web 2.0, 13

Wiki, 13, 14, 214, 282

Will Wright, 21, 77, 141, $142,144,145,147,149$, $153,154,161,163,164$, 169, 170, 185, 189, 190, 201, 209, 212, 275

wooden toys, 96, 104

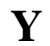

YouTube, 283 


\section{BIBLIOGRAPHY}

A.Hagedorn\&Co. (1914). "Big Business Builders". Games \& Toys. The Leading Trade Journal, 1(1).

Abdi, K. (2007). Interview (Face Your World participant ed.).

Addams, J. (1921 [1909]). The Spirit of Youth and the City Streets. New York: The Macmillan Company.

Akrich, M. (1992). "The De-Scription of Technical Objects". In W.

E. Bijker \& J. Law (Eds.), Shaping technology/building society: studies in sociotechnical change (pp. 205-224). Cambridge, Mass.: MIT.

Akrich, M., \& Latour, B. (1992). "A Summary of a Convenient Vocabulary for the Semiotics of Human and Nonhuman Assemblies". In W. E. Bijker \& J. Law (Eds.), Shaping technology/building society: studies in sociotechnical change (pp. 259-264). Cambridge, Mass.: MIT.

Al-Kodmany, K. (2006). "Computer-Based Public Participation". In E. Sendich (Ed.), Planning and urban design standards (pp. 63-64). Hoboken: John Wiley \& Sons.

Alcorn, A. (2006). 'The Modern Boy is Air-Minded': Boy Consumers and the Model Airplane League of America. Paper presented at the Society for the History Of Technology (SHOT) Annual Meeting.

Alexander, C., Ishikawa, S., \& Silverstein, M. (1977). A pattern language: towns, buildings, construction. New York: Oxford University Press.

Amakizan, H. (2007). Interview (Face Your World participant ed.).

Ames, S. C., \& Ames, S. (2006). "Community Visioning". In E. Sendich (Ed.), Planning and urban design standards (pp. 55-56). Hoboken: John Wiley \& Sons.

Anker. (2007). "Welcome at Anker Steinbaukasten". Retrieved August 21, 2007, from http://www.ankerstein.de

AnnieW. (2002). "Re: Anyone play the TSO Play-Test and decided not to buy the official game?" Retrieved August 21, 2007, from http://groups.google.com/group/alt.games.thesims/browse frm/thread/4c89ef7839115c30/2e32a83d93 a70c6e? $\mathrm{q}=\mathrm{TSO} \& \mathrm{rnum}=94 \# 2 \mathrm{e} 32 \mathrm{a} 83 \mathrm{~d} 93 \mathrm{a} 70 \mathrm{c} 6 \mathrm{e}$

Anonymous. (1862). Routledge's nursery picture book, containing upwards of six hundred and thirty illustrations. London ; New York: Routledge, Warne, and Routledge.

Anonymous. (1900). How Department Stores are Carried on in America: The Business Man's Publishing Company.

Anonymous. (1914a). "Constructional Toys of Merit". Games \& Toys. The Leading Trade Journal, 1(2). 
Anonymous. (1914b). "The Press and the Toy Trade. Trading with the Enemy". Games \& Toys. The Leading Trade Journal, $1(6)$.

Anonymous. (1915). "Transfers for the Toy Trade. Wood for the Toy Trade". Games \& Toys. The Leading Trade Journal, 1(7).

Anonymous. (1919). "Toy Industry in Germany". Games \& Toys. The Leading Trade Journal, V(LIV).

Anonymous. (1923, March 17). "Health Preferred". Time.

Anonymous. (1924, November 24). "Week". Time.

Anonymous. (2006). "How Can You Use The Dangerous Book for Boys". Retrieved August 10, 2007, from http://www.amazon.com/Dangerous-Book-Boys-ConnIggulden/dp/0061243582

Arendt, H. (1998 [1958]). The Human Condition. Chicago: University of Chicago Press.

Ariès, P. (1962). Centuries of childhood: a social history of family life (R. Baldick, Trans.). New York: Random House.

Arnstein, S. R. (1969). "A Ladder of Citizen Participation". Journal of the American Institute of Planners, 35(4), 216-224.

Arnstein, S. R. (2003). "A Ladder of Citizen Participation". In R. T. LeGates \& F. Stout (Eds.), The City Reader (3rd ed., pp. 244-255). London: New York: Routledge.

Auerbach, S. (1999). Toys for a Lifetime. Enhancing Childhood Through Play. New York: Byron Preiss

Baldwin, R. E. (2001). "Core-periphery model with forwardlooking expectations". Regional Science and Urban Economics, 31(1), 21-49.

Barab, S., Thomas, M., Dodge, T., Squire, K., \& Newell, M. (2004). "Reflections from the Field. Critical Design Ethnography: Designing for Change" Anthropology and Education Quarterly, 35(2), 254-268.

Barthes, R. (1993 [1957]). Mythologies. London: Vintage.

Bastiaan. (1859). De speelkamer: uitspanningen in den gezelligen kinderkring. Rotterdam: Nijgh.

Baum, D. "Dave's LEGO site". Retrieved August 22, 2007, from http://www.baumfamily.org/dave/lego/index.html

Bavaria. (2006). "wild men drinking Bavaria beer". Retrieved August 10, 2007, from http://www.youtube.com/watch?v=zcT93NZQ8wE

Beckett, A. (1996). "Revenge of the town planners". The London Independent.

Beets, P., \& Sandwijk, G. v. (ca. 1865a). De spring in 't veld: vermakeijke lichaamsoefeningen voor de jeugd. Leiden: Noothoven van Goor.

Beets, P., \& Sandwijk, G. v. (ca. 1865b). Spelen in de vrije lucht en in de speelkamer. Leiden: Noothoven van Goor. 
Bernard, J. (1906). Du mouvement d'organisation de defense du petit commerce Francais. Paris: A. Michalon.

Bernard, J., \& Hoffman, L. (1911). "Le petit commerce et les grands magasins". La Reforme sociale, 61, 293-303.

BetaNews. (2005). "The Sims Online 1.1235.2.0". Retrieved September 11, 2007, from http://fileforum.betanews.com/detail/The Sims Online/1 $\underline{101518992 / 1}$

Bijker, W. E. (1995). Of bicycles, bakelites, and bulbs: toward a theory of sociotechnical change. Cambridge, Mass.: MIT Press.

Bijker, W. E. (2001). "Technology, Social Construction of". In N. J. Smelser \& P. B. Baltes (Eds.), International encyclopedia of the social \& behavioral sciences (1st ed., pp. 15522-15227). Amsterdam ; New York: Elsevier.

Bisset, K. (2006). "Meccano in the United States". Retrieved August 13, 2007, from http://www.usmeccano.com/

BlastTheory. (2001). "Can You See me Now?" Retrieved August 23, 2007, from http://www.blasttheory.co.uk/bt/work cysmn.html

BlastTheory. (2003). "Uncle Roy All Around You". Retrieved August 23, 2007, from http://www.blasttheory.co.uk/bt/work uncleroy.html

Blom, T. (2004). "The Multi-level Governance Approach to European Integration. Some Critical Considerations." Maastricht: University Maastricht.

Bogost, I. (2006). "Disaffected!" [Computer Game]: Persuasive Games.

Bogost, I. (2007a). "Fatworld" [Computer Game]: Persuasive Games.

Bogost, I. (2007b). Persuasive games: the expressive power of videogames. Cambridge, Mass.: MIT Press.

Bogost, I., \& Frasca, G. (2007). "watercoolergames". Retrieved August 21, 2007, from http://www.watercoolergames.com/

Boissier, F., \& Lachaux, G. (1894). "Contribution a l'etude de la kleptomanie". Annales Medico-Psychologiques.

Boon, M. (1935). "Speeltuinen". Rotterdam: Nijgh \& Van Ditmar.

Borgatti, S. P., \& Everett, M. G. (1999). "Models of core-periphery structures". Social networks: an international journal of structural analysis, 21(4), 375-396.

Bowlby, R. (1985). Just Looking. Consumer culture in Dreiser, Gissing and Zola. New York, London: Methuen.

Bradley, M. (1896). Paradise of Childhood London: George Philip \& Son.

Brandweek.com. (2006). "Dove Joins DIY Ad Creative Marketplace". Retrieved September 12, 2007, from 
http://www.brandweek.com/bw/news/recent display.jsp? vnu content $\mathrm{id}=1003522261 \& \mathrm{imw}=\mathrm{Y}$

Bray, H. (2004). "Justice has its price in Sim world". The Boston Globe Retrieved August 17, 2007, from http://www.boston.com/news/globe/living/articles/2004/0 $1 / 14 /$ justice has its price in sim world

Brett, A., Moore, R., \& Provenzo, E. (1993). The Complete Playground Book. Syracuse: Syracuse University Press.

BrickBrothers. (2006). "Once upon a time...". Retrieved June 15, 2007, from http://www.brothersbrick.com/2006/08/12/once-upon-a-time/

Brickfactory. "The Brickfactory". Retrieved September 25, 2007, from http://www.hccamsterdam.nl/brick/index.htm

Britton, J. (1996-2003). "Jackie's Architectural Pages". Retrieved September 18, 2007, from http://www.architoys.net/index.html

Broekhuizen, J. (2007). Interview (Designer Public Space from the ward Slotervaart ed.).

Brouwer, M. (2007). Interview (Intern at De Kunsthal, Rotterdam ed.).

Brown, B. (1995). "American Childhood and Stephen Crane's Toys". American Literary History, 7(3), 443-476.

Bruggen, T. v. d. (2007). "Kapla. The Magic Plank". Retrieved August 13, 2007, from http://www.kapla.com/

Brunton, J., \& Rice, T. (2007). "CAWs.ws - \#1 source for CAWs \& More". Retrieved July 6, 2007, from http://caws.ws/

Buckingham, D. (2000). After the death of childhood: growing up in the age of electronic media. Cambridge ; Malden, MA: Polity Press.

Burns, J. (1979). Connections: ways to discover and realize community potentials. Stroudsberg; New York; London: Dowden Hutchinson and Ross : McGraw-Hill.

Calloway, S. (1996). The Golden Age of Shopping 1910 to 1940. London: Random House.

Calvert, K. L. F. (1992). Children in the house: the material culture of early childhood, 1600-1900. Boston, MA: Northeastern University Press.

CaptainSyrup. (2002). "SimCity: The Syrup FAQ". Retrieved August 23, 2007, from http://faqs.ign.com/articles/369/369282p1.html

Carter, R. B. (Ed.). (1883). Our Homes and How to Make them Healthy. London: Clearing House.

CartoonDollEmporium. (2007). "Cartoon Doll Emporium - Dress Up Games and Doll Makers". Retrieved July 6, 2007, from http://www.cartoondollemporium.com/

Cascio, J. (2004). "The map is not the Terrain; the sim is not the City. To Know It for the First Time - Place, Environment 
and Ecology". Retrieved December 15, 2006, from http://www.worldchanging.com/archives/001622.html

Cavallo, D. (1981). Muscles and Morals. Organized Playgrounds and Urban Reform, 1880-1920. Philadelphia: University of Pennsylvania Press.

CBC. (2004). "Lego Sues Factboard". Retrieved September 25, 2005, from http://www.cbc.ca/thecurrent/2004/200411/20041125.ht $\underline{\mathrm{ml}}$

CCA. (2007). "Canadian Centre for Architecture". Retrieved September 18, 2007, from http://www.cca.qc.ca/table.asp?lang=eng

Certeau, M. d. (1988). The practice of everyday life. Berkeley, Calif. ; London: University of California Press.

Charlot, S., Gaigné, C., Robert-Nicoud, F., \& Thisse, J.-F. (2006). "Agglomeration and welfare: The core-periphery model in the light of Bentham, Kaldor, and Rawls". Journal of public economics, 90(1), 325-348.

Chase-Dunn, C. K., \& Hall, T. D. (1991). Core/periphery relations in precapitalist worlds. Boulder; Oxford: Westview.

Chudacoff, H. (2007). Children at Play: An American History. New York: NYU Press.

Ckought. (2002). "Sims Online (maybe Maxis will read and rethink)". Retrieved August 21, 2007, from http://groups.google.com/group/alt.games.thesims/browse frm/thread/395c96e 2b438163e/3fc144f650 1b5567? q=TSO\&rnum $=393 \# 3 \mathrm{fc} 144 \mathrm{f} 6501 \mathrm{~b} 5567$

Cogan, E. C., \& Cogan, O. (2006a). "Public Hearings". In E. Sendich (Ed.), Planning and urban design standards (pp. 62). Hoboken: John Wiley \& Sons.

Cogan, E. C., \& Cogan, O. (2006b). "Public Meetings". In E. Sendich (Ed.), Planning and urban design standards (pp. 59-61). Hoboken: John Wiley \& Sons.

Compocastles. (1914). "The War and the Toy Trade Resolved". Games \& Toys. The Leading Trade Journal, 1(4).

Consalvo, M. (2003). It's a queer world after all: studying The Sims and sexuality: GLAAD Center for the Study of Media \& Society.

Consalvo, M. (2007). Cheating: gaining advantage in videogames. Cambridge, Mass. ; London: MIT Press.

ConsoleCheatCodes. "The Sims Cheats". Retrieved December 12, 2006, from http://www.consolecheatcodes.com/pc/thesimscheats.htm 1

Coolidge, S. S. C. W., pseud.]. (1873). What Katy did. A story. London: Ward Lock \& Tyler. 
Correspondent, G. T. (1914). "Continental Letter. The Leipzig Messe". Games \& Toys. The Leading Trade Journal, 1(1).

Coupland, D. (1996). Microserfs. London: Flamingo.

Cross, G. (1997). Kids' stuff: toys and the changing world of American childhood. Cambridge, Mass: Harvard University Press.

Cross, G. (2004). The cute and the cool: wondrous innocence and modern American children's culture. Oxford ; New York: Oxford University Press.

Currie, M. (2006). "Chaos in the core-periphery model". Journal of Economic Behavior \& Organization, 60(2), 252-275

Dale, T. (1981). Harrods. The Store and the Legend. London: Pan Books.

Dan, H. (1907). English shop-fronts old and new: a series of exemples by leading architects. London: Batsford .

Dargahi, N., \& Bremer, M. (1996). Spelen met SimCity 2000: Macht, Politiek en Strategie (L. Vissers, Trans. 2nd ed.). Schoonhoven: Academic Service informatica.

Davidson, R., \& Vine, S. (2007). The Great Big Glorious Book for Girls. New York, N.Y.: Viking.

Debik, K. (1998). "Holz spielt mit. Erinnerungen an Baukästen aus sächischen Gebirgen und ein Plädoyer für Holz". In J. Feldkamp (Ed.), Legen, stecken, schrauben - spielend bauen. Begleitschrift zur Ausstellung des Industriemuseums Chemnitz gemeinsam mit dem Deutschen Spielemuseum e.V. vom 15. November 1998 bis zum 31. Januar 1999 Chemnitz: Industriemuseum Chemnitz.

Delman, T. F., Løssing, T., \& Lykke-Olesen, A. (2007). Interview (Designers of The Harbour Game ed.).

Donath, J. S. (1998). "Identity and Deception in the Virtual Community". In M. Smith \& P. Kollock (Eds.), Communities in Cyberspace (pp. 29-59). London: Routledge.

Dormann, C., \& Biddle, R. (2006). "A Geo-Wiki Game for Urban Exploration and Community Participation". Retrieved August 21, 2007, from http://hot.carleton.ca/hottopics/articles/geo-gameplay/

Dorst, J. v. (2007). Interview (Retired carpenter and construction toy fan ed.).

Dubuisson, P. (1902). Les voleuses de grands magasins. Paris: A. Storck et Compagnie.

Dupouy, R. (1905). "De la kleptomanie". Journal de Psychologie Normale et Pathologique.

EA.com. "About The Sims 2". Retrieved September 24, 2006, from http://thesims2.ea.com/about/index ts2.php 
EA.com. "SimCity 4 Experience". Retrieved December 12, 2006, from http://simcity.ea.com/

EA.com. "SimCity 4 Screenshots". Retrieved August 20, 2007, from

http://simcity.ea.com/about/simcity4/screenshots.php

EA.com. "The Sims Online". Retrieved December 21, 2006, from http://www.eagames.com/official/thesims/thesimsonline/ us/nai/index.jsp

EA.com. "What is SimCity.com?" Retrieved December 15, 2006, from

http://simcity.ea.com/about/simcityweb/simcityweb.php

EA.com. (2005). "Unleashed Game Patch" [Computer Game Patch]: Electronic Arts.

EA.com. (2007a). "Sim Exchange". Retrieved August 20, 2007, from

http://thesims2.ea.com/exchange/search.php?view=new\& search $=1 \&$ asset type $=$ story $\% 22$.

EA.com. (2007b). "The Sims 2 H\&M Fashion Stuff Screenshots". Retrieved July 5, 2007, from http://thesims2.ea.com/about/sp5 screenshots.php

Edgeworth, M., \& Edgeworth, R. L. (1801 [1798]). Practical Education (Vol. 1). London: J. Johnson.

Ekman, I. (2005, July 2-3). "Lego braces for big changes". International Herald Tribune, p. $9 \& 11$.

Elliott, A., \& Lemert, C. C. (2006). The new individualism: the emotional costs of globalization. London: Routledge.

Engelsman, H. (2007). Interview (Area Developer at housing corporation De Alliantie ed.).

Epstein, S. (2003). "Inclusion, Diversity, and Biomedical Knowledge Making: The Multiple Politics of Representation". In N. Oudshoorn \& T. J. Pinch (Eds.), How users matter: the co-construction of users and technologies (pp. 173-190). Cambridge, Mass. ; London: MIT.

Eriksson, T. (1996). "SimLego" [Computer Program].

Feyeux, A. (1883). "La question des grands magasins et des petits magasins". La Reforme sociale, 5, 358-364.

Fiorino, D. J. (1990). "Citizen Participation and Environmental Risk: A Survey of Institutional Mechanisms" Science, Technology, \& Human Values, 15(2), 226-243.

Fisher-Price. (2007). "Smart Cycle TM Physical Learning Arcade System". Retrieved April 26, 2007, from http://www.fisherprice.com $/ \mathrm{fp}$.aspx $? \mathrm{st}=5450 \& \mathrm{e}=$ mainproduct

Flanagan, M. (2003). "Une Maison de Pouppée Virtuelle Capitaliste? The Sims: Domesticité, Consommation et Féminité". In M. Roustan (Ed.), La Pratique du Jeu 
Vidéo. Réalité ou virtualité? (pp. 175-188). Paris: l'Harmattan.

Flynn, B. (2003). "Geography of the Digital Hearth". Information, Communication \& Society, 6(4), 551-576.

Foehr, U. G. (2006). "Media Multitasking Among American Youth: Prevalence, Predictors and Pairings". Retrieved August 17, 2007, from http://www.kff.org/entmedia/7592.cfm

Frasca, G. (2001). "The Sims: Grandmothers are cooler than trolls". Game Studies Retrieved February 24, 2005, from http://www.gamestudies.org/

Frasca, G. (2006). "Videogrames of the Oppressed: Critical Thinking, Education, Tolerance, and Other Trivial Issues" In N. Wardrip-Fruin \& P. Harrigan (Eds.), First person: new media as story, performance, and game (pp. 85-94). Cambridge, Mass.: MIT Press.

Friedberg, A. (1993). Window Shopping. Cinema and the Postmodern. California: University of California Press.

Friedman, A. (1995). "Model Homes and Dream Houses". In C. Dufresne (Ed.), Dream Houses, Toy Homes (pp. 7-27). Québec: Centre Canadien d'Architecture/Canadian Centre for Architecture.

Friedman, T. (1995). "Making Sense of Software: Computer Games and Interactive Textuality". In S. G. Jones (Ed.), Cybersociety: Computer-mediated communication and community (pp. 73-89): Sage Publications.

Fröbel, F. (1887). The Education of Man (W. N. Hailmann, Trans. Vol. 1). New York: Appleton and Company.

Fröbel, F. (1897). Pedagogics of the Kindergarten. Or, his ideas concerning the play and playthings of the child. (J. Jarvis, Trans.). London: Edward Arnold.

Fuchs, M., Manthorp, S., \& Schlusmans, V. (2006). "PlastiCity" [Computer Game].

Furnée, J. H. (2003). "Winkeletalages als Moderne Massamedia. Visuele Cultuur en Sociale Verhoudingen in Den Haag, 1850-1890". De negentiende eeuw: documentatieblad Werkgroep 19e eeuw, 27(2), 74 - 106.

Gamages. (1913). "Gamages Mammoth Bargain Clearance" Advertisement Cataloguing Sale Items from Gamages Department Store London: Gamages.

Gamespot. "SimCity 4: Deluxe Edition". Retrieved December 15, 2006, from http://www.gamespot.com/pc/strategy/simcity4deluxeedit ion/hints.html

Garrigues, H. (1898). Les Grands Magasins de nouveautes et le petit commerce de detail. Paris: Librarie Nouvelle de Droit et de Jurisprudence. 
Gesell, A. L. (1906). "The Psychology of Human Jealousy". The American Journal of Psychology, XVII(4), 452-480.

Gillin, J. L. (1918). Wholesome Citizens and Spare Time. Cleveland: Cleveland Foundation.

Ginsburg, K. R. (2007). "The Importance of Play in Promoting Healthy Child Development and Maintaining Strong Parent-Child Bonds Guidance for the Clinician in Rendering Pediatric Care". Pediatrics, 119(1), 182-191.

Girard, M. H. (1845). "Kleptomanie". Gazette Medicale de Paris.

Gjøls-Andersen, P. (2001). The Internal Dimensions of Branding. A Case Study of the Change on Brand Strategy in Lego from a Focus on the Famous Building Brick to Introducing a Broad Variety of Lego Products in the Children's Universe. Copenhagen Business School, Copenhagen.

Gjøls-Andersen, P., \& Karmark, E. (2005). "Corporate Brand Stretch - Brand Extension in a Corporate Branding Perspective". In M. Schultz, M. A. Yun \& F. F. Csaba (Eds.), Corporate branding: purpose/people/process : towards the second wave of corporate branding (pp. 151179). Copenhagen: Copenhagen Business School Press.

Glas, R. (2007). "Playing Another Game; Twinking in World of Warcraft". Paper presented at the DiGRA 2007: Situated Play.

Golder, S. A., \& Donath, J. (2004). Social Roles in Electronic Communities. Paper presented at the Internet Research 5.0. Retrieved December 15, 2006, from http://web.media.mit.edu/ golder/projects/roles/golder20 04.pdf.

GothamGazette. (2007a). "Ground Zero Planner". Retrieved August 21, 2007, from

http://www.gothamgazette.com/rebuilding_nyc/groundze roplanner/\#

GothamGazette. (2007b). "Plan Your Future Park". Retrieved August 21, 2007, from http://www.gothamgazette.com/parksgame/

Gottmann, J. (1980). "Preface". In J. Gottmann (Ed.), Centre and periphery: spatial variation in politics Beverly Hills; London: Sage.

Green, P. (1899). A History of Nursery Rhymes. London: Greening. Greenberg, J. (2006). "Interview with Soren Lund, Lego Mindstorms and Product \& Marketing Development Director" Friends Talking Retrieved June 21, 2007, from http://friendstalking.joelandkaren.com/?p=23

Grint, K., \& Woolgar, S. (1997). The machine at work: technology, work, and organization. Cambridge: Polity Press. 
Groeneveld, S. (2007). Interview (Digitale Pioniers, Kennisland Financial supporter Face Your World ed.).

H\&M. (2007). "H\&M IN COOPERATION WITH THE SIMS 2". Retrieved September 11, 2007, from http://www.hm.com/nl/press/pressreleases/_prfashion.n

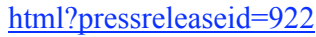

Hall, P. G. (2002). Cities of tomorrow: an intellectual history of urban planning and design in the twentieth century (3rd ed.). Oxford: Basil Blackwell.

Hall, S., \& Smith, T. (1903). "Showing off and Bashfulness as Phases of Self-Consciousness". The pedagogical seminary: international record of educational literature, institutions and progress, 10, 159-199.

Hameetman, F. (2007). Interview (Educational program leader at De Kunsthal, Rotterdam ed.).

Hansen, J. (2007). "Not Quite C". Retrieved August 20, 2007, from http://bricxcc.sourceforge.net/nqc/

Hansen, O. S. (1997). Grote zakensuccessen. Godtfred Kirk Christiansen en Lego (M. C. Solleveld, Trans.). Gilze: Dahlgaard Media B.V.

Hanson, M. (1993). Minibrix - The Unique Rubber Building Toy. Henley on Thames: MW Models.

Håpnes, T. (1996). "Not in Their Machines: How Hackers Transform Computers into Subcultural Artefacts". In M. Lie \& K. H. Sørensen (Eds.), Making technology our own? Domesticating technology into everyday life (pp. 121-150). Oslo: Scandinavian University Press.

Harbers, H. (1996). "Politiek van de technologie". Kennis en Methode, 3, 308-315.

Hardyment, C. (1984). Dream Babies. Child Care from Locke to Spock. Oxford: Oxford University Press.

Hartoog, I. d. (2007). Interview (Face Your World project supporter ed.).

Healy, C. (2007, July 1). "Hey, Man, Let's Play Video Game Dress-Up". The New York Times

Heeswijk, J. v. (2007). Interview (Initiator Face Your World ed.).

Heeswijk, J. v., \& Kaspori, D. (2002-ongoing). "Face Your World" [Public Participation Tool].

Heeswijk, J. v., Kaspori, D., \& Mosterd, R. (2005-2006). "Face Your World 2.0 (Slotervaart)". Retrieved September 28, 2007, from http://www.faceyourworld.nl/slotervaart

Heeswijk, J. v., Kaspori, D., Mosterd, R., \& Berg, L. v. d. (20062007). "Face Your World Rotterdam". Retrieved September 28, 2007, from http://www.faceyourworld.nl/rotterdam

Hendricks, B. (2001). Designing for Play. Aldershot: Ashgate. 
Herring, S., Job-Sluder, K., Scheckler, R., \& Barab, S. (2002). "Searching for Safety Online: Managing Trolling in a Feminist Forum". The Information Society, 18(5), 371384.

Herz, J. C. (2000, February 10). "The Sims Who Die With the Most Toys Win". The New Yrok Times.

Herz, J. C., \& Macedonia, M. R. (2002). "Computer games and the military: two views". Retrieved February 14, 2006, from http://purl.access.gpo.gov/GPO/LPS23406

Hewitt, K., \& Roomet, L. (1979). Educational toys in America, 1800 to the present. Burlington, Vt.: Robert Hull Fleming Museum, University of Vermont.

Hills, M. (2002). Fan cultures. London; New York: Routledge.

Hilton, M., Styles, M., \& Watson, V. (1997). Opening the nursery door: reading, writing and childhood 1600-1900. London: Routledge.

Hippel, E. v. (2005). Democratizing innovation. Cambridge, Mass.: MIT Press.

Hjarvard, S. (2004a). Brand new toys. Paper presented at the International Colloquium "Pluridisciplinary Perspectives on Child and Teen Consumption.

Hjarvard, S. (2004b). "From Bricks to Bytes: The Mediatization of a Global Toy Industry". In I. G. Bondeberg, Peter (Ed.), European Culture and the Media (Vol. 1, pp. 43-63). Bristol: Intellect Books.

Hoeve, L. (2007). Interview (Communication advisor from the ward Slotervaart ed.).

Hommels, A. (2005). Unbuilding cities: obduracy in urban sociotechnical change. Cambridge, Mass.: MIT Press.

Hoogeveen, R. (2007). Interview (Area developer at housing corporation De Alliantie - Financial supporter Face Your World ed.).

Hughes, J. (2007). "Brick Fetish". Retrieved June 16, 2007, from http://www.brickfetish.com/

Huhtamo, E. (2005). "Slots of Fun, Slots of Trouble: an Archeology of Arcade Gaming". In J. Raessens \& J. H. Goldstein (Eds.), Handbook of computer game studies (pp. 3-21). Cambridge, Mass.: MIT Press.

Huisingh, A. (2007). Interview (Former head of Culture and Education at AFK - Financial supporter Face Your World ed.).

Iggulden, C., \& Iggulden, H. (2006). The dangerous book for boys. London: HarperCollins.

Ingham, A. (1928). Gamage's Children's Annual. London: Gamage Book Department. 
Jacobson, M. A. (1994). Being a boy again: autobiography and the American boy book. Tuscaloosa: University of Alabama Press.

Jenkins, H. (1992). Textual Poachers: Television Fans and Participatory Culture: Routledge New York.

Jenkins, H. (2000). "Complete Freedom of Movement: Video Games as Gendered Play Spaces". In J. Cassell \& H. Jenkins (Eds.), From Barbie to Mortal Kombat gender and computer games (pp. 262-297). Cambridge, Mass.: MIT Press.

Jenkins, H. (2002). "Interactive Audiences?" In D. Harries (Ed.), The new media book (pp. 157-170). London: British Film Institute.

Jenkins, H. (2006a). Convergence Culture: Where Old and New Media Collide. New York: New York University Press.

Jenkins, H. (2006b). Fans, Bloggers, and Gamers: Exploring Participatory Culture. New York; London: New York University Press.

Jenkins, H. (2006c). "From a 'Must Culture' to a 'Can Culture': Legos and Lead Users". Retrieved June 21, 2007, from http://www.henryjenkins.org/2006/10/from_a must_cult ure to a can c.html

Jenkins, H., \& Thorburn, D. (2003). "Introduction: The Digital Revolution, the Informed Citizen, and the Culture of Democracy". In H. Jenkins, D. Thorburn \& B. Seawell (Eds.), Democracy and new media (pp. 1-17). Cambridge, Mass.: MIT Press.

Jessiman, J. (1995). "LDraw" [Computer Program].

Johan. "The Sims Online Cheats - Bots, Automation Tools, and Codes". Retrieved December 15, 2006, from http://www.mysimsonlinecheats.com/

Johan@MySimsOnlineCheats. (2007). "E-mail Communication. RE: question".

JonhB. (2006). "Cactus Flora Mod" [Computer Game Modification]: www.simtropolis.com.

Jørgensen, U. (1998). The LEGO brick system under reconstruction - an era of constructional toys challenged by the information age. Paper presented at the Path Creation and Dependency Conference.

Jung, J. (2003). "SimCity FAQ Ver 0.03". Retrieved December 15,2006 , from http://faqs.ign.com/articles/387/387910p1.html

Juul, J. (2005). Half-real: video games between real rules and fictional worlds. Cambridge, Mass. ; London: MIT Press.

Kammen, J. v. (2003). "Who Represents the Users? Critical Encounters between Women's Health Advocates and Scientists in Contraceptive R\&D". In N. Oudshoorn \& T. 
J. Pinch (Eds.), How users matter: the co-construction of users and technologies (pp. 151-172). Cambridge, Mass. ; London: MIT.

Karsten, L. (1995). Building identities: gender perspectives on children and urban space. Paper presented at the Building identities: Gender perspectives on children and urban space.

Karsten, L. (2002). "Mapping childhood in Amsterdam: The spatial and social construction of children's domains in the city". $T$ dschrift voor economische en sociale geografie: orgaan der Nederlandsche Vereeniging voor Economische Geographie, 93(3), 231-241.

Karsten, L. (2003a). "Children's Use of Public Space: The Gendered World of the Playground". Childhood: a global journal of child research, 10(4), 457-474.

Karsten, L. (2003b). "Het onzichtbare kind. Over de (on)mogelijkheid om buiten de spelen - De veranderde leefsituatie van kinderen en de steeds schaarser wordende (stedelijke) publieke ruimte zet het onderwerp kinderen en buitenspelen hoog op de agenda". Openbaar bestuur, 13(2), 8-11.

Karsten, L. (2004). "Speelruimte onder druk". Vr_et_d en samenleving: Nederlands-Vlaams t_dschrift voor vr_et_dskunde, 22(3), 45.

Karsten, L., \& Beckers, T. (1995). Kinderen en vrijetijd. Den Haag: Stichting Recreatie.

Kaspori, D. (2007). Interview (Architect on Face Your World team ed.).

Keen, A. (2007). The Cult of the Amateur: How Today's Internet is Killing our Culture and Assaulting our Economy. London: Nicholas Brealey.

Kerstens, M. (1997). "It's all in the game!" Rooilijn: mededelingen van het planologisch en demografisch instituut, 15-19.

Key, E. (1909). The Century of the Child. New York: Putnam; The Knickerbocker Press.

Kinetz, E. (2005, April 2-3). "Putting away childish things". International Herald Tribune, pp. 16-17.

Kline, S. (1993). Out of the Garden: toys, TV and children's culture in the age of marketing. London: Verso.

Kline, S., Dyer-Witheford, N., \& De Peuter, G. (2003). Digital play: the interaction of technology, culture, and marketing. Montreal; Ithaca [New York]: McGillQueen's University Press.

Koerner, B. I. (2006). "Geeks in Toyland". Wired, 14.

Kollision. (2002). "The Harbour Game" [Public Participation Tool]. Denmark: Projektgruppen Havnen På Spil. 
König, W. (2000). Geschichte der Konsumgesellschaft. Stuttgart: Franz Steiner Verlag.

Kreek, G. (2007). Interview (Face Your World participant ed.).

Kretzmann, J. P., \& McKnight, J. L. (2006). "Asset Mapping". In E. Sendich (Ed.), Planning and urban design standards (pp. 53-54). Hoboken: John Wiley \& Sons.

Kücklich, J. (2006). "The Game Industry and the Crisis of Creativity". The Creativity, 9.

Lacassagne, A. (1896). "Les vols a l'etalage dans les grands magasins". Revue de L'Hypnotisme et de la Psychologie Physiologique, 2.

Lachmann, M. (1999). "MLCAD" [Computer Program].

LadyWolf. (2006). "Re: Question for Research Purpose". Retrieved September 25, 2006, from http://boards.stratics.com/phpbin/sims/showflat.php?Cat $=\&$ Number $=629976 \&$ page $=1$ \&view $=$ collapsed $\& \mathrm{sb}=5 \& 0=\&$ fpart $=1$

Lamvik, G. M. (1996). "A Fairy Tale on Wheels: The Car as a Vehicle for Meaning within a Norwegian Subculture". In M. Lie \& K. H. Sørensen (Eds.), Making technology our own? Domesticating technology into everyday life (pp. 151-170). Oslo: Scandinavian University Press.

Lane, A. (1998). "The Joy of Bricks". Retrieved January 21, 2005, from

http://www.randomhouse.com/boldtype/0802/lane/excerp t bricks.html

LaPlante, A., \& Seidner, R. (1999). Playing for profit: how digital entertainment is making big business out of child's play. New York ; Chichester: Wiley.

Lasegue, C. (1879). "Le vol aux etalages". L'Union Medicale.

Latour, B. (2004). "How to Talk About the Body? The Normative Dimension of Science Studies". Body \& Society, 10(2-3), 205-229.

Lauwaert, M. (2006). "Get Up \& Play". In B. Neitzel \& R. F. Nohr (Eds.), Das Spiel mit dem Medium. Partizipation Immersion - Interaktion Zur Teilhabe an den Medien von Kunst bis Computerspiel (pp. 48-63): Schüren Presseverlag.

Lauwaert, M. (2007). "Challenge Everything? Construction Play in Will Wright's SIMCITY". Games and Culture, 2(3), 194212.

Lauwaert, M. (2008). "Playing Outside the Box - On LEGO Toys and the Changing World of Construction Play". History and Technology.

Lauwaert, M., \& Hendriks, M. (2006). "Een constante, duizelingwekkende omkering". $D W B, 5-6,751-758$. 
Lauwaert, M., Wachelder, J., \& Walle, J. v. d. (2004).

"Computerspellen en de Geschiedenis van Angst. Het

Gebruik en Misbruik van Historische Vergelijkingen".

Tijdschrift voor Mediageschiedenis, 2, 31-52.

Lauwaert, M., Wachelder, J., \& Walle, J. v. d. (2007). "Frustrating

Desire. On Repens and Repositio, or the Attractions and Distractions of Digital games". Theory, Culture \& Society, 24(1), 89-108.

LEGO. "Blacksmith Shop". Retrieved April 18, 2007, from http://shop.lego.com/Product/Default.aspx?p=3739

LEGO. "Fan Designs His Own LEGO Set! The 'My Own Creation' Series". Brick Street Journal Retrieved April, 18, 2007, from

http://club.lego.com/eng/newsandfeatures/story.asp?conte ntid $=313$

LEGO. "LEGO Ambassadors". Retrieved April 18, 2007, from http://www.lego.com/eng/info/default.asp?page=ambassa dors

LEGO. "LEGO Certified Professionals". Retrieved June 20, 2007, from

http://www.lego.com/eng/info/default.asp?page=affiliates

LEGO. "LEGO Factory Fan Designed Exclusives". Retrieved April 18, 2007, from

$\underline{\text { http://shop.lego.com/product/Factory/Default.aspx?cn=15 }}$ 7

LEGO. "LEGO Factory". Retrieved April 18, 2007, from http://factory.lego.com/

LEGO. (1975). A Brick - and the story behind it: LEGO Company.

LEGO. (1979). Heden en verleden. Denmark: LEGO Company.

LEGO. (1982). 50 years of play. Billund: LEGO Group.

LEGO. (1997). Developing a Product Leaflet. Billund: LEGO Group.

LEGO. (2004). "Annual Report 2004 LEGO Group". Retrieved August 17, 2007, from http://www.lego.com/eng/info/default.asp?page=annualre port

LEGO. (2005a). "Annual Report 2005 LEGO Group". Retrieved August 17, 2007, from http://www.lego.com/eng/info/default.asp?page=annualre port

LEGO. (2005b). "LEGO Timeline". Retrieved August 6, 2005, from http://www.lego.com/eng/info/default.asp?page=timeline LEGO. (2006). "Annual Report 2006 LEGO Group". Retrieved August 17, 2007, from http://cache.lego.com/downloads/aboutus/annualreport20 06UK.pdf 
LEGO. (2007a). "LEGO Online Store - CREATOR Sets". Retrieved June 20, 2007, from http://shop.lego.com/Product/?p=4956

LEGO. (2007b). "Legoland Discovery Centre Berlin". Retrieved July 31, 2007, from http://www.legolanddiscoverycentre.com/

Lentz, W. (2007). Interview (Director of SKOR - Financial supporter and original commissioner of Face Your World ed.).

Leroy-Beaulieu, P. (1875). "Les grands magasins universels et les petits detaillants". L'Economiste Francais.

Letulle, M. (1887). "Voleuses honnetes ebauche medico-legale". Gazette Medicale de Paris.

Levi-Strauss, C. (1966). The savage mind (La pensee sauvage). London: Weidenfeld \& Nicolson.

Lewis, M. J. (1992). "Toys That Teach". In M. J. Lewis (Ed.), Apprendre de Toutes Pièces. Toys That Teach. Montreal: Centre Canadien d'Architecture.

Lie, M. (1996). "Gender in the Image of Technology". In M. Lie \& K. H. Sørensen (Eds.), Making technology our own? Domesticating technology into everyday life (pp. 201222). Oslo: Scandinavian University Press.

Lie, M., \& Sørensen, K. H. (1996). "Making technology our own? Domesticating technology into everyday life". In M. Lie \& K. H. Sørensen (Eds.), Making technology our own? Domesticating technology into everyday life (pp. 1-30). Oslo: Scandinavian University Press.

Liebschner, J. (1992). A child's work: freedom and play in Froebel's educational theory and practice. Cambridge: Lutterworth Press.

Lieshout, M. v., Bijker, W. E., \& Egyedi, T. M. (2001). "Social Learning". In M. v. Lieshout, T. M. Egyedi \& W. E. Bijker (Eds.), Social learning technologies: the introduction of multimedia in education (pp. 37-59). Aldershot: Ashgate.

Lilleker, G. (1998). "LEGO (early)". Retrieved December 12, 2005, from http://www.personal.u-net.com/ lilleker/conlego.htm

Lilley, I. (1967). Friedrich Froebel. A selection from his writings. Cambridge: University Press.

LindenLab. (2003). "Second Life" [Online computer game]. San Francisco: Linden Lab.

Lingens, P. (1999). "Bausteine. Einleitende Betrachtungen". In U. Leinweber (Ed.), Baukästen. Technisches Spielzeug vom Biedermeier bis zur Jahrtausendwende. Ausstellungskatalog (Vol. 7, pp. 12-33). Wiesbaden: VMA Verlag - Drei Lilien Edition. 
Linn, S. (2004). Consuming kids: the hostile takeover of childhood. New York: New Press.

Linn, S. (2005). Consuming kids: protecting our children from the onslaught of marketing and advertising. New York: Anchor Books.

Lithgow, A. (1987). "Analysis: Astonishing secret behind the world's most famous toy. The ghost that is haunting LEGO land". Retrieved September 16, 2007, from http://www.best-lock.com/new/page.html

Lobo, D. G. (2004). "Playing with Urban Life: How SimCity Influences Planning Culture". Technology \& Cities(6).

Lobo, D. G. (2005). A City is not a Toy. How SimCity Plays with Urbanism. Paper presented at the Architecture and engineering. Retrieved September 16, 2007, from http://www.geocities.com/daniellobo99/Lobo_CityToy05 LSE.pdf.

Lobo, D. G., \& Schooler, L. (2004). "Playing with Urban Life: How SimCity Influences Planning Culture". Technology \& $\operatorname{Cities}(6)$.

Loudon, J. C., \& Loudon, J. W. ([1838] 1982). The suburban gardener, and villa companion. New York: Garland Pub.

LOWLUG. (2007). "Lego Factory". Retrieved June 18, 2007, from http://www.lowlug.nl/forum/viewtopic.php?t=3952\&post $\underline{\text { days }}=0$ \& postorder $=$ asc $\&$ vote $=$ viewresult

LuckyHawk. (2006). "Scammers \& Me". Retrieved September 10, 2006, from http://boards.stratics.com/phpbin/sims/showflat.php?Cat $=\&$ Number $=628202$ \&page $=2$ $\underline{\text { \&view }=\text { collapsed } \& \mathrm{sb}=5 \& \mathrm{o}=\& \text { fpart }=1}$

Ludlow, P. (2003). "Evangeline: Interview with a child cyberprostitute in TSO". Retrieved November 15, 2005, from http://www.alphavilleherald.com/archives/000049.html

Ludlow, P., \& Wallace, M. (2006). Only a Game: Online Worlds and the Virtual Journalist Who Knew Too Much. Unpublished Unpublished Manuscript.

Lugnet. "'MOC' Blacksmith Shop on lego.com". Retrieved April 18,2007 , from http://news.lugnet.com/castle/?n=11209\&t=i\&v=a

Lundestad, C., \& Hommels, A. (2007). "Software vulnerability due to practical drift". Ethics and Information Technology, $9(2)$.

Lunier, M. 1. (1848). "Des vols aux etalages". Annales MedicoPsychologiques.

Lury, C. (2004). Brands : the logos of the global economy. London ; New York: Routledge.

Lynch, K. (1984). Good city form. Cambridge, Mass: MIT Press. 
MacIntyre, J. (2005). "Sim civics". Retrieved February 21, 2006, from

http://www.boston.com/news/globe/ideas/articles/2005/0 8/07/sim civics/

Mackay, H., Carne, C., Beynon-Davies, P., \& Tudhope, D. (2000). "Reconfiguring the User: Using Rapid Application Development". Social Studies of Science, 30(5), 737-757.

mandmjeffers1. (2007). "Celebrate Mom 2007". Lot Exchange

Retrieved July 3, 2007, from

http://thesims2.ea.com/exchange/

Manzini, E., \& Cau, P. (1989). The material of invention.

Cambridge, Mass: MIT Press.

Margerum, R. (2006). "Stakeholder Identification". In E. Sendich (Ed.), Planning and urban design standards (pp. 49-50). Hoboken: John Wiley \& Sons.

Martin Saint-Léon, E. (1911). Le petit commerce francais sa lutte pour la vie. Paris: Victor Lecoffre.

Massey, D. B. (1994). Space, place and gender. Cambridge: Polity.

Matt, S. J. (2002). "Children's Envy and the Emergence of the Modern Consumer Ethic, 1890-1930". Journal of Social History, 36(2), 283-302.

Mattel. (2007). "BarbieGirls". Retrieved July 5, 2007, from http://www.barbiegirls.com/home.html

Maxis. (1989). "SimCity Classic" [Computer Game]: Maxis.

Maxis. (1992). "SimCity 2000" [Computer Game]: Maxis.

Maxis. (1999). "SimCity 3000" [Computer Game]: Electronic Arts.

Maxis. (2000a). "Livin' Large" [Computer Game Expansion Pack]:

Electronic Arts.

Maxis. (2000b). "The Sims" [Computer Game]: Electronic Arts.

Maxis. (2001a). "Hot Date" [Computer Game Expansion Pack]:

Electronic Arts.

Maxis. (2001b). "House Party" [Computer Game Expansion Pack]:

Electronic Arts.

Maxis. (2002a). "The Sims Online" [Online Computer Game]:

Electronic Arts.

Maxis. (2002b). "Unleashed" [Computer Game Expansion Pack]:

Electronic Arts.

Maxis. (2002c). "Vacation" [Computer Game Expansion Pack]:

Electronic Arts.

Maxis. (2003a). "Makin' Magic" [Computer Game Expansion

Pack]: Electronic Arts.

Maxis. (2003b). "SimCity 4" [Computer Game]: Electronic Arts.

Maxis. (2003c). "Superstar" [Computer Game Expansion Pack]:

Electronic Arts.

Maxis. (2004a). "The Sims 2" [Computer Game ]: Electronic Arts.

Maxis. (2004b). "The Urbz. Sims in the City" [Game Boy Advance

Computer Game]: Electronic Arts. 
Maxis. (2006a). "The Sims 2: Family Fun Stuff" [Computer Game Stuff Pack]: Electronic Arts.

Maxis. (2006b). "The Sims 2: Glamour Life Stuff" [Computer Game Stuff Pack]: Electronic Arts.

Maxis. (2006c). "The Sims 2: Happy Holiday Stuff" [Computer Game Stuff Pack]: Electronic Arts.

Maxis. (2006d). "The Sims 2: Open for Business" [Computer Game Expansion Pack]: Electronic Arts.

Maxis. (2007a). "The Sims 2 H\&M Fashion Stuff" [Computer Game Stuff Pack]: Electronic Arts.

Maxis. (2007b). "The Sims 2: Celebration! Stuff" [Computer Game Stuff Pack]: Electronic Arts.

Maxis. (forthcoming). "Spore" [Computer Game]: Electronic Arts. McAtee, C. (1997). "The Elements of Toy Towns". In E. Tingley (Ed.), La ville en jeux: du 22 octobre 1997 au 31 mai 1998 = Toy town: from 22 October 1997 to 31 May 1998. Montreal: Centre Canadien d'Architecture.

McClary, A. (1997). Toys with nine lives: a social history of American toys. North Haven, Connecticut: Linnet Books.

McKee, J. (2005). "Announcing LEGO Ambassadors". Retrieved April 18, 2007, from http://news.lugnet.com/lego/?n=3116

Meikle, J. L. (1997). American plastic: a cultural history. New Brunswick, N.J: Rutgers University Press.

Mény, Y., \& Wright, V. (1985). Centre-periphery relations in Western Europe. London: Allen \& Unwin.

Mey, T. (1999). "Baukästen vom Biedermeier bis zur Jahrhundertwende. Das Spiel mit Holzbaukästen". In U. Leinweber (Ed.), Baukästen. Technisches Spielzeug vom Biedermeier bis zur Jahrtausendwende. Ausstellungskatalog (Vol. 7, pp. 34-47). Wiesbaden: VMA Verlag - Drei Lilien Edition.

Mike. (2002). "I'm disappointed..." Retrieved August 17, 2007, from http://groups.google.com/group/alt.games.thesims/browse thread/thread/83f92730fe0f0059/7705b8b1 $992 \mathrm{eb} 2 \mathrm{db} ? \mathrm{tvc}=2 \& \mathrm{q}$

Miklaucic, S. (2003). "God Games and Governmentality.

Civilization II and Hypermediated Knowledge" In J. Z. Bratich, J. Packer \& C. McCarthy (Eds.), Foucault, cultural studies and governmentality (pp. 317-335). Albany: State University of New York Press.

Molesworth, M., \& Denegri-Knott, J. (2007). "Digital Play and the Actualization of the Consumer Imagination". Games and Culture, 2(2), 114-133.

Molleindustria. (2006). "McDonald's Videogame" [Computer Game]: Molleindustria. 
Mollerup, P. (2001). Collapsible: the genius of space-saving design. San Francisco, Calif.: Chronicle.

MUJI. (2007). "Suburbia in a Bag". Retrieved August 20, 2007, from http://www.mujionline.co.uk/

Mumford, L. (1961). The city in history: its origins, its transformations, and its prospects ([1st ed.). New York,: Harcourt Brace \& World.

Mumford, L. (1965). "The Garden City Idea and Modern Planning". In F. J. Osborn (Ed.), Garden Cities of ToMorrow (pp. 29-40). Cambridge, Mass.: M.I.T. Press.

Muñiz, A. S. G., \& Carvajal, C. R. (2006). "Core-periphery structure models: An alternative methodological proposal". Social networks: an international journal of structural analysis, 28(4), 442-448.

Nasaw, D. (1985). Children of the city: at work and at play (1st ed.). Garden City, N.Y.: Anchor Press/Doubleday.

NCI. (2006). "Charrettes". In E. Sendich (Ed.), Planning and urban design standards (pp. 57-58). Hoboken: John Wiley \& Sons.

Nieborg, D. (2006). The Expansion Pack Economy. Paper presented at the Media Change and Social Theory. The 2nd annual ESRC Centre for Research on Socio-Cultural Change conference.

Nintendo. (2007). "Wii". Retrieved August 21, 2007, from http://wii.nintendo.com/

Nishikawa, N. I. (2006). "Surveys". In E. Sendich (Ed.), Planning and urban design standards (pp. 51-52). Hoboken: John Wiley \& Sons.

Noell, M. (2004). "Des Architekten liebstes Spiel: Baukunst aus dem Baukasten". Figurationen. Gender, Literatur, Kultur, 1.

Noschka, A., \& Knerr, G. (1986). Bauklötze staunen: zweihundert Jahre Geschichte der Baukästen. München: Hirmer Verlag - Deutsches Museum.

Obermeyer, N. J. (1998). "The Evolution of Public Particpation GIS". Cartography and Geographic Information Systems, 25(2), 65-66.

Olson, E. (2001). "BrickDraw3D" [Computer Program].

Olsson, K. (2003). "Fritids". Retrieved September 24, 2007, from http://www.buf.kristianstad.se/villa/masart/fritids.html

Ooms, M. (2007). Interview (Intern at De Kunsthal, Rotterdam ed.).

Oudshoorn, N., \& Pinch, T. J. (2003). "Introduction: How Users and Non-Users Matter". In N. Oudshoorn \& T. J. Pinch (Eds.), How users matter: the co-construction of users and technologies (pp. 1-25). Cambridge, Mass. ; London: MIT. 
Oudshoorn, N., Rommes, E., \& Stienstra, M. (2004). "Configuring the User as Everybody: Gender and Design Cultures in Information and Communication Technologies". Science, Technology \& Human Values, 29(1), 30-63.

Page, H. (1938). Playtime in the first five years. Croydon,: Surrey, Watson \& Crossland.

PandoraSims. "Pandora Sims". Retrieved August 20, 2007, from http://www.pandorasims.net/

Papert, S. (1991). "Situating Constructionism". In S. Papert \& I. Harel (Eds.), Constructionism. Research Reports and Essays, 1985-1990 by the Epistemology \& Learning Research Group (pp. 1-11). New Jersey: Ablex Publishing Corporation.

Papert, S. (1993). Mindstorms: children, computers, and powerful ideas (2nd ed.). New York: Basic Books.

Parkinson, E. (1999). "Re-constructing the Construction Kit - Reconstructing Childhood: A Synthesis of the Influences which have Helped to Give Shape and Form to Kit-based Construction Activities in the Primary School Classroom". International Journal of Technology and Design Education, 9(2), 173-194.

Parthasarathy, S. (2003). "Knowledge Is Power: Genetic Testing for Breast Cancer and Patient Activism in the United States and Britain". In N. Oudshoorn \& T. J. Pinch (Eds.), How users matter: the co-construction of users and technologies (pp. 133-150). Cambridge, Mass. ; London: MIT.

Paulk, C. (2006). "Signifying Play: The Sims and the Sociology of Interior Design". Game Studies: the international journal of computer game research, 6(1).

Pearce, C. (2002). "Story as Play Space". In L. King (Ed.), Game on: the history and culture of videogames (pp. 112-119). London: Laurence King Pub.

Pearce, C. (2004). "Towards a Game Theory of Game". In N. Wardrip-Fruin \& P. Harrigan (Eds.), First person: new media as story, performance, and game (pp. 143-153). Cambridge, Mass.: MIT Press.

PEGI. (2004). "Pan European Games Information". Retrieved November 15, 2005, from http://www.pegi.info

PenguinWiki. (2007). "A Million Penguins". Retrieved September 12,2007 , from http://www.amillionpenguins.com/wiki/index.php/About

Pia. (2007). "Pia's Antique Gallery". Retrieved August 21, 2007, from http://www.rubylane.com/shops/piatik/item/PS0104-07-04

PICO. (2006). "PICO Cricket Kit". Retrieved January 18, 2006, from http://www.playfulinvention.com/ 
Pollock, L. A. (1983). Forgotten children: parent-child relations from 1500 to 1900. Cambridge [Cambridgeshire] ; New York: Cambridge University Press.

Poser, S., \& Zachmann, K. (Eds.). (2003). Homo faber ludens: Geschichten zu Wechselbeziehungen von Technik und Spiel (Vol. Band 4). Frankfurt am Main: Peter Lang.

Pursell, C. (1992). "The Long Summer of Boy Engineering". In J. L. Wright (Ed.), Possible Dreams: Enthusiasm for Technology in America (pp. 35-43). Dearborn: Henry Ford Museum \& Greenfield Village.

QueenFerny. (2006). "Re: Question for Research Purpose". Retrieved September 25, 2006, from http://boards.stratics.com/phpbin/sims/showflat.php?Cat $=\&$ Number $=629976 \&$ page $=1$ \&view $=$ collapsed $\& s b=5 \& 0=\&$ fpart $=1$

Raessens, J. (2005). "Computer Games as Participatory Media Culture". In J. Raessens \& J. H. Goldstein (Eds.), Handbook of computer game studies (pp. 373-389). Cambridge, Mass.: MIT Press.

Raessens, J., \& Goldstein, J. H. (Eds.). (2005). Handbook of computer game studies. Cambridge, Mass.: MIT Press.

Rainwater, C. (1922). The Play Movement in the United States. Washington: McGrath Publishing Company.

Rauno, T. (2001a). The French market for toys \& games. London: Euromonitor.

Rauno, T. (2001b). The Italian market for toys \& games. London: Euromonitor.

Rauno, T. (2002). The Spanish market for toys \& games. London: Euromonitor.

Rejeski, D., \& Sawyer, B. (2002). "Serious Games Initiative". Retrieved December 15, 2006, from http://www.seriousgames.org/index $2 . h t m l$

Richtel, M., \& Stone, B. (2007, June 6). "Doll Web Sites Drive Girls to Stay Home and Play". The New York Times

Rideout, V. J., \& Hamel, E. (2006). "The Media Family: Electronic Media in the Lives of Infants, Toddlers, Preschoolers and their Parents". Retrieved August 17, 2007, from http://www.kff.org/entmedia/upload/7500.pdf

Rideout, V. J., Vandewater, E. A., \& Wartella, E. A. (2003). "Zero to Six. Electronic Media in the Lives of Infants, Toddlers and Preschoolers" Retrieved August 17, 2007, from http://www.kff.org/entmedia/upload/Zero-to-SixElectronic-Media-in-the-Lives-of-Infants-Toddlers-andPreschoolers-PDF.pdf

Roberts, D. F., Foehr, U. G., \& Rideout, V. J. (2005). "Generation M: Media in the Lives of 8-18 Year-0lds". Retrieved 
August 17, 2007, from

http://www.kff.org/entmedia/7251.cfm

Roberts, D. F., Foehr, U. G., Rideout, V. J., \& Brodie, M. (1999).

"Kids \& Media@ the New Millennium". Retrieved

August 17, 2007, from

http://www.kff.org/entmedia/loader.cfm?url=/commonsp ot/security/getfile.cfm\&PageID $=13267$

Rokkan, S., Urwin, D., \& Aarebrot, F. H. (1987). Centre-periphery structures in Europe: an ISSC workbook in comparative analysis. Frankfurt; New York: Campus Verlag.

Rosenzweig, R., \& Blackmar, E. (1992). The park and the people: a history of Central Park. Ithaca, N.Y.: Cornell University Press.

Roth, M. (2002). "The Bible vs. the Ikea Catalogue - Which is Winning Hearts?" Martin Roth Christian Commentary Retrieved July 5, 2007, from http://www.martinrothonline.com/MRCC23.htm

Rowe, G., \& Frewer, L. J. (2004). "Evaluating Public-Participation Exercises: A Research Agenda". Science, technology, \& human values, 29(4), 512-557.

Rutter, J., \& Bryce, J. (2006). Understanding digital games. Thousand Oaks, CA: SAGE Publications.

Rybczynski, W. (1995). City life: urban expectations in a new world. New York ; London: Scribner.

Sætnan, A. R. (1996). "Speaking of Gender...: Intertwinings of a Medical Technology Policy Debate and Everyday Life". In M. Lie \& K. H. Sørensen (Eds.), Making technology our own? Domesticating technology into everyday life (pp. 31-64). Oslo: Scandinavian University Press.

Salen, K., \& Zimmerman, E. (2004). Rules of play: game design fundamentals. Cambridge, Mass. ; London: MIT.

Salen, K., \& Zimmerman, E. (2006). The game design reader: a Rules of play anthology. Cambridge, Mass. ; London: Mit.

Salmon, E. G. (1886). "What Girls Read". Nineteenth Century, 20, 515-529.

Sanoff, H. (1988). "Participatory Design in Focus". Arch. \& Comport. / Arch. Behav., 4(1), 27-42.

Schiesel, S. (2006). "Welcome to the New Dollhouse". Retrieved May 7, 2006, from

http://www.nytimes.com/2006/05/07/arts/07schi.html?ei $=5088 \& \mathrm{en}=68 \mathrm{a} 3 \mathrm{~d} 7 \mathrm{baf} 99601 \mathrm{ad} \& \mathrm{ex}=1304654400 \& \mathrm{adxnn}$ $1=1 \&$ partner=rssnyt\&emc $=$ rss\&pagewanted $=$ print\&adxn $\underline{n l x}=1149591792-\mathrm{dBs} 5 \mathrm{fP} 7 \mathrm{ryNfR} 7 \mathrm{dMlP0} 0 \mathrm{~Gb}+\mathrm{Q}$

Schiffer, M. B. (1991). The portable radio in American life.

Tucson: University of Arizona Press. 
Schmiedeler, E. (1927). The industrial revolution and the home: a comparative study of family life in country, town and city (PhD Thesis ed.). Washington: Washington Catholic University of America.

Schönberg, E. (1908). Wat kan en moet de winkelier van het warenhuis leeren? Rotterdam: W.L. \& J. Brusse.

Schrijver, J. (1907a). "Van Kinderen en Speelgoed". De Vriend des Huizes. Tijdschrift voor het Huisgezin, 58-64.

Schrijver, J. (1907b). "Van Kinderen en Speelgoed". De Vriend des Huizes. Tijdschrift voor het Huisgezin, 119-124.

Seabrook, J. (2006). "Game Master Will Wright changed the concept of video games with the Sims. Can he do it again with Spore?" The New Yorker, 88-99.

Segel, E. (1986). "As the Twig Is Bent..." In E. Flynn \& P. Schweickart (Eds.), Gender and reading: essays on readers, texts, and contexts. Baltimore; London: Johns Hopkins University Press.

Seiter, E. (1995). Sold separately: children and parents in consumer culture. New Brunswick, N.J.: Rutgers University Press.

Selten, P., Adriaanse, C., \& Becker, B. (1996). Af en toe met pa en moe... : de speeltuinbeweging in Nederland 1900-1995. Utrecht: De Tijdstroom.

Shils, E. (1975). Center and periphery: essays in macrosociology. Chicago: University of Chicago Press.

ShinyEntertainment. (2003). "Enter the Matrix": Atari/Warner Brothers Interactive.

Silverstone, R., \& Haddon, L. (1996). "Design and the Domestication of Information and Communication Technologies: Technical Change and Everyday Life". In R. E. Mansell \& R. Silverstone (Eds.), Communication by design: the politics of communication and information technologies (pp. 44-74). Oxford: Oxford University Press.

Silverstone, R., \& Hirsch, E. (1992). "Introduction". In R. Silverstone \& E. Hirsch (Eds.), Consuming technologies: media and information in domestic spaces (pp. xiii, 241). London; New York: Routledge.

Silverstone, R., Hirsch, E., \& Morley, D. (1992). "Information and communication technologies and the moral economy of the household". In R. Silverstone \& E. Hirsch (Eds.), Consuming technologies: media and information in domestic spaces (pp. 15-31). London ; New York: Routledge.

Simmons, D. (2007). "Re: Its starting to happen..." Retrieved April 25, 2007, from http://news.lugnet.com/color/?n=1333\&t=i\&v=a 
Simonsen, C. (2006). "LEGO Press Release". Retrieved June 20, 2007, from

http://www.lego.com/eng/info/default.asp?page=pressdet ail\&contentid $=21555 \&$ countrycode $=2057 \&$ yearcode $=20$ $06 \&$ archive $=$ true

Singer, D. (2005). "Personal Communication".

SIRE. (2006). "Digitaal Pesten". Retrieved August 17, 2007, from http://www.sire.nl/index.php?id=21\&campagne=3\#

Siskind, D. (2000-ongoing). "Brickmania". Retrieved April 18, 2007, from www.brickmania.com

Smallbone, F., \& Hanson, M. (2007). "Minibrix". Retrieved September 18, 2007, from http://www.minibrix.com/

Smith, A. (2005). "Bricksmith. Virtual Lego modeling for your Macintosh" [Computer Program].

Smith, D. B. (1980). Inside the great house: planter family life in eighteenth-century Chesapeake Society. Ithaca, N.Y.: Cornell University Press.

SmokeD. (2006). "Funny Events?" Retrieved June 15, 2006, from http://groups.google.com/group/alt.games.the-sims2/browse frm/thread/c550775c892505aa/c0ba49ad0ada2 933? lnk=gst\&q $=$ funny \&rnum $=2 \# \mathrm{c} 0 \mathrm{ba} 49 \mathrm{ad0ada} 2933$

Snyder, D. (2004). "Playroom". In B. Colomina, A. Brennan \& J. Kim (Eds.), Cold war hothouses: inventing postwar culture, from cockpit to playboy (pp. 124-142). New York, NY: Princeton Architectural Press.

Sony. (2005). "EyeToy". Retrieved August 21, 2007, from http://www.eyetoy.com/

Sotiropoulos, C. S. (2001). "Where Words Fail: Rational Education Unravels in Maria Edgeworth's The French Governess". Children's literature in education, 32(4), 305-322.

Squeegee. (2003). "Something Fishy TSO Comes Part II". Retrieved August 21, 2007, from http://groups.google.com/group/alt.games.thesims/browse frm/thread/cce63ed5390c900d/41ddd12ac5 ea6b3c?q=TSO\&rnum $=4 \# 41$ ddd $12 \mathrm{ac} 5 \mathrm{ea} 6 \mathrm{~b} 3 \mathrm{c}$

Stardoll. (2003-ongoing). "Stardoll. Your Paperdoll Heaven". Retrieved July 6, 2007, from http://www.stardoll.com/en/ Starr, P. (1994). "Seductions of Sim. Policy as a Simulation Game". The American Prospect, 17, 19-29.

Steele, J. (2006). "Re: Question for Research Purpose". Retrieved September 25, 2006, from http://boards.stratics.com/phpbin/sims/showflat.php?Cat $=\&$ Number $=629976 \&$ page $=1$ $\&$ view $=$ collapsed $\& \mathrm{sb}=5 \& 0=\&$ fpart $=1$

Steen, F., Greenfield, P., Davies, M. S., \& Tynes, B. (2006). "What Went Wrong With The Sims Online: Cultural Learning and Barriers to Identification in a Massively Multiplayer Online Role-Playing Game" In P. Vorderer \& J. Bryant 
(Eds.), Playing video games: motives, responses, and consequences (pp. 307-323). Mahwah, N.J.: Lawrence Erlbaum Associates.

Stephens, C. (2005). "Marking the difference in Lego ${ }^{\mathrm{TM}}$ parts". Retrieved September 16, 2007, from http://isodomos.com/

Stevenson, R. L. (1883). Treasure Island. London: Cassell \& Co.

Stewart, S. (1993). On longing: narratives of the miniature, the gigantic, the souvenir, the collection. Baltimore ; London: Johns Hopkins University Press.

Sticht, W. (2002-ongoing). "Walther's STABIL Metallbaukästen". Retrieved May 9, 2007, from http://home.arcor.de/stabil baukasten modelle/walther/si nhalt.html

Strassoldo, R. (1980). "Centre-Periphery and System Boundary: Culturological Perspectives". In J. Gottmann (Ed.), Centre and periphery: spatial variation in politics Beverly Hills; London: Sage.

Stratics. (2003). "The Sims Online Stratics. Community Corner. Image Gallery". Retrieved July 5, 2007, from http://sims.stratics.com/content/gallery/sod/archives.php

Stratics. (2006). "Poll Archive". Retrieved July 5, 2007, from http://sims.stratics.com/content/community/pollarchive.p $\underline{\mathrm{hp}}$

Sumner, W. G. (1877). "What Our Boys Are Reading". Scribner's Monthly: an Illustrated Magazine for the People, 15, 681-685.

Susskind, L. E. (2006). "Consensus Building and Dispute Resolution". In E. Sendich (Ed.), Planning and urban design standards (pp. 66-67). Hoboken: John Wiley \& Sons.

Sutherland, B. (2006). "The Real Sim City". Retrieved September 15,2006 , from http://news.bbc.co.uk/2/hi/technology/5105534.stm

Sutorius, A., \& Midderigh-Bokhorst, J. B. (1912). In de speelkamer. 's-Gravenhage: Erven Martin G. Cohen.

Sutton-Smith, B. (1986). Toys as culture. New York, N.Y.: Gardner Press.

TheAntiDrug. (2007). "Digital Technology 101". Retrieved April 30, 2007, from http://www.theantidrug.com/Emonitoring/index.asp

ThereInc. (2003). "There" [Online computer game]. Silicon Valley, CA: Makena Technologies.

Thurston, H. W. (1918). Delinquency and Spare Time. Cleveland: Cleveland Foundation. 
Trease, G. (1975). "The Revolution in Children's Literature". In E. Blishen (Ed.), The thorny paradise: writers on writing for children. Harmondsworth: Kestrel Books.

Turkle, S. (1996). Life on the screen: identity in the age of the Internet. London: Weidenfeld \& Nicolson.

Twist, J. (2004). "Simulating life, love and the Universe". BBC News. Technology. Retrieved September 16, 2007, from http://newsvote.bbc.co.uk/mpapps/pagetools/print/news.b bc.co.uk/2/hi/technology/3645552.stm

UNFPA. (2007). "Unleashing the Potential of Urban Growth". Retrieved August 22, 2007, from http://www.unfpa.org/swp/2007/english/introduction.htm 1

Unwin, R. s. (1912). "Nothing gained by overcrowding! How the garden city type of development may benefit both owner and occupier" (3d ed.): Westminster.

V\&A. (2007). "High chair at the V\&A Museum of Childhood". Retrieved August 17, 2007, from http://www.vam.ac.uk/moc/collections/childcare/furnitur e/high chair/index.html

Vinther. (2005). "My collection of old LEGO's". Retrieved September 27, 2005, from http://www.vinthers.dk/old.htm

Wachelder, J. (2003). "Democratizing Science: Various Routes and Visions of Dutch Science Shops". Science, Technology, \& Human Values, 28(2), 244-273.

Wade, R. (1971). "The Periphery Verus the Center". In B. Stave (Ed.), Urban bosses, machines, and progressive reformers. Lexington: Heath.

Walters, W. (2004). "Color change: Let's go straight to the CEO!" Retrieved April 25, 2007, from http://news.lugnet.com/color/?n=625

Ward, L. (2006, November 14). "Hi-tech toys offer no educational gain, say researchers". The Guardian.

Wardrip-Fruin, N., \& Harrigan, P. (Eds.). (2006). First person: new media as story, performance, and game. Cambridge, Mass.: MIT Press.

Werry, R. (2007). Interview (Intern at De Kunsthal, Rotterdam ed.). Wetzel, G. (2006). "architectoys.com". Retrieved August 13, 2007, from http://www.architectoys.com/

White, B. D. (2007). "Its starting to happen..." Retrieved April 25, 2007, from http://news.lugnet.com/color/?n=1333\&t=i\&v=a

Whitehead, I. (2000). "Will Wright wants you to rule your own urban empire". Architectural Record, 188, 246. 
Whorton, J. W. (2006). "Facilitation". In E. Sendich (Ed.), Planning and urban design standards (pp. 65). Hoboken: John Wiley \& Sons.

Wien, H. (2007). Interview (Project leader Face Your World from the ward Slotervaart - Financial supporter Face Your World ed.).

Wiencek, H. (1987). The World of LEGO Toys. New York: Abrams.

Wiggers, R., Kouwenberg, H., \& Karsten, L. (1996). Kindert_d: de $v r$ et dsbesteding van Amsterdammertjes in kaart gebracht Amsterdam: Stedel_k Beheer Amsterdam, onderafdeling Recreatie.

Williams, R. H. (1991). Dream worlds: mass consumption in late nineteenth-century France. Berkeley: University of California Press.

Woodcock, B. S. (2005). "MMOG Active Subscriptions 21.0. Subscribers: 0 - 120,000". Retrieved August 24, 2007, from http://www.mmogchart.com/

Woolgar, S. (1991). "Configuring The User: the case of usability trials". In J. Law (Ed.), A Sociology of monsters: essays on power, technology, and domination (pp. 57-99). London: Routledge.

Wright, W. (2005a). The Future of Content. Paper presented at the Game Developers Conference Europe. Retrieved December 15, 2006, from http://www.gdceurope.com/.

Wright, W. (2005b). Time and simulation. Paper presented at the When 2.0: Time and Timing Conference. Retrieved December 15, 2006, from http://www.release10.com/events/When2index.php.

Wuyts, T. (1999). "SIMCITY 3000 - Guide (version 1.11)". Retrieved December 15, 2006, from http://www.thespoiler.com/STRATEGY/Maxis/simcity3000.2.html

Wyatt, S. (2003). "Non-Users Also Matter: The Construction of Users and Non-Users of the Internet". In N. Oudshoorn \& T. J. Pinch (Eds.), How users matter: the co-construction of users and technologies (pp. 67-79). Cambridge, Mass. ; London: MIT.

XMAT. (2007). "Introducing the all new GamerCycleTM fitness system!!!" Retrieved April 26, 2007, from http://www.gamercycle.com/

Young, \& Rubican. "Brand Asset Valuator". Retrieved December 12, 2006, from http://www.brandassetvaluator.com.au/

YouTube. (2006). "RE: A Message From Chad and Steve". Retrieved October 11, 2007, from http://www.youtube.com/video response view all? $\mathrm{v}=\mathrm{Q}$ CVxQ 3Ejkg 
Zachmann, K. (2003). "Homo faber ludens junior oder: Die Technisierung des Kinderzimmers". In S. Poser \& K.

Zachmann (Eds.), Homo faber ludens: Geschichten zu

Wechselbeziehungen von Technik und Spiel (Vol. Band 4, pp. 203-225). Frankfurt am Main: Peter Lang.

Zide, L. (1996). "LeoCAD" [Computer Program]. 


\section{NEDERLANDSTALIGE SAMENVATTING}

In dit proefschrift wordt de veranderende relatie tussen producenten en consumenten onderzocht aan de hand van speelgoed en spel. Consumenten zijn steeds vaker ook producenten van media producten en worden in toenemende mate actief betrokken bij het ontwikkelen en promoten van producten. Op die manier spelen zij een belangrijke rol in de creatie en het voortbestaan van de merken die fabrikanten op de markt brengen. Deze toename in zogenaamde 'prosumers' wordt vaak omschreven met termen als 'many-to-many cultuur' en 'participatieve cultuur.' Zulke termen geven aan dat meerdere mensen bijdragen aan een product of service die vervolgens voor meerdere mensen toegankelijk wordt gemaakt. Dit 'door ons en voor ons' model wordt ondersteund door software applicaties die ook wel 'sociale media' worden genoemd. Via blogs, wikisites, file transfer protocollen en dergelijke wordt een netwerk gecreëerd waarin informatie, data, kennis en inhoud worden uitgewisseld. Een van de effecten van deze participatieve cultuur is de explosieve groei van actieve gebruikersgroepen die rondom producten ontstaan. De waarde van dit many-to-many model, en dan met name de mogelijkheid die het biedt om traditioneel ver van elkaar verwijderde actoren met elkaar te verbinden, is niet onopgemerkt gebleven. Zowel commerciële als niet-commerciële sectoren trachten many-to-many gemeenschappen rond hun producten op te zetten en te onderhouden om zo van hun activiteiten te kunnen leren. Van politici tot beleidsmakers, van kunstenaars tot architecten, van industriegiganten tot non-profit organisaties; overal zien we het many-to-many paradigma aan het werk. De wereld van speelgoed, computerspellen en spelen is een van de plaatsen waar dit model zich duidelijk manifesteert. 
In dit proefschrift onderzoek ik de manier waarop het many-to-many model onder invloed van technologische ontwikkelingen veranderingen teweegbrengt in speelgoed en spel. Ik kijk daarbij naar de mechanismen die in dit model aan het werk zijn om spelers te betrekken in een 'door ons voor ons' paradigma. Ik situeer deze twee hoofdvragen historisch in de context van de 'commodificatie', het tot consumeerbaar product worden van spel en speelgoed, de 'domesticatie' of 'verhuislijking' van kind en spelen en de 'urbanisatie' of verstedelijking van de leefwereld van het kind. In combinatie met de historische context tonen de drie case studies - LEGO speelgoed, de computerspellen van Will Wright en het burger participatieproject Face Your World - het many-tomany model aan het werk en in beweging. Ik toon daarbij aan dat de plaats van het spel verandert - zowel in letterlijke zin (spelen is steeds vaker een binnenshuis activiteit) als in figuurlijke zin (spelers worden steeds vaker producenten van hun spel). De effecten hiervan op spel en speelgoed worden onderzocht aan de hand van het centrum/periferie differentiatiemodel.

Centrum en periferie vormen samen de 'geografie van spel', een constellatie van tastbare en niet-tastbare elementen, van sociale contacten en de omgang met het speelgoed zelf. Het centrum van de geografie bestaat uit gefaciliteerde of mogelijk gemaakte spelpraktijken. Deze gefaciliteerde spelpraktijken worden gevormd door het samengaan van het design (de materiële en technologische eigenschappen) en het discours (wat tot uitdrukking komt in bijvoorbeeld de handleiding en reclames) van speelgoed. Het centrum van de geografie bestaat met andere woorden uit spelpraktijken die gefaciliteerd worden door 'scripts', voorziene gebruikers en gebruiken van het speelgoed. Ik ga in dit proefschrift niet uit van één correct gebruik van een artefact, maar van meerdere gefaciliteerde gebruiken die in design en 
discours tot uitdrukking komen. Omdat spelen in essentie het testen van grenzen is, wijken spelers in hun daadwerkelijke spel zeer vaak af van dat wat voor hen gefaciliteerd wordt. Ze gebruiken het design van speelgoed op een onvoorziene wijze of wijken af van het discours omtrent een bepaald spel. Via een centrifugale beweging, een middelpuntsvliegende kracht weg van het centrum, eigenen de gebruikers zich zo het artefact toe en belanden in de periferie van de spelgeografie. De periferie bestaat met andere woorden uit divergente spelactiviteiten die afwijken van het design en discours, van het script en de voorziene gebruikers en gebruiken van speelgoed. In deze periferie bevinden zich ook de many-to-many activiteiten van fans - hier worden objecten en kennis, 'user-geproduceerde content' en 'end-user kennis' uitgewisseld. Dankzij het Internet en de daarmee samenhangende technologische innovaties op software gebied, heeft de periferie aan zichtbaarheid en toegankelijkheid gewonnen en is deze belangrijker geworden voor speelgoedbedrijven.

Het belang van deze verschuiving komt op verschillende manieren tot uitdrukking. Ten eerste zien we een toename in 'trage centripetale toe-eigening': bedrijven gebruiken steeds vaker input uit de periferie voor het lanceren van nieuwe producten. Bedrijven leren van de voorkeuren van gebruikers van hun producten, hoe hun product daadwerkelijk wordt gebruikt, wat de wensen en kritiekpunten zijn. Hierdoor dragen gebruikers tot op zeker niveau bij aan het herconfigureren van gebruikers en gebruiken van een artefact. Dit impliceert echter ook een gedeeltelijke commodificatie van perifere, many-to-many activiteiten. Ten tweede wordt ook 'snelle centripetale toe-eigening' steeds gebruikelijker: spelers brengen activiteiten en producten vanuit de periferie over naar het centrum binnen het bestek van één spel of product. Software updates of modificaties voor een spel kunnen 
snel en makkelijk van de periferie (waar ze gemaakt worden door fans) 'migreren' naar het centrum (waar ze vervolgens gebruikt worden). Via deze beweging kunnen spelers voor een deel de gebruiker en de gebruiken co-configureren, mede vormgeven. De case studie omtrent de computerspellen van Amerikaans game designer Wright - SimCity en The Sims - toont aan hoe computerspelbedrijven steeds vaker rekenen op deze snelle centripetale toe-eigening om spellen van inhoud te voorzien. Hierdoor 'commodificeert', commercialiseert de perifere, many-to-many cultuur.

Het eerste hoofdstuk "New Toys, Different Children" legt de basis voor de notie van speelgoed als intermediair, als spiegel en motor van sociale processen. Dit proefschrift gaat ervan uit dat speelgoed een actieve rol speelt in het doorgeven en aanzwengelen van sociale en culturele processen en veranderingen. Speelgoed bemiddelt als het ware tussen maatschappelijke processen en het individu, de speler. Via speelgoed komen bepaalde veranderingen de wereld van de speler binnen. Tussen het midden van de $19^{\mathrm{e}}$ en de eerste decennia van de $20^{\mathrm{e}}$ eeuw zien we drastische veranderingen in de productie, consumptie en variëteit van speelgoed, de functie van speelgoed in het leven van kinderen en de plaats van kinderen in de samenleving. Deze veranderingen vinden plaats binnen het gegeven van de constructie van het 'onschuldige kind' en de steeds verder uit elkaar lopende spelwerelden van jongens en meisjes. Bouwdozen en mechanisch speelgoed beantwoordden aan de vraag naar speelgoed voor binnenshuis. Omdat het speelgoed niet geschikt was om buiten mee te spelen versterkte het de domesticatie, het aan huis gebonden zijn van kind en spel. Terwijl dit speelgoed kinderen en hun spel afschermde van de buitenwereld imiteerde het vaak in het design en discours deze 'boze 
buitenwereld'. De focus in dit hoofdstuk ligt specifiek op de opkomst van het warenhuis en de daarmee gepaard gaande ideeën omtrent het kind als consument, de privé kamer en het scheiden van de volwassen wereld en die van het kind en de speelplaats (later de speeltuin) als veilige en stichtelijke stedelijke plaats voor kinderen zonder eigen speelkamer.

Het tweede hoofdstuk "Core and Periphery of Play" gaat vervolgens dieper in op de keuze van dit proefschrift voor constructiespeelgoed en het centrum/ periferie differentiatiemodel. De focus van dit proefschrift is zowel op niet-digitaal constructiespeelgoed, met LEGO als meest prominent voorbeeld, als op digitaal constructiespeelgoed met Wrights spellen en Face Your World als voorbeelden. Tevens verschuiven we hiermee van entertainment constructiespeelgoed naar constructiespeelgoed met 'serieuze' doelstellingen, namelijk burgerparticipatie in stedelijke vernieuwing. Constructiespeelgoed is een uitmuntende focus omdat het speelgoed zelf de processen van commodificatie (industriële massaproductie en verkoop in de nieuwe warenhuizen), domesticatie (bedoeld voor spel binnenshuis op een glad en schoon oppervlak) en urbanisatie (imitatie van stedelijke configuraties en revoluties van de publieke sfeer) belichaamt. In de $19^{\mathrm{e}}$ eeuw wint constructiespeelgoed aan populariteit en variëteit.

Sindsdien is zowel het materiaal (van hout en steen naar staal en plastic en uiteindelijk naar digitale 'materialen') als de kern (van bouwen naar ontwerpen) van constructiespeelgoed veranderd. Vroege bouwdozen waren doorgaans houten of stenen blokken zonder koppelingmechanisme die het bouwen van abstracte en architecturale objecten faciliteerden, mogelijk maakten. Vanaf het einde van de $19^{\mathrm{e}}$ eeuw wordt er met staal, plastic en verschillende koppelingsmechanismen geëxperimenteerd die het ontwerpen en construeren van meer diverse en 
complexe objecten faciliteren. Meccano is een bekend en populair voorbeeld van constructiespeelgoed als design en ontwerp speelgoed. Digitaal constructiespeelgoed voegt hier nog een extra laag aan toe omdat het geprogrammeerd en proceduraal speelgoed is dat zich over tijd en ruimte visueel ontwikkelt. De veranderende spelpraktijken met constructiespeelgoed zijn aan de hand van het centrum/periferie model, zoals hierboven uiteengezet, onderzocht.

Hoofdstuk drie, "The Journey not the Destination" behandelt LEGO speelgoed vanaf de jaren ' 40 tot nu. De relatie tussen technologische innovaties, bedrijfsideologie, 'branding' en marketing vormen de kern van dit hoofdstuk. De LEGO geschiedenis toont de opkomst van het many-to-many model en de consequenties van het al dan niet hanteren van dit model. De veranderende LEGO spelpraktijken verwijzen naar manieren en condities van postindustriële productie. In de jaren ' 40 zien we het LEGO bedrijf overstappen van hout op plastic als basismateriaal voor speelgoed. In de jaren ' 50 faciliteren innovaties op het gebied van plastic injectie machines de ontwikkeling van het bekende LEGO koppelingsmechanisme: noppen op de blokken en buisjes onderaan. Hierdoor worden LEGO constructies stabieler en de mogelijke designs diversifiëren. De $21^{\mathrm{e}}$ eeuw ziet vervolgens de beweging naar een many-tomany model van product design met het actief betrekken van volwassen LEGO Mindstorms fans in het ontwikkelingproces van een nieuwe Mindstorms LEGO robotica kit.

Doorheen deze veranderingen zien we de geografie van het LEGO spel mee veranderen. Vanaf de jaren ' 50 groeit de LEGO geografie door het nieuwe koppelingsmechanisme en het LEGO 'spelsysteem' dat toelaat alles van het LEGO merk met elkaar te combineren. Deze expansieve geografie kwam in de jaren ' 90 onder druk te staan door een onfortuinlijke 
poging van het LEGO bedrijf om de LEGO brand op te rekken en hun producten te diversifiëren. LEGO kleding en pretparken, computerspellen en 'life style' producten brachten het LEGO merk en de spelgeografie ernstige schade toe. In 2004 is dan ook een reddingsoperatie in gang gezet die via een hernieuwde focus op de LEGO steentjes en de LEGO fans tracht het bedrijf en het LEGO merk weer op de been te helpen.

Met hoofdstuk vier, "Pimp my Game", verschuift de focus naar digitale constructie en simulatiespellen. SimCity brengt de speler in contact met een specifieke visie op stedelijke planning en stedelijke ontwikkeling. Net als historische speelgoed dorpen brengt SimCity stedelijke configuraties tot bij de spelers en familiariseert hen met bepaalde stedelijke veranderingen. The Sims neemt de domesticale sfeer als onderwerp en, net als $19^{\mathrm{e}}$-eeuwse speelgoedhuizen, simuleert het de constructie van die huizen en het leven binnenin die huizen. Het beduidend minder populaire spel The Sims Online heeft de suggestie van constructiespel, narratief spel en sociale relaties maar niet de actualisatie daarvan. Het design van het spel laat geen centripetale toe-eigening toe en frustreert daarmee de spelers die een uitlaatklep vinden in asociaal spelgedrag. Een kernaspect van 'gezonde' digitale spelgeografieën is namelijk de verregaande vormen van zowel snelle als trage centripetale toeeigening. Spelers produceerden bijvoorbeeld tot wel 90\% van de inhoud van The Sims 1 . Het is vaak niet meer te achterhalen welke inhoud van computerspellen afkomstig is van computerspelbedrijven en wat van spelers. In de nog grotendeels niet-digitale LEGO geografie kunnen we vaak aangeven wanneer, waar en waarom het LEGO bedrijf gebruik maakt van de manyto-many activiteiten. In de gedigitaliseerde Sims geografie is dit bijna niet meer mogelijk. De centrifugale en centripetale bewegingen zijn zo snel, 
vloeiend en alomtegenwoordig dat het welhaast onmogelijk is om nog te achterhalen wie wat produceerde en waar. De periferie wint hierdoor aanzienlijk aan macht en controle over het centrum maar moet ook aan autonomie inboeten.

Het vijfde hoofdstuk "Playing the City" heeft als leidende case studie het unieke participatie project Face Your World dat plaatsvond in Amsterdam in 2005. Dit project werd geïnitieerd door de Nederlandse kunstenares Jeanne van Heeswijk en faciliteert door een gevarieerd participatie traject de deelname van kinderen en volwassen aan het ontwerp van een nieuwe park voor de Amsterdamse buitenwijk Slotervaart. Het participatie traject bestond uit 49 bijeenkomsten, meetings en workshops die met name gericht waren op volwassenen uit de buurt en een intensief designproces met buurtkinderen. Dit designproces bestond uit tekenen, boetseren en het werken met een digitaal constructiespel: de Interactor. Deze Interactor faciliteerde overleggen, samenwerken, ontwerpen en experimenteren. Het uiteindelijke ontwerp voor het park is goedgekeurd en het park zal naar schatting in 2010 gerealiseerd worden. Het spelen met de Interactor had een duidelijk doel: het ontwerpen van een buurtpark dat door de verschillende etnische groepen in de buurt gesteund zou worden. Dit verkleint de perifere ruimte voor divergent spel. In een 'serieuze' spelgeografie neemt het centrum relatief veel plaats in omdat de uitkomst van groot belang is voor verschillende partijen. Dit soort intensieve participatie trajecten maximaliseren het many-to-many model en betrekken burgers in beleidsontwikkeling, ontwerp en uitvoering. Hierbij wordt de many-to-many cultuur niet zozeer gecommodificeerd of vercommercialiseerd als wel geïnstrumentaliseerd. Het 'door ons voor ons' aspect wordt daarmee geen aspect van een 'gezonde' spelgeografie zoals bij entertainment spellen, maar een gefaciliteerd aspect van het centrum. 
De drie case studies tonen hoe de min of meer solitaire en individuele $19^{\mathrm{e}}$-eeuwse spelgeografieën door middel van het Internet en 'sociale software' transformeren in ge-netwerkte en druk bevolkte geografieën. Contact via tijdschriften, radio programma's, festivals en clubs in de laat $19^{\mathrm{e}}$ en begin $20^{\mathrm{e}}$-eeuwse spelgeografieën is versterkt via Internet forums en platforms die spelers in een ongekende interconnectiviteit met elkaar verbinden. In deze manyto-many geografieën zijn spelers steeds vaker producenten en actieve participanten in een 'brand universum'. Daarbij kunnen de posities van speler, consument en producent imploderen. Dit brengt een verschuiving in machtsverhoudingen met zich mee. In de many-to-many cultuur wordt de periferie steeds belangrijker en spelers hebben meer toegang tot en macht over het centrum. Niettegenstaande dat de many-to-many cultuur vaak wordt beschouwd als de ultieme vorm van consumenten emancipatie, feit blijft dat de bedrijven beslissen of de grenzen tussen consumenten en producenten vervagen. Met de toenemende commodificatie en instrumentalisatie van het many-to-many paradigma omvat de 'ons' van het 'door ons voor ons' paradigma niet alleen fans en gebruikers van producten maar ook commerciële bedrijven en niet-commerciële instellingen. 


\section{CURRICULUM VITAE}

Maaike Lauwaert (1978, Antwerp) graduated with honors in 2001 at the Faculty of Arts and Social Sciences, University of Maastricht on French semiotics and early animation movies by Walt Disney. Between 2001 and 2003 she worked as a junior researcher at the Faculty of Arts and Social Sciences on a collaborative project about computer games and the emerging discipline of game studies with Joseph Wachelder and Johan van de Walle. During this period she co-wrote the NWO project proposal Transformations in Perception and Participation: Digital Games together with a group of colleagues from the University of Maastricht and University of Amsterdam (UvA). The project was selected for funding in 2003 and she started working in this project as a $\mathrm{PhD}$ student. During her time at Maastricht University's Faculty of Arts and Social Sciences she took part in and completed the WTMC (science, technology and modern culture) graduate school training program, taught classes on both the Bachelor and Master level, presented her work at various international conferences and co-organized international conferences and symposia. She publishes widely, both in peer-reviewed journals and popular magazines, on computer games, contemporary art and American comics. 